\author{
UNIVERSIDADE DE SÃO PAULO \\ INSTITUTO DE GEOCIÊNCIAS \\ DEPARTAMENTO DE MINERALOGIA E GEOTECTÔNICA
}

LIVRE-DOCÊNCIA

\title{
MINERALOGIA, ANÁLISE E DATAÇÃO DE MONAZITA E XENOTIMA COM MICROSSONDA ELETRÔNICA E APLICAÇÕES
}

Silvio Roberto Farias Vlach

Compilação e sistematização das contribuições ao tema, análise crítica e estudos em andamento. Texto apresentado para o Concurso de Livre - Docente, na área de Mineralogia Básica e Aplicada, Departamento de Mineralogia e Geotectônica. 


\section{UNIVERSIDADE DE SÃO PAULO INSTITUTO DE GEOCIÊNCIAS}

DEPARTAMENTO DE MINERALOGIA E GEOTECTÔNICA

LIVRE-DOCÊNCIA

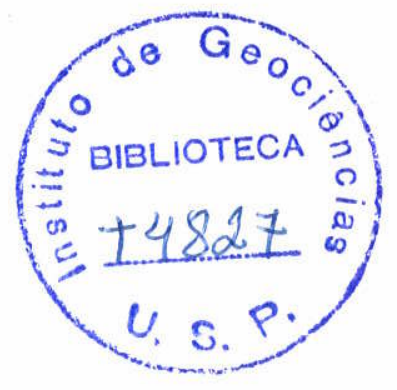

MINERALOGIA, ANÁLISE E DATAÇÃO DE MONAZITA E XENOTIMA COM MICROSSONDA ELETRÔNICA E APLICAÇÕES

Silvio Roberto Farias Vlach

Compilação e sistematização das contribuições ao tema, análise crítica e estudos em andamento. Texto apresentado para 0 Concurso de Livre-Docente, na área de Mineralogia Básica e Aplicada, Departamento de Mineralogia e Geotectônica.

São Paulo 2008 


\section{Para Ana Julia,}

que também queria brincar de monazita 


\section{ÍNDICE TEMÁTICO}

\section{CAPÍTULO I}

1. Apresentação e histórico 02

2. Plano de apresentação $\quad 04$

3. Aspectos cristaloquímicos gerais da monazita 06

4. Datação química com microssonda eletrônica: evolução do método

e instrumental 08

5. Compilação de contribuições sobre o tema 12

Softwares $\quad 12$

Trabalhos inéditos e publicados $\quad 12$

$\begin{array}{ll}\text { 6. Referências bibliográficas } & 15\end{array}$

\section{CAPITULO $\|$}

Análise e dataçāo $T h-U-P b_{T}$ de monazita em microssonda eletrônica: procedimentos analiticos e de tratamento de dados

$\begin{array}{ll}\text { RESUMO } & 20\end{array}$

$\begin{array}{ll}\text { INTRODUÇÃO } & 21\end{array}$

FUNDAMENTOS TEÓRICOS E PREMISSAS 23

CONDIÇÕES INSTRUMENTAIS E ANALÍTICAS 25

Instrumentação $\quad 26$

$\begin{array}{ll}\text { Set-up instrumental } & 27\end{array}$

Voltagem de aceleraçāo da coluna eletrônica 28

Corrente e diâmetro do feixe eletrônico 29

Tempo morto e análise da distribuição de pulsos (PHA) 31

Set-up elemental: interferências espectrais, contornos e correções 32

Varreduras espectrométricas WDS 33

Contornos e correções de interferências espectrais $\quad 37$

Limites de deteç̧ão e de quantificação 39

ANÁLISE, TRATAMENTO E APRESENTAÇÃO DE DADOS 40

Modelos de idades químicas $\quad 41$ 
Avaliação dos resultados: precisão e acurácia 45

PROCEDIMENTOS PRÁTICOS DE AMOSTRAGEM E ANÁLISE 49

Microscopia de luz transmitida, refletida e de eletrons retro-

espalhados $\quad 49$

Calibração elemental, avaliação e análises $\quad 51$

Mapas composicionais $\quad 52$

ESTUDO DE CASOS $\quad 53$

NOTAS CONCLUSIVAS

AGRADECIMENTOS $\quad 59$

REFERÊNCIAS $\quad 59$

LEGENDA DE FIGURAS $\quad 65$

LEGENDA DE TABELAS $\quad 68$

FIGURAS $\quad 69$

$\begin{array}{ll}\text { TABELAS } & 77\end{array}$

\section{CAPÍTULO III}

Idades do metamorfismo e do magmatismo granítico no Terreno Embu e vizinhanças (SE do Brasil) e implicações : Uma contribuição da datação Th-U-Pb ${ }_{T}$ de monazita e xenotima com EPMA

$\begin{array}{ll}\text { RESUMO } & 81\end{array}$

INTRODUÇÃO

SITUAÇÃO GEOLÓGICA E GEOCRONOLOGIA GERAL 84

AMOSTRAGEM, PROCEDIMENTOS ANALÍTICOS E DE TRATAMENTO DE $\begin{array}{ll}\text { DADOS } & 87\end{array}$

$\begin{array}{ll}\text { RESULTADOS } & 89\end{array}$

Idades químicas para o metamorfismo regional e a geração de migmatitos $\quad 89$

Terreno Embu $\quad 89$

Terreno Serra do Mar $\quad 91$

Complexo Piracaia 93

Idades químicas para o magmatismo granítico 94

Ortognaisses e o magmatismo tonalítico-granodioritico precoce 94

O Batólito Quebra Cangalha 95 
Os plutons Mauá e Mogi das Cruzes

Sumário da cronologia dos eventos metamórficos e magmáticos

Deformação, recristalização e recomposição dos relógios químicos

Implicações para a evolução geológica 104

AGRADECIMENTOS

REFERÉNCIAS

LEGENDA DE FIGURAS

FIGURAS

TABELAS

\section{CAPÍTULO IV}

Mecanismos de substituição de monazita e xenotima por coronas de apatita-allanita-epidoto-torita em rochas ortognássicas e graniticas do Terreno Embu (SE do Brasil) e implicações : evidências texturais e químicas

RESUMO

INTRODUÇÃO

SITUAÇÃO GEOLÓGICA E OCORRÊNCIA DE CORONAS DE SUBSTITUIÇÃO EM MONAZITA E XENOTIMA

AMOSTRAS ESTUDADAS E MÉTODOS ANALÍTICOS

Relações texturais de substituição de monazita e xenotima

Coronas centradas em monazita

Coronas centradas em xenotima

Variações composicionais das fases minerais

Monazita e xenotima primárias 
$\begin{array}{ll}\text { DISCUSSÃO } & 145\end{array}$

Natureza e mecanismos de substituição 145

Coronas centradas em monazita $\quad 145$

Coronas centradas em xenotima $\quad 148$

Metamorfismo vs. alteração pós-magmática $\quad 150$

Implicações para geocronologia e mobilidade de elementos HFS 152

NOTAS CONCLUSIVAS 153

$\begin{array}{ll}\text { AGRADECIMENTOS } & 155\end{array}$

REFERÊNCIAS 155

$\begin{array}{lr}\text { LEGENDA DE FIGURAS } & 160\end{array}$

LEGENDA DE TABELAS 163

$\begin{array}{ll}\text { FIGURAS } & 164\end{array}$

$\begin{array}{ll}\text { TABELAS } & 172\end{array}$

\section{CAPITULO V}

Comentários gerais sobre análise, datação e aplicações da monazita 176

Análise crítica do método químico com microssonda eletrônica e aplicabilidade

Aplicaçōes geotermométricas

Estabilidade de monazita e xenotima em rochas graniticas e metamórficas

Aplicaçōes industriais $\quad 182$

Referências bibliográficas 182 


\section{CAPÍTULO I}

\section{Apresentação e histórico}

A determinação de idades químicas de cristalização ou fechamento do sistema químico de alguns minerais portadores de Th elou $U$, com destaque para monazita e xenotima, a partir da quantificação das abundâncias elementais de $\mathrm{Th}, \mathrm{U}$ e $\mathrm{Pb}$ total tornou-se, sem dúvida, uma das aplicações mais interessantes e importantes da microssonda eletrônica (EPMA, electron probe micro-analyser) no campo das geociências da atualidade. A importância do método e o crescente interesse despertado na comunidade científica internacional nos últimos anos devido ao seu potencial para o estudo e a correlação de diversos processos em petrologia em micro-escala resultou em um enorme acervo de trabalhos dedicados ao tema.

Esta trabalho apresenta e analisa criticamente a metodologia desenvolvida e otimizada no Laboratório de Microssonda Eletrónica do Instituto de Geociências e discute algumas das aplicações e contribuições para o conhecimento da evolução geocronológica de cinturões metamórficos e do magmatismo granítico associado. Os estudos foram desenvolvidos no contexto da linha de pesquisa Minerais máficos e acessórios como indicadores petrológicos, metalogenéticos e geocronológicos inaugurada pelo autor ao final da década de 90 e atualmente aprofundada com colaboração de colegas e estudantes. Já naquela época nos era claro que questões fundamentais ligadas à gênese e evolução de rochas ígneas e metamórficas deveriam de alguma forma estar registradas na evolução das micro-estruturas, texturas e variações composicionais ao longo do tempo dos minerais que as constituem, particularmente das fases máficas e acessórias. 
Após a otimização do laboratório e preocupados em explorar o potencial pleno do equipamento JEOL-JXA8600S instalado, iniciamos o desenvolvimento de procedimentos específicos para análise de minerais como allanita e titanita, enfatizando a quantificação dos elementos terras raras (RRE) e de alguns elementos traços mais típicos ( $\mathrm{Zr}, \mathrm{Nb}$, etc.) cujos resultados foram publicados parcialmente em Vlach (1966) e mais recentemente em Vlach e Gualda (2007), entre outros.

$\mathrm{Na}$ época foram também iniciados projetos envolvendo alunos de graduação visando a micro-análise de minerais raros presentes em rochas graníticas da Província Graciosa e em rochas alcalinas do Maciço Alcalino Poços de Caldas, com resultados excelentes. As maiores dificuldades residiam na capacidade limitada do sistema de automação (TN-5500) acoplado ao EPMA, que praticamente impedia a análise simultânea e um número superior a 12 elementos, a utilização silmultânea eficaz dos sistemas de dispersão de comprimentos de onda (WDS) e de energia (EDS) e o trabalho sistemático paralelo com imagens digitais eletrônicas.

Estes problemas foram sanados em 1997 com a instalação do novo sistema de automação (Voyager, Therno-Noran) com capacidade muito superior, adquirido com apoio da Fundação de Amparo à Pesquisa do Estado de São Paulo (FAPESP). Imediatamente a seguir foram iniciados testes para a datação de monazita, utilizando-se de algumas amostras de granitos peraluminosos do Estado de São Paulo. Os principais problemas para a implementação de rotinas analiticas eram a ausência de padrões elementais adequados para análise de RRE e $\mathrm{Pb}$ e, especialmente, a falta de monazita com determinações isotópicas independentes de idade, que permitissem comparar resultados, bem como aferir e refinar os protocolos analíticos.

A medida que estas questões foram sendo resolvidas o estabelecimento do método foi uma decorrência perfeitamente natural. Os primeiros resultados obtidos já revelavam o seu potencial e foram publicados por volta de 1999 (Vlach et al. 1999a, 1999b, Vlach e Nogueira Neto 1999). Ao término do ano seguinte, os procedimentos analíticos e de tratamento de dados, incluindo os necessários programas para correções de efeitos de interferência espectral e para cálculos de idades de acordo com diversos métodos, para monazita e xenotima estavam concluídos e totalmente operacionais; adicionalmente já se dispunham de dados obtidos em amostras com determinações isotópicas em número suficiente para atestar a confiabilidade do 
método (e.g. Vlach 2001). Algumas otimizações foram efetuadas nos anos seguintes, mas pouco alteraram a essência dos procedimentos originais. Na década de 2000 , diversos trabalhos, alguns recentes, discutem diversos aspectos especificos e relevantes relacionados aos procedimentos analíticos e de tratamento de dados (e.g. Scherrer et al. 2000, Pyle et al. 2005, Jercinovic et al. 2005,2008 , Hetherington et al. 2008), parte significativa dos quais já se encontravam pelo menos parcialmente contemplados na referência citada.

Entretanto, embora um número significativo de dados tenha sido obtido no laboratório desde então, diversas tenham sido as publicações efetuadas e tenha existido a preocupação de divulgar o método e o seu potencial em mineralogia, petrologia e geocronologia, os protocolos analíticos e os procedimentos desenvolvidos pelo autor nunca foram publicados na sua forma integral e discutidos comparativamente a outros similares apresentados em literatura. Uma quantidade significativa de dados - cerca de 1500 determinações analíticas pontuais para mais de 50 amostras - obtidos em etapas analíticas efetuadas nestes anos foram também publicados em sua maioria de forma parcial, como resumos expandidos ou trabalhos curtos.

O objetivo principal deste trabalho é a apresentação, discussão e sistematização do método tal como empregado no laboratório e dos dados geocronológicos obtidos nos últimos anos para rochas metamórficas, migmatíticas e do magmatismo granítico da região do Terreno Embu (e.g. Campos Neto 2000) e vizinhanças, no Estado de São Paulo, e a exemplificação da aplicação da análise micro-estrutural/textural e química pontual de minerais acessórios para a compreensão de certos processos crustais que envolvem reequilíbrios minerais em rochas ortognáissicas e graníticas e implicações para a mineralogia e petrologia.

\section{Plano de apresentação}

O texto foi estruturado de forma a contemplar alguns aspectos fundamentais associados ao desenvolvimento de procedimentos de análise de monazita (e xenotima) em microssonda eletrônica, aplicações para geocronologia através do método químico de datação $\mathrm{Th}-\mathrm{U}-\mathrm{Pb}_{\mathrm{T}}$ e o 
estudo de processos mineralógicos e relevantes para a compreensão da evolução de rochas metamórficas e graníticas.

Neste panorama, após uma parte introdutória em que são apresentados brevemente algumas caracteristicas cristaloquimicas da monazita, a evolução histórica do método de datação química $e$ as contribuições para o tema deste a sua implementação, o trabalho inclui especialmente três manuscritos preparados para breve submissão em periódicos científicos. No Capítulo II, são apresentados os procedimentos analíticos e de tratamento de dados para datação de monazita desenvolvidos no laboratório, os quais são discutidos e comparados com similares adotados em laboratórios do exterior, à luz da literatura moderna existente sobre o tema. Alguns exemplos mais típicos de aplicação e são apresentados.

No capítulo seguinte (III), pretende-se demonstrar o potencial do método para datação sistemática de eventos metamórficos e do magmatismo granítico peraluminoso em segmentos especificos da crosta continental, utilizando-se para tanto dos dados acumulados nos últimos anos para rochas metamórficas, migmatíticas e graníticas do Terreno Embu e vizinhanças, no estado de São Paulo, região sudeste do Brasil. Este exemplo mostra como o método permite elaborar um arcabouço cronológico lógico e com excelente precisão para a evolução de cinturões metamórficos desenvolvidos sob condições de temperaturas médias a altas. llustra também situações em que, devido a alta resolução espacial, a metodologia é capaz de descriminar química e geocronologicamente populações poligenéticas de monazita e/ou xenotima, as quais podem resultar em idades sem significado geológico real quando analisadas com métodos isotópicos convencionais que se utilizam de "amostras totais" constituidas por cristais isolados ou frações de cristais

O Capítulo IV trata de processos de substituição de monazita e xenotima por coronas de apatita, torita, allanita, epidoto, feições micro-estruturais muito típicas em ortognaisses e granitos da área estudada e discute processos de formação com base em informações microestruturais/texturais e químicas. Estes processos são relevantes para a mineralogia e petrologia das rochas graníticas uma vez que permitem avaliar a estabilidade das fases minerais de interesse e trazem algumas implicações relativas à mobilidade de elementos químicos, 
particularmente os elementos terras raras (RRE) que podem ser relevantes em processos evolutivos da crosta continental.

Os manuscritos são apresentados em português por uma questão formal, mas pretende-se submetê-los em lingua inglêsa. Por esta razão algumas abreviações e notações típicas que aparecem nos textos, tabelas e a maioria dos diagramas e mapas encontram-se com os textos e legendas internos escritos em inglês. Da mesma forma, e também por uma questão de exigüidade de tempo, as figuras, mapas, tabelas e respectivas legendas são apresentadas conjuntamente ao final de cada capítulo, ao invés de inseridas de forma convencional e seqüencial no texto principal.

Finalmente, no capítulo $\vee$ são adicionados alguns comentários gerais sobre o método de datação, outras aplicações e sobre a importância do estudo micro-esturutal, textural e químico de minerais portadores de REE, Th e $U$ em mineralogia, petrologia e geocronologia.

\section{Aspectos cristaloquímicos gerais da monazita}

O grupo da monazita inclui fosfatos e silicatos diversos de REE e Th. A monazita-Ce, o membro mais comum nos ambientes naturais, pode ser representada pela fórmula mínima geral (Ce, La, Nd, Th) $\mathrm{PO}_{4}$ e cristaliza no sistema monoclínico, com cela unitária do grupo espacial $\mathrm{P} 2{ }_{1} / \mathrm{n}$ contendo 4 moléculas (e.g., Chang et al. 1998). A monazita-Ce é um dos membros finais de soluções sólidas parciais que incluem adicionalmente a cheralita $\left[(\mathrm{Th}, \mathrm{Ca}, \mathrm{Ce})(\mathrm{P}, \mathrm{Si}) \mathrm{O}_{4}\right]$ e a huttonita $\mathrm{ThSiO}_{4}$. A sua estrutura é caracterizada por tetraedros $\mathrm{P}(\mathrm{Si}) \mathrm{O}_{4}$ variavelmente distorcidos, aos quais se intercalam poliedros de tipo $\mathrm{MO}_{9}$ ocupados preferencialmente por átomos de $\mathrm{Ce}, \mathrm{o}$ metal mais abundante (e.g. Ueda 1953). Estes poliedros são relativamente grandes e mostram marcada preferência pelos REE mais leves (La-Gd) em detrimento aos REE pesados.

Monazita-Ce é a mais típica da grande maioria das rochas graníticas peraluminosas, de migmatitos e de rochas metapelíticas. Apresenta abundâncias relativas $\mathrm{Ce}>\mathrm{La}>\mathrm{Nd}>\mathrm{Pr}>\mathrm{Sm}>$ Gd que resultam em padrões RRE em geral com fracionamento significativo do lado das LRRE e, naturalmente, entre as LRRE e HREE e que são caracterizados por apresentarem anomalias negativas de Eu bem marcadas. Monazita-La também parece ser relativamente comum (cf. Chang 
et al. 1998), ao passo que monazita-Nd, com concentrações também relativamente altas de Sm e padrão de REE tipicamente côncavo são mais raras, ocorrendo apenas em algumas rochas alcalinas e carbonatitos (e.g. Blanco et al. 1998).

No sítios tetraédricos, o $\mathrm{P}$ pode estar parcialmente substituido por Si, uma troca que implica naturalmente em alguma distorção adicional. Nos sítios $M$, os cations mais comuns, além de $\operatorname{REE}(Y)$ e Th, incluem principalmente $\mathrm{Ca}$ e $U$ em quantidades variáveis. As variações composicionais mais típicas de monazita podem ser descritas, além da subsituição simples $Y \leftrightarrow$ REE, pelas substituições acopladas definidas pelos vetores $[\mathrm{Ca},(T h, U)][R E E]_{-2}$ e $[(T h, U), S i][P]-$ ${ }_{1}[R E E]_{-1}$, denominados brabantítico e huttonítico, respectivamente (Förster 1998). Elementos que ocorrem freqüentemente em quantidades menores ou, mais tipicamente traços, incluem $\mathrm{Ti}, \mathrm{Al}, \mathrm{Fe}$, $\mathrm{Mg}, \mathrm{Mn}, \mathrm{Pb}, \mathrm{S}$ e eventualmente algum $\mathrm{K}, \mathrm{Nb}$ e $\mathrm{Zr}$, além de $\left(\mathrm{H}_{2} \mathrm{O}\right)^{+}$em quantidades inferiores a $1 \%$ em peso (Chang et al. 1998, Förster 1998).

As quantidades relativamente elevadas dos elementos radioativos Th e $U$ (em geral $\mathrm{ThO}_{2}$ até ca. 20.0 e $\mathrm{UO}_{2}$ até 1.5-2.0\% em peso) gera quantidades significativas dos isótopos radiogênicos estáveis de $\mathrm{Pb}\left({ }^{206} \mathrm{~Pb},{ }^{207} \mathrm{~Pb} e{ }^{208} \mathrm{~Pb}\right)$, os últimos das séries radioativas do ${ }^{238} \mathrm{U},{ }^{235} \mathrm{U}$ ${ }^{232} \mathrm{Th}$, respectivamente, no decorrer do tempo geológico. Uma das características mais notáveis deste mineral está associada a adequação do $\mathrm{Pb}$ radiogênico aos sítios $\mathrm{MO}_{9}$ da estrutura, o que torna a monazita um mineral muito resistente aos efeitos colaterais do processo de decaimento radioativo e deve ser destacado que mesmo monazitas formadas há 2-3 Ga, parecem não mostrar efeitos significativos de metamictização e desestabilização estrutural (e.g. Vlach e Dantas 2001). $\mathrm{A}$ adequação do $\mathrm{Pb}$ à estrutura cristalina e adicionalmente o fato que de a sua difusão requer, em princípio, um mecanismo de difusão dupla, descrito por exemplo pela reação $[\mathrm{Pb}(\mathrm{Th}, \mathrm{U})]_{[R E E]_{-2}}$ (e.g. Podor e McCuney 1977) fazem com que a difusão de $\mathrm{Pb}$ no estado sólido seja negligível em temperaturas até ca. $850^{\circ} \mathrm{C}$ ou mais e, portanto, não é de se esperar difusão de $\mathrm{Pb}$ significativa no durante processos petrológicos atuantes em ambientes da crosta continental (e.g. Gardés et al. 2007). Por outro lado, processos de desestabilização de monazita de origem magmática ou metamórfica sob temperaturas médias a altas e abertura dos sistemas químicos e isotópicos - sob a influência de soluções deutéricas e/ou hidrotermais de baixa temperatura, ou ainda associadas à metamorfismo imposto - gerando monazita neoformada por processos de dissolução e 
reprecipitação, ou substiuição parcial por apatita, allanita e/ou epidoto por processos de dissolução e cristalização destas fases são relativamente comuns nestes ambientes (e.g., Finger et al. 1998, Vlach 2001, Seydoux-Guillaume et al. 2002, Vlach submetido).

Estas características, aliadas aos fatos de que a monazita é uma fase que concentra a grande maioria das LREE das rochas e toma parte de reações minerais com potencial geotermométrico, tornaram este mineral extremamente relevante, não somente para a determinação de idades de processos magmáticos e de metamorfismo, mas também para estudos de detalhe que pretendem identificar, analisar e quantificar processos petrológicos relevantes registrados por vezes apenas em micro-escala nestas rochas.

\section{Datação química com microssonda eletrônica: evolução do método e instrumental}

Os primeiro métodos de datação geocronológica concebidos eram de natureza química e se baseavam nas quantidades de $\mathrm{He}$ e/ou $\mathrm{Pb}$ acumuladas nos minerais a partir da desintegração radioativa do $\mathrm{U}$ e/ou Th. Estes métodos foram aplicados com maior ou menor sucesso por diversos pesquisadores, particularmente do exterior (ver revisão em Faure 1986). A partir dos anos 20 do século passado, o desenvolvimento e da disponibilização dos espectrômetros de massa - que permitem a quantiticação de isótopos de elementos químicos - estes métodos foram rapidamente abandonados em detrimento aos baseados em sistemáticas isotópicas, muito mais confiáveis e que resultam em reprodutibilidade e acurácia muito superiores.

O método de datação química, a partir da quantificação de $\mathrm{Th}, \mathrm{U}$ e $\mathrm{Pb}$ total com microssonda eletrônica teve suas origens por volta dos anos 1960. As primeiras aplicações, em minerais como uraninita e torita, e cálculos de idades químicas foram apresentados por Ranchin (1968) e Cuney et al. (1982) in Parslow et al. (1985), mas não despertaram a merecida atenção da comunidade cientifica, em parte devido ao caráter relativamente raro dos minerais estudados por estes autores e em parte devido às dificuldades instrumentais e analíticas inerentes à época. Coube a J. F. W. Bowles em 1990 colocar de forma mais firme o método na literatura, demonstrando a sua aplicabilidade ao estudo de uraninita presente em sedimentos, rochas 
sedimentares, metassedimentares e graníticas, bem como a sua viabilidade geral quando comparado com os métodos isotópicos convencionais. Entretanto, os procedimentos utilizados pelo autor para a conversão dos dados analíticos em idades químicas, bem como as estimativas dos erros envolvidos, eram bem aproximados e simplificados.

O grande impulso para o desenvolvimento e conseqüente difusão do método partiu, sem dúvida, do trabalho pioneiro de Suzuki e Adachi (1991) em que os autores elaboraram uma sistemática coerente e consistente de análise e datação química, denominada CHIME (CHemical (sochron MEthod) e a aplicaram com grande sucesso para monazita, xenotima e zircăo. Neste trabalho, os autores discutem questões analiticas específicas e críticas para cada um destes minerais e desenvolvem procedimentos refinados, muito apropriados, para conversão e tratamento dos dados analíticos. A seguir, Montel e colaboradores (e.g., Montel et al. 1996), além de refinarem alguns detalhes analíticos para monazita, apresentam um esquema alternativo, relativamente mais simples, para o tratamento e a apresentação dos resultados e respectivos erros em uma base estatística clássica, partindo da equação que relaciona as quantidades de $\mathrm{Pb}$ total medidas com as quantidades de $\mathrm{Pb}$ comum, as abundâncias atuais de Th e $\mathrm{U}$ e a idade da amostra. A grande vantagem deste último procedimento é a sua aplicabilidade em quaisquer situações em que as quantidades de $\mathrm{Pb}$ comum (inicial) presentes na monazita, ou seja incorporadas quando da formação do mineral, podem ser negligenciadas quando comparadas às abundâncias totais de $\mathrm{Pb}$, uma condição em geral satisfeita a julgar pelos dados isotópicos existentes na época (e.g. Parrish 1990) e confirmada sistematicamente pela maioria dos dados isotópicos que têm sido apresentados recentemente em literatura.

O procedimento destes últimos autores permite calcular uma idade específica para cada ponto analisado no EPMA, enquanto o procedimento CHIME requer uma boa dispersão de valores pontuais de Th e/ou U para que uma isócrona adequada possa ser bem definida e, naturalmente, parte da premissa de que todos os pontos analisados apresentam a mesma idade ; por outro lado, este último pode ser aplicado em situações em que a abundância de $\mathrm{Pb}$ comum seja significativa porém constante. Uma variante do método isocrônico, de interesse apenas geral, elaborada por Rhede et al. (1996), possibilita a obtenção de idades isocrônicas U-Pb e Th-Pb independentes nos casos em que há significativa dispersão de valores para Th e U na amostra. 
Diversos resultados obtidos com datações isotópicas convencionais com TIMS (Thermic Ionization Mass Spectrometry) já evidenciavam claramente problemas relativamente sérios associados com análise de "amostras totais" (cf. Faure 1986). Entretanto, somente a partir da análise micro-estrutural/textural de detalhe com imagens de eletrons retro-espalhados (BSE) e de cátodo-luminescência (CL), do advento das microssonda iônicas (SIMS, Secondary lon Mass Spectrometry e SHRIMP, Sensitive High Resolution Ion Microprobe, e.g. Compston et al. 1984) e da datação de monazita com microssonda eletrônica, a importância da resolução espacial analítica tornou-se evidente para a comunidade geocronológica e científica em geral. De fato, os trabalhos efetuados mostravam que o caráter poligenético de cristais de zircão e/ou monazita é muito mais a norma do que a exeção, particularmente em se tratando de rochas crustais antigas, de evolução policíclica complexa, e que diferentes zonas intracristalinas podem registrar processos petrológicos distintos e separados no tempo. Adicionalmente, dados micro-analíticos mostram cada vez mais que as assembléias minerais presentes nas rochas com freqüência não se encontram em equilíbrio pleno, podendo incluir frações geneticamente diferenciadas (e.g. Marsh 2006). A resolução destas situações requer naturalmente, equipamentos que permitam análises com alta resolução espacial e, neste particular, a microssonda eletrônica revela-se ímpar por possibilitar a melhor possível.

A partir dos trabalhos pioneiros mencionados, diversos pesquisadores apresentaram contribuições significativas de caráter metodológico ou ilustrando aplicações relevantes para situações geológicas variadas. Vale a pena destacar, entre outras contribuições com enfoque metodológico, os trabalhos de Williams et al. (1999), que apresentam os primeiros mapas composicionais e de distribuição de idades em monazita, de Cocherie et al. (1998), Cocherie e Albarede (2001), que apresentam uma significativa otimização nos procedimentos de cálculo de idades, e, mais recentemente, os trabalhos de Pyle et al. $(2005)$, Jercinovic et al. $(2005,2008)$ e Hetherington et al. (2008). Paralelamente, diversos dados experimentais têm mostrado que a difusão de $\mathrm{Pb}$ na estrutura da monazita é extremamente limitada nas temperaturas comuns observadas em processos de metamorfismo e magmatismo em crosta continental (e.g. SeydouxGuillaume et al. 2002, Gardés et al. 2007), aumentando ainda mais o espectro de aplicação da datação de monazita. 
O laboratório de microssonda do Instituto de Geociências da USP foi pioneiro na implementação e otimização da metodologia de datação química de minerais portadores de Th e/ou $U$ e os principais procedimentos utilizados foram concluídos por volta de 2001 (e.g. Vlach et al., 1999a, Vlach 2001). Procedimentos similares foram implementados no laboratório de microssonda da Universidade Federal do Rio Grande do Sul (Tickyj et al. 2004) mas logo a seguir interrompidos. Atualmente, procedimentos alternativos, avaliação de otimizações adicionais com apoio adicional de técnicas de ICP-MS-LA (Inductively-Coupled Plasma Mass Spectrometry with Laser Ablation) estão sendo estudados e analisados pela Dra. Lucelene Martins, no âmbito do seu pós-doutorado, sob supervisão do autor.

Análises com EPMA com o objetivo de datações químicas $\mathrm{Th}-\mathrm{U}-\mathrm{Pb}_{\mathrm{T}}$ são apenas um caso especial de análises de elementos menores e traços, que exigem cuidados e procedimentos bem mais criteriosos em relação às análises convencionais. O interesse crescente da comunidade científica neste tipo de análise tem motivado os fabricantes de EPMA a otimizar os espectrômetros de dispersão de comprimentos de onda para que as intensidades dos sinais característicos dos elementos $(P)$ sejam incrementadas em relação aos sinais da radiação de fundo $(B)$ e diminuir os limites de detecção e de quantificação, de forma a permitir a quantificação de elementos em pequenas abundâncias com reprodutibilidade e acurácia adequadas. No caso das datações Th-U$\mathrm{Pb}_{T}, \circ \mathrm{Pb}$, que em geral está presente em quantidades da ordem de centenas a pouco milhares de ppm, é o elemento crítico e, como será discutido no Capítulo II, as incertezas das idades químicas dependem essencialmente das incertezas na sua determinação. Nestes panorama, vale a pena destacar particularmente que cristais analisadores de "grande área" e contadores especiais, que resultam em melhoria substancial nas razões $P / B$, têm sido implementados na maioria dos equipamentos produzidos nos últimos anos e incrementado significativamente o potencial do EPMA para análises de elementos menores e traços. Interferências espectrais são também questões críticas na análise destes elementos e diversos modelos para a avaliar a curvatura da radiação de fundo e permitir a determinação mais precisa da sua intensidade sob a linha espectral em análise têm sido otimizados (e.g. Jercinovic et al. 2008). Finalmente, vale também a pena destacar, a título de demonstração da expansão do método, que as versões mais 
recentes do EPMA SX-100 fabricado pela CAMECA já incorporam software opcional específico para procedimentos de datação de monazita.

\section{Compilação de contribuições sobre o tema}

Apresenta-se a seguir uma listagem de trabalhos de base e publicações derivadas de resultados obtidos no laboratório, incluindo aplicações diversas para monazita, xenotima e torita em rochas ígneas e metamórficas do Estado de São Paulo e de outras regiões do Brasil. Este apanhado, embora não comentado caso a caso, ilustra bem a pesquisa efetuada no laboratório durante os últimos anos e a experiência adquirida, bem como dá ao leitor uma idéia da evolução das idéias do autor e co-autores sobre o tema principal da tese.

\section{Softwares}

CORRECT : planilha EXCEL ${ }^{(T M)}$ para correçōes de interferências espectrais simples e múltiplas em espectroscopia de dispersão de comprimentos de onda (WDS), com opção para computação de idades a partir de determinações quantitativas de Th, $\mathrm{U}$ e $\mathrm{Pb}_{\mathrm{T}}$ em minerais portadores de Th e/ou U., 2000.

AGE_MONA : (com colaboraçăo de Guilherme A. R. Gualda): programa para organização, tratamento de dados quantitatitos $\mathrm{Th}-\mathrm{U}-\mathrm{Pb}_{\mathrm{T}}$ e cálculos de idades químicas através de diversos modelos pontuais, incluindo modelamento de Monte Carlo, e isocrônicos, com interface lógica para aplicações no programa Isoplol de (Ludwig 2003), 2001.

\section{Trabalhos inéditos e publicados}

Las monacitas-(Nd) con samario de los diques carbonatificos del sector nororiental de la Sierra de Cobres, Salta, Argentina. Em colaboração com M. Blanco, M. Ulbrich e H. Echeveste. In: Reunión de Mineralogia e metalogenia, 4, 1998, Bahía Blanca. NINMET'98 EDIUNS. p. 63-69, 1998.

Electron microprobe monazite dating: first results for two granites from Southeastem Brazil. Com colaboração de G. Gualda e C. Chiessi. In: South American Symposium on isotope Geology, 2, Cordoba. Actas, p. 518-521, 1999.

Electron microprobe $T h-P b$ and U-Pb monazite dating. Com colaboração de G. Gualda e C. Chiessi. Acta Microscópica, 8: 141-142, 1999. 
Datação de eventos metamórficos em monazita com microssonda eletrônica: exemplos de rochas supracrustais do sudeste brasileiro. Com colaboraçăo de M. Campos Neto e F. Negri. In: Simpósio de Geologia do Sudeste, 6, São Pedro. Resumos, p. 14, 1999.

Sistemática (Th/U)-Pb de datação de monazita em microssonda eletrônica: estudo de rochas metamónficas policíclicas da regiäo de Granja, CE. Com colaboração de J. Nogueira Neto. In: Congresso de Geoquímica dos Paises de Lingua Portuguesa, 5, Porto Seguro. Anais, p. 374-376, 1999

Datação Th/U-Pb de monazita com microssonda eletrônica. Em colaboração com C. Chiessi e G. Gualda. In: Simpósio de Iniciação Cientifica da USP, 7, São Paulo. Resumos, 2: 273, 1999.

Microprobe monazite dating and the ages of some granitic and metamorphic rocks from Southeastem Brazil. Com colaboração de G. Gualda.Revista Brasileira de Geociências, 30(1): 214-218, 2000.

Geocronologia de minerais acessórios pelo método Th-U-Pb total com microssonda eletrônica: monazita, torita, xenotima e uraninita. Programa de pós-Graduação em Mineralogia e Petrologia. Instituto de Geociências. USP. (inédito). 81 p, 2001.

Microprobe monazite constraints for an early (ca. 790 Ma) Brasiliano Orogeny: the Embu Terrane, Southeastern Brazil. In: South American Symposium on Isotope Geology, 3, Pucón. Extended Abstracts Volume $(C D)$, p. 265-268, 2001.

A comparison between chemical and isotopic dating methods: Th-U-total $\mathrm{Pb}$ (monazite, microprobe) and U$\mathrm{Pb}$ (zircon, SHRIMP). Com colaboração de C. Correia. In: South American Symposium on Isotope Geology, 3, Pucón. Extended Abstracts Volume (CD), p. 79-82, 2001.

Polygenetic monazite from the São José do Campestre Massif, Borborema Province, NE Brazil: insights from EPMA chemical and dating studies. Com colaboraçăo de E. Dantas $/ n$ : South American Symposium on Isotope Geology, 3, Pucón. Extended Abstracts Volume (CD), p. 83-86, 2001.

Datação de monazita de ortognaisses da região de Jambeiro, Leste do Estado de São Paulo: um estudo em microssonda eletrônica. Em colaboração com T. Augusto. In: Simpósio Internacional de Iniciação Científica da USP, 9, São Paulo. Resumos (CD), 2001.

Idades $T h-U-P b_{T}$ de monazita e geotermobarometria de rochas metapeliticas de alto grau do Sistema Orogênico Itabuna-Salvador-Curaçá, BA, Brasil: um estudo em microssonda eletrônica. Com colaboração de E. Del Lama. Geologia USP, Série Cientifica, 2: 9-22, 2002.

Structure, metamorphism, and age of the Pampean-Famatian Orogenies in the western Sierra de San Luis. Em colaboração com P. Gonzalez, A. Sato, M. Basei e E. Llambias. In: Congreso Geologico Argentino, 15, Calafate. Actas, 2: 51-56, 2002. 
Magmatismo granítico com idade Pb-Pb de 780 Ma nos Domínios Socorro e Embu na Região de São Francisco Xavier (SP), sudeste brasileiro. Em colaboração com F. Negri, M. Oliveira e M. Maambira. In: Congresso Brasileiro de Geologia, 41, João Pessoa. Anais, 1: 458, 2002.

Quimismo e dataçáo Th-U-Pb em xenotima e monazita: exemplo do Granito Mogi das Cruzes, Leste da Faixa Ribeira, SP, e implicaçöes. In: Congresso Brasileiro de Geologia, 41, João Pessoa. Anais, 1: 479, 2002.

Sistemática de datação de monazita em rochas granítica: identificação de eventos superpostos no Batolito Natividade da Serra pela combinação de TIMS e EPMA. Com colaboração de V. Janasi e A. Alves. In: Congresso Brasileiro de Geologia, 41, João Pessoa. Anais, 1: 511, 2002.

Granitos peraluminosos da porção central da Faixa Ribeira, Estado de São Paulo: sucessivos eventos de reciclagem da crosta continental no Neoproterozóico. Em colaboração com V. Janasi, A. Alves e R. Leite. In: Congresso Brasileiro de Geologia, 41, João Pessoa. Anais, 1: 311, 2002.

Penecontemporaneous syenitic-phonolitic and basic-ultrabasic-carbonatitic rocks at the Poços de Caldas alkaline massif, SE Brazil: geologic and geochronologic evidence. Em colaboração com H. Ulbrich, M. Ulbrich e K. Kawashita. Revista Brasileira de Geociências, 32(1): 15-26, 2002.

Granitos peraluminosos da porção central da Faixa Ribeira, Estado de São Paulo: sucessivos eventos de reciclagem da crosta continental no Neoproterozbico. Em colaboração com V. Janasi, A. Alves e R. Leite. Geologia USP, Série Cientifica, 3: 13-24, 2003.

Química mineral e idades (Th-U)-Pb em monazitas de rochas paraderivadas do Complexo de Granja (Noroeste da Província Borborema). Em colaboração com J. Nogueira Neto, A. Fetter, T. Santos, C. Verissimo, M. Arthaud e M. Lima. In: Congresso Brasiteiro de Geoquímica, 9, Belém. Livro de Resumos Expandidos, p. 407-409, 2003.

Contact metamorphism in metapelites from the Nova Lima Group, Rio das Velhas Supergroup, Quadrilatero Ferrifero: a monazite $T h-U-P b_{T}$ dating by the electron-probe microanalyser. Com colaboração de $M$. Campos Neto, R. Caby e M. Basei. In: South American Symposium on Isotope Geology, 4, Salvador. Short Papers, 1: $307-310,2003$.

Aplicações da microssonda eletrônica (EPMA) em geocronologia e evolução crustal. In: Simpósio 40 anos de Geocronologia no Brasil, 2004, São Paulo. Boletim de Resumos, p. 4, 2004.

Quimica mineral, geoermobarometria e geocronologia $T$ h-U-P $P b_{T}$ em monazita de sillimanita-granada-biotita gnaisses do Complexo Embu, Setor Centro-Sul do Cinturão Ribeira, SP. Em colaboração com F. Negri e A. Teixeira. In: Congresso Brasileiro de Geologia, 42, Araxá. Anais, 2004. 
Early Paleozoic structural and metamorphic evolution of Western Sierra de San Luis (Argentina), in relation to Cuyania accretion. Em colaboração com P. Gonzales, A. Sato, E. Llambias e M. Basei. Gondwana Research, 7:1157-1170, 2004.

Migração de orógenos e superposição de orogêneses: um esboço da colagem brasiliana no Sul do Cráton do São Francisco, SE-Brazil. Em colaboração com M. Campos Neto, M. Basei, R, Caby, G. Szabó e P. Vasconcelos. Geologia USP, Série Cientifica, 4: 13-40, 2004.

Idades ThuPbr em monazite do monzogranito de Calde, Maciço Granitico de Castro Daire (Centro de Portugal). Em colaboração com S. Leite, R. Azevedo e J. Santos. In: Congresso de Geoquímica dos Paises de Lingua Portuguesa, 8, Aveiro. Actas, 1: 231-235, 2005.

Monazite presenvation and formation during anatexis: An example from garnet-bearing migmatite, Brazil. Em colaboração com L Martins e V. Janasi. Geochimica et Cosmochimica Acta, v. 71, p. A629, 2007.

Reaction microtextures of monazite: Correlation between chemical and age domains in the Nazare Paulista migmatite, SE Brazil. Em colaboração com L. Martins e V. Janasi. Chemical Geology. (no prelo), 2008.

\section{Referências bibliográficas}

Blanco, M. ; Ulbrich, M. N. C. ; Echeveste, H. \& Vlach, S. R. F. Las monacitas-(Nd) con samario de los diques carbonatíticos del sector nororiental de la Sierra de Cobres, Salta, Argentina. In: Reunión de Mineralogia e metalogenia, 4, 1998, Bahía Blanca. NINMET'98 EDIUNS, 1998. p. $63-69,1998$.

Bowles, J.F.W., 1990. Age dating of individual grains of uraninite in rocks from electron microprobe analysis. Chemical Geology, 83:47-53.

Campos Neto, M.C., 2000. Orogenic systems from Southwestern Gondwana: an approach to Brasiliano-Pan African Cycle and orogenic collage in Southeastern Brazil. $I n$ : Cordani, U.G., Milani, E.J., Thomaz Filho, A., Campos, D.A. (ed). Tectonic evolution of South America: $31^{\circ}$ International Geological Congress (Rio de Janeiro, Brasil), p. 335-365. 
Chang, L.L.Y., Howie, R.A., Zussman, J., 1998. Rock Forming Minerals, Vol 5B. Nonsilicates:Suiphates, Carbonates, Phosphates, Halides, $2^{\text {nd }}$ Ed., 383 p. The Geological Society, London.

Cocherie, A., Albarede, F., 2001. An improved U-Th-Pb age calculation for electron microprobe dating of monazite. Geochimica et Cosmochimica Acta, 65:4509-4522.

Cocherie, A., Legendre, O. Peucat, J-J., Kouamelan, A.N., 1998. Geochronology of poligenetic monazites constrained by in situ electron microprobe Th-U-total lead determination: Implications for lead behavior in monazite. Geochimica et Cosmochimica Acta, 62:24752497.

Compston, W., Williams, I.S., Meyer, J.I., 1984. U-Pb geocronology of zircons from lunar breccia 73217 using a sensitive high mass-resolution ion microprobe. Journal Geophysical Research, 89 (Supplement B):525-534.

Faure, G., 1987. Principles of isotope geology. $2^{\text {th }}$. John Wiley \& Sons. New York. 589 p.

Finger, F., Broska, I., Roberts, M.P., Schermaier, A., 1998. Replacement of primary monazite by apatite-allanite-epidote coronas in amphibolite facies granite gneiss from the eastern Alps. American Mineralogist, 83:248-258.

Förster, H.-J., 1998. The chemical composition of REE-Y-Th-U-rich accessory minerals in peraluminous granites of the Ersgebirge-Fichtelgebirge region, Germany, Part I: The monazite-(Ce)-brabantite solid solution series. American Mineralogist, 83:259-272.

Gardés, E., Montel, J-M, Seydoux-Guillaume, A.M., Wirth, R., 2007. Pb diffusion in monazite: New constraints from the experimental study of $\mathrm{Pb}^{2+} \leftrightarrow \mathrm{Ca}^{2+}$ interdiffusion. Geochimica et Cosmochimica Acta, 71:4036-4043.

Hetherington, C.J., Jercinovic, M.J., Willians, M.L., Mahan, K., 2008. Understanding geological processes with xenotime: composition, chronology, and a protocol for electron probe microanalysis. Chemical Geology, 254:133-147.

Jercinovic, M.J., Williams, M.L., 2005. Analytical perils (and progress) in electron microprobe trace element analysis applied to geochronology: background acquisition, interferences, and beam irradiation effects. American Mineralogist, 90:526-546. 
Jercinovic, M.J., Williams, M.L., Lane, E.D., 2008. In-situ trace element analysis of monazite and other fine-grained accessoty minerals by EPMA. Chemical Geology, 254:197-215.

Ludwig, K.R., 2003. Isoplot 3.00. A Geochronological Toolkit for Microsoft Excel. Berkeley Geochronological Center Special Publication, 4. 70 p.

Marsh, B.D., 2006. Dynamics of magmatic systems. Elements, 2:287-292.

Montel, J-M., Foret, S. Veschambre, M., Nicollet, C., Provost, A., 1996. Electron microprobe dating of monazite. Chemical Geology, 13:37-53.

Parrish, R.R., 1990. U-Pb dating of monazite and its applications to geological problems. Canadian Journal of Earth Science, 27:1431-1450.

Parslow, G.R., Brandstatter, F., Kurat, G. Thomas, D.J., 1985. Chemical ages and mobility of U and Th in anatectites of the Cree Lake zone, Saskatchewan. Canadian Mineralogist, 23:543-552.

Podor, R., Cuney, M., 1997. Experimental study of Th-bearing $\mathrm{LaPO}_{4}\left(780^{\circ} \mathrm{C}, 200 \mathrm{Mpa}\right)$ : Implications for monazite and actinide orthophosphate stabilyity. American Mineralogist, 82:765-771.

Pyle, J.M., Spear, F.S., Wark, D.A., Daniel, C.G., Storm, L.C., 2005. Contributions to precision and accuracy of monazite microprobe ages. American Mineralogist, 90:547-577.

Ranchin, G., 1968. Contribution à l'étude de la répartition de l'uranium à l'état de traces dans les roches granitiques saines les uranites à teneur élevée du Massif de Saint-Sylvestre (Limousin - Massif Central Français). Science Terre, 13:161-205.

Rhede, E., Wendt, I., Förster, H-H., 1996. A three-dimensional method for calculating independent chemical U-Pb- and Th-Pb-ages of accessory minerals. Chemical Geology, 130:247-253.

Scherrer, N.C., Engi, M. Gnos, E., Jakob, V., Lechti, A., 2000. Monazite analysis: from sample preparation to microproge age dating and REE quantification. Schweizerische Mineralogische und Petrographische Mitteilungen, 80:93-105.

Seydoux-Guillaume, A-M., Paquete, J-L., Wiedenbeck, M., Montel, J-M., Heinrich, W., 2002. Experimental resetting of the U-Th-Pb systems in monazite. Chemical Geology, 191:165181. 
Suzuki, K., Adachi, M. 1991. Precambrian provenance and Silurian metamorphism of the Tsubonosawa paragneiss in the South Kitakami Terrane, Northeast Japan, revealed by the chemical Th-U-total $\mathrm{Pb}$ isochron ages of monazite, zircon and xenotime. Geochemical Journal, 25:357-376.

Tickyj, H., Hartmann, L.A., Vasconcellos, M.A.Z., Phillip, R.P., Remus, M.V.D., 2004. Electron microprobe dating of monazite substantiates ages of major geological events in the southern Brazilian shield. Journal of South American Earth Sciences, 16:699-713.

Ueda, T., 1953. The crystal structure of monazite $\left(\mathrm{CePO}_{4}\right)$. Memoir Collection Sciences, University of Kyoto (Serie B), 20:225-246.

Vlach, S.R.F., 2001. Geocronologia de minerais acessórios pelo método Th-U-Pb total com microssonda eletrônica: monazita, torita, xenotima e uraninita. Programa de pós-Graduação em Mineralogia e Petrologia. Instituto de Geociências. USP. (inédito). 81 p.

Vlach, S.R.F., 2001. Microprobe monazite constrainst for an early (ca. $790 \mathrm{Ma}$ ) Brasiliano Orogeny: The Embu Terrane, Southeastern Brazil. In: South American Symposium on Isotope Geology, 3. Pucón. Extended Abstracts Volume (CD), p. 265-268.

Vlach, S. R. F., 1996. Gequímica de elementos terras raras em allanita e titanita de rochas graníticas de Morungaba (SP) e implicações preliminares. Boletim do Instituto de Geociências da USP (Publicação Especial), 18: 67-69.

Vlach, S.R.F., Dantas, E.L., 2001. Polygenetic monazite from the São José do Campestre Massif, Borborema Province, NE Brazil: insights from EPMA chemical and dating studies. In: South American Symposium on Isotope Geology, 3. Pucón, CH. Extended Abstracts (CD), p. 8386.

Vlach, S.R.F., Gualda, G.A.R., Chiessi, C.M., 1999b. Electron microprobe monazite dating: first results for two granites from Southeastern Brazil. In: South American Symposium on Isotope geology, 2. Cordoba, AG. Actas, 518-521.

Vlach, S.R.F., Gualda, G.A.R., Chiessi, C.M., 1999a. Electron microprobe Th-Pb and U-Pb monazite dating. Acta Microscopica, 8:141-142.

Vlach, S. R. F., Nogueira Neto, J. A., 1999. Sistemática (Th/U)-Pb de datação de monazita em microssonda eletrônica: estudo de rochas metamórficas policíclicas da região de Granja, 
CE. In: Congresso de Geoquímica dos Paises de Lingua Portuguesa, 5, 1999, Porto Seguro. Anais, p. 374-376.

Vlach, S.R.F., Gualda, G.A.R., 2000. Microprobe monazite dating and the ages of some granitic and metamorphic rocks from Southeastern Brazil. Revista. Brasileira de Geociências, $30: 214-218$.

Williams, M.L., Jercinovic, M.J., Terry, M.P., 1999. Age mapping and dating of monazite on the electron microprobe: Deconvoluting multistage tectonic histories. Geology, 27:1023-1026. 


\section{CAPÍTULO II}

\section{Análise e datação $T h-U-P b_{T}$ de monazita em microssonda eletrônica:} procedimentos analíticos e de tratamento de dados

A metodologia de datação de minerais portadores de Th e/ou $U$ com microssonda eletrônica (EPMA), com destaque para monazita, tem se desenvolvido e ganho importância crescente na literatura internacional, particularmente devido a sua grande resolução espacial e versatilidade, as quais permitem correlacionar diversos processos petrológicos específicos, por vezes registrados apenas em micro-escala em minerais e rochas, com idades absolutas. Embora a acurácia do método seja inferior a alcançada com os métodos isotópicos convencionais em até uma ordem de grandeza, a microssonda eletrônica ainda é o equipamento que permite a melhor resolução espacial, alcançando uns poucos $\mu \mathrm{m}^{3}$ em algumas situações.

A quantificação de elementos menores e traços com EPMA com precisão e acurácia adequadas envolve estratégias instrumentais, analíticas e de tratamento de dados próprias, significativamente mais rigorosas quando comparadas com as normalmente empregadas para análises convencionais, uma vez que diversas questões menos relevantes na análise de elementos que ocorrem em quantidades de maiores, podem ser tornar críticas no caso dos - elementos traços. A análise de monazita, xenotima e outros minerais portadores de Th e/ou U com objetivo da datação química Th-U-Pb é um destes casos. Cada EPMA é um equipamento único no que se refere ao número e as características dos espectrômetros de dispersão de 
comprimentos de onda (WDS) e dos respectivos sistemas de automação. Desta forma, procedimentos analítico-instrumentais, particularmente no caso de análise de elementos menores e traços, devem necessariamente se adequar as especificidades de cada laboratório. O melhor protocolo analítico, entre os diversos disponíveis deverá ser o mais simples e o que se utiliza do menor número de artifatos e de correções numéricas. A indisponibilidade de padrões químicos e de idade certificados para monazita é uma questão crítica para a avaliação e aferição do método e dos protocolos com o necessário detalhe.

Neste trabalho, as estratégias analítica e de tratamento de dados adotadas no Laboratório de Microssonda Eletrônica do Instituto de Geociências da Universidade de São Paulo, Brasil, que conta com um EPMA JEOL-JXA8600S e um sistema de automação ThermoNoran-Voyager 4.3, é apresentada, discutida e comparada com similares existentes. A influência de fatores instrumentais (voltagem de aceleração da coluna eletrônica, corrente e diâmetro do feixe eletrônico, características dos detectores e distribuição de pulsos de energia no SCA) e de interferências espectrais sobre os elementos determinantes de idade (Th, $U$ e $P b)$ são destacadas. A mensuração de $\mathrm{Pb}$ pode ser feita por meio de interpolação linear da radiação de fundo, desde que sejam efetuadas correções adequadas para a interferência do Th. Os procedimentos adotados para correção de interferências, propagação dos erros, tratamento de dados e apresentação final das idades químicas e para amostragem e análise são enfatizados.

Alguns exemplos típicos de aplicação, destacando os aspectos mais relevantes do método, são discutidos.

\section{INTRODUÇÃO}

Desde as primeiras aplicações em uraninita e torita (e.g. Parslow et al. 1985, Bowles 1990), a datação quimica $\mathrm{Th}-\mathrm{U}-\mathrm{Pb}_{\mathrm{T}}$ com microssonda eletrônica (EPMA) experimentou grande desenvolvimento nos últimos anos. A alta resolução espacial do EPMA, ainda não alcançada por outra técnica pontual, aliada a possibilidade de se obter simultaneamente informações químicas e 
geocronológicas bem controladas texturaimente em seções delgadas polidas, além do seu caráter em geral não destrutivo, incentivaram muito a sua crescente aplicação.

Nas últimas décadas, a datação química foi aplicada em diversos minerais portadores de Th elou U, como monazita, xenotima, zircão e uraninita (e.g. Suzuki and Adachi 1991, Montel et al. 1996, Cocherie et al. 1998, Williams et al. 1999, Geisler and Schleicher 2000, Kempe 2003). Monazita $\left[(\mathrm{Ce}, \mathrm{La}, \mathrm{Nd}, \mathrm{Th}) \mathrm{PO}_{4}\right]$ é um dos minerais mais apropriados e utilizados porque não incorpora quantidades significativas de $\mathrm{Pb}$ comum quando da sua formação (e.g. Parrish, 1990), em geral contém quantidades de Th e/ou $\mathrm{U}$ que geram teores mensuráveis de $\mathrm{Pb}$ radiogênico em intervalos de tempo geologicamente reduzidos, a difusão de $\mathrm{Pb}$ na sua estrutura é muito baixa em condições crustais (e.g. Cherniak et al. 2004, Gardés et al. 2007) e apresenta distribuição relativamente ampla na crosta continental. Monazita aparece como fase acessória primária em diversas rochas ígneas, metamórficas de médio a alto grau, pegmativos e associações hidrotermais diversas e, como fase detrítica, em sedimentos e rochas psamíticas (e.g. Overstreet 1967, Chang et al. 1998). Uma ocorrência inusitada é descrita em basaltos lunares por Lovering et al. (1974). Adicionalmente, o quimismo de monazita é informação essencial para estudos sobre as condições de saturação dos LRRE em sistemas magmáticos (e.g. Rapp and Watson 1986, Montel 1993, Bea 1996) e determinações geotermométricas em rochas igneas e metamórficas (e.g. Gratz and Heinrich 1998, Pyle et al., 2001).

Estas características coverteram o quimismo e a datação química de monazita em ferramentas poderosas para solucionar problemas geológicos com história evolutiva complexa, envolvendo superposição de processos tectônicos e/ou petrológicos mais ou menos discretos no decorrer do tempo geológico, colocando-os sob uma perspectiva nova. Este potencial incentivou o desenvolvimento de procedimentos analítico-instrumentais e de tratamento de dados refinados, tendo em vista a obtenção de composições químicas e idades precisas e acuradas (e.g. Cocherie et al. 2000, Pyle et al. 2005, Jercinovic and Willians 2005), que trouxeram também significativa contribuição para a análise de elementos traços em geral com EPMA.

A datação química de monazita, xenotima e zircão foi pioneirizada por Suzuki and Adachi (1991) que desenvolveram o método CHIME (CHemical Isochron MEthod). A determinação de idades pontuais em monazita e o seu tratamento estatístico foram elaborados por Montel et al. 
(1996), enquanto Williams et al. (1999) obtiveram os primeiros mapas de distribuição de idades em cristais. O método é simples e baseia-se na mensuração de $\mathrm{Th}, \mathrm{U}$ e $\mathrm{Pb}_{\mathrm{T}}$ com precisão e acurácia adequadas. Entretanto, fatores que incluem desde a preparação de amostras, o set-up instrumental, a calibração e a leitura de intensidades, até o tratamento dos dádos introduzem diversos tipos de erro, cuja abordagem requer cuidados específicos (e.g. Scherrer et al. 2000, Pyle et al. 2005, Jercinovic and Williams 2005, Lisowiec 2006).

Procedimentos para datação de monazita, xenotima e torita, foram desenvolvidos no Laboratório de Microssonda Eletrônica do Instituto de Geociências da Universidade de São Paulo há vários anos (Vlach et al. 1999a, 1999b) e desde então têm sido otimizados e aplicados com sucesso em diferentes situações geológicas (e.g. Vlach and Gualda 2000, Vlach and Del Lama 2002, Vlach et al. 2003, Martins et al. 2008). Neste trabalho apresenta-se uma revisão dos conceitos e dos principais fatores que afetam a precisão e a acurácia do método, com ênfase em monazita, e a abordagem proposta pelo laboratório. Vantagens e desvantagens dos diferentes modelos para redução e conversão de dados e apresentação de resultados são discutidos, tendo em vista a obtenção de idades e informações químicas que subsidiem interpretações geológicas e petrológicas consistentes. Alguns exemplos de aplicações para situações geológicas típicas e dos resultados obtidos no laboratório são apresentados e discutidos.

\section{FUNDAMENTOS TEÓRICOS E PREMISSAS}

Em sistemas fechados com Th e $U$, a quantidade total de $\mathrm{Pb}$ presente após decorrido um certo intervalo de tempo será igual a soma da quantidade de $\mathrm{Pb}$ presente inicialmente no sistema $\left(\mathrm{Pb}_{0}\right.$, inicial ou comum) com a produzida pelo decaimento dos isótopos radioativos de $T h$ e $U$. Após alcançado o equilíbrio secular das séries radioativas do Th e do $U$, a razão de produção dos isótopos estáveis de $\mathrm{Pb}$ é proporcional à razão de decaimento dos isótopos radiogênicos destes elementos. As equações de decaimento radioativo e de produção dos isótopos estáveis de $\mathrm{Pb}$ podem ser escritas na forma: 
${ }_{90}^{232} \mathrm{Th} \rightarrow{ }_{82}^{208} \mathrm{~Pb}+6 \alpha+4 \beta^{-}+39,8 \mathrm{MeV} /$ atom $\quad \mathrm{e} \quad{ }_{82}^{208} \mathrm{~Pb}={ }_{82}^{208} \mathrm{~Pb}_{0}+{ }_{90}^{232} \mathrm{Th} \times \exp \left({ }^{232} \lambda_{7 h} t-1\right)$ (Eq. 1)

${ }_{92}^{238} U \rightarrow{ }_{82}^{206} \mathrm{~Pb}+8 \alpha+6 \beta^{-}+47,4 \mathrm{MeV}$ /atom e $\quad{ }_{82}^{206} \mathrm{~Pb}={ }_{82}^{206} \mathrm{~Pb}_{0}+{ }_{92}^{238} U \times \exp \left({ }^{238} \lambda_{U} t-1\right)$ (Eq. 2$)$

${ }_{92}^{235} U \rightarrow{ }_{82}^{207} \mathrm{~Pb}+7 \alpha+4 \beta^{-\prime}+45,2 \mathrm{Mev} /$ atom $\quad$ e $\quad{ }_{82}^{207} \mathrm{~Pb}={ }_{82}^{207} \mathrm{~Pb} b_{0}+{ }_{92}^{235} U \times \exp \left({ }^{235} \lambda_{U} t-1\right) \quad$ (Eq. 3)

em que as partículas $\alpha$ representam núcleos de $\mathrm{He}\left({ }_{2}^{4} \mathrm{He}\right)$, as partículas $\beta^{-}$representam elétrons e $t$ é o tempo decorrido. $O$ subescrito 0 indica as quantidades isotópicas iniciais e $\lambda$ é a constante de decaimento radioativo.

O conteúdo total de $\mathrm{Pb}$ presente no sistema de referência é dado pela soma das contribuições destas séries radioativas, resultando na equação transcendental :

$P b_{T}=P b_{0}+T h \times K^{T h} \times\left(\exp \left({ }^{232} \lambda_{T h} t\right)-1\right)+U \times\left[K^{U 8} \times\left(\exp \left({ }^{238} \lambda_{U} t\right)-1\right)+K^{U 5} \times\left(\exp \left({ }^{235} \lambda_{U} t\right)-1\right)\right]$

em que $\mathrm{Pb}_{T}$, Th e $U$ são os teores totais de $\mathrm{Pb}$, Th e $\mathrm{U}$, expressos em \% em peso, presentes após decorrido o tempo $t$ (em anos), $\mathrm{Pb}_{0}$ é a quantidade inicial de $\mathrm{Pb}(t=0)$ e $\lambda$ é a constante de decaimento radioativo $\left({ }^{232} \lambda_{\text {Th }}=4.94752 \mathrm{E}-11,{ }^{238} \lambda_{U}=15.5125 \mathrm{E}-11 \mathrm{e}{ }^{235} \lambda_{U}=\right.$ 98.4850E-11, Steiger and Jäger 1977), dadas em ano ${ }^{-1}$. As constantes $\mathrm{K}$ contemplam abundâncias isotópicas relativas $(A b)$ e massas atômicas elementais $(A r): K^{\text {Th }}=$ $\left(A b^{232} \mathrm{Th}\right)\left(\mathrm{Ar} r^{208} \mathrm{~Pb}\right) /(\mathrm{ArTh}), \mathrm{K}^{\mathrm{U8}}=\left(\mathrm{Ab} b^{238} \mathrm{U}\right)\left(\mathrm{Ar}{ }^{206} \mathrm{~Pb}\right) /(\mathrm{ArU}), \mathrm{K}^{\mathrm{U5}}=\left(\mathrm{Ab}^{235} \mathrm{U}\right)\left(\mathrm{Ar}{ }^{207} \mathrm{~Pb}\right)(\mathrm{ArU})$ e valem $0.896405,0.859157$ e 0.006261 , respectivamente.

Esta é a equação fundamental para o cálculo da idade de sistemas fechados, a partir de quantidades atuais medidas de $T h, U$ e $\mathrm{Pb}_{\mathrm{T}}$, quando $\mathrm{Pb}_{0}$ é conhecido, insignificante em relação ao $\mathrm{Pb}_{\mathrm{T}}(\cong 0)$, ou ainda constante. Merece ser ressaltado que não existem garantias plenas de que as premissas embutidas sejam sempre rigorosamente válidas e, como medida de precaução, os resultados devem ser tomados a priori como datas, as quais são atribuídas o status de idade quando têm significado geológico e representatividade reais. 
Monazita é muito resistente a fenômenos de metamictização (Karioris et al 1991) e as quantidades incorporadas de $\mathrm{Pb}$ quando da sua formação $\left(\mathrm{Pb}_{0}\right)$ parecem ser insignificantes na maioria dos casos, raramente uitrapassando ca. $1 \%$ do $\mathrm{Pb}$ radiogênico acumulado em poucas centenas de milhões de anos (Parrish 1990, Kingsbury et al. 1993). Ao contrário do zircão, o Pb é estável na estrutura da monazita (Podor e Cuney 1997) e apresenta coeficientes de difusão muito baixos nos intervalos de temperatura e de tempo em que ocorrem os principais processos geológicos na crosta continental (Seydoux-Guillaume et al. 2002, Cherniak et al. 2004, Gardés et al. 2007).

\section{CONDIÇÕES INSTRUMENTAIS E ANALITICAS}

A análise de elementos traços $(<10000 \mathrm{ppm})$ com EPMA exige um exame mais cuidadoso das condições instrumentais, analíticas e de eventuais procedimentos para correção de interferências espectrais, tornando-se por vezes desafios interessantes. Este é o caso da datação química, uma vez que os minerais adequados podem apresentar quantidades de Th e/ou $U$ e, particularmente $\mathrm{Pb}_{\mathrm{T}}$, desta ordem de grandeza. Adicionalmente, existem diversas configurações instrumentais para um EPMA (e.g. Goldstein et al. 1992, Reed 1993) e, mesmo em equipamentos equivalentes, cada componente (e.g., espectrômetros, cristais analisadores, contadores e amplificadores de pulsos) apresenta características próprias e deve ser considerado único.

A otimização dos procedimentos analíticos visa a obtenção de dados quantitativos de qualidade, com precisão e acurácia adequadas para os elementos determinantes de idade (Th, $U$, $\mathrm{Pb}_{\mathrm{T}}$ ) em um intervalo de tempo compativel, utilizando-se da abordagem mais simples possivel. Os principais fatores a serem considerados são revisados e discutido a seguir, após a apresentação do instrumental disponível no nosso laboratório. 
Instrumentação

O EPMA do laboratório de Microssonda Eletrônica do Instituto de Geociências da Universidade de São Paulo é um equipamento JEOL-JXA8600S com 05 espectrômetos WDS com Círculo de Rowland de $140 \mathrm{~mm}$. Cada espectrômetro dispõe de dois cristais analisadores intercambiáveis de tipo Johann (Johann 1931, in Reed 1993), dois dele, um (E1, com cristais STE/TAP), outro (E2, TAP/PET), são providos de contadores proporcionais de fluxo com janela de polipropileno e fluxo contínuo de ca. $90 \% \mathrm{Ar}+10 \%$ metano (P10) sob pressão atmosférica; os três outros espectrômetros (E3-E5, PET/LiF) apresentam contadores selados com fina janela de Be, prenchidos com $X e$ sob baixa pressão ( $<60$ torr). Janelas colimadoras de raios $X$ com fendas de 300,500 e $3000 \mu \mathrm{m}$ permitem minimizar a desfocalização em relação ao ângulo ideal de difração de Bragg. $O$ ângulo take-off dos raios $X$ é $40^{\circ}$ e as posições de sintonização espectral são dadas em L, a distância, em $\mathrm{mm}$, do centro do cristal analisador ao ponto de incidência do feixe eletrônico na amostra:

$$
L(m m)=n \times \frac{R}{d} \times \lambda
$$

em que $R(\mathrm{~mm})$ é o raio do Círculo de Rowland, d $(\AA)$ o espaçamento interplanar do cristal analisador, $\lambda(\AA)$ o comprimento de onda da radiação, $n$ a ordem da difração e $60 \leq L \leq 260$. $O$ passo mínimo do motor dos espectrômetros é $0.005 \mathrm{~mm}$.

O sistema é completado com um espectrômetro de dispersão de energia (EDS) de fabricação NORAN e um sistema Voyager (vs. 4.1.1) de fabricação THERMO-NORAN para automação e redução de dados analíticos. As correções para os efeitos de matriz e as transformações de intensidades em \% atômicas e em peso de elementos ou óxidos são efetuadas rotineiramente com o programa PROZA (e.g. Bastin e Heijligers 1990).

Um cold finger pode ser usado para minimizar a contaminação da amostra. O EPMA e o sistema de automação estão ligados a uma linha de energia limpa provida por um grupo no-Break, alimentado pela rede ou alternativamente por um grupo gerador que, além de evitar interrupções no trabalho, dá grande estabilidade e os sistemas são desligados apenas para manutenção. A 
sala em que se situa o EPMA é isolada e conta com climatização de tipo air-split que resulta em variações de temperatura inferiores a $1^{\circ} \mathrm{C}$ em condições controladas de trabalho.

As seções delgadas polidas de rocha são preparadas com o equipamento automático de desbaste e polimento PM4 de alta precisão da Logitech, utilizando-se de alumina para polimento. Grãos são montados sobre lâminas delgadas com resina convencional e depois polidos. A metalização é feita com $C$ em um evaporador Auto-306 da Edwards Instruments sob vácuo de $2.10^{-5}$ torr. A espessura da película de $C(250 \pm 15 \mathrm{~nm})$ é controlada com fino filme de quartzo.

Uma platina automática Digimax, da MicroBeam, acoplada a um microscópio petrográfico com luzes transmitida e refletida permite marcar coordenadas $(x, y)$ de localização de pontos com excelente precisão. Uma planilha converte estas coordenadas para as equivalentes na platina do EPMA, facilitando muito o posicionamento de pontos para análise.

\section{Set-up instrumental}

A escolha das condições do feixe eletrônico incidente depende da composição da amostra e dos objetivos do trabalho e é sempre um compromisso entre fatores como resolução espacial, efeitos de matriz, estatística de contagens, deteriorização da amostra e pode ser tarefa difícil, particularmente quando a amostra contêm elementos leves e pesados. A maximização das contagens, da razão $P / B$ (razão entre as intensidades de pico e background) e da resolução espacial e minimização dos limites de deteç̧ão e da deteriorização da amostra são os objetivos a serem perseguidos. A voltagem de aceleração da coluna eletrônica e a corrente do feixe são os parâmetros principais a ser considerados, mas procedimentos que envolvem intensidades de sinais elevadas e problemas de interferência espectral exigem cuidados específicos com efeitos de tempo-morto e com a análise da distribuição de pulsos (PHA, Pulse Heigh Analysis) no Single Channel Analyser (SCA), que serão discutidos seguir. A utilização de janelas colimadoras com fendas estreitas otimiza as razões $P / B$ e aumenta a resolução espectral, mas acarreta desvantagens relacionadas à diminuição das intensidades totais e à focalização da amostra, entre outras (e.g. Reed 1993) e no procedimento adotado no laboratório as fendas são colocadas em 
largura máxima. Defletores eletrostáticos evitam a entrada de eletrons espalhados nos detectores de raios $X$.

\section{Voltagem de aceleração da coluna eletrônica}

A intensidade dos raios $X$ característicos depende da sobrevoltagem (U, a razão entre a energia do feixe incidente, $E_{0}$ e a energia critica de excitação de uma determinada linha espectral, $E_{c}$ ) e pode ser aproximada para $(U-1)^{1.67}$ (e.g. Reed 1993). Valores entre 2 e 3 são em geral apropriados para a obtenção de sinais adequados. As energias criticas de excitação para as linhas medidas para elementos de interesse em monazita situam-se entre $1.84 \mathrm{keV}$ (Si K) e ca. $7.0 \mathrm{keV}$ (MREE L); Th, $\mathrm{U}$ e $\mathrm{Pb}$ apresentam energias das linhas $\mathrm{M}$ de $3.32,3.56$ e $2.50 \mathrm{keV}$, respectivamente, assim um valor mínimo de $E_{0} \approx 15 \mathrm{keV}$ é necessário. Na literatura, são encontrados valores entre 15 e $25 \mathrm{kV}$ para a voltagem de aceleração da coluna (Williams 1996, Scherrer et al. 2000). $O$ aumento de $U$ resulta em intensidades de sinais e razões $P / B$ mais elevadas e, portanto, em limites de deteç̧ão menores, mas a penetração dos eletrons na amostra será maior, aumentando o volume de produção raios $\mathrm{X}$ e a sua absorção, diminuindo a resolução espacial analítica.

Simulações dos volumes de interação dos eletrons e de produção de raios $X$ para $\mathrm{Ce}, T h$, $\mathrm{U}$ e $\mathrm{Pb}$ em função da energia do feixe são apresentadas por Pyle et al. (2005) para composiçōes de monazita com teores moderados e altos de Th mostram que eles são similares sob $15 \mathrm{keV}$, mas bem constratados para $25 \mathrm{keV}$. Entretanto, os volumes de emissão de raios $\mathrm{X}$ são os mais relevantes. Na Figura 1 apresentam-se curvas $\phi(\rho z)$ de geração e emissão de raios $X$ calculadas com o programa PROZA para elementos de interesse em monazita com composição típica, para energias de 15 e $25 \mathrm{keV}$. Estes diagramas mostram que a resolução espacial obtida para $15 \mathrm{keV}$ é bem superior à obtida com $25 \mathrm{keV}$ e que a razão entre os raios $\mathrm{X}$ emitidos e produzidos é bem inferior para $25 \mathrm{keV}$, devido a sua maior absorção na amostra. Mais imortante, é a verificação de que sob $25 \mathrm{keV}$, os volumes de emissão dos raios $\mathrm{X}$ característicos $\mathrm{Pb} M$ são significativamente diferentes, mais rasos, que os volumes de Th M e U M e, em menor grau que os volumes de $Y L$, 
estes mais reduzidos, assim como os volumes para Si K e P K, não apresentados nas figuras. Portanto, se existem variações composicionais significativas na escala destas diferenças, a análise perderá qualidade. Adicionalmente, as voltagens mais elevadas podem acentuar problemas de fluorescência secundária nas zonas limitrofes entre domínios composicionalmente distintos.

A utilização de uma voltagem de aceleração da coluna de $15 \mathrm{kV}$ é mais adequada para resolver variações composicionais finas. Voltagens mais elevadas $(20,25 \mathrm{kV})$ podem ser empregadas para cristais homogêneos, ganhando-se alguma precisão analítica pontual (Scherrer et al. 2000, Pyle et al. 2005), mas o ganho nos erros de médias populacionais calculadas em procedimentos de datação é pequeno.

\section{Corrente e diâmetro do feixe eletrônico}

Para uma determinada voltagem, a intensidade dos sinais aumenta com a corrente do feixe eletrônico. Entretanto, quanto maior a corrente, maior o diâmetro mínimo possivel para o feixe eletrônico e maior o aumento da temperatura no ponto de impacto sobre a amostra, que pode trazer, como conseqüencia séria, a deteriorização da amostra. A variação de temperatura é dada pela equação de Castaing (1951):

$\Delta T\left({ }^{0} K\right)=4,8 \times \frac{i_{B} \times E_{0}}{\lambda_{r} \times d}$ 
em que $i_{B}(\mu A)$ é a corrente, $E_{0}(k e V)$ a energia e $d(\mu \mathrm{m})$ o diâmetro do feixe eletrônico. $\lambda_{T}$ é a constante de condutibilidade térmica da amostra $(\mathrm{W} / \mathrm{cmK})$ que varia entre 0 e 1 , sendo máxima em metais. Correntes da ordem de $300 \mathrm{nA}$ resultarão em variações $\Delta \mathrm{T}$ da ordem de $300^{\circ} \mathrm{K}$ para valores de $\lambda_{T}$ típicos de materiais cristalinos (ca. 0.1 ), sendo 15 vezes maiores que as produzida sob condições convencionais $(20 \mathrm{nA})$. O aumento do diâmetro do feixe contorna parcialmente este problema, mas diminui a resolução espacial.

A deteriorização da amostra altera a intensidades medidas dos raios $X$ e a corrente da amostra. Metalização homogênea e de alta qualidade e uma ligação eficiente entre a cobertura e o porta-amostra são necessários. Nos procedimentos analíticos convencionais utiliza-se $C$, mas as suas condutividades elétrica e térmica relativamente baixas podem acarretar deteriorização severa sob correntes elevadas (e.g. Goldstein et al. 1992). A combinação de uma voltagem mais elevada com correntes mais baixas pode ser uma solução em alguns casos. A metalização com Au minimiza este efeito, mas introduz indesejáveis linhas da familia $A u M \gamma$ nas zonas espectrais de interesse para a datação química e aumenta a absorção dos raios $X$ emitidos (Jercinovic $e$ Williams 2005); adicionalmente, dificulta a utilização dos mesmos padrões para datação e para análises quantitativas convencionais de outros minerais. Fenômenos de migração dos elementos mais leves ( $P, S i$ e $S$ quando presente), ou mesmo volatilização, acarretam incrementos proporcionais das intensidades dos elementos mais pesados (Th, $U, P b$ e REE). Jercinovic e Williams (2005) mostram significativo aumento do coeficiente de retro-espalhamento nos pontos analisados em monazita com metalização de $\mathrm{C}$, indicativos de aumento do número atômico médio. Adicionalmente, quando existe vaporização, buracos podem ser produzidos no ponto de impacto do feixe, eliminando a condição de planidade da superficie (Reed 1993) essencial para quantificaçăo.

Testes efetuados no laboratório sob correntes, diâmetros de feixe e tempos de integração de contagens variados em cristais com composições diversas, mostraram que, em geral valores

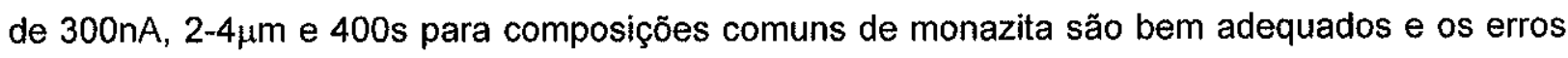
introduzidos podem ser acomodados no erro sistemático associado ao método. Na Figura 2 
apresenta-se um diagrama que ilustra as variações das intensidades medidas para $\mathrm{Ce} L \alpha$, Th $M \alpha$, U M $\beta, Y L \alpha$ e $\mathrm{Pb} M \alpha$ em função do tempo. Entre 0 e $450 \mathrm{~s}$, as intensidades de $\mathrm{Th}, \mathrm{U}, \mathrm{Y}$ e $\mathrm{Pb}$ parecem se manter constantes, mas observa-se para $\mathrm{Ce}$, o elemento mais abundante, um aumento leve e progressivo até ca. $450 \mathrm{~s}$, passando-se de valores médios de 3300 para $3350 \mathrm{cps}$ $(1.5 \%)$, seguido por uma queda brusca para $3200 \mathrm{cps}$, que também afeta os demais elementos. Após 550 s observou-se uma queda de $6 \%$ na corrente absorvida pela amostra. No caso de padrões, lidos sob as mesmas condições da amostra, estes efeitos podem ser desprezados, uma vez que os tempos típicos de leitura são de 10 s ou menos.

Para minimizar eventuais variações, $U$ e $\mathrm{Pb}$ são lidos simultaneamente; Th é lido também junto a maior parte do tempo (após as leituras de $\mathrm{P}$ e, eventualmente, $\mathrm{S}$ ). O sistema Voyager monitora constantemente a corrente absorvida, permitindo ao operador avaliar a deteriorização amostral em tempo real. Para uma corrente do feixe de $300 \mathrm{nA}$, a corrente absorvida varia entre 217 e 208 nA em dependência da composição da monazita. Testes simples ao início de uma rotina para datação permitem verificar se ocorrem variações bruscas, intermitentes, ou se as variações totais são superiores a ca. $4 \%$. Se não existem evidências de problemas de preparação de amostras, como no caso comum de análise de xenotima ou de monazita com quantidades mais elevadas de $\mathrm{S}$, diminue-se a corrente e/ou o tempo total de integração de contagens.

\section{Tempo-morto e análise da distribuição de pulsos (PHA)}

As intensidades medidas precisam ser corrigidas para o feito do tempo-morto, o tempo necessário para que o sistema eletrônico termine de processar um foton e esteja apto a reconhecer um novo que chega. Este efeito é particularmente relevante quando altas razões de contagens (cps, counts per second) estão envolvidas e quando estas são bem distintas em padrões e amostras. O tempo morto depende das características e do set-up dos detectores e da eletrônica envolvida na amplificação e transmissão dos sinais (e.g. Goldstein et al. 1992, Reed 1993) e, portanto, é específico para cada espectrômetro de cada equipamento. Valores típicos se situam entre 1 e $2 \mu$ s e, para um valor de $2 \mu$ s, uma intensidade medida de $10000 \mathrm{cps}$ 
corresponderá a uma intensidade real de $10200 \mathrm{cps}(2 \%)$. No laboratório, sob condições de $15 \mathrm{kV}$ e $300 \mathrm{nA}$, os padrões $\mathrm{UO}_{2}, \mathrm{ThSiO}_{4}, \mathrm{PbS}, \mathrm{PbCr}_{2} \mathrm{O}_{4}, \mathrm{YAIG}$ (granada sintética de $\mathrm{Y}$ e Al) e $\mathrm{YPO}_{4}$ apresentam contagens líquidas da ordem de 40500,17000, 21000, 15000, 102000 e $117000 \mathrm{cps}$ para as linhas $U M \beta$, Th $M \alpha, P b M \alpha$ e $Y L \alpha$, enquanto que uma típica monazita de um granito $\left(\mathrm{ThO}_{2}=4.42, \mathrm{UO}_{2}=0.186, \mathrm{PbO}=0.176\right.$ e $\mathrm{Y}_{2} \mathrm{O}_{3}=1.87, \%$ em peso $)$ apresenta $800,62,30$ e 2940 cps, respectivamente.

O tempo-morto deve ser determinado experimentalmente para cada espectrômetro. Em espectrômetros WDS, ele pode ser considerado de tipo no-extendable e ser obtido plotando-se a razão entre as intensidades medidas e a corrente do feixe vs intensidades medidas (e.g. Reed 1993), utilizando-se, por exemplo, de leituras de padrões metálicos sob correntes variadas. No equipamento JEOL-JXA8600 do laboratório, os valores obtidos variam de 2.4 (E1) a 1.8 (E2) e entre 1.5 e 1.2 (E3, E4 e E5) $\mu \mathrm{s}$.

A voltagem dos pulsos no SCA depende, entre outros fatores eletrónicos (cf. Goldstein et al. 1992) da energia do foton considerado, do ganho dos amplificadores e da voltagem aplicada aos detectores (Bias) e do tipo de detector. A seleção de uma janela de energia, fixando uma linha de base e o intervalo da janela (ou seja, modo diferencial), no SCA permite filtrar pulsos devidos a ruídos, radiação de fundo, interferências espectrais e pulsos decorrentes de ordens de difração superiores a 1, quando as suas voltagens se situam em intervalos distintos das características do pulso a ser medido. Uma precaução a ser tomada, quando se trabalha com contagens muito elevadas está relacionada a possibilidade de drift na distribuição de pulsos em direção a voltagens mais baixas, atravessando a linha de base fixada e acarretando perda de contagens (e.g. Goldstein et al. 1992, Reed 1993). No caso de monazita a utilização do modo diferencial é essencial para minimização de interferências e otimização das razões P/B (v. a seguir), mas o seu set-up deve considerar também os padrões, uma vez que alguns deles produzem intensidades entre 1 e 2 ordens de grandeza superiores.

\section{Set-up elemental: interferências espectrais, contornos e correções}


Um dos aspectos desafiadores na análise de monazita é a presença de interferências nas linhas espectrais dos RRE e dos elementos determinantes de idade, particularmente $U$ e $P b$, em elevado número. Diversas podem ser eliminadas selecionando-se linhas espectrais e/ou off-sets para leitura de bakground e/ou janelas de energia adequados, após análise detalhada de espectros WDS das regiões de interesse e das distribuições de pulsos no SCA. Sempre que possivel este procedimento deve ser preferido; entretanto, existem interferências que não podem ser contornadas e necessitam de correção. Procedimentos e protocolos para a análise de diversos minerais de ETR encontram-se discutidos exaustivamente em literatura (e.g. Williams 1996, Reed e Buckley 1998 e referências citadas). A seguir dar-se-á ênfase apenas aos elementos relevantes para o procedimento de datação, particularmente de monazita. O protocolo utilizado no laboratório para análise e datação de monazita-Ce é sumarizado na Tabela1.

\section{Varreduras espectrométricas WDS}

A resolução espectral depende de fatores geométricos do cristal analisador, do raio do Círculo de Rowland (Reed 1993) e das características de cada equipamento. Modelamentos matemáticos permitem uma boa aproximação para os espectros WDS sob condições instrumentais e para quaisquer composições desejadas e permitem avaliar problemas de interferência e definir parâmetros analíticos a priori, os quais devem ser refinados experimentalmente. O programa Virtual WDS (Reed e Buckley 1996) é utilizado rotineiramente no laboratório para esta tarefa.

As linhas $M$ de Th, $U$ e Pb são quantificadas utilizando-se de cristais PET. As linhas M $\alpha$ apresentam intensidades até ca. $30 \%$ superiores às das linhas $\mathrm{M} \beta$ e são mais adequadas. No caso dos detectores de fluxo $(\mathrm{P} 10)$ esta relação é menor para o U devido à linha de absorção Ka do $\operatorname{Ar}$ (cf. Goldstein et al. 1992). De qualquer forma, a linha U M é em geral escolhida devido à interferência muito severa da linha $M \beta$ do Th sobre a linha $M \alpha$ do $U$.

Cristais PET apresentam excelente refletividade, mas a sua resolução é relativamente baixa e, além de se deteriorarem mais facilmente que cristais TAP e LiF, apresentam coeficiente 
de expansão linear relativamente alto (ca. 1.2E-4 $\perp$ a (002), Jenkins e DeVries 1982, Reed 1993), sendo muito susceptiveis às variações de temperatura, as quais provocam desvios na posição de sintonização das linhas espectrais. Em um espectrômetro típico, as variações $(\Delta \mathrm{L}) /{ }^{\circ} \mathrm{C}$ são da ordem de $0.015,0.018,0.025 \mathrm{~mm}$ nas posições de $U \mathrm{M} \beta$ (119.02), Th $\mathrm{M} \alpha$ (132.54) e $\mathrm{Pb} \mathrm{M} \alpha$ (169.31), respectivamente. Pyle et al. (2005) estimaram uma perda de intensidade de ca. $20 \%$ da linha $\mathrm{Pb} \mathrm{M} \alpha$ para uma variação de $5^{\circ} \mathrm{C}$; naturalmente, este efeito aumenta com o aumento da resolução espectral. Na prática as intensidades medidas de $\mathrm{P} \mathrm{K \alpha}\left(\mathrm{L}=197.24 \mathrm{~mm}, \operatorname{com}(\Delta \mathrm{L}) /{ }^{\circ} \mathrm{C} \cong\right.$ 0.035) podem ser utilizadas para monitorar este efeito. No laboratório ele não parece relevante em condições bem controladas de trabalho.

O tipo de detector utilizado (P10 vs $\mathrm{Xe}$ ) resulta em diferenças significativas nos espectros de interesse. A linha de absorção $K$ do $\operatorname{Ar}\left(3.202 \mathrm{keV}, L_{A}=123.98 \mathrm{~mm}\right)$ traz diminuição significativa da intensidade da radiação de fundo para valores maiores de $L_{A}$ e aumenta significativamente as razões $P / B$ (e.g. Goldstein et al. 1992), enquanto a linha de absorção $L$ do Xe aparece somente em $L=72.82 \mathrm{~mm}$. Adicionalmente, as diferentes energias de $\mathrm{K} \alpha$ do $\mathrm{Ar}$ $(2.957 \mathrm{keV})$ e $\mathrm{L} \alpha 1$ do $\mathrm{Xe}(4.109 \mathrm{keV})$, geram picos de escape com voltagens diferentes no SCA. A intensidade dos picos de escape é da ordem de $5 \%$ da intensidade do pico principal no primeiro caso, mas bem inferior no segundo, devido a maior dificuldade de absorção das linhas do $X e L$ no respectivo gás (Reed 1993). A influência destes fatores com ênfase para o set-up de U e $\mathrm{Pb}$ é analisada por Pyle et al. (2005). No laboratório, ambos elementos são lidos em espectrômetros com detectores de $\mathrm{Xe}(\mathrm{E} 3, \mathrm{E} 4)$, enquanto o Th é lido no espectrômetro E2 (P10).

A linha ThM $\alpha$ é de mensuração simples. Interferências menores nas regiões de interesse para leitura de background incluem Nd L $\beta 2-15$, Ce Ly, Gd L $\alpha 1$ e La Ly no lado negativo e Nd L $\beta 6$ no lado positivo. São linhas de segunda ordem que podem ser eliminadas ou minimizadas através de PHA; entretanto, deve-se cuidar de amostras com teores relativamente baixos de The altos de $\mathrm{Nd}$ e/ou Gd respectivamente, porque o pico de escape Ar K $\alpha-G d L \alpha 1$ tem energia similar a da linha Th M $\alpha$. Na prática, considerando a intensidade teórica dos picos de escape, esta interferência pode ser desconsiderada para as concentrações de Gd normalmente encontradas em monazita comum. 
Interferências relevantes para a quantificação de $U \mathrm{M} \beta$ e $\mathrm{Pb} M \alpha$ são destacadas por Susuki e Adachi (1991), Scherrer et al. (2000) e Pyle et al. (2005), entre outros. Varreduras detalhadas para as regióes de interesse obtidas com o nosso equipamento para composições típicas de monazita são apresentadas nas Figuras 3 e 4.

A linha $U M \beta$ apresenta interferências severas de linhas $M$ de primeira ordem do $T h$, particularmente Th $\mathrm{M} \gamma$, de $\mathrm{K} \mathrm{K \alpha}$, além da linha de absorção Th AM5 (Figura 3). As interferências do Th podem ser contornadas ou corrigidas numericamente (cf. item seguinte) e K é tipicamente ausente em monazita e xenotima. Interferências menores são produzidas pelas linhas da família $L \alpha$ do Ho e $L \beta$ do $G d(n=2)$. Diversas linhas de segunda ordem, como as linhas $L \alpha 2$ e da família $\mathrm{L} \beta$ do $\mathrm{Eu}, \mathrm{Gd}$ e $\operatorname{Pr}$ aparecem na região de leitura de background negativo, enquanto as linhas M4$O 2$ do Th, $L \gamma$ do Nd e do $\operatorname{Pr}, L \beta 2-15$ do $S m, L \alpha 2$ do $D y$, linhas $L \beta$ do $E u$ e $L \gamma$ do $Y b$ aparecem na região do background positivo. A exeção das linhas Th e do $\mathrm{K}$ e do pico de escape $\mathrm{Xe} L \alpha 1-\mathrm{Nd} \mathrm{L} \gamma$ (negligivel), estas interferências são evitadas ajustando-se janela apropriada no SCA. O procedimento utilizado no laboratório para estimar o background envolve interpolação linear a partir dos off-sets \pm 3.9 (Figura 3). O modelamento da radiação do contínuo (e.g. Reed e Buckley 1996) indica que os valores de background obtidos com este procedimento são superestimados em ca. $0.15 \%$ e os teores medidos de $U$ são subestimados em quamtidades inferiores a ca. 30 ppm em relação aos valores reais.

A linha $\mathrm{Pb} M \alpha$ apresenta interferencias importantes das linhas Th $M \zeta 1,2$ e $Y L . \gamma 2,3$, as primeiras afetando posições do caracteristico e da região de interesse para o bakground, as outras apenas do característico. Interferem do lado negativo do background as linhas de segunda

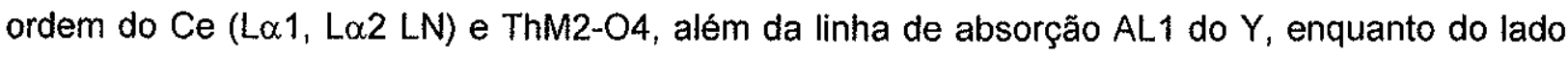
positivo, La (L $\alpha 1, L \alpha 2)$, Nd LL e linhas de primeira ordem do $S: K \alpha 1,2, K \alpha+, K \alpha 3$ e $K \alpha 4$ (Figura 4). As interferências devidas às linhas do $\mathrm{Ce}$ e do La podem ser minimizadas com PHA. Os ortofosfatos de La e Ce (Jarosewich e Boatner 1991), normalmente utilizados como padrões para $\mathrm{RRE}$, contêm impurezas em quantidades variáveis e irregularmente distribuidas de $\mathrm{Pb}$ (Donovan et al. 2003) e são interessantes para a análise dos efeitos destes elementos na linha $\mathrm{M} \alpha$ do $\mathrm{Pb}$. 
No Figura 4, o espectro do vidro RRE (com 3.21, 3.65, 3.79 e 1.81\% em peso de La, Ce, Pr e Y, cf. Drake e Weill 1972) é adicionado para comparação.

As interferências das linhas $M \zeta$ do Th e da familia $K$ do $S$ podem ser contornadas empiricamente, mas a do $Y L \gamma$ não e a complexidade geral do espectro na região de interesse tem incentivado o modelamento da radiação do contínuo para interpolar valores de background (e.g., Geisler e Schleicher 2000. Pyle et al. 2005), procedimento desejável particularmente quando as quantidades medidas de $\mathrm{Pb}$ são muito baixas, como no caso de datação de zircão, e praticamente obrigatório no caso da utilização de metalização com $A u$, devido a inclusão de linhas $M$ deste elemento na região de interesse (Jercinovic e Williams 2005). Se as correções de interferências de $\mathrm{Y}$ e Th sobre a $\mathrm{Pb} \mathrm{M} \alpha$ forem relativamente altas, a seleção da linha $\mathrm{Pb} \mathrm{M} \beta$, que necessita apenas de correção menor para a interferência de $U \zeta M$ pode resultar mais adequada para quantificação (Scherrer et al. 2000) e, naturalmente, é a única alternativa viável para a análise de $\mathrm{Pb}$ em xenotima. Os off-sets mais apropriados para obter a intensidade do background a partir de interpolação linear se situam no lado negativo, em uma região estreita entre as caudas dos picos Ce $L \alpha 2$ e Th $M \zeta$, nas vizinhanças e idealmente antes da linha PbM5-O3 (Figura 4) e, no lado positivo, após a linha $S K \alpha 1,2$. Valores de $-3.65 /+3.9$ não utilizados normalmente no laboratório. $A$ posição -3.65 é critica e, como mostrado por Jercinovic et al. (2008) a região nas vizinhanças deste off-set não é adequada para mensuração e interpolação linear simples, uma situação contornada no nosso procedimento (cf. item seguinte). No lado positivo, a melhor posição depende da presença e quantidade de $S$. O valor selecionado é otimizado para valores de $S<0.2$ $\%$ em peso, situação mais típica em monazita comum. Os valores de background interpolados linearmente a partir destes off-sets não simétricos e corrigidos para a interferência de Th são superestimados em ca. $0.14 \%$, o que equivale a menos de ca. $15 \mathrm{ppm}$ no valor medido de $\mathrm{Pb}$.

Para uma correção consistente da interferência do $\mathrm{YL} \gamma$ sobre $\mathrm{Pb} M \alpha$ é necessário que este elemento seja determinado com a devida acurácia. Em espectrômetros com cristal TAP, a posição de sintonização do $Y(L=70.23 \mathrm{~mm})$ corresponde a uma região com acentuada curvatura do contínuo, que apresenta interferências importantes de $\mathrm{Nd} L \beta 1-4 \quad(n=3)$ no característico e no background, $P K \alpha$ e Pr $L \beta 2-15$, bem como $Y L \beta 1(n=1)$ no lado negativo e Ce $L \beta 2-15(n=1)$, Sm 
$L \alpha 1(n=3)$, Si $K \alpha$ e Ca $K \alpha(n=1)$. Linhas da familia $L \beta$ do $S r$ interferem tanto no característico como nas regiões de interesse para background e não são filtradas no SCA. Pequenos off-sets foram escolhidos de forma a compensar estes efeitos da melhor forma possivel, com base em varreduras de padrões diversos (cf. Tabela 1).

Efeitos de fluorescência secundária nas zonas limitrofes entre fases minerais distintas devem ser considerados quando se analisam as zonas marginais externas de cristais em seções delgadas de rocha, particularmente quando as concentrações dos elementos excitados pela fluorescência nos minerais vizinhos são relativamente altas, uma vez que a radiação primária pode percorrer distâncias superiores a $10 \mu \mathrm{m}$ (e.g. Goldstein et al. 1992, Reed 1993, 1996). Este efeito é bem ilustrado por Jercinovic e Williams (2005) para monazita em contato com feldspato potássico. Os autores mostram que quantidades detectáveis de $K$, devidas a fluorescência provocada pela radiação $L$ dos LREE no feldspato, aparecem a partir de 10-15 $\mu \mathrm{m}$ de distância do contato com este mineral e aumentam exponencialmente com a diminuição da distância, indicando que a intensidade da radiação primária é mantida por distâncias de até ca. $20 \mu \mathrm{m}$. O efeito, năo corrigido, sobre a linha $U M \beta$ e, por conseqüencia, para as idades mais jovens calculadas para estas zonas pode ser crítico e situações deste tipo exigem a determinação quantitativa de $\mathrm{K}$ e respectivas correções.

A fluorescência secundária pode afetar também a região de interesse para análise de $Y$ em cristais TAP. A análise de efeitos similares em zonas limítrofes entre domínios intracristalinos com variações composicionais significativas, particularmente no que se refere aos elementos que apresentam energias críticas de excitação mais elevadas seria muito desejável.

\section{Contornos e correçōes de interferências espectrais}

Quando as interferências não evitadas com PHA afetam simultaneamente posições da linha caracteristica e de leitura de background do elemento de referência, caso típico de de Th $M \zeta 1,2$ sobre $\mathrm{Pb} M \alpha$ e, em menor grau, da familia $K$ do $S$ sobre $\mathrm{Pb} M \alpha$ e de Th $M \gamma$ sobre $U \mathrm{M} \beta$, elas podem ser eliminadas ou, pelo menos, minimizadas com procedimentos empíricos 
relativamente simples, desde que a forma e posição dos picos não se alterem e que a intensidade dos raios $X$ varie linearmente, como demonstrado por Reed (1993). De fato, quando a interferência é pequena, posições de leitura de background podem ser encontradas, com apoio de padrões contendo teores variáveis do elemento interferente e nulos do elemento interferido, de forma a compensá-la, ou seja obtendo-se $P / B \cong 0$, considerando os desvios estatísticos. Esta abordagem já foi utilizada no laboratório mas, atualmente, as correções de Th sobre $U$ e Th e $Y$ sobre $\mathrm{Pb}$ são feitas numericamente, conforme descrito a seguir.

A posição negativa de off-set para a quantificação de $\mathrm{Pb} \mathrm{M \alpha}$ é a mais crítica devido as interferências de $\mathrm{Pb} M 5-\mathrm{O} 3$ e Th M 1,2 . Jercinovic et al. (2008) argumentam que a interpolação linear simples para medir a intensidade do background na linha $\mathrm{Pb} \mathrm{M} \alpha$ não é adequada devido particularmente a estas interferências. Entretanto, considerando-se que as intensidades das linhas $\mathrm{Pb} \mathrm{M} \alpha$ e M5-O3 guardam, em princípio, relação constante entre padrões e amostras para uma mesma condição instrumental as eventuais contribuições desta última linha devem se cancelar na razões-k (razões entre as intensidades de amostras e padrões). Os efeitos da interferência de Th M 1,2 são corrigidos, por sua vez, considerando simultaneamente as intensidades medidas nas posições do característico e de bakground e o seu efeito deve ser também cancelado.

As formulações simples para correções de interferências (e.g. Âmli and Griffin 1975, Roeder 1985) corrigem as intensidade medidas (cps/nA) de forma diretamente proporcional, considerando fatores empíricos determinados para cada espectrômetro. De forma geral, a intensidade corrigida de um elemento $A$ que sofre interferência de um elemento $B$ é dada por:

$$
I(A)_{c o r, \text { Samp }}=I(A)_{\text {meas,Samp }}-I(B)_{\text {meas, Stl, pos } A} \times \frac{I(B)_{\text {meas, Samp }}}{I(B)_{\text {meas, Std }}}
$$

em que $I(B)_{\text {meas,Std,posA }}$ é a intensidade de $B$ na posição de sintonização de $A$, medida em um padrão que não contém o elemento $A$.

Este procedimento é adequado quando amostras e padrões apresentam composições similares. Na prática, como as suas composições são, em geral, bem diferentes, é necessário introduzir uma correção para os efeitos de matriz. A título de exemplo, os fatores (ZAF) calculados 
pelo programa PROZA para Th $\mathrm{M}$ e $\mathrm{Y} L$ nos padrões $\mathrm{ThSiO}_{4}, \mathrm{YALG}$ e $\mathrm{YPO}_{4}$ são $1.1548,1.3363$ e 1.1603, respectivamente, enquanto que em monazita típica, variam em geral entre 1.30 e 1.32 e entre 1.50 e 1.52. As correções aplicadas no laboratório derivam das formulações de Donovan et al. (1993) e Fialin et al. (1997), como segue:

$$
I(A)_{c o r, \text { Samp }}=I(A)_{m e a, \text {,Samp }}-I(B)_{m e a, \text { Std , pos } A} \times \frac{C_{(B)}^{\text {Samp }}}{C_{(B)}^{\text {Std }}} \times \frac{(Z A F)_{(B)}^{\text {Samp }}}{(Z A F)_{(B)}^{\text {Std }}}
$$

Os fatores $F$ de linhas secundárias $L$ e $M$ podem ser bem distintos dos das linhas primárias e não são conhecidos em geral, sendo freqüentemente aproximados para o valor da linha primária ou para a unidade. Uma dificuldade adicional relacionada a superposição das linhas $Y \mathrm{~L} \gamma$ sobre $\mathrm{Pb}$ M $\alpha$ é a possibilidade de desvios dos picos destas linhas em monazita em relação aos padrões utilizados, especialmente YALG, para medir as suas intensidades (Jercinovic e Williams 2005).

As correções numéricas devem idealmente ser introduzidas no processo iterativo de correção dos efeitos de matriz. O programa Age_Cor desenvolvido no laboratório na forma de planilha Excel efetua estas correções on line, mas por dificuldades de interface com o programa de quantificação do sistema Voyager, as correções são aplicadas aos resultados finais apenas. Como as intensidades envolvidas de $\mathrm{U}$ e $\mathrm{Pb}_{\mathrm{T}}$ são pequenas, este procedimento é bem adequado (Donovan et al. 1993).

\section{Limites de deteç̧ão e de quantificação}

O limite de deteção de um elemento em uma amostra, para um nível de confiança definido pelo coeficiente crítico $z_{c}$, pode ser escrito na forma:

$$
C_{D L, \text { Samp }}=\frac{z_{c} \times \sqrt{2 \times I_{B, \text { samp }} \times T_{B, \text { Samp }}}}{K_{\text {Std }} \times T_{B, \text { Samp }}}
$$

em que $C_{D L}$ é dado em \% em peso do elemento, $I_{B} e T_{B}$, são a intensidade (cps) e o tempo de integração de contagens para a radiação de fundo e $\mathrm{K}$ a intensidade medida por unidade de 
concentração do elemento (cps / \% em peso) no padrão. Corrigindo para os efeitos de matriz no padrão, podemos escrever:

$$
K_{S t d}=\frac{I_{P, S t d}-I_{B, S t d}}{C_{S d d} \times(Z A F)_{S t d}}
$$

em que $I_{p}$ é a intensidade medida no pico. Combinando as equações:

$$
C_{D L, \text { Samp }}=\left(\frac{C_{S t d} \times(Z A F)_{S t d}}{I_{P, S t d}-I_{B, S t d}}\right) \times z_{c} \times \sqrt{2 \times\left(\frac{I_{B, \text { Samp }}}{T_{B, \text { Samp }}}\right)}
$$

O limite de detecção expressa a menor valor para a abundância de um elemento para que este possa ser estatisticamente considerado presente na amostra. Na prática é interessante estimar a quantidade elemental mínima mensurável, ou seja que resulta em uma incerteza aceitável, por exemplo um erro relativo de 10\%. Potts (1996) define um limite de quantificação $\operatorname{com} z_{c}=10$.

A Figura 5 ilustra a variação do limite de detecção para $\mathrm{Pb}$ para alguns intervalos de confiança em função do tempo de integração de contagens para o espectrômetro E4 para as condições analíticas adotadas no laboratório. Para um nivel de confiança de $95 \%$, os limites de deteç̧ão e de quantificação deste elemento em monazita típica são da ordem 80 e 400 ppm, respectivamente. No caso de Th e $U$, os limites de deteç̧ão alcançados são da ordem de 90 ppm.

\section{ANÁLISE, TRATAMENTO E APRESENTAÇÃO DE DADOS}

Uma boa análise para datação é antes de tudo uma boa análise de química mineral e o procedimento analítico para datação de monazita deve contemplar uma análise pontual mais completa possivel. Análises completas, além de fornecerem subsídios para identificar e/ou avaliar processos petrogenéticos associados a eventuais variações de idades e alguns parámetros intensivos de cristalização, permitem controlar os resultados analíticos. Boas análises completas 
resultam em totais adequados e, mais importante, em proporções catiônicas compativeis com as fórmulas estruturais. No caso de minerais portadores de REE, a exeção de casos especiais, os padrões normalizados destes elementos devem também ser coerentes.

A precisão e acurácia das idades obtidas estabelecem limites para as interpretações petrogenéticas e/ou geotectônicas e os procedimentos para a sua avaliação devem ser bem estabelecidos. Estes tópicos serão discutidos com algum detalhe a seguir considerando-se os diferentes modelos para a obtenção de idades químicas.

\section{Modelos de idades químicas}

Idades químicas podem ser calculadas através de modelos pontuais e isocrônicos, os quais são revisados a seguir. Os modelos são apresentados por facilidade em ordem de complexidade e os elementos determinantes de idade são expressos em $\%$ em peso mas, na prática, a utilização de proporções atômicas é mais lógica no caso dos modelos isocrônicos.

Se $\mathrm{Pb}_{0}$ é um valor conhecido, insignificante ou ainda nulo, a idade $t$ pontual pode ser calculada a partir das quantidades medidas e corrigidas de $\mathrm{Th}, \mathrm{U}$ e $\mathrm{Pb}$ T por iteração simples da equação (4), como aplicado originalmente por Montel et al. (1996). Os termos exponenciais desta equação podem ser expandidos para séries de potências, segundo a formulação de TaylorMaclaurin:

$$
\exp (\lambda t)=1+\lambda t+\frac{(\lambda t)^{2}}{2 !}+\frac{(\lambda t)^{3}}{3 !}+\ldots
$$

Um primeiro valor para $t$ pode ser obtido pela expansão de primeiro grau, na forma:

$$
t_{M a} \approx \frac{22,500 \times\left(P b_{T}-P b_{0}\right)}{T h+3.14 \times U}
$$

Este valor permite obter uma primeira aproximação para $\mathrm{Pb}_{\top}$ com a equação (4) e iniciar o processo iterativo, até a convergência desejada. O programa Age_Cor calcula as idades pontuais on-line, após efetuar as correções para as interferências espectrais, seguindo este procedimento. 
Um conjunto de $\mathrm{N}$ pontos isócronos, define uma população de idades. Quando a distribuição das idades se aproxima de uma distribuição normal, o que geralmente ocorre para uma grande amostra $(N \geq 30)$, a idade média da população pode ser calculada pela média ponderada pelo inverso da variança dos valores individuais determinados.

Se a quantidade $\mathrm{Pb}_{0}$ é constante, a equação (4) corresponde a equação de um plano no espaço de coordenadas $\mathrm{Th}-\mathrm{U}-\mathrm{Pb}_{\mathrm{T}}$, que pode ser escrita na forma:

$x \times T h+y \times U-P b_{T}+P b_{0}=0$

em que:

$x=K^{T h} \times\left(\exp \left({ }^{232} \lambda_{r h} t\right)-1\right)$

e

$y=K^{U 8} \times\left(\exp \left({ }^{238} \lambda_{U} t\right)-1\right)+K^{U 5} \times\left(\exp \left({ }^{235} \lambda_{U}\right)-1\right)$

Um conjunto de determinações $\left(T h, U, \mathrm{~Pb}_{T}\right)$ representativas de pontos isócronos e com dispersão apropriada define este plano, cujos coeficientes $\left(x, y, P b_{0}\right)$ podem ser calculados com métodos clássicos de ajuste, conforme proposto originalmente por Rhede et al. (1996). Os coeficientes $x$ e $y$ permitem calcular idades Th- $\mathrm{Pb}$ e U-Pb independentes. Para o caso Th- $\mathrm{Pb}$ :

$t_{T h-P b}=\frac{1}{{ }^{232} \lambda_{T h}} \times \ln (1+1.115567 \times x)$

em que o fator que 1.115567 transforma o Th expresso em peso para proporção atômica. O desenvolvimento do coeficiente $y$ permite determinar a idade U-Pb.

As quantidades medidas de $U$ podem ser convenientemente transformadas em quantidades equivalentes de $T h\left(T h_{e q}\right)$, ou seja, a quantidade de Th que gera a mesma quantidade de $\mathrm{Pb}$ radioativo que a originada pelo $\mathrm{U}$ medido em um certo intervalo de tempo. Definindo-se a quantidade $T h^{*}=T h_{\text {meas }}+T h_{\text {eq }}$, podemos eliminar o termo $U$ e converter a equação $(x)$ em uma equação de reta em coordenadas $\mathrm{Th}^{*} \mathrm{e} \mathrm{Pb}_{\mathrm{r}}$ :

$a T h^{*}-P b_{7}+P b_{0}=0$ 
Esta formulação, expressa originalmente em \% em peso de óxidos, é a base do método CHIME, desenvolvido por Suzuki and Adachi (1991). Equalizando os termos a direita da equação (4), podemos escrever:

$$
T h^{*}=T h_{\text {meas }}+U_{\text {meas }} \times \frac{\left\lfloor K^{U 8} \times\left(\exp \left({ }^{238} \lambda_{U} t\right)-1\right)+K^{U 5} \times\left(\exp \left({ }^{235} \lambda_{U} t\right)-1\right)\right]}{K^{r h} \times\left(\exp \left({ }^{232} \lambda_{\text {th }} t\right)-1\right)}
$$

e calcular Th* para um valor especifico de $t$, para quaisquer conjuntos de medidas (Th, $\mathrm{U}$ e $\mathrm{Pb}_{\mathrm{T}}$ ). Analogamente, pode-se definir e calcular $U^{*}=U_{\text {meas }}+U_{\text {eq }}$ quando as quantidades medidas de $U$ forem as mais relevantes, caso típico de uraninita, zircão e xenotima.

O coeficiente angular a da reta ajustada e definida por pontos isócronos $\left(\mathrm{Th}^{*}, \mathrm{~Pb}_{\mathrm{T}}\right)$ permite calcular a idade $t$, de acordo com a equação $(x$, substituindo a quantidade $x$ por a), enquanto $o$ seu intercepto no eixo $\mathrm{Th}^{*}$ corresponde a uma estimativa de $\mathrm{Pb}_{0,}$ naturalmente válida quando esta quantidade for constante. Nas situações em que a dispersão de dados não permite obter precisão adequada para o coeficiente $a$, a isócrona é por vezes, forçada para a origem $\left(T h^{*}, \mathrm{~Pb}_{T}\right)_{0}=(0 \pm$ $2 \sigma, 0 \pm 2 \sigma$ ), e.g. Cocherie et al. (1998), procedimento que introduz um certo viés na incerteza do coeficiente angular (cf. Ludwig, 2003).

Um modelo alternativo de diagrama isocrônico foi desenvolvido por Cocherie e Albarede (2001). Assumindo $\mathrm{Pb}_{0}=0$ e dividindo a equação $(\mathrm{y})$ por $\mathrm{Pb}_{\mathrm{T}}$, temos:

$x \times \frac{T h}{P b_{T}}+y \times \frac{U}{P b_{r}}-1=0$

equação de uma reta $\mathrm{Th} / \mathrm{Pb}_{\mathrm{T}}=f\left(\mathrm{U} / \mathrm{Pb}_{\mathrm{T}}\right)$, com coeficiente angular $(y / x)$ dado por:

$$
y / x=-\frac{\left[\left(K^{U 8} \times\left(\exp \left({ }^{238} \lambda_{U}\right)-1\right)\right)+\left(K^{U 5} \times\left(\exp \left({ }^{235} \lambda_{U}\right)-1\right)\right)\right]}{K^{T h} \times\left(\exp \left({ }^{232} \lambda_{T h}\right)-1\right)}
$$

Os interceptos nos eixos $\mathrm{Th} / \mathrm{Pb}_{\mathrm{T}}$ e U/Pb resultam respectivamente em idades $\mathrm{Th}-\mathrm{Pb}$ e $\mathrm{U}$ $\mathrm{Pb}$ independentes. $\mathrm{A}$ idade $\mathrm{Th}-\mathrm{Pb}$ é obtida pela equação: 


$$
t_{T h-P b}=\frac{1}{{ }^{232} \lambda_{T h}} \times \ln \left(1+\frac{1}{K^{2 h} \times\left(T h / P b_{T}\right)_{0}}\right)
$$

em que $\left(T h / \mathrm{Pb}_{\mathrm{T}}\right)_{0}$ é o intercepto no eixo $\mathrm{Th} / \mathrm{Pb}_{\mathrm{T}}$. $A$ idade $t_{\mathrm{U}-\mathrm{Pb}}$ é obtida com o termo $\mathrm{y}$. Quando o ajuste da reta é adequado e as idades Th- $\mathrm{Pb}$ e U-Pb são concordantes, pode-se calcular uma idade provável bem mais precisa que a dos métodos isocrônicos convencionais, a partir da média ponderada das razões $\mathrm{Th} / \mathrm{Pb}$ e $\mathrm{U} / \mathrm{Pb}$ e das envoltórias de erros definidas, por exemplo, pelo programa Isoplot.

Os resultados obtidos através do método pontual e do modelo $(\mathrm{Th} / \mathrm{Pb})=f(\mathrm{U} / \mathrm{Pb})$ têm significado quando $P b_{0} \cong 0$, o que parece ser a regra geral para monazita e xenotima naturais. As desvantagens dos modelos isocrônicos são a premissa assumida a priori de que o conjunto de determinações analíticas ajustado representa pontos isócronos e a necessidade de dispersão de Th e/ou $\mathrm{U}$ (ou $\mathrm{Th} / \mathrm{Pb}$ e $\mathrm{U} / \mathrm{Pb}$ ) suficiente para que um ajuste significativo de planos ou retas. Por outro lado, como as idades dependem apenas da inclinação dos planos e/ou retas, se algum erro sistemático ou uma combinação destes erros resultar em adição ou subtração de quantidades constantes em Th, $\mathrm{U}$ e/ou $\mathrm{Pb}_{\mathrm{T}}$, eles não influenciam as idades.

Uma planilha Excel, Age_Mona, foi desenvolvida em colaboraçăo de Guilherme A. R. Gualda para calcular as idades e/ou gerar os parâmetros necessários para os cálculos de idades segundo estes modelos. Idades pontuais e respectivas incertezas (cf. item seguinte) são calculadas através de modelamento de Monte Carlo ou por iteração da equação (4). Uma modificação oportuna em relação aos procedimentos para cálculos isocrônicos é a transformação das quantidades envolvidas e incertezas em frações atômicas, o que permite chamar e inserir dados automaticamente no programa Isoplot (Ludwig, 2003) e obter diretamente idades Th*$\mathrm{Pb} / \mathrm{U}^{*} \mathrm{~Pb}$, médias ponderadas e os interceptos para os cálculos propostos por Rhede et al. (1996) e Cocherie e Albarede (2000). O programa Isoplot é muito versátil, emprega métodos robustos de cálculo e se converteu em uma referência em geocronologia. 
Avaliação dos resultados: precisão e acurácia

Erros, alguns quantificáveis outros não, podem ser introduzidos em diversas etapas de um trabalho, que incluem desde a questão de representatividade, até a preparação da amostra e a análise e tratamento final dos resultados. Excluindo-se estes primeiros e os erros relacionados à operação inadequada do equipamento, o erro final de uma determinação com EPMA inclui contribuições de erros aleatórios, associados ao processo de geração e raios $X$ e de integração de pulsos, que afetam a precisão (ié. a reprodutibilidade dos resultados) e de erros sistemáticos, que dependem de fatores analíticos e instrumentais e afetam a acurácia dos resultados (o quanto o valor obtido se aproxima do valor real). Erros aleatórios podem ser minimizados, mas não eliminados e, por vezes, são considerados como representativos dos erros totais, admitindo-se que os sistemáticos foram minimizados. Scherrer et al. (2000), Pyle et al (2005) e Lisowiec (2006) examinam em detalhe os principais fatores que afetam a acurácia e a precisão do método.

A propagação dos erros associados às diversas etapas analíticas, até a obtenção da idade final, pode ser feita com auxílio da formulação clássica de Bevington (1969) para a propagação de incertezas de variáveis primárias $x_{1}, x_{2}, \ldots x_{n}$ para a variável secundária y descrita por uma função y $=f\left(\mathrm{x}_{1}, \mathrm{x}_{2} \ldots \mathrm{x}_{\mathrm{n}}\right)$ :

$\sigma_{y}^{2}=\sum_{i=1}^{n}\left(\frac{\partial y}{\partial x_{i}}\right)^{2} \times \sigma_{x_{i}}^{2}+\sum_{i=1}^{n}\left(\frac{\partial y}{\partial x_{i}} \times \frac{\partial y}{\partial x_{j}}\right) \times s_{x_{i} x_{j}}$

em que $\sigma^{2}$ e $S$ representam a variança e a covariança, respectivamente. Quando as variáveis primárias são independentes, com erros não correlacionados, $s=0$.

O sistema de Voyager se utiliza da estatística de Poisson para avaliar as incertezas associadas às determinação analíticas, que correspondem numericamente às incertezas propagadas para as razões-k (razão entre intensidades cps/nA medidas para amostra e padrão), resultando em desvio padrão e erro relativo dados por:

$$
\sigma_{k}=k \times \sqrt{\frac{\sigma_{S p}^{2}}{I_{S p}^{2}}+\frac{\sigma_{S d d}^{2}}{I_{S t d}^{2}}} \quad \Leftrightarrow \quad \varepsilon_{k}=\frac{\sigma_{k}}{k}
$$


Na prática, como este procedimento considera apenas a estatística de contagem de pulsos, as incertezas reais são subestimadas, sendo em geral 2 vezes superiores, e em qualquer determinação analítica os fatores sistemáticos devem necessariamente ser considerados (cf. Goldstein et al. 1992). Lisowiec (2006) mostra, por exemplos, que as incertezas assumidas em algumas publicações são inferiores às reais, com implicações óbvias para as interpretações apresentadas.

$\mathrm{Na}$ ausência de padrões específicos que permitam aferir mais precisamente a acurácia das determinações de monazita no laboratório, atribui-se aos erros sistemáticos $\left(\varepsilon_{S}\right)$ um valor algo arbitrário de $2 \%$, que considera os erros estimados para as correções de efeitos de matriz, entre 1 e $2 \%$ (e.g. Reed 1996) e testes efetuados com padröes convencionais no laboratório. Assim, o erro relativo nas determinações de $\mathrm{Th}, \mathrm{U}$ e $\mathrm{Pb}_{\mathrm{T}}$ é calculado para uma nível de confiança de $95 \%$ na forma:

$\varepsilon_{T}=\sqrt{\varepsilon_{k}^{2}+\varepsilon_{S}^{2}}$

Naturalmente, para composições comuns, as maiores contribuições para o erro final serão da estatística de contagens para $\mathrm{U}$ e $\mathrm{Pb}_{\mathrm{T}}$ e dos erros sistemáticos para Th.

As intensidades medidas de $\mathrm{U}$ e $\mathrm{Pb}_{\mathrm{T}}$ incorporam uma parcela devida às interferências de Th e de Th e $Y$, respectivamente, de forma que as incertezas devidas à estatística de contagens são maiores que as calculadas. Adicionalmente, as correções de interferências introduzem incertezas adicionais. Pyle et al. (2005) apresentam formulação extensa para avaliar incertezas de intensidades sujeitas a interferências e mostram que o seu efeito no caso de composições normais de monazita é de menor importância. O programa Age_Cor calcula os erros relativos das intensidades corrigidas por propagação de erros na equação $(y)$, através da aproximação:

$\varepsilon\left(I(A)_{\text {cor,Samp }}\right)=\frac{\left[\left(I(A)_{\text {meas,Samp }} \times \varepsilon\left(I(A)_{\text {meas,Samp }}\right)\right)^{2}+\left(I(B)_{\text {meas,Samp, posA }}\right)^{2} \times\left(\varepsilon\left(I(B)_{\text {meas, Str, pos } A}\right)^{2}+\varepsilon\left(C(A)_{\text {Samp }}\right)\right)^{2}\right]^{\frac{1}{2}}}{I(A)_{\text {Samp }}}$ 
adequada quando se tem

$\frac{(Z A F)_{(B), \text { sid }}}{C_{(B), \text { std }} \times(Z A F)_{(B), \text { samp }}} \approx c t e$

Em seguida, o programa avalia as incertezas para as idades pontuais calculadas através de modelamento de Monte Carlo e de propagação numérica a partir das incertezas estimadas para $\mathrm{Th}, \mathrm{U}$ e $\mathrm{Pb}_{\mathrm{T}}$. No primeiro caso, é obtida uma distribuição normal de idades a partir de valores aleatórios para $\mathrm{Th}, \mathrm{U}$ e $\mathrm{Pb}_{\mathrm{T}}$ limitados pelo intervalo das incertezas, a qual define a média da população e a incerteza associada. No segundo, aplica-se a fórmula de Bevington (1969) para a expansão de Taylor-Maclaurin de segundo grau da equação da idade, que pode ser escrita na forma:

$$
a \times t^{2}+b \times t+c=0
$$

em que:

$$
\begin{aligned}
& a=\frac{1}{2} \times\left[\left({ }^{232} \lambda_{T h}\right)^{2} \times K^{T h} \times T h+\left({ }^{238} \lambda_{U}\right)^{2} \times K^{U 8} \times U+\left({ }^{235} \lambda_{U}\right)^{2} \times K^{U 5} \times U\right] \\
& b={ }^{232} \lambda_{T h} \times K^{T h} \times T h+{ }^{238} \lambda_{U} \times K^{U 8} \times U+{ }^{235} \lambda_{U} \times K^{U 5} \times U \\
& c=P b_{0}-P b_{T}
\end{aligned}
$$

Esta expansão resulta em excelente aproximação para a idade quando as quantidades $(\lambda t)$ são inferiores a 0.3. Assume-se que as incertezas em $T h, U$ e $\mathrm{Pb}_{\mathrm{T}}$ não são correlacionadas $\mathrm{e}$, portanto, as covarianças envolvidas são nulas. As incertezas obtidas com este método são comparáveis as avaliadas através de Monte Carlo para a maioria das situações analisadas.

A análise das equações de erros mostra que as incertezas propagadas para as idades dependem essencialmente das incertezas associadas às determinações de $\mathrm{Pb}_{T}$, as quais aumentam rapidamente com a diminuição da sua quantidade na amostra. Admitindo-se que $\mathrm{Pb}_{0} \cong$ 0 , os valores medidos de $\mathrm{Pb}_{\mathrm{T}}$ dependem apenas das abundâncias de The $\mathrm{U}$ e do tempo decorrido e, assim, simulações obtidas a partir de concentrações destes elementos e idades variáveis com apoio das equações de propagação de erros permitem prever os erros esperados nos cálculos de idades individuais em função de $T^{*}$ e do tempo decorrido e avaliar de forma quantitativa os 
limites naturais de aplicabilidade do método, como ilustrado na Figura 6. A título de exemplo o diagrama mostra que os erros relativos, esperados para um grau de confiança de $95 \%$, para monazita com $\mathrm{Th}^{*}=8 \%$ em peso (portanto relativamente rica em $\mathrm{ThO}_{2}$ e/ou $\mathrm{UO}_{2}$ ) são da ordem de $25,5.5,3.5$ e $2.0 \%$ para intervalos de tempo de $0.1,0.5,1.0$ e $2.0 \mathrm{Ga}$, respectivamente, ou seja, os resultados esperados para as idades pontuais serão $100 \pm 25,500 \pm 28,1000 \pm 35 \mathrm{e}$ $2.000 \pm 40 \mathrm{Ma}$. Como esperado, o diagrama mostra claramente que a aplicabilidade do método se extende para amostras cada vez mais jovens a medida que os valores Th* aumentam.

O erro padrão propagado para a média populacional $\left(\sigma_{\mathrm{Mp}}\right)$ é dado, de acordo com a formulação de Bevington (1969), fazendo $S=0$, pela equação:

$$
\sigma_{M p}^{2}=\frac{1}{\sum_{i=1}^{n} \frac{1}{\sigma_{i}^{2}}}
$$

Em que $\sigma_{i}$ é o erro padrão de cada determinação pontual. Assim, este diagrama também pode ser utilizado para uma avaliação prévia do número mínimo necessário de determinações analíticas para se alcançar um erro padrão da média desejável em uma população relativamente homogênea em termos de $\mathrm{Th}^{*}$.

O procedimento adotado no laboratório é mais prudente em relação à avaliação de erros propagados quando comparado a outros divulgados em literatura (e.g. Pyle et al. 2005, Cocherie e Albarede 2001), que possivelmente subestimam os erros reais (cf. discussão em Lisowiec 2006). Em geral, os erros avaliados com a sistemática utilizada para médias populacionais são duas vezes superiores aos obtidos por este último autor.

A acurácia dos procedimentos de datação de monazita do laboratório foi aferida e é monitorada periodicamente analisando-se amostras de referência interna do laboratório com idades determinadas através de métodos isotópicos. Os cristais tipicamente utilizados são provenientes de granitos com idades entre 280 e $620 \mathrm{Ma}$ e de metapelitos de médio a alto grau com idades entre 625 e $780 \mathrm{Ma}$, rochas com estruturas e texturas muito homogêneas. Análises completas representativas de monazita para alguns destes padrões são apresentadas na Tabela 2. Na Figura 7 são comparados os resultados obtidos através de datações isotópicas e químicas. 
Em todos os casos, as diferenças se situam dentro das margens de erro calculadas, o que garante excelente confiabilidade para os resultados obtidos.

Apesar da consistência dos resultados, padrões reconhecidos de monazita com composições e idades bem determinadas são necessários, não somente para comparar os diversos procedimentos analíticos e de tratamento de dados existentes, mas principalmente para definir melhor a acurácia dos resultados obtidos com EPMA. Neste sentido, resultados com erros muito baixos devem ainda ser interpretados com a merecida cautela.

\section{PROCEDIMENTOS PRÁTICOS DE AMOSTRAGEM E ANÁLISE}

As preparações comuns para análises objetivando a datação quimica são seções delgadas polidas convencionais e montagens de concentrados. No laboratório trabalha-se normaimente com seções delgadas, que permitem identificar o contexto textural e/ou micro-estrutural dos cristais analisados. Neste procedimento, a amostragem é mais reduzida e ocasional quando comparado com montagens de grãos. Normalmente duas ou três seções delgadas de cada amostra são preparadas para análise de monazita, para as quais as coordenadas dos cristais identificados (ou suspeitos) são registradas através da platina Digimax. As corridas para datação de minerais portadores de Th e/ou $U$ são efetuadas no laboratório em períodos semanais inteiramente dedicados ao procedimento.

\section{Microscopia de luz transmitida, refletida e de eletrons retro-espalhados}

As paragêneses minerais e as propriedades ópticas (e.g. Chang et al. 1998) permitem, após alguma experiência, identificar monazita e contrastá-la de zircăo e/ou xenotima na maioria dos casos com microscopia de luz transmitida ou refletida. Monazita tipicamente absorve luz 
amarelo-alaranjada, apresenta clivagens e extinção inclinada em cortes prismáticos distintos de (100), não evidencia zonalidades de qualquer tipo, nem sinais de metamictização e gera halos pleocróicos bem mais intensos que zircão ou mesmo xenotima. Sob luz refletida, não mostra estruturas zonais e birreflectância interna, típicas da maioria dos cristais de zircão. Casos duvidosos, em geral cristais mais diminutos, são facilmente resolvidos com EDS e/ou imagens BSE em poucos segundos. Adicionalmente, a análise para datação de cristais muito pequenos, < ca. $40 \mu \mathrm{m}$, que aparecem geralmente como inclusões em outros minerais em seções delgadas, é em geral evitada devido a sua maior susceptibilidade a problemas de preparação e analíticos associados à proximidade de zonas limítrofes entre minerais.

Imagens BSE em modo composicional são extremamente úteis para identificar domínios composicionais contrastados, não detectados ao microscópio comum ou em imagens $\mathrm{CL}$. Composições típicas apresentam números atômicos médios $(\bar{Z})$ entre $38 \mathrm{e} 42$, bem superiores a maioria dos acessórios comuns (zircão, xenotima, etc.). Um $\overline{\Delta Z}$ de 0.6-0.7 causa variação de ca. $1 \%$ no coeficiente de retroespalhamento (e.g. Reed 1996), facilmente detectável em imagens de boa qualidade, mas imagens equalizadas de alta resolução permitem constrastar domínios com $\overline{\Delta Z}$ ainda menores. Monazita pode conter, além de $\mathrm{Pb}$, quantidades menores ou em traços de $\mathrm{S}$, $\mathrm{Sr}, \mathrm{Mn}, \mathrm{Fe}, \mathrm{Al}$, bem como algum $\mathrm{F}$ e $(\mathrm{OH})$ (e.g. Chang et al. 1998), mas as variações composicionais típicas podem ser adequadamente descritas pelos vetores brabantítico, $[\mathrm{Ca}(T h, U)][R E E]_{-2}$ e huttonítico, $[\mathrm{Si}(T h, U)][(R E E) P]_{-1}$ e pela substituição simples Y[RRE]-1 (e.g. Förster 1998). As primeiras resultam em aumento de $\bar{Z}$, algo mais acentuado no caso do vetor huttonítico, mas se há substituição paralela de REE por $Y$ este efeito pode ser compensado em maior ou menor grau.

Estudos mais recentes mostram que a abertura do sistema químico e/ou isotópico em monazita e geração de cristais poligenéticos, com distintos domínios de idades, está associada preferencialmente a processos que envolvem mecanismos de dissolução e reprecipitação e/ou neoformação e desenvolvimento de sobrecrescimentos e não a difusão significativa de $\mathrm{Pb}$ em estado sólido (e.g. Seydoux-Guillaume et al. 2002, Gardés et al. 2007), portanto, variações químicas mais ou menos significativas associadas a estes processos devem ser esperadas. 
Assim, domínios não-isócronos em cristais de monazita em geral mostram algum contraste em imagens BSE de alta resolução, tornando-as guias excepcionais para orientar as análises pontuais.

\section{Calibração elemental, avaliação e análises}

Após testes preliminares para a presença de $S$ (e K, se necessário) e estabilidade sob as condições instrumentais preferidas, é feita a sintonização espectral, verificação das condições do SCA e a calibração dos elementos nos padrões (cf. Tabela 1), sob as mesmas condições instrumentais. Entre 5 e 10 leituras com tempos reduzidos de contagem são integradas. A aferição do set-up instrumental e da calibração em cada corrida é feita analisando-se monazita (5-15 medidas) de uma ou duas amostras de referência. A monazita do monzogranito E-0013A, com ca. $590 \mathrm{Ma}$, é em geral preferida porque apresenta variações marcadas nas abundâncias de Th, U e Y. A qualidade dos resultados é avaliada quanto ao fechamento analítico, idealmente entre 99 101 \% e a adequação das proporções catiônicas: $\mathrm{Si}+\mathrm{P}$ e soma dos demais cations entre 3.96 e 4.04 para $16 \mathrm{O}$, considerando-se erros relativos de $1 \%$. Quando estes requisitos são satisfeitos e a diferença da idade média calculada para a amostra de referência e a idade isotópica é inferior a ca. 2-3 \%, o procedimento prossegue, iniciando-se a análise das amostras desejadas. Quando amostras relacionadas são analisadas em corridas distintas, são refeitas leituras das amostras previamente analisadas para comparação e validação das idades relativas. Normalmente são estas as etapas mais trabalhosas em todo o procedimento de datação.

Imageamento BSE é feito sistematicamente $e$, junto com informações petrográficas, utilizado para seleção de grãos para as análises pontuais, que podem ser feitas em modo assistido ou automático. O primeiro é preferido, uma vez que permite monitorar variações nas condições analíticas e os resultados em tempo real; adicionalmente, idades pontuais calculadas ponto a ponto com o programa Age_Cor permitem ao operador mudar a estratégia analítica planejada inicialmente a medida que os dados são produzidos. O EPMA do laboratório não dispõe de focalização automática e o modo automático é utilizado apenas para a obtenção de perfís 
analiticos de extenção limitada, sobre um único cristal. Em geral são obtidas cerca de 25-35 determinações para cada população de idade.

O tempo minimo para uma determinação completa (cf. Tabela 1) é determinado pelo tempo de integração de contagens de $\mathrm{Pb}_{\top}$ e U, que é, em princípio, de $400 \mathrm{~s}$. Considerando o tempo para reposicionamento de espectômetros, redução de dados e posicionamento do ponto seguinte, uma análise total pode ser obtida a cada $10 \mathrm{~min}$. Alguns protocolos para datação de monazita sugeridos em literatura parecem bem mais complexos e consumidores de tempo (e.g. Jercinovic e Williams 2005). Análises completas com precisão e acurácia significativas podem perfeitamente ser obtidas em equipamentos automáticos bem calibrados e estáveis com 05 espectrômetros configurados de forma a manter dois dedicados para a mensuração de $\mathrm{U}$ e $\mathrm{Pb}$ respectivamente e um terceiro para Th e $P$ (e S, se necessário). Nestes casos, não parece haver ganho significativo em precisão ou acurácia quando se efetuam corridas distintas, inicialmente para determinar a composição química e após para mensurar especificamente os elementos determinantes de idade, como sugerido por Pyle et al. (2005).

\section{Mapas composicionais}

Mapas ilustrando variações de idade em cristais de monazita, a partir do mapeamento WDS quantitatito de Th, $U, P b$ e $Y$, e conversão das intensidades elementais em idades pixel a pixel foram obtidos pioneiramente por Williams et al. (1999). As idades médias dos dominios podem ser obtidas estatisticamente através da análise da distribuição dos valores de cada pixel. Este procedimento é muito útil para ilustrar visualmente os padrões de distribuição de domínios de idades em cristais com variações significativas de idades.

Mapeamentos quantitativos WDS são ainda pouco explorados no laboratório devido a dificuldades inerentes ao sistema Voyager. Mapeamentos qualitativos ou semi-quantitativos, dot mapping, obtidos por varredura do feixe eletrônico, integrando informações dos espectrômetros WDS e EDS, são utilizados para ilustrar algum aspecto especifico, como destacado na seção seguinte. Entretanto, devido a defocagem em relação ao Círculo de Rowland e conseqüente perda de intensidade do sinal, estas imagens são adequadas apenas quando a magnificação da coluna 
eletrônica é alta (ca. > 500), ou seja, para cristais ou zonas cristalinas com dimensões inferiores a ca. $0.3 \mathrm{~mm}$.

Os procedimentos para datação de monazita sugeridos recentemente por Jercinovic e Williams (2005) são trabalhosos e incluem diversas etapas, que envolvem mapeamentos sucessivos para seleção de grãos, geração de mapas de idades e troca de metalização (C por $\mathrm{Au}$ ) das amostras, seguidas por análises pontuais específicas. São muito adequados e informativos mas, alternativamente, um bom trabalho de petrografia acompanhado por imagens BSE de alta resolução e análises quantitativas em pontos selecionados criteriosamente resultam, ao nosso ver, em informações qualitativas e quantitativas equivalentes.

\section{ESTUDO DE CASOS}

Nesta seção são apresentados três exemplos que ilustram algumas das características e o potencial do método químico de datação em monazita. O primeiro exemplo, compara idades e erros calculados para um mesmo conjunto de dados analíticos através dos métodos isocrônicos e pontuais, o segundo ilustra o potencial das imagens BSE para a identificação de domínios composicionais e do método para identificar populações distintas com idades relativamente próximas em monazita poligenética. O último caso ilustra a relevância dos dados pontuais com EPMA para identificar e decifrar casos em que cristais poligenéticos e/ou frações de cristais de monazita apresentam comportamento isotópico tipicamente discordante.

$\mathrm{Na}$ figura 8, apresentam-se resultados e representações, de acordo com os principais métodos discutidos, para monazita de um monzogranito leucocrático (Amostra APAB-956), inequigranular, com estrutura maciça da região de Morungaba, São Paulo, SE do Brasil. A monazita ocorre como cristais idiomórficos $(0.2-0.8 \mathrm{~mm})$ associados com biotita, ilmenita, zircăo e alguma apatita, de forma instersticial ao minerais félsicos. Foram obtidas 31 análises pontuais completas para dois cristais com fino zonamento recorrente, marcado por variações significativas nos teores de Th $(3.4-10.5 \%$ em peso), $U(0.137-0.582 \%)$ e também $Y(0.5-2.2 \%)$. Quatro 
análises foram rejeitadas, por apresentarem excesso de $\mathrm{Si}+\mathrm{P}$ e idades significativamente mais jovens (540-550 Ma).

As idades obtidas são idênticas, considerando-se os erros (Tabela 3). A idade U-Pb calculada segundo Rhede et al. (1996) apresenta erros bem maiores (50 Ma) devido aos erros analíticos mais elevados nas determinações de $U$, quando comparados aos erros associados ao Th, e às características da dispersão dos pontos analíticos, mas a média ponderada das idades Th- $\mathrm{Pb}$ e U-Pb é igual à idade obtida pelo método $\mathrm{CHIME}$. A grande diferença entre os resultados obtidos para os cálculos isocrônicos e de médias ponderadas está justamente nos erros associados, que diminuem de ca. 16-22 Ma no primeiro caso para um erro padrão da média (SE) de 6-8 Ma no segundo caso, que resulta similar à média calculada pelo método Tukey's Biweight, e para 8-12 Ma, considerando-se a mediana de uma distribuição gaussiana. Os erros obtidos forçando as isócronas 2D para zero são pouco menores neste exemplo, mas resultam em valores pouco mais pobres para o MSWD. O desvio padrão (SD), uma medida da dispersão das idades individuais obtidas em relação a média simples da população, é $28 \mathrm{Ma}$.

Considerando-se que determinações analíticas com EPMA apresentam excelente reprodutibilidade em condições bem controladas, a idade média ponderada e o erro padrão da média associado podem ser selecionados como os valores mais prováveis para a população quando acompanhados por uma avaliação adequada da acurácia das determinações. As médias ponderadas pelo inverso da variança e dos erros padrões associados covergem e diminuem, respectivamente, de forma rápida com o número de determinações e, quando as determinações individuais são de boa qualidade e os erros associados não são muito elevados (< ca. $60 \mathrm{Ma}$ ), não há ganho expressivo em se obter um número de determinações muito superior a 25-35 (Figura 9). Nos casos em que caracteristicas da amostra requerem condições analíticas mais brandas (correntes e/ou tempos de integração de contagens inferiores aos adotados em rotina) e/ou os teores de $\mathrm{Pb}_{\mathrm{T}}$ sejam baixos, ca. $500-1000$ ppm, um número bem superior de determinações pontuais será necessário para minimizar os erros da média populacional.

O segundo exemplo mostra parcialmente os resultados obtidos para um sillimanitagranada-biotita-gnaisse (Amostra Em-004B) neoproterozóico do Complexo Piracaia, coletado na região em que este complexo está em contato tectônico com o Terreno Embu, na região Leste do 
Estado de São Paulo, SE do Brasil. Estes gnaisses foram submetidos à deformação por cizalhamento em condições do fácies xistos-verdes, com abundante neoformação de muscovita e biotita. Foram analisados cristais xenomórficos relativamente bem desenvolvidos, por vezes rompidos e deformados, de monazita (Vlach submetido).

A imagem BSE para um destes cristais (Figura 10) mostra uma zona central com zonamento predominantemente setorial, com tonalidades cinzas variadas parcialmente envolvida por uma borda externa irregular, com tonalidades variáveis, mas pouco mais escuras. Os valores $\bar{Z}$ obtidos através das médias obtidas para três análises quantitativas nas zonas $z 1$, interna, e $z 2$, externa, bem constrastadas na imagem não equalizada, são 41.2 e 40.7 , respectivamente $(\overline{\Delta Z}=$ $0.5)$.

As idades pontuais das zonas centrais do cristal variam entre ca. 610 e $650 \mathrm{Ma}$, enquanto nas zonas marginais situam-se entre ca. 570 e $610 \mathrm{Ma}$, sugerindo a existência de duas populações, uma interpretação apoiada pelas micro-estruturas de zonamento observadas e pelo contexto geológico. Observa-se, entretanto, superposição significativa dentro das margens dos erros individuais, em geral entre 40 e $60 \mathrm{Ma}$. Situações como esta, que envolvem a identificação e deconvolução de componentes de uma população heterogênea, foram tratadas através de modelos de mistura por Sambridge and Compston (1994). Uma versão simplificada, válida para distribuições normais, do algorítmo desenvolvido por estes autores foi inserida na versão 3.00 do programa Isoplot (Ludwig 2003). A aplicação deste modelo para a amostra permite identificar duas populações estatisticamente significativas, uma com idade provável de $627 \pm 14 \mathrm{Ma}$ outra com $588 \pm 18 \mathrm{Ma}$., com um misfit relativo muito adequado, próximo a unidade.

Estes resultados são concordantes com a evolução neoproterozóica da região (Vlach, em preparação) e demonstram que, em situações favoráveis, o método químico de datação de monazita permite constrastar populações com diferenças de idade tão baixas quanto ca. $30 \mathrm{Ma}$. Merece ser destacado que, independentemente de diferenças menores nos valores absolutos obtidos relacionados a alguma inacurácia nas determinações, o intervalo de tempo registrado entre processos associados ao metamorfismo progressivo e ao retro-metamorfismo superimposto tem significado geológico real e relevante. 
A amostra que ilustra o último exemplo é um biotita-granada gnaisse (Amostra CE-118), em parte migmatítico, do Maciço São José do Campestre, um núcleo arqueano da Província Borborema, no Estado do Ceará, região Nordeste do Brasil. Os resultados aqui apresentados foram retrabalhados a partir de dados originais paresentados parcialmente por Vlach e Dantas (2001). Resultados isotópicos U/Pb convencionais (TIMS) prévios revelaram duas populações principais de cristais (Figura 11): uma homogênea, constituída de cristais menores, mais idiomórficos e límpidos, concordantes ou com leve discordância reversa, com ca. 570-580 Ma., outra formada por cristais maiores, mais xenomórficos e menos límpidos, que resultaram em marcada discordância, apontando para um intercepto superior em ca. 3.0 Ga (Dantas et al. 1999). Mapas composicionais (dot-maps) WDS obtidos para um cristal típico da segunda geração evidenciam zonamento mais ou menos normal de $\mathrm{Pb}$ e complexo de Th, $\mathrm{Y}$ e $\mathrm{U}$, fortemente sugestivo de que o cristal original foi infiltrado por soluções que substituiram certas zonas da monazita original, talvez mais fragilizadas por processos de metamictização, por uma variedade mais rica em $\mathrm{Y}$ (HREE) e $U$ e pobre em $T$, e $\mathrm{Pb}_{\mathrm{T}}$. O mapa de $U$ mostra, adicionalmente, a forte influência da interferência de $\mathrm{K} K \alpha$ onde aparece feldspato potássico.

As idades obtidas para estes domínios, calculadas pelas médias ponderadas, são ca. 2.99 $\pm 0.01 \mathrm{Ga}$ e $580 \pm 25$ Ma respectivamente, compativeis com a interpretação que os resultados isotópicos discordantes são devidos a mistura de distintas frações destas duas populações, química e isotopicamente distintas. Este é um exemplo limite, em que o grau de discordância é muito elevado. Tipicamente, a evolução dos terrenos metamórficos e do magmatismo associado em ambientes da crosta continental traz situações em que as diferenças de idades das populações presentes podem ser bem pequenas, ca. < $100 \mathrm{Ma}$, como no caso do exemplo anterior apresentado. Nestas situações, dados isotópicos para monazita poligenética podem parecer concordantes ou apenas levemente discordantes e idades de mistura podem ser tomadas erroneamente como idades reais de cristalização da monazita:

Este exemplo serve também para analisar a variação de erros em função da composição e da idade da amostra. As quantidades medidas de $\mathrm{Th}, \mathrm{U}$ e $\mathrm{Pb}_{\mathrm{T}}$ nas zonas jovens e antigas do cristal variam entre $7,000-25,000,1,500-7,000$ e $500-900$ a $14,000-35,000,700-1,900$ e 2,300$5,800 \mathrm{ppm}$, respectivamente. Estes valores resultam em erros elevados (90-150 Ma) para as 
idades pontuais da população jovem e, portanto, um erro padrão mais alto para a média ponderada, similar ao do desvio padrão da população (24 Ma, cf. Figura 11). Nestes casos, para se minimizar o erro padrão da média, uma quantidade bem maior de determinações pontuais deve ser efetuada. Simulações simples mostram que triplicando-se o seu número os erros resultantes serão reduzidos em ca. $40 \%$ e serão da ordem de $15 \mathrm{Ma}$. Por sua vez, os erros das determinações individuais da população antiga, com teores bem mais elevados em $\mathrm{Pb}_{\mathrm{T}}$, são muito inferiores e o erro padrão propagado para a média populacional é de apenas $11 \mathrm{Ma}$, mas a dispersão relativa dos dados é bem maior, com um desvio padrão da média próximo a $60 \mathrm{Ma}$.

\section{NOTAS CONCLUSIVAS}

Os procedimentos e os principais problemas do método de datação química de monazita com microssonda eletrônica, enfatizando aspectos relacionados às determinações quantitativas, estratégias para correções de interferências espectrais e ao tratamento dos dados analíticos são analisados e discutidos.

O melhor protocolo analítico para um EPMA especifico é o mais simples capaz de gerar resultados com precisão e acurácia compativeis com as limitações inerentes ao método. A interpolação linear para a quantificação do background da linha $\mathrm{Pb} \mathrm{M} \alpha$ é perfeitamente factível desde que as correções para a interferência das linhas Th $M \xi 1,2$ sejam adequadamente consideradas e corrigidas e não parece, em princípio, haver necessidade de procedimentos mais sofisticados. A reprodutibilidade das determinações com EPMA é excelente, entretanto, a falta de padrões composicionais e de idade especificos impede a aferição adequada dos resultados e a comparação dos diferentes protocolos apresentados em literatura. As idades $\mathrm{Th}-\mathrm{U}-\mathrm{Pb}_{\mathrm{T}}$ obtidas no laboratório do Instituto de Geociências para monazita com variações significativas nas abundâncias de Th, $U$ e $Y$ são perfeitamente comparáveis com idades isotópicas independentes considerando-se os intervalos de erros. Os erros associados às determinações pontuais e os limites de aplicabilidade do método podem ser adequadamente previstos conhecendo-se as 
quantidades de $T h, U$ e a idade. Modelagens simples de Monte Carlo reafirmam que os erros apresentados para idades médias ponderadas de populações isócronas são, em geral, subestimados quando se assume que os erros instrumentais são insignificantes em relação aos estatísticos e idades reportadas com erros inferiores a ca. $<1-2 \%$ devem ser analisadas ainda com alguma cautela.

O cálculo de idades médias de uma população isocrônica a partir das determinações individuais, considerando-se $\mathrm{Pb}_{0}=0$, é o procedimento de aplicação mais simples, direta e ampla, uma vez que a obtenção de isócronas químicas de boa qualidade requer uma boa dispersão dos valores de Th e/ou U. Por outro lado, os métodos isocrônicos podem ser muito úteis nos casos em que quantidades significativas, mas constantes, de $\mathrm{Pb}_{0}$ sejam detectadas, quando algum tipo de erro sistemático adiciona ou subtrai quantidades constantes em $\mathrm{Th}, \mathrm{U}$ e $\mathrm{Pb}$ ou ainda como controle geral dos procedimentos e resultados. Quando a reprodutibilidade das determinações pontuais é adequada e os erros propagados para as idades não são muito elevados (ca. <60 Ma), um número próximo a ca. 25-35 determinações para cada população de idade é suficiente, uma vez que o ganho final, em termos de erros padrões (SE) da média populacional, não será significativo para um número de análises muito mais elevado.

As aplicações mais relevantes do método são as que envolvem situações geológicas que favorecem a formação de cristais de monazita de natureza poligenética, devido a sua excelente resolução espacial. Sob condições controladas, os procedimentos implementados permitem identificar com significado estatístico populações que apresentam diferenças de idade da ordem de $30 \mathrm{Ma}$. As informaçōes registradas em imagens BSE, variações composicionais e nas características petrográficas e micro-estruturais/texturais permitem em geral contrastar diferentes domínios químicos e de idade e são informações complementares essenciais para atribuir ou não significado geológico para as diferenças calculadas e, em caso positivo, apesar da dificuldade de aferição da acurácia dos resultados, eles têm significado real em termos relativos. Possíveis efeitos de fluorescência secundária nas proximidades de zonas limítrofes de monazita com outros minerais formadores das rochas ou zonas internas com variações composicionais e de idade muito marcadas em um mesmo cristal devem ser considerados com cautela, uma vez que 
potencialmente diminuem a resolução espacial real da análise e podem resultar em valores híbridos ou mesmo espúrios, sem significado analítico e geológico.

As quantidades de $\mathrm{Pb}_{0}$, em geral negligiveis em monazita natural, aliadas à baixa taxa de difusão do $\mathrm{Pb}$ na estrutura do mineral incrementam significativamente a aplicabilidade do método para a resolução de problemas petrológicos críticos. De fato, a integração de informações microestruturais/texturais, químicas, geotermométricas e geocronológicas representadas pontualmente ou em seções e mapas para monazita poligenética permite identificar e correlacionar processos mineralógicos e petrológicos em micro-escala, determinar alguns parâmetros intensivos de cristalização envolvidos e posicioná-los de forma absoluta no tempo geológico, o que representa um avanço significativo para as geociências.

Os dados analíticos completos referentes aos exemplos discutidos neste trabalho e as planilhas/programas Age_Cor e Age_Mona utilizados no laboratório podem ser obtidos através de solicitação ao autor.

\section{AGRADECIMENTOS}

À Fundação de Amparo à Pesquisa do Estado de São Paulo (FAPESP), pelo apoio constante ao Laboratório de Microssonda Eletrônica do Instituto de Geociências da Universidade de São Paulo e ao projeto de infraestrutura FAPESP, Proc. 95/5728-2, que permitiu a otimização do sistema de automação do referido laboratório. O Dr. lan Steele da Universidade de Chicago forneceu diversos padrões analíticos utilizados rotineiramente no laboratório durante os últimos anos. Marcos Mansueto e Paulo Molinaro prestaram o necessário suporte nas etapas analíticas e de preparação das amostras utilizadas neste trabalho.

\section{REFERENNCIAS}


Åmli, R., Griffin, W.L., 1975. Microprobe analysis of REE minerals using empirical correction factors. American Mineralogist, 60:599-606.

Bastin, G.F., Heijligers, H.J.M., 1990. Progress in electron-probe microanalysis. Materialwissenschaft und Werkstoffechnik, 21:216-221.

Bea, F., 1996. Residence of REE, Y, Th, and U in granites and crustal protoliths: Implications for the chemistry of crustal melts. Journal of Petrology, 37:521-552.

Bevington, P.R., 1969. Data reduction and error analysis for the physical scinces, 326 p. McGrawHill, San Francisco.

Bowles, J.F.W., 1990. Age dating of individual grains of uraninite in rocks from electron microprobe analysis. Chemical Geology, 83:47-53.

Castaing, R. , 1951. Application of electron probes to local chemical and crystallographic analysis. Thesis, University of Paris, 132 p. (Translated by Duwez, P. And Wittry, D.B., 1955, California Instituto of Technology).

Chang, L.L.Y., Howie, R.A., Zussman, J., 1998. Rock Forming Minerals, Vol 5B. Nonsilicates:Sulphates, Carbonates, Phosphates, Halides, $2^{\text {nd }}$ Ed., 383 p. The Geological Society, London.

Cherniak, D.J., Watson, E.B., Grove, M. Harrison, T.M., 2004. Pb diffusion in monazite: a combined RBS/SIMS study. Geochimica et Cosmochimica Acta, 68:829-840.

Cocherie, A., Albarede, F., 2001. An improved U-Th-Pb age calculation for electron microprobe dating of monazite. Geochimica et Cosmochimica Acta, 65:4509-4522.

Cocherie, A., Legendre, O. Peucat, J-J., Kouamelan, A.N., 1998. Geochronology of poligenetic monazites constrained by in situ electron microprobe Th-U-total lead determination: Implications for lead behavior in monazite. Geochimica et Cosmochimica Acta, 62:24752497.

Dantas, E., Van Schmus, W.R., Hackspacher, P., Fetter, A., 1999, Identification of multiple orogenic/metamorpic events in polycyclic terranes; possibilities and limitations. Insights from the Borborema Province, NE Brazil. In: SIMPÓSIO NACACIONAL DE ESTUDOS TECTO̊NICOS, 7. Anais...Lençóis, SBG. pp. 15-17. 
Donovan, J.J., Snyder, D.A., Rivers, M.L., 1993. An improved interference correction for trace element analysis. Microbeam Analysis, 2:23-28.

Donovan, J.J., Hanchar, J.M., Picolli, P.M., Schrier, M.D., Boatner, L.A., Jarosewich, E., 2003. A re-examination of the rare-earth-element orthophosphate standards in use for electronmicroprobe analysis. Canadian Mineralogist, 41:221-232.

Drake, M.J., Weill, D.F., 1974. New rare earth element standards for electron microprobre analysis. Chemical Geology, 10:179-181.

Fialin, M. Outrequin, M., Staub, P-F., 1997. A new tool to treat peak overlaps in electron-probe microanalysis of rare-earth-element L-series X-rays. European Journal of Mineralogy, 9:965-968.

Förster, H-J., 1998. The chemical composition of REE-Y-Th-U-rich accessory minerals in peraluminous granites of the Ersgebirge-Fichtelgebirge region, Germany, Part I: The monazite-(Ce)-brabantite solid solution series. American Mineralogist, 83:259-272.

Gardés, E., Montel, J-M, Seydoux-Guillaume, A.M., Wirth, R., 2007. Pb diffusion in monazite: New constraints from the experimental study of $\mathrm{Pb} 2+\leftrightarrow \mathrm{Ca} 2+$ interdiffusion. Geochimica et Cosmochimica Acta, 71:4036-4043.

Geisler, T., Schleicher, H., 2000. Improved U-Th-total Pb dating of zircons by the electron microprobe using a simple new background modeling procedure and $\mathrm{Ca}$ as a chemical criterion of fluid-induced U-Th-Pb discordance in zircon. Chemical Geology, 163:269-285.

Goldstein, J.I., Newbury, D.E., Echlin, P. , Joy, D.C., Romig Jr., A.D., Lyman, C.E., Fiori, C., Lifshin, E., 1992. Scanning Electron Microscopy and X-Ray Microanalysis, $2^{\text {nd }}$ Ed., 820 p., Plenum Press, New York.

Gratz, R., Heinrich, W., 1998. Monazite-xenotime thermometry. Experimental calibration of the miscibility gap in the binary system $\mathrm{CePO}_{4}-\mathrm{YPO}_{4}$. American Mineralogist, 82:772-780.

Janasi, V.A., Alves, A., Vlach, S.R.F., Leite, R.J., 2003. Granitos peraluminosos da porção central da Faixa Ribeira, Estado de São Paulo: Eventos de reciclagem da crosta continental no Neoproterozóico. Geologia USP (Série Científica), 3:13-24.

Jarosewich, E., Boatner, L.A., 1991. Rare-earth element reference samples for electron microprobe analysis. Geostandard Nesletter, XV, 397-399. 
Jenkies, R., DeVries, J., 1982. Practical X-ray Spectrometry. Xxxp. Springer-Verlag, Berlin.

Jercinovic, M.J., Williams, M.L., 2005. Analytical perils (and progress) in electron microprobe trace element analysis applied to geochronology: background acquisition, interferences, and beam irradiation effects. American Mineralogist, 90:526-546.

Jercinovic, M.J., Williams, M.L., Lane, E.D., 2008. In-situ trace element analysis of monazite and other fine-grained accessoty minerals by EPMA. Chemical Geology, 254:197-215.

Karioris, F.G., Gowda, K., Cartz, L., 1991. Heavy ion bombardment on monocinic $\mathrm{ThSiO}_{4}, \mathrm{ThO}_{2}$, and monazite. Radiation Effects Letters, 58:1-3.

Kempe, U., 2003. Precise electron microprobe age determination in altered uraninite: consequences on the intrusion age and the metallogenic sifnificance of the Kirchberg granite (Erzgebirge, Germany). Contributions to Mineralogy and Petrology, 145:107-118.

Kingsbury, J.A., Miller, C.F., Wooden, J.J., Harrison, T.M., 1993. Monazite paragenesis and U-Pb systematics in rocks of the eastern Mojave Desert, California, U.S.A.:Implications for themochronometry. Chemical Geology, 110:147-167.

Leite, S. M., Vlach, S. R. F., Azvedo, M. R., Santos, J. F., 2005. Idades Th-UPb em monazite do monzogranito de Calde, Maciço Granítico de Castro Daire (Centro de Portugal). In: Congresso de Geoquímica dos Países de Lingua Portuguesa, 8. Aveiro. Actas, 1: 231-235.

Lisowiec, N., 2006. Precision estimation in electron microprobe monazite dating: Repeated measurements versus statistical (Poisson) based calculations. Chemical Geology, 234:223235.

Lovering, J.F., Wark, D.A., Gleadow, A.J.W., Britten, R., 1974. Lunar monazite: a late-stage (mesostasis) phase in mare basalt. Earth and Planetary Science Letters, 21:164-168.

Ludwig, K.R., 2003. Isoplot 3.00. A Geochronological Toolkit for Microsoft Excel. Berkeley Geochronological Center Special Publication, 4. 70 p.

Martins, L. Vlach, S.R.F., Janasi, V.A., in press, Reaction microtextures of monazite: correlation between chemical and age domains in the Nazaré Paulista migmatite, SE Brazil. Chemical Geology, 
Merlet, C., Bodinier, J-L., 1990. Electron microprobe determination of minor and trace transition elements in silicate minerals: A method and its application to mineral zoning in the peridotite nodule PHN 1611. Chemical Geology, 83:55-69.

Montel, J-M., Foret, S. Veschambre, M., Nicollet, C., Provost, A., 1996. Electron microprobe dating of monazite. Chemical Geology, 13:37-53.

Overstreet, W.C., 1967. The geological occurrence of monazite. United States Geological Survey Professional Paper, 530, $327 \mathrm{p}$.

Parrish, R.R., 1990. U-Pb dating of monazite and its applications to geological problems. Canadian Journal of Earth Science, 27:1431-1450.

Parslow, G.R., Brandstatter, F., Kurat, G. Thomas, D.J., 1985. Chemical ages and mobility of U and Th in anatectites of the Cree Lake zone, Saskatchewan. Canadian Mineralogist, 23:543-552.

Roeder, P.L., 1985. Electron-microprobe analysis of minerals for rare-earth elements: use of calculated peak-overlap corrections. Canadian Mineralogist, 23:263-271.

Podor, R., Cuney, M., 1997. Experimental study of Th-bearing LaPO4 (780 C, $200 \mathrm{Mpa}$ ): Implications for monazite and actinide orthophosphate stabilyity. American Mineralogist, $82: 765-771$.

Potts, P.J., 1996. A Handbook of Silicate Rock Analysis, 622 p. Chapman Hall, London.

Pyle, J.M., Spear, F.S., Wark, D.A., Daniel, C.G., Storm, L.C., 2005. Contributions to precision and accuracy of monazite microprobe ages. American Mineralogist, 90:547-577.

Pyle, J.M., Spear, F.S., Rudnick, R.L., McDonough, W.F., 2001. Monazite-xenotime-garnet equilibrium in metapelites and a new monazite-garnet thermometer. Journal of Petrology, 42:2083-2107.

Rapp, R.P., Watson, E.B., 1986. Monazite solubility and dissolution kinetics: implications ofr the thorium and ligh rare earth chemistry of feisic magmas. Contributions to Mineralogy and Petrology, 94:304-316.

Reed, S.B.J. 1993. Electron Microprobe Analysis, $2^{\text {nd }}$ Ed., 326p. Cambrigde University Press, New York. 
Reed, S.B.J. 1996. Electron Microprobe Analysis and Scanning Electron Microscopy in Geology, 201 p. Cambrigde University Press, New York.

Reed, S.J.B., Buckley, A., 1996. Virtual WDS. Mikrochimica Acta, 13:479-483.

Reed, S.B.J., Buckley, A., 1998. Rare-earth determination in minerals by electron-probe microanalysis: application of spectrum synthesis. Mineralogical Magazine, 62:1-18.

Rhede, E., Wendt, I., Förster, H-H., 1996. A three-dimensional method for calculating independent chemical U-Pb-and Th-Pb-ages of accessory minerals. Chemical Geology, 130:247-253.

Sambridge, M.S., Compston, W., 1994. Mixture modeling of multi-component data sets with application to ion-probe zircon ages. Earth and Planetary Science Letters, 128:373-390.

Scherrer, N.C., Engi, M. Gnos, E., Jakob, V., Lechti, A., 2000. Monazite analysis: from sample preparation to microproge age dating and REE quantification. Schweizerische Mineralogische und Petrographische Mitteilungen, 80:93-105.

Scott, V.D., Love, G., Reed, S.B.J., 1995. Quantitative Electron Microprobe Analysis. Ellis Horwood. 2nd. New York. 311 p.

Seydoux-Guillaume, A-M., Paquette, J-L., Wiedenbeck, M., Montel, J-M., Heinrich, W., 2002. Experimental resetting of the U-Th-Pb systems in monazite. Chemical Geology, 191:165181.

Steiger, R.H., Jäger, E., 1977. Subcomission on geochronology: convention on the use of decay constants in geo- and cosmochronology. Earth and Planetary Science Letters, 36:359-362.

Suzuki, K., Adachi, M. 1991. Precambrian provenance and Silurian metamorphism of the Tsubonosawa paragneiss in the South Kitakami Terrane, Northeast Japan, revealed by the chemical Th-U-total $\mathrm{Pb}$ isochron ages of monazite, zircon and xenotime. Geochemical Journal, 25:357-376.

Vlach, S.R.F., Gualda, G.A.R., 2000. Microprobe monazite dating and the ages of some granitic and metamorphic rocks from Southeastern Brazil. Revista Brasileira de Geociências, $30: 214-218$.

Vlach, S. R. F., Correia, C. T., 2001. A comparison between chemical and isotopic dating methods: Th-U-total $\mathrm{Pb}$ (monazite, microprobe) and U-Pb (zircon, SHRIMP). In: South American Symposium on Isotope Geology, 3.Pucón. Extended Abstracts Volume (CD), p. 79-82. 
Vlach, S.R.F., Dantas, E.L., 2001. Polygenetic monazite from the São José do Campestre Massif, Borborema Province, NE Brazil: insights from EPMA chemical and dating studies. In: South American Symposium on Isotope Geology, 3. Pucón, CH. Extended Abstracts (CD), p. 8386.

Vlach, S.R.F., Del Lama, E.A., 2002. Idades $\mathrm{Th}-\mathrm{U}-\mathrm{Pb}_{\mathrm{T}}$ de monazita e geotermobarometria de rochas metapelíticas de alto grau do Sistema Orogênico Itabuna-Salvador-Curaçá, BA, Brasil: um estudo em microssonda eletrônica. Geologia USP (Série Científica), 2:9-22.

Vlach, S.R.F., Gualda, G.A.R., Chiessi, C.M., 1999a. Electron microprobe Th-Pb and U-Pb monazite dating. Acta Microscopica, 8:141-142.

Vlach, S.R.F., Gualda, G.A.R., Chiessi, C.M., 1999b. Electron microprobe monazite dating: first results for two granites from Southeastern Brazil. In: South American Symposium on Isotope geology, 2. Cordoba, AG. Actas, 518-521.

Vlach, S.R.F., Campos Neto, M.C., Caby, R., Basei, M.A.S., 2003. Contact metamorphism in metapelites from the Nova Lima Group, Rio das Velhas SuperGroup, Quadrilatero Ferrifero: a monazite Th-U-PbT dating by the electron-probe microanalyser. In: South American Symposium on Isotope Geology, 4. Salvador, BR. Short Papers, 1:307-310.

Williams, C.T., 1996. Analysis of rare earth minerals. in: Jones et al. (Eds.) Rare Earth Minerals:Chemistry, origin and ore deposits. The Mineralogical Society Series, 7. pp. 327348, Chapman Hall, London.

Williams, M.L., Jercinovic, M.J., Terry, M.P., 1999. Age mapping and dating of monazite on the electron microprobe: Deconvoluting multistage tectonic histories. Geology, 27:1023-1026.

\section{LEGENDA DE FIGURAS}

Figura 1. Curvas $\varphi(\rho z)$ ilustrando a distribuição de raios-X gerados $(\mathrm{Ge})$ e emitidos $(\mathrm{Em})$ com a profundidade para energias do feixe eletrônico incidente de 15 e $25 \mathrm{keV}$ para as linhas espectrais analisadas de elementos criticos para datação em monazita típica, com $T h=6.0, U=0.50, \mathrm{La}=$ 14.0, $\mathrm{Ce}=27.0, \mathrm{Nd}=10.0, \mathrm{Y}=0.50, \mathrm{~Pb}=0.50, \mathrm{P}=13.5$ e O $=28.0(\%$ em peso $), \rho=5 \mathrm{~g} / \mathrm{cm}^{3} . \mathrm{A}$ 
diferença entre as áreas sob as curvas de geração e emissão corresponde aos raios $\mathrm{X}$ absorvidos pela amostra.

Figura 2. Diagrama ilustrando as variações de intensidades das linhas espectrais de $\mathrm{Ce}, \mathrm{Th}, \mathrm{Y}, \mathrm{U}$ e $\mathrm{Pb}$ nos espectrômetros $\mathrm{E} 5, \mathrm{E} 2, \mathrm{E} 1, \mathrm{E} 3$ e $\mathrm{E} 4$, respectivamente, em funçăo do tempo de submissão ao feixe eletrônico para as condições instrumentais indicadas, em monazita de biotita monzogranito (Amostra APAB-1216).

Figura 3. Varreduras WDS da região de interesse para $U M \beta$ para monazita cianita-granada granulito de Varginha (Amostra VGr). As intensidades foram suavizadas pela função $I_{i}=\frac{I_{i-2}+I_{i+2}}{4}+\frac{I_{i-1}+I_{i+1}}{2}$. Barras verticais, não desenhadas em escala, indicam as posições de interferências espectrais esperadas em monazita. Barras horizontais indicam posições adequadas para leitura da radiação de fundo. Espectrômetro E3, voltagem de aceleração da coluna: $15 \mathrm{kV}$, corrente do feixe eletrônico: $300 \mathrm{nA}$, diâmetro: $5 \mu \mathrm{m}$, passo: $0.01 \mathrm{~mm}$, tempo de integração: 4s. Janelas do SCA otimizadas em modo diferencial.

Figura 4. Varreduras WDS da região de interesse para $\mathrm{Pb} M \alpha$ para monazita de biotita monzogranitos dos plutons Piedade (Amostra PD-562, superior) e Areia Branca (Amostra APAB1216), intermediário e para o vidro RRE3 (Drake e Weill 1974). Intensidades suavizadas (cf. legenda da Figura 3). Barras verticas, não desenhadas em escala, indicam as posições de interferências espectrais esperadas em monazita. Barras horizontais indicam posições adequadas para leitura da radiação de fundo. Espectrômetro E4, voltagem de aceleração da coluna: $15 \mathrm{kV}$, corrente do feixe eletrônico: $300 \mathrm{nA}$, diåmetro: $5 \mu \mathrm{m}$, passo: $0.01 \mathrm{~mm}$, tempo de integração: $4 \mathrm{~s}$. Janelas do SCA otimizadas em modo diferencial.

Figura 5. Variação do limite de deteç̧ão do $\mathrm{Pb}$ em função do tempo de integração de contagens de background $\left(T_{B}\right)$ e do coeficiente crítico $z_{c}$ para as condições instrumentais indicadas no espectrômetro E4. 
Figura 6. Diagrama ilustrando a relação entre os erros padrões, para um nivel de confiança de 95 $\%$, propagados para a idades pontuais através da propagação numérica em função das quantidades medidas de $T^{*}$ e da idade para as condições instrumentais indicadas. $f_{U}$ é o fator para a conversão do $U$ medido $\left(U_{\text {meas }}\right)$ em equivalente em $T h\left(T h_{e q}\right) . T h^{*}=T h_{\text {meas }}+f_{U}^{*}\left(U_{\text {meas }}\right)$, em que $f_{u} \approx 3.17+0.21^{*} t+0.05^{*} t^{2}$ e $t$ é dado em Ga.

Figura 7. Comparação entre as idades obtidas através de métodos isotópico e químico para amostras de referência utilizadas no laboratório. Amostras: biotita monzogranitos Calde (K-Ar em biotita, Leite et al. 2005) e Natividade (U/Pb em monazita, TIMS, Janasi et al. 2003), granada leuco-monzogranito Nazaré Paulista (U/Pb em monazita, TIMS, dados inéditos), cianita-granada granulito Varginha (VGr, U/Pb em monazita, TIMS, dados inéditos), sillimanita-granada gnaisse TC-3 (U/Pb em zircão, SHRIMP, Vlach e Correia, 2001).

Figura 8. Comparação entre idades obtidas para a Amostra APAB-956 e entre possiveis representações gráficas para os métodos isocrônicos e médias ponderadas pelo inverso da variança. A: Secões Th vs $\mathrm{Pb}_{\mathrm{T}}$ e U vs $\mathrm{Pb}_{\mathrm{T}}$ do espaço Th-U-Pb (proporções atômicas) e isócronas

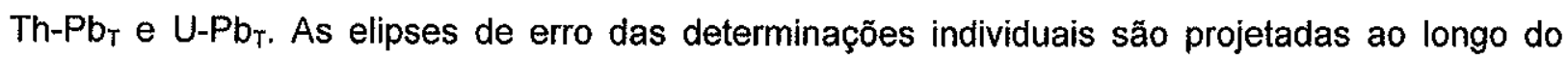
plano ajustado sobre a intersecção (cheias) e ortogonalmente sobre a seção de referência (vazias) para comparação. B: Isócrona $\mathrm{Th}^{*}-\mathrm{Pb}_{\mathrm{T}}$. C: Diagrama mostrando as distribuições das densidades de probabilidade gaussianas para cada determinação pontual, sua somatória e para a média ponderada pelo inverso da variança da população. No inset apresenta-se um diagrama de barras que mostra a dispersão dos resultados individuais em relação à média calculada.

Figura 9. Diagramas mostrando as variações das médias ponderadas pelo inverso da variança e dos erros padrões da média (SE) calculados numericamente em função do número $\mathrm{N}$ de amostras consideradas no cálculo das médias, para monazita do biotita monzogranito APAB-956. Discussão no texto. 
Figura 10. Resultados de datação para monazita poligenética de sillimanita-granada gnaisse retrometamórfico Em-004B. Imagem BSE de cristal xenomórfico típico. A zona interna do cristal, mais antiga, apresenta zonamento predominentemente setorial, a zona externa mais jovem é irregular e mostra em média menor coeficiente de retroespalhamento. As zonas demarcadas z1 e z2 apresentam $\Delta \bar{Z}$ de 0.5 . A combinação dos contrastes micro-estruturais/texturais e químicos, aliados ao bom ajuste dos cálculos de desmistura suportam bem a separação das duas populações como definidas. Discussão no texto.

Figura 11. Resultados de datação de monazita para o gnaisse migmatítico $\mathrm{Ce}-118$. Superior esquerda: diagrama de concórdia ilustrando duas populações de monazita, uma mais jovem concordande ou com leve discordância reversa e outra, mais antiga, fortemente discordante. Superior direita: Mapas de raios $X$ (WDS) qualitativos mostrando a distribuição de $T h, U, Y$ e $\mathrm{Pb}$ em cristal poligenético de monazita. No mapa de $U M \beta$, as intensidades de $U$ não estão corrigidas para interferência de $\mathrm{K} K \alpha$, como evidenciado pela elevada concentração aparente de $\mathrm{U}$ no cristal de feldspato potássico. Observar em especial a presença de in-fillings irregulares com contatos bruscos, bem marcados nos mapas pelo aumento nas concentrações de $Y$ e $U$ e diminuição de Th, resultantes de processos de dissolução e reprecipitação de monazita. O mapa de $\mathrm{Pb}$ mostra zonamento mais regular de tipo concêntrico, que em parte acompanha o zonamento observado no mapa de $\mathrm{Th} . \mathrm{KF}=$ feldspato potássico, $\mathrm{Grt}=$ granada, $\mathrm{Zr}=$ zricão. Inferior esquerda: histogramas mostrando a distribuição de idades pontuais das populações neoproterozóica e arquena. Inferior direita: diagramas de barras mostrando a dispersão das idades pontuais obtidas para as duas populações em relação às médias ponderadas pelo inverso da variança (traço grosso suave). Observar que a dispersão relativa das idades é muito superior no primeiro caso. Discussão no texto. 
Tabela 1. Set-ups instrumental e elemental para análise e datação de Ce-monazita no Laboratório de microssonda eletrônica do Instituto de Geociências da Universidade de São Paulo. Bck+, Bck-, off-sets positivo e negativo para interpolação linear da intensidade da radição de fundo sob a linha espectral analisada. BsL, Win, valores da Linha de Base e da Janela de Energia do SCA (V). Padrões: $n$ : minerais naturais, sem identificação: compostos sintéticos. ( $\left.{ }^{*}\right)$ linhas espectrais para as quais não há um off-set, positivo ou negativo, adequado para mensuração. (§): off-sets críticos dependendo da composição da monazita analisada. Ver texto.

Tabela 2. Análise representativas WDS, proporções catiónicas, idades pontuais e erros para alguns cristais típicos de monazita utilizados como amostras de referência no Laboratório de Microssonda Eletrônica da Universidade de São Paulo. $c=$ núcleo, $\mathrm{i}=$ zona intermediária, $\mathrm{r}=$ borda, na = não analisado, bd = abaixo do limite de detecção.

Tabela 3. Sumário dos resultados obtidos para a datação de monazita da amostra de monzogranito APAP-956 através de métodos isocrônicos e médias populacionais (SE = erro padrão da média ponderada, $\mathrm{SD}=$ desvio padrão da média simples) 


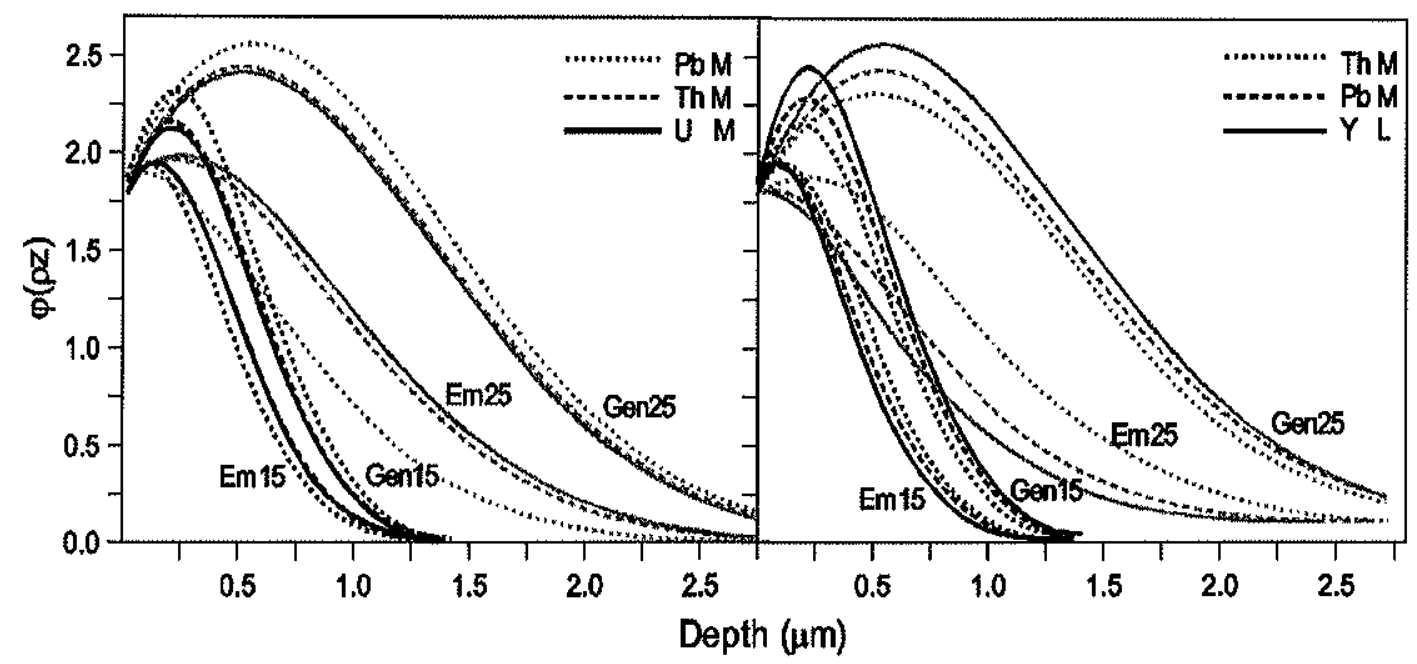

Figura 1

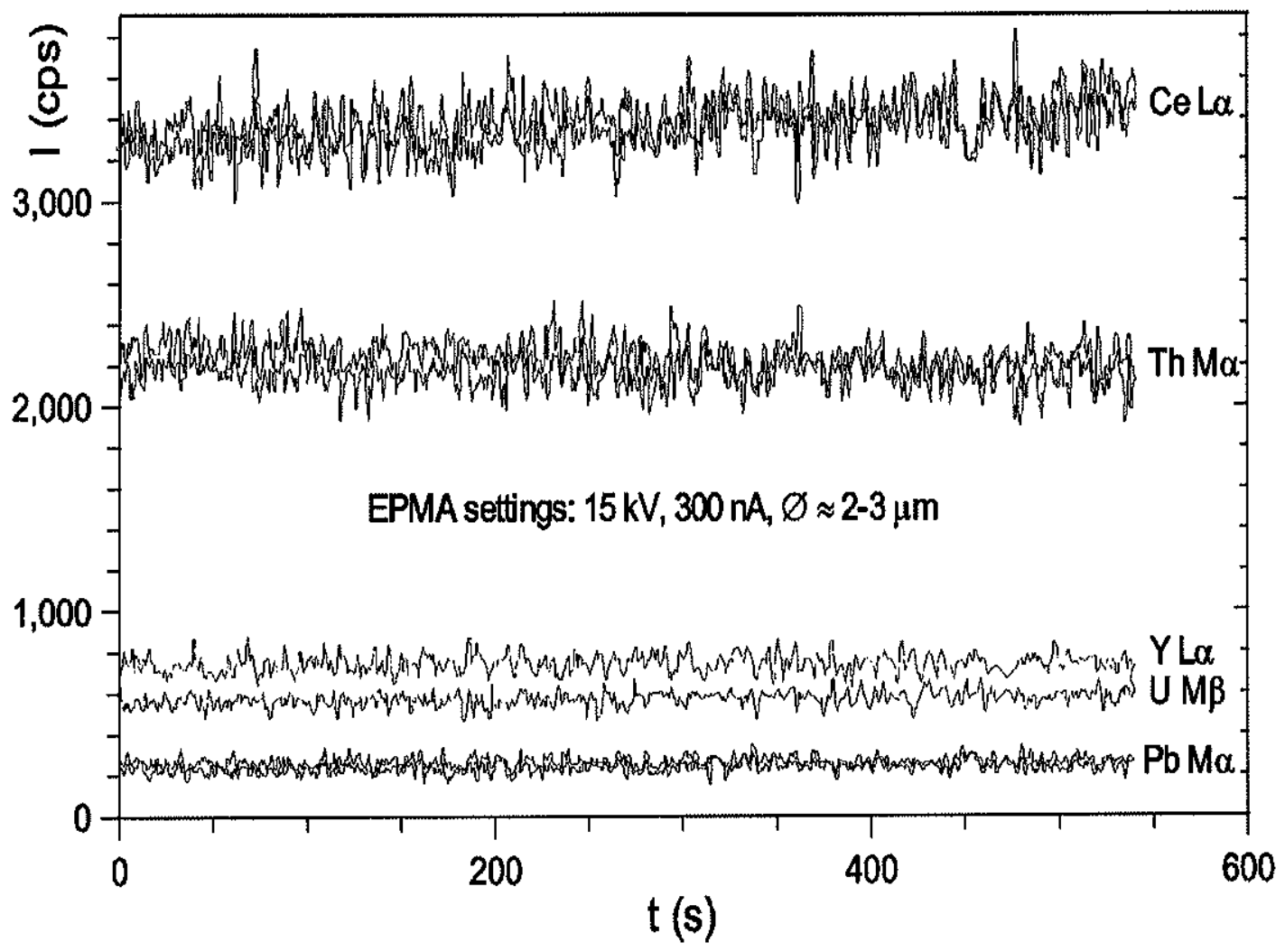

Figura 2 


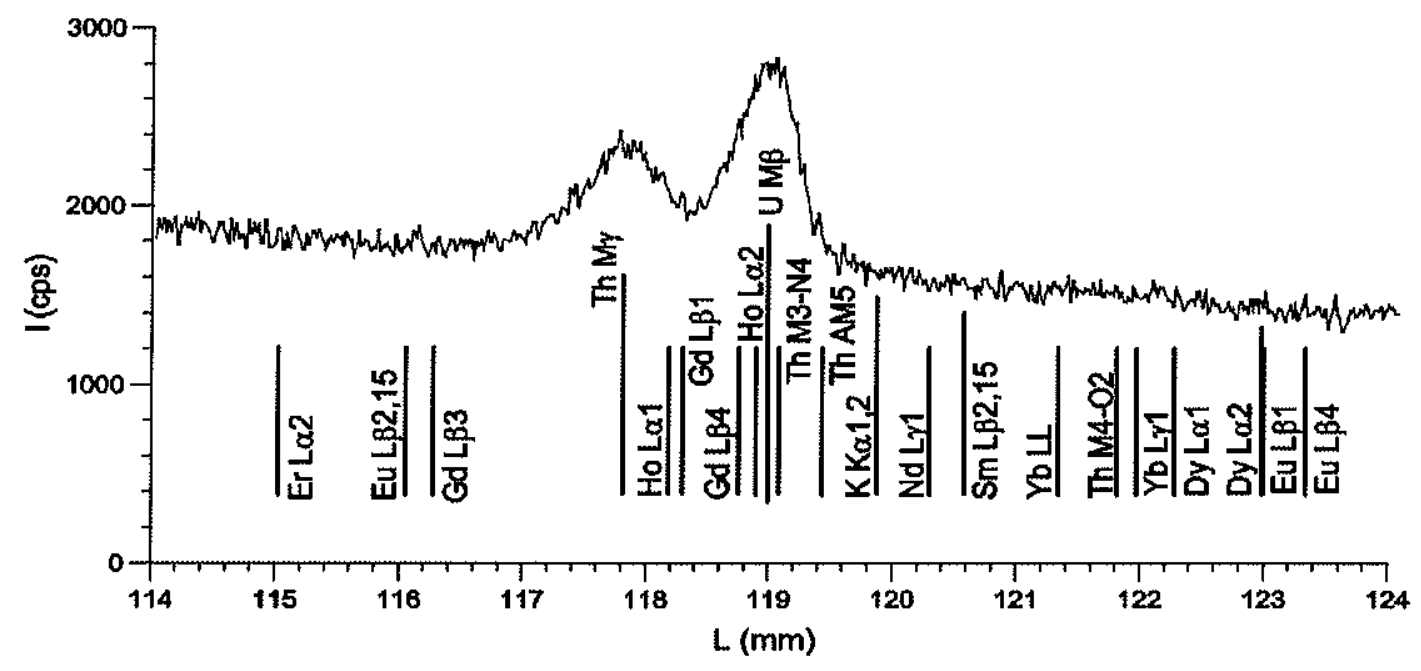

Figura 3

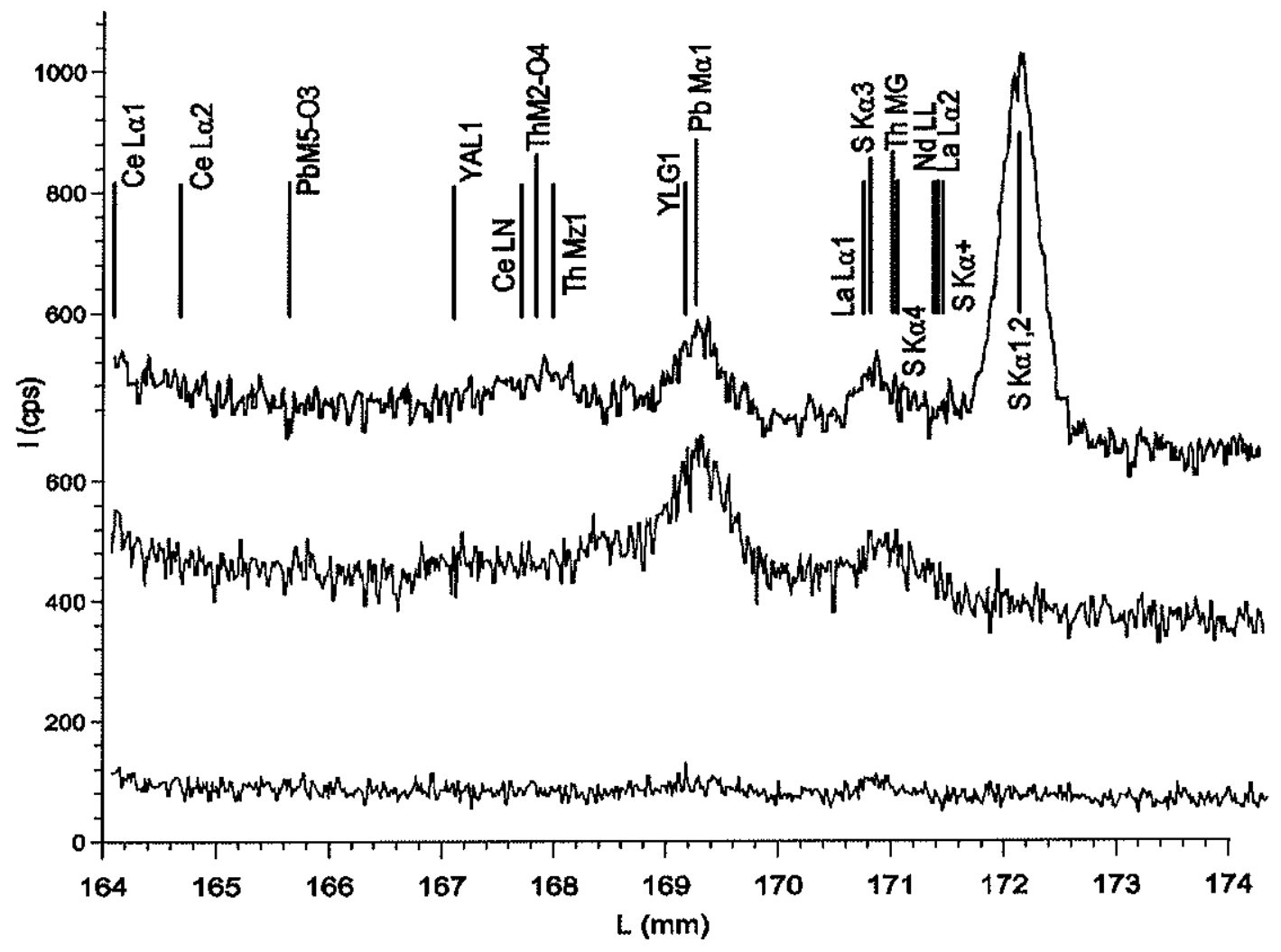

Figura 4 


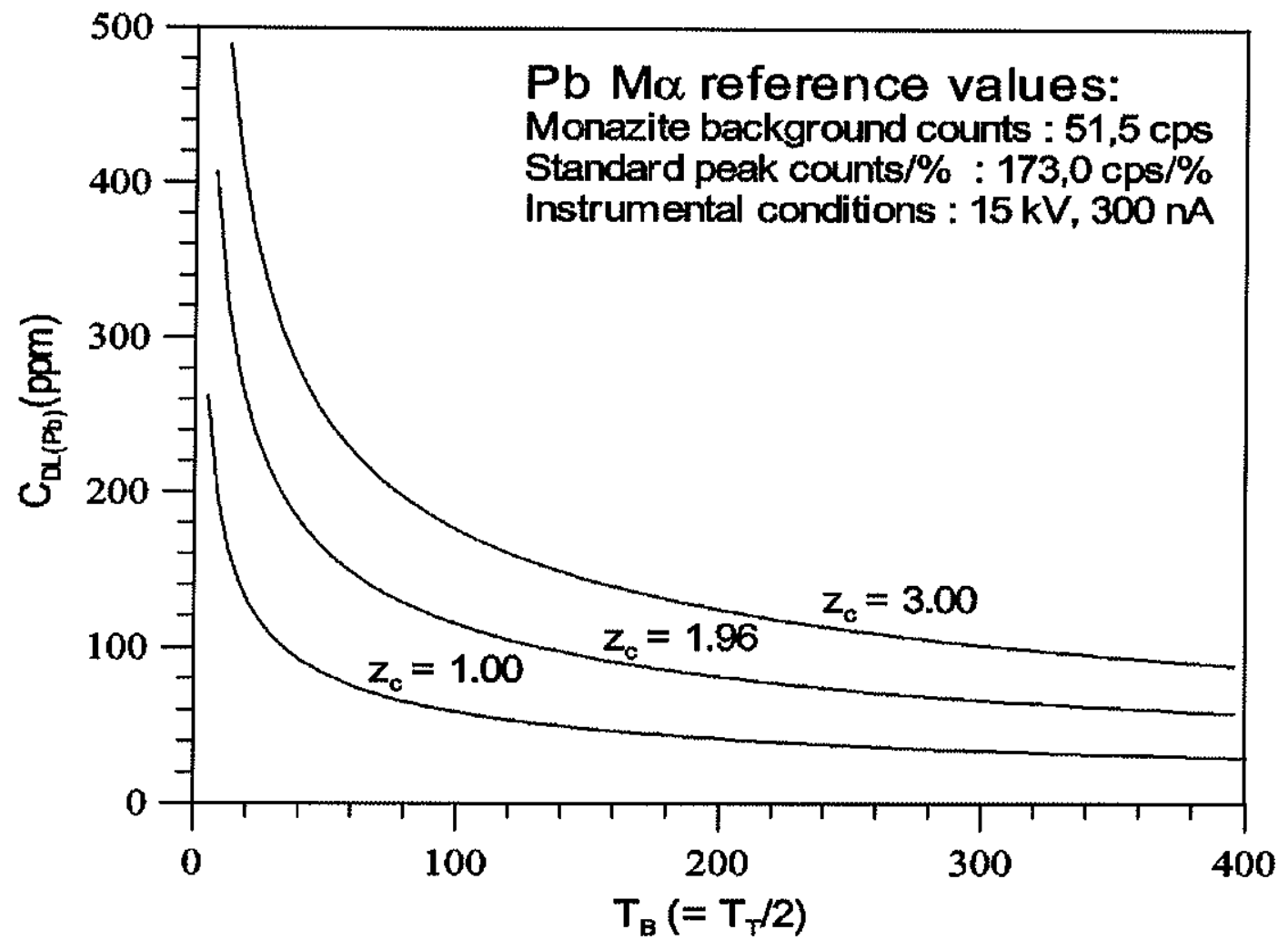

Figura 5

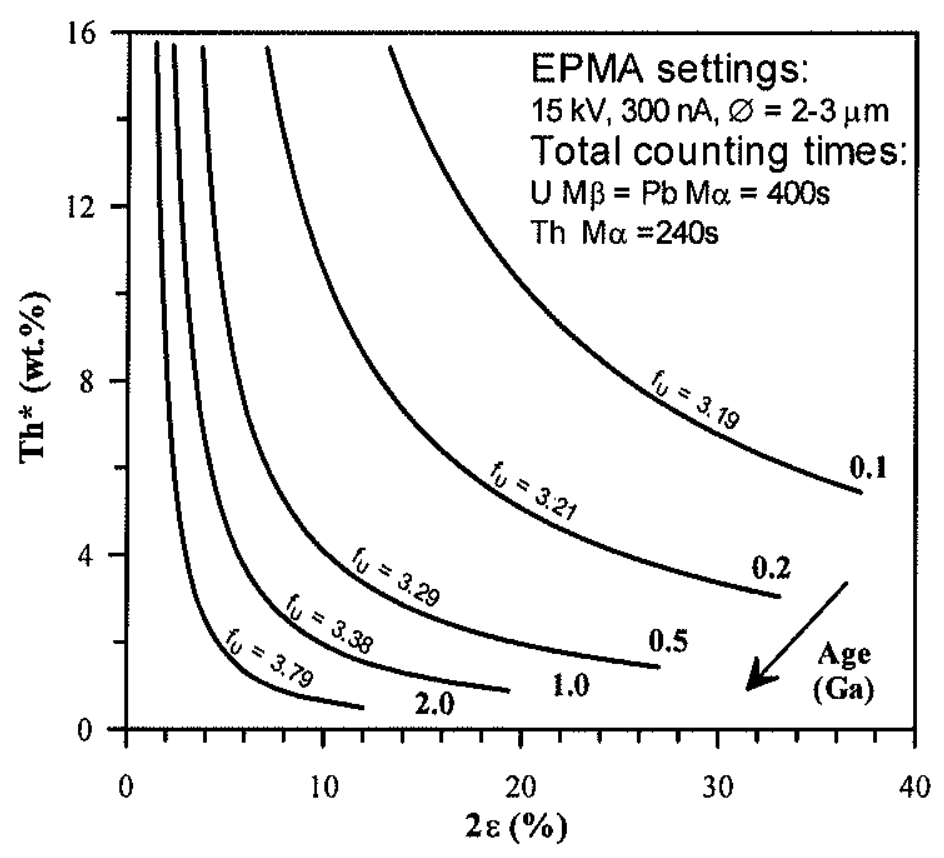

Figura 6 


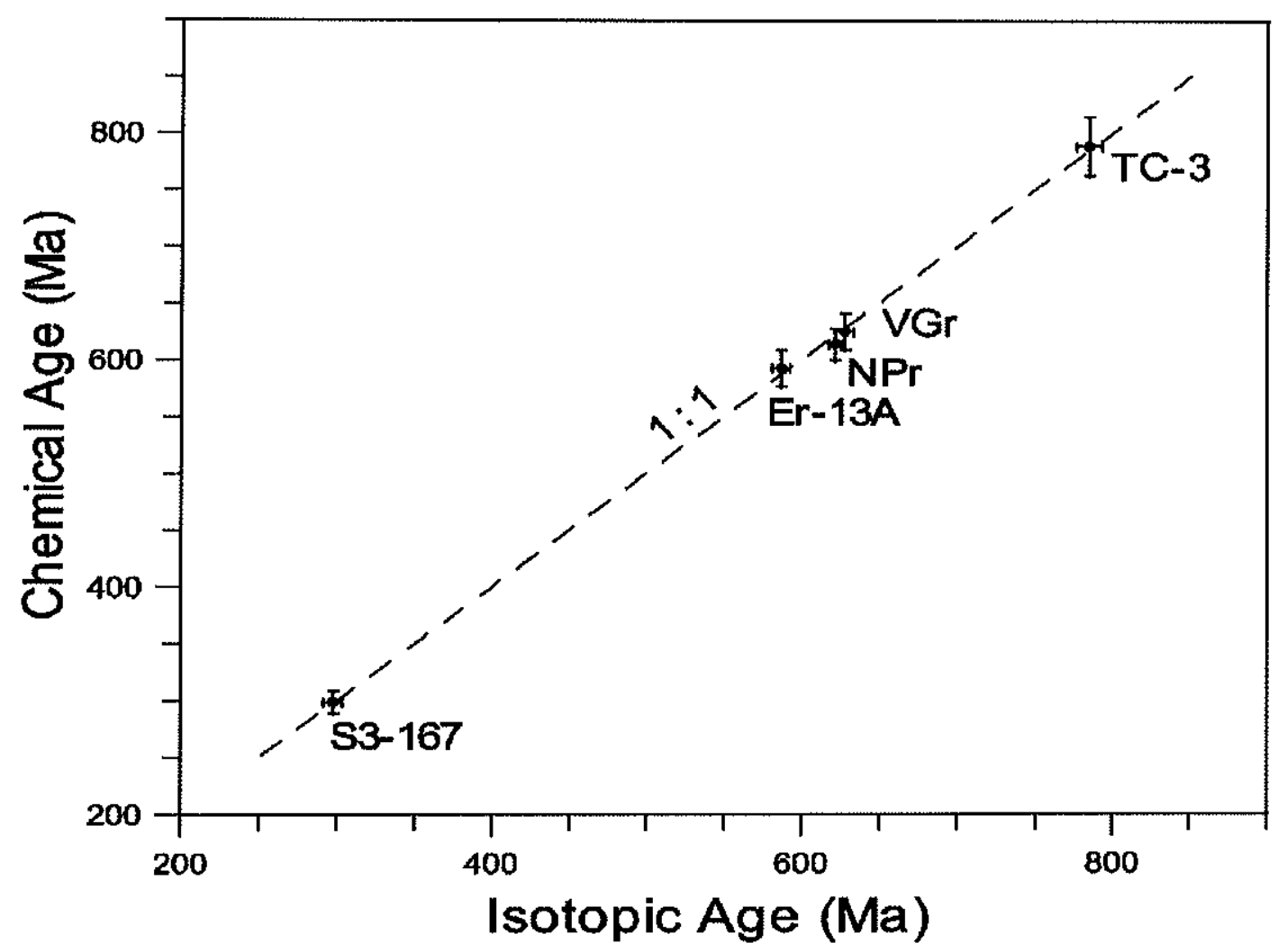

Figura 7 
Sample APAB-956 ( $\mathbf{N}=27$ )
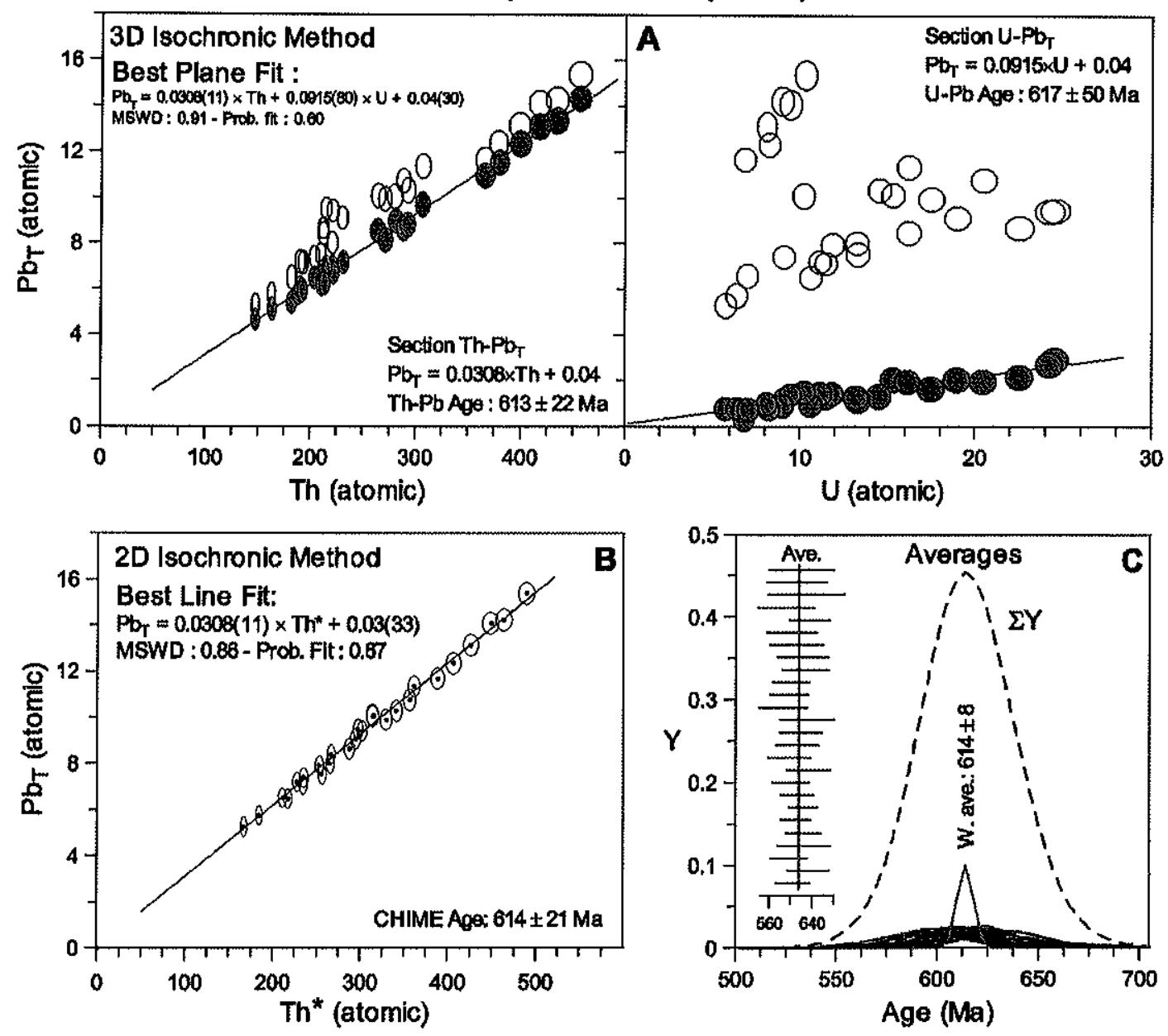

Figura 8 


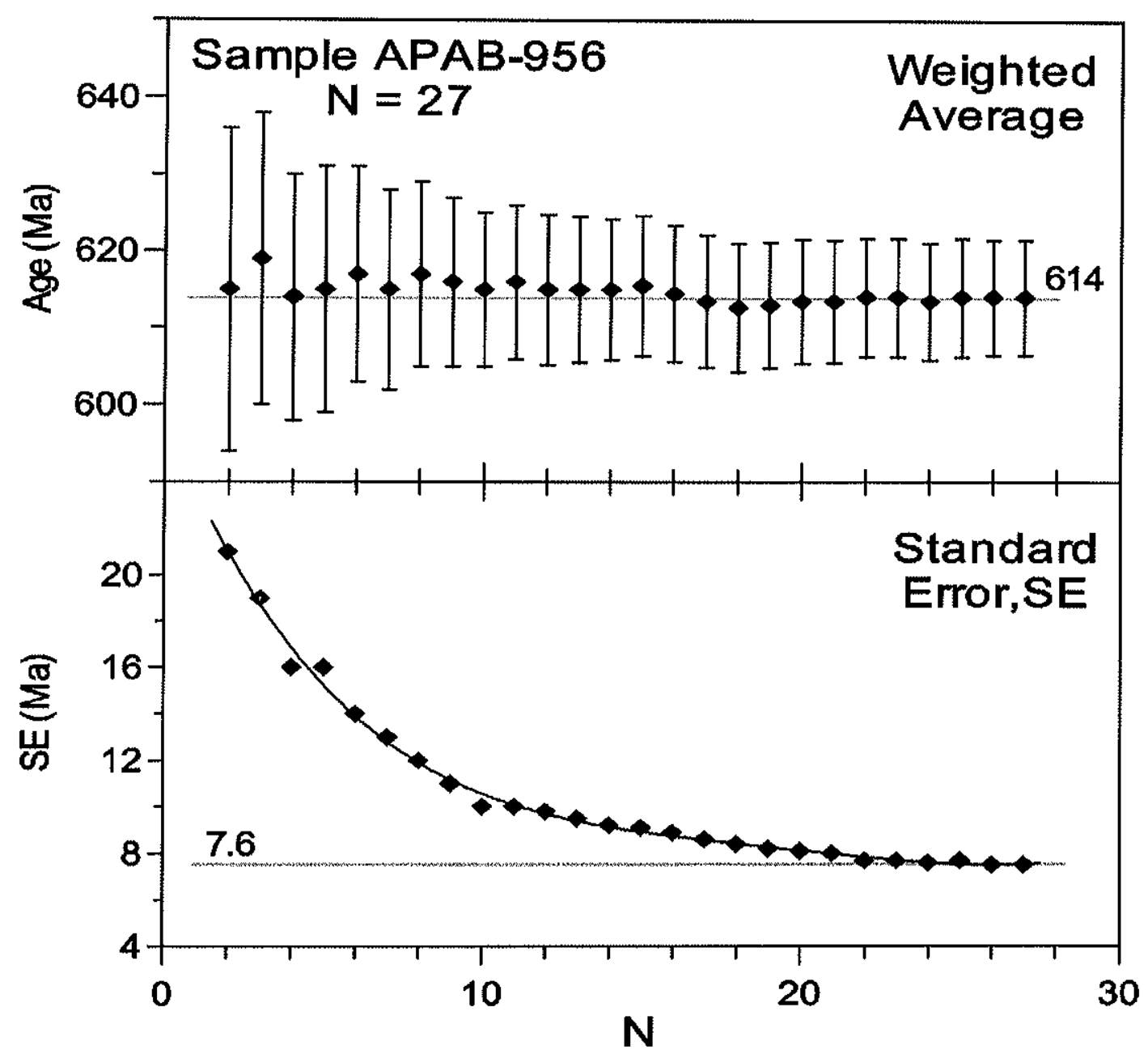

Figura 9

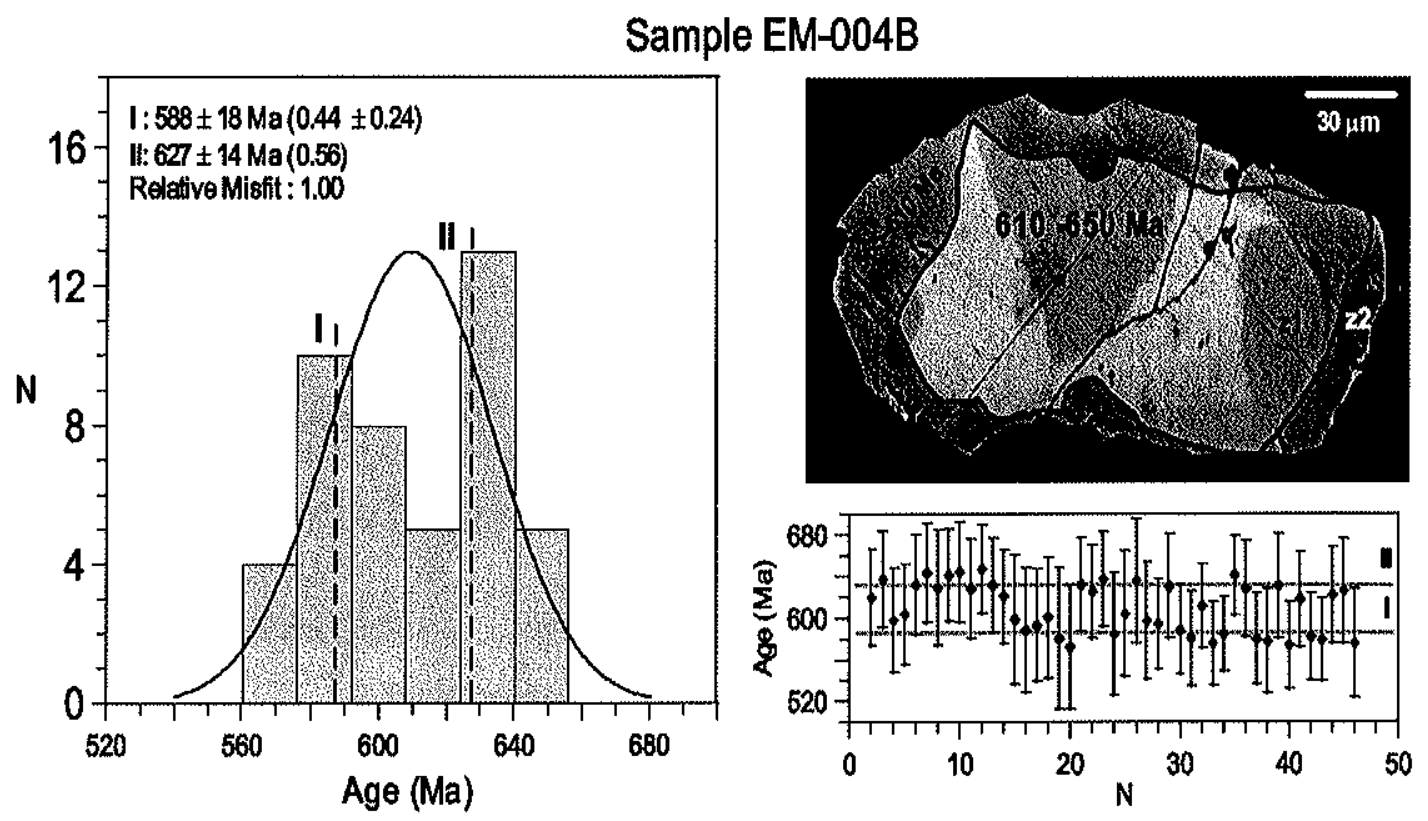

Figura 10 

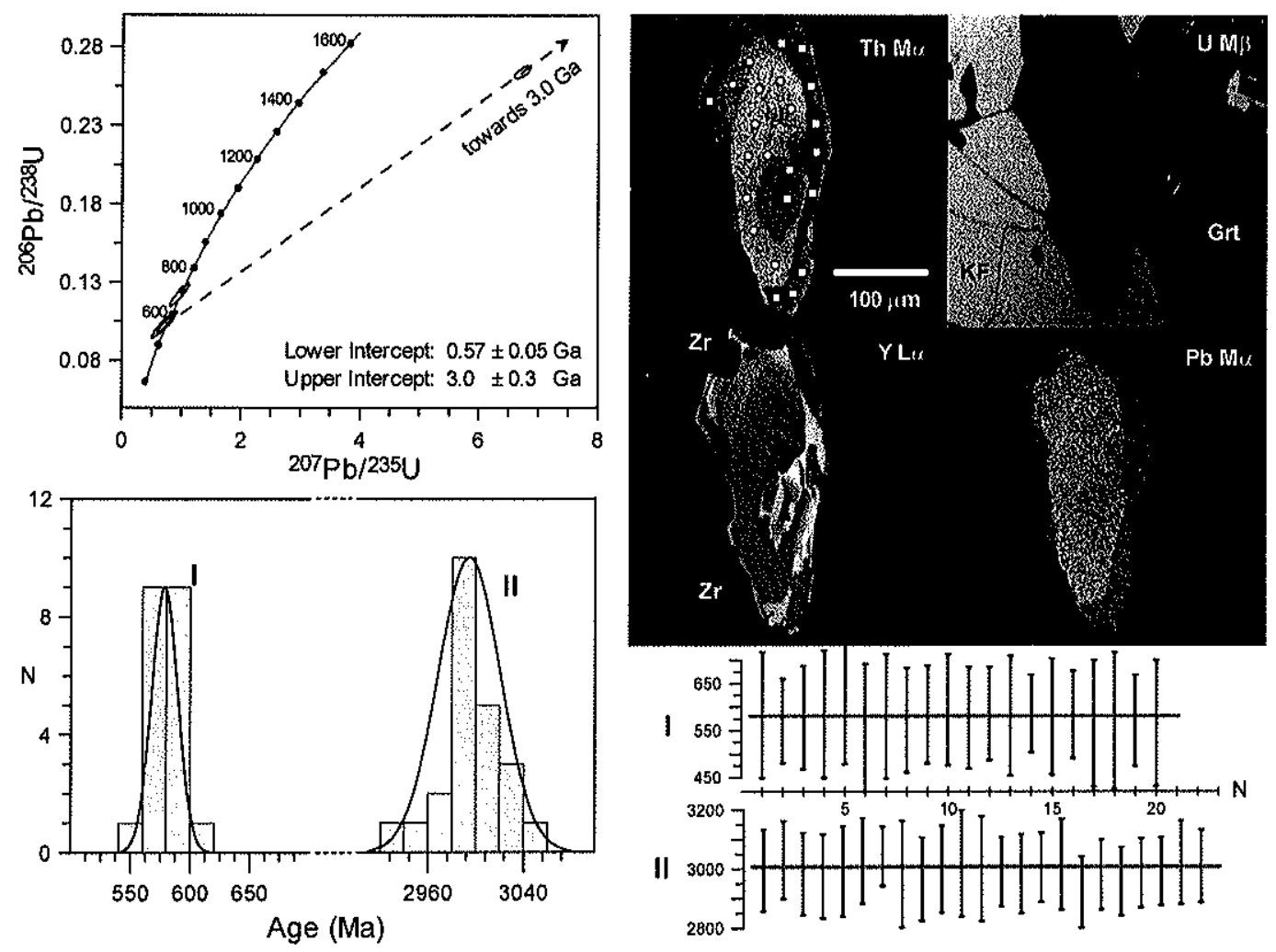

Sample Ce-118

I: Weight Ave: $579 \pm 17 \mathrm{Ma}$, MSWD: 0.1, Prob Fit: 1, SD (95\%) : 24 Ma, Median: $580+5 /-8 \mathrm{Ma}$ II: Weight Ave: $3003 \pm 12 \mathrm{Ma}$, MSWD: 2.7 , Prob Fit: 0, SD (95\%); 58 Ma, Median: $2992+17 /-10 \mathrm{Ma}$

Figura 11 
Tabela 1

I. Setup: [Ce-monazite $(Z \approx 41) \mathrm{CHV}: 15 \mathrm{kV}$ Beam : $300 \mathrm{nA}, \varnothing \approx 2-3 \mu \mathrm{m}$ ]

\begin{tabular}{|c|c|c|c|c|c|c|c|c|c|}
\hline \# & Elm & Line & Crystal & LPos (mm) & Bck- & Bckt & BsL & Win & Standard \\
\hline 01 & $\mathrm{Si}$ & $\mathrm{K} \alpha$ & TAP & 77.330 & $1.650^{8}$ & 1.050 & 1.12 & 4.00 & $\mathrm{ThSiO}_{4}$ \\
\hline 02 & Th & $\mathrm{M} \alpha$ & PET (P10) & 132.240 & $1.800^{\S}$ & 1.600 & 0.72 & 2.40 & $\mathrm{ThSiO}_{4}$ \\
\hline 03 & $\mathrm{U}$ & $M \beta$ & PET (Xe) & 119.000 & $3.980^{\S}$ & 3.980 & 1.32 & 2.40 & $\mathrm{UO}_{2}$ \\
\hline 04 & $\mathrm{Al}$ & $\mathrm{K} \alpha$ & TAP & 90.580 & $3.250^{\S}$ & 0.850 & 1.04 & 4.00 & YAIG \\
\hline 05 & La & $L \alpha$ & LIF & 185.320 & 1.450 & 1.650 & 0.68 & 2.00 & $\mathrm{LaPO}_{4}$ \\
\hline 06 & $\mathrm{Ce}$ & $L \alpha$ & LIF & 178.070 & 1.450 & 1.650 & 0.72 & 2.00 & $\mathrm{CePO}_{4}$ \\
\hline 07 & $\mathrm{Pr}$ & $L \beta$ & LIF & 157.030 & 0.750 & 0.850 & 0.92 & 2.00 & $\mathrm{PrPO}_{4}$ \\
\hline 08 & $\mathrm{Nd}$ & $L \beta$ & LIF & 150.660 & 0.900 & 1.000 & 0.96 & 2.00 & $\mathrm{NaPO}_{4}$ \\
\hline 09 & $\mathrm{Sm}$ & $L \beta$ & LIF & 138.950 & 0.550 & 0.550 & 1.12 & 2.00 & $\mathrm{SmPO}_{4}$ \\
\hline 10 & $\mathrm{Gd}$ & $L \beta$ & LIF & 128.420 & 1.000 & 1.000 & 1.32 & 2.00 & $\mathrm{GdPO}_{4}$ \\
\hline 11 & $\mathrm{~Tb}^{*}$ & $L \beta$ & LIF & 123.590 & 0.450 & ב-..-- & 1.42 & 2.00 & REE1 \\
\hline 12 & Dy & $L \beta$ & LIF & 118.990 & 0.650 & $0.550^{\S}$ & 1.44 & 2.00 & $\mathrm{DyPO}_{4}$ \\
\hline 13 & $\mathrm{Er}^{*}$ & $L \alpha$ & LIF & 124.110 & 0.750 & -....-- & 1.36 & 2.00 & REE1 \\
\hline 14 & $Y_{b^{*}}$ & $L \alpha$ & LIF & 116.250 & - & 1.450 & 1.48 & 2.00 & $\mathrm{YbPO}_{4}$ \\
\hline 15 & $Y$ & $\mathrm{~L} \alpha$ & TAP & 69.980 & 1.250 & 0.700 & 1.24 & 4.00 & $\mathrm{YPO}_{4} / \mathrm{YAIG}$ \\
\hline 16 & $\mathrm{Fe}$ & $\mathrm{K} \alpha$ & $\mathrm{LiF}$ & 134.640 & $0.750^{\S}$ & 0.650 & 1.16 & 2.24 & Hematite $^{n}$ \\
\hline 17 & $\mathrm{Ca}$ & $\mathrm{K} \alpha$ & LIF & 233.570 & 0.700 & 1.100 & 0.60 & 1.52 & Ca2P/Titanite ${ }^{n}$ \\
\hline 18 & $\mathrm{~Pb}$ & $\mathrm{M} \alpha$ & $\operatorname{PET}(X e)$ & 169.250 & 3.650 & $3.900^{\S}$ & 0.48 & 2.32 & $\mathrm{PbS}^{n} / \mathrm{PbCr}_{2} \mathrm{O}_{4}$ \\
\hline 24 & $P$ & $\mathrm{~K} \alpha$ & PET(P10) & 196.900 & 2.100 & 2.650 & 0.64 & 2.00 & $\mathrm{NdPO}_{4}$ \\
\hline 25 & $S^{*}$ & $\mathrm{~K} \alpha$ & PET(P10) & 171.940 & 2-- & 2.000 & 0.68 & 2.00 & $\mathrm{PbS}^{n}$ \\
\hline
\end{tabular}

II. Spectrometer, detector Bias (V), element, and counting time(s) distribution

\begin{tabular}{cccccc}
\hline \#Run & TAP1,1716 & PET2,1690 & PET3,1690 & PET4,1724 & LiF5,1664 \\
\hline 01 & $\mathrm{Y}(30)$ & $\mathrm{P}(20)$ & $\mathrm{U}(400)$ & $\mathrm{Pb}(400)$ & $\mathrm{Ca}(20)$ \\
02 & $\mathrm{Si}(20)$ & $\mathrm{Th}(280)$ & & $\mathrm{La}(20)$ \\
03 & $\mathrm{Al}(30)$ & & & $\mathrm{Ce}(20)$ \\
04 & & & & $\mathrm{Pr}(20)$ \\
05 & & & & $\mathrm{Nd}(20)$ \\
06 & & & & $\mathrm{Sm}(40)$ \\
07 & & & & $\mathrm{Fe}(20)$ \\
08 & & & & $\mathrm{Gd}(40)$ \\
09 & & & & $\mathrm{Dy}(40)$ \\
10 & & & & $\mathrm{Yb}(40)$
\end{tabular}


Tabela 2

\begin{tabular}{|c|c|c|c|c|c|c|c|c|c|c|c|c|}
\hline \multirow{3}{*}{$\begin{array}{l}\text { Sample } \\
\text { Grain } \\
\text { Point } \\
\text { ID } \\
\end{array}$} & \multirow{2}{*}{\multicolumn{3}{|c|}{$\frac{E m-013 A \text { (granite) }}{15}$}} & \multicolumn{3}{|c|}{$\begin{array}{l}\$ 3-167 \\
\text { (granite) }\end{array}$} & \multirow{2}{*}{\multicolumn{3}{|c|}{$\frac{T C-3 \text { (gneiss) }}{2}$}} & \multicolumn{3}{|c|}{ VGr (granulite) } \\
\hline & & & & 4 & 6 & & & & & 1 & 2 & 2 \\
\hline & $14, i$ & $1, r$ & $4, c$ & $2, \mathrm{C}$ & $4, i$ & $8, r$ & $3, i$ & $2, i$ & $10, r$ & $1, i$ & $2, \mathrm{c}$ & $2, r$ \\
\hline \multicolumn{13}{|c|}{ Oxides (wt.\%) } \\
\hline $\mathrm{SiO}_{2}$ & 1.84 & 0.27 & 0.03 & 0.42 & 0.16 & 0.37 & 1.21 & 1.16 & 0.55 & 0.22 & 0.23 & 0.23 \\
\hline $\mathrm{ThO}_{2}$ & 13.78 & 7.17 & 2.92 & 10.53 & 6.78 & 4.97 & 8.93 & 8.89 & 5.52 & 4.56 & 4.79 & 5.75 \\
\hline $\mathrm{UO}_{2}$ & 0.643 & 1.009 & 1.047 & 1.424 & 2.581 & 0.111 & 0.120 & 0.125 & 0.222 & 0.19 & 0.16 & 0.17 \\
\hline $\mathrm{Al}_{2} \mathrm{O}_{3}$ & bd & 0.04 & 0.07 & 0.02 & bd & bd & bd & bd & 0.02 & bd & 0.03 & $b d$ \\
\hline $\mathrm{La}_{2} \mathrm{O}_{3}$ & 11.55 & 13.64 & 15.60 & 9.68 & 10.54 & 15.39 & 14.74 & 14.35 & 15.83 & 13.76 & 15.21 & 14.68 \\
\hline $\mathrm{Ce}_{2} \mathrm{O}_{3}$ & 24.38 & 27.51 & 30.06 & 23.74 & 24.22 & 30.45 & 29.86 & 29.92 & 31.86 & 30.12 & 31.26 & 30.52 \\
\hline $\mathrm{Pr}_{2} \mathrm{O}_{3}$ & 2.66 & 2.91 & 2.97 & 2.96 & 2.98 & 3.16 & 3.10 & 3.02 & 3.06 & 3.38 & 3.25 & 3.29 \\
\hline $\mathrm{Nd}_{2} \mathrm{O}_{3}$ & 10.50 & 10.30 & 10.38 & 10.88 & 11.06 & 11.24 & 10.73 & 11.07 & 11.26 & 12.72 & 11.83 & 11.90 \\
\hline $\mathrm{Sm}_{2} \mathrm{O}_{3}$ & 2.16 & 2.02 & 1.60 & 2.65 & 2.62 & 1.45 & 1.23 & 1.34 & 1.19 & 2.06 & 1.56 & 1.71 \\
\hline $\mathrm{Gd}_{2} \mathrm{O}_{3}$ & 1.62 & 1.37 & 1.14 & 1.81 & 2.11 & 0.99 & 0.63 & 0.63 & 0.26 & 1.28 & 0.67 & 0.85 \\
\hline $\mathrm{Tb}_{2} \mathrm{O}_{3}$ & 0.14 & 0.18 & 0.09 & na & na & na & bd & bd & $b d$ & bd & bd & bd \\
\hline $\mathrm{Dy}_{2} \mathrm{O}_{3}$ & 0.52 & 0.56 & 0.55 & 0.89 & 1.18 & 0.31 & 0.11 & 0.08 & 0.07 & 0.24 & 0.08 & 0.13 \\
\hline $\mathrm{Er}_{2} \mathrm{O}_{3}$ & 0.06 & 0.10 & 0.14 & na & na & na & bd & bd & bd & bd & bd & bd \\
\hline $\mathrm{Yb}_{2} \mathrm{O}_{3}$ & 0.12 & 0.10 & 0.11 & 0.10 & 0.10 & 0.07 & 0.05 & 0.07 & 0.06 & 0.08 & bd & bd \\
\hline $\mathrm{Y}_{2} \mathrm{O}_{3}$ & 1.36 & 1.46 & 1.52 & 2.33 & 2.81 & 0.90 & 0.21 & 0.21 & 0.05 & 0.44 & 0.07 & 0.18 \\
\hline $\mathrm{FeO}$ & $b d$ & bd & bd & 0.06 & 0.25 & bd & bd & $b d$ & 0.02 & bd & bd & bd \\
\hline $\mathrm{CaO}$ & 1.28 & 1.54 & 0.83 & 2.18 & 1.84 & 0.78 & 0.76 & 0.76 & 0.80 & 0.81 & 0.84 & 0.83 \\
\hline $\mathrm{PbO}$ & 0.402 & 0.270 & 0.158 & 0.188 & 0.194 & 0.067 & 0.322 & 0.311 & 0.211 & 0.14 & 0.14 & 0.17 \\
\hline $\mathrm{P}_{2} \mathrm{O}_{5}$ & 27.12 & 30.09 & 30.48 & 29.60 & 30.09 & 29.66 & 28.32 & 28.54 & 29.74 & 29.20 & 29.50 & 29.70 \\
\hline Sum & 100.14 & 100.52 & 99.72 & 99.47 & 99.51 & 99.91 & 100.30 & 100.47 & 100.71 & 99.20 & 99.62 & 100.10 \\
\hline
\end{tabular}




\begin{tabular}{|c|c|c|c|c|c|c|c|c|c|c|}
\hline Sample & Em-013A (granite) & & $\begin{array}{l}\text { S3-167 } \\
\text { (granite) }\end{array}$ & & & $T C-3$ (gneiss) & & VGr (gra & ulite) & \\
\hline Grain & 15 & & 4 & 6 & & 2 & & 1 & 2 & 2 \\
\hline $\begin{array}{l}\text { Point } \\
\text { ID }\end{array}$ & $14, i$ & $4, \mathrm{c}$ & $2, \mathrm{c}$ & $4, i$ & $8, r$ & $3, i$ & $10, r$ & $1, \mathrm{i}$ & $2, c$ & $2, r$ \\
\hline
\end{tabular}

\section{Cation proportions (on the basis of 16 )}

\begin{tabular}{|c|c|c|c|c|c|c|c|c|c|c|c|c|}
\hline $\mathrm{Si}$ & 0.296 & 0.042 & 0.005 & 0.066 & 0.024 & 0.058 & 0.192 & 0.184 & 0.086 & 0.035 & 0.036 & 0.036 \\
\hline Th & 0.505 & 0.254 & 0.104 & 0.377 & 0.241 & 0.178 & 0.323 & 0.321 & 0.196 & 0.165 & 0.173 & 0.206 \\
\hline U & 0.023 & 0.035 & 0.036 & 0.050 & 0.090 & 0.004 & 0.004 & 0.004 & 0.008 & 0.007 & 0.006 & 0.006 \\
\hline $\mathrm{Al}$ & - & 0.008 & 0.012 & 0.004 & - & - & - & - & 0.003 & - & 0.006 & - \\
\hline La & 0.686 & 0.783 & 0.896 & 0.561 & 0.607 & 0.892 & 0.865 & 0.839 & 0.912 & 0.809 & 0.888 & 0.853 \\
\hline $\mathrm{Ce}$ & 1.437 & 1.567 & 1.713 & 1.365 & 1.385 & 1.752 & 1.739 & 1.736 & 1.822 & 1.759 & 1.812 & 1.761 \\
\hline $\mathrm{Pr}$ & 0.156 & 0.165 & 0.169 & 0.169 & 0.170 & 0.181 & 0.179 & 0.175 & 0.174 & 0.196 & 0.187 & 0.189 \\
\hline $\mathrm{Nd}$ & 0.604 & 0.572 & 0.577 & 0.610 & 0.617 & 0.631 & 0.609 & 0.627 & 0.628 & 0.724 & 0.669 & 0.670 \\
\hline $\mathrm{Sm}$ & 0.120 & 0.108 & 0.086 & 0.143 & 0.141 & 0.079 & 0.067 & 0.073 & 0.064 & 0.113 & 0.085 & 0.093 \\
\hline $\mathrm{Gd}$ & 0.086 & 0.070 & 0.059 & 0.094 & 0.109 & 0.051 & 0.033 & 0.033 & 0.014 & 0.068 & 0.035 & 0.045 \\
\hline Tb & 0.007 & 0.009 & 0.005 & - & - & - & - & - & - & - & - & - \\
\hline Dy & 0.027 & 0.028 & 0.028 & 0.045 & 0.059 & 0.016 & 0.006 & 0.004 & 0.004 & 0.012 & 0.004 & 0.007 \\
\hline $\mathrm{Er}$ & 0.003 & 0.005 & 0.007 & - & - & - & - & - & - & - & - & - \\
\hline $\mathrm{Yb}$ & 0.006 & 0.005 & 0.005 & 0.005 & 0.005 & 0.004 & 0.002 & 0.003 & 0.003 & 0.004 & - & - \\
\hline$Y$ & 0.117 & 0.121 & 0.126 & 0.195 & 0.233 & 0.075 & 0.018 & 0.017 & 0.004 & 0.037 & 0.006 & 0.015 \\
\hline $\mathrm{Fe}$ & - & - & - & 0.008 & 0.033 & - & - & - & 0.002 & - & - & - \\
\hline $\mathrm{Ca}$ & 0.220 & 0.256 & 0.139 & 0.367 & 0.308 & 0.130 & 0.129 & 0.129 & 0.134 & 0.138 & 0.142 & 0.140 \\
\hline $\mathrm{Pb}$ & 0.017 & 0.011 & 0.007 & 0.008 & 0.008 & 0.003 & 0.014 & 0.013 & 0.009 & 0.006 & 0.006 & 0.007 \\
\hline$P$ & 3.695 & 3.963 & 4.017 & 3.937 & 3.979 & 3.945 & 3.814 & 3.829 & 3.933 & 3.942 & 3.954 & 3.963 \\
\hline Sum & 8.008 & 8.004 & 7.989 & 8.006 & 8.090 & 7.999 & 7.999 & 7.991 & 7.996 & 8.017 & 8.009 & 7.991 \\
\hline
\end{tabular}

\section{Th, $U$, and $\mathrm{Pb}_{T}$ concentrations (ppm), point ages and standard errors (95\%)}

\begin{tabular}{|c|c|c|c|c|c|c|c|c|c|c|c|c|}
\hline Th & 121070 & 63040 & 25700 & 92570 & 59550 & 43660 & 78460 & 78120 & 48530 & 40074 & 42095 & 50490 \\
\hline SE & 2485 & 1320 & 581 & 1920 & 1253 & 933 & 1627 & 1620 & 1028 & 852 & 890 & 1440 \\
\hline$U$ & 5670 & 8890 & 9230 & 12550 & 22755 & 975 & 1060 & 1100 & 1960 & 1640 & 1437 & 1498 \\
\hline SE & 165 & 220 & 226 & 287 & 482 & 111 & 112 & 112 & 117 & 124 & 123 & 124 \\
\hline $\mathrm{Pb}$ & 3730 & 2510 & 1470 & 1740 & 1800 & 625 & 2990 & 2890 & 1960 & 1300 & 1290 & 1560 \\
\hline$S E$ & 125 & 103 & 95 & 96 & 97 & 80 & 116 & 115 & 98 & 95 & 94 & 98 \\
\hline $\begin{array}{l}\text { Age } \\
\text { (Ma) }\end{array}$ & 593 & 604 & 583 & 293 & 304 & 298 & 806 & 781 & 786 & 635 & 612 & 625 \\
\hline SE & 26 & 32 & 51 & 22 & 21 & 57 & 40 & 40 & 52 & 58 & 60 & 52 \\
\hline
\end{tabular}


Tabela 3

\begin{tabular}{|c|c|c|c|c|}
\hline $\begin{array}{l}\text { Chemical } \\
\text { Method }\end{array}$ & $\begin{array}{l}\text { Age } \\
\text { (Ma) }\end{array}$ & SE & MSWD & $\begin{array}{ll}\text { Prob. } & \text { SD } \\
\text { fit } & \end{array}$ \\
\hline \multicolumn{5}{|c|}{ 3D chemical isochron: Rhede et al. (1996), modified } \\
\hline Th- $\mathrm{Pb}_{\mathrm{T}}$ age & 613 & 22 & 0.91 & 0.60 \\
\hline $\mathrm{U}-\mathrm{Pb}_{\mathrm{T}}$ age & 617 & 50 & 0.91 & 0.60 \\
\hline $\begin{array}{l}\text { Weighted } \\
\text { Average }\end{array}$ & 614 & 20 & & \\
\hline \multicolumn{5}{|c|}{ 2D chemical iscohron: Suzuki and Adachi (1991), modified } \\
\hline Model 1 & 614 & 21 & 0.86 & 0.67 \\
\hline Model 1 , to 0 & 611 & 16 & 0.83 & 0.72 \\
\hline Robust fit & 616 & $21 /-23$ & & \\
\hline Robust fit, to 0 & 612 & 18 & & \\
\hline \multicolumn{5}{|c|}{ Averages: (Montel et al. 1996, Ludwig 2003) } \\
\hline $\begin{array}{l}\text { Weighted } \\
\text { Average }\end{array}$ & 614 & 8 & 0.48 & 0.99 \\
\hline Tukey`s BiWeight & 615 & 6 & & \\
\hline Median & 613 & $11 /-8$ & & \\
\hline
\end{tabular}




\title{
CAPÍTULO III
}

\author{
Idades do metamorfismo e do magmatismo granítico no Terreno Embu \\ e vizinhanças (SE do Brasil) e implicações: Uma contribuição da \\ datação Th-U-Pb de monazita e xenotima com EPMA
}

RESUMO

Idades químicas de cristalização e de re-equilibrios superimpostos obtidas com microssonda eletrônica para monazita e xenotima de rochas metamórficas, migmatíticas e granitos intrusivos do Terreno Embu e vizinhos, Leste do Estado de São Paulo, SE do Brasil registram os principais eventos geológicos que marcam a evolução neoproteozóica da região. Eventos de metamorfismo regional de temperaturas médias a altas em facies anfibolito são registrados no Terreno Embu (ca. $790 \mathrm{Ma}$ ), na nappe Socorro (ca. $625 \mathrm{Ma}$ ) e no Terreno Serra do Mar (ca. 590-570 Ma). O extenso magmatismo granítico de natureza tipicamente peraluminosa que caracteriza os terrenos Embu e Serra do mar ocorreu em pelo menos três epiśdios distintos. Um magmatismo precoce no Terreno Embu, representado principalmente por tonalitos e granodioritos peraluminosos, atualmente ortognaisses, apresenta idades de ca. $790 \mathrm{Ma}$, similares às obtidas para o evento principal de metamorfismo. Nesta região, este período foi caracterizado principalmente por movimentos tectônicos compressionais. O Batólito Quebra Cangalha colocouse provavelmente há ca. $670 \mathrm{Ma}$, mas o significado deste magmatismo no contexto regional ainda é pouco claro. No Terreno Serra do Mar, o metamorfismo regional em fácies anfibolito, com geração abundante de migmatitos, foi datado em ca. $590 \mathrm{Ma}$. Nesta época, diversos plutons sintectônicos se colocaram nos terrenos Embu e Serra do Mar (plutons Mauá, Mogi das Cruzes, 
Batólito Natividade da Serra), controlados por expressivas zonas de cizalhamento transcorrentes que provocaram deformação e recristalização dos metassedimentos Embu e Piracaia em facies xistos verdes. Possivelmente estes movimentos foram os responsáveis pela justaposição dos domínios Embu e Socorro-Guaxupé e pela configuração atual da Faixa Ribeira na região. Os ciclos magmáticos na área estudada são encerrados pela colocação de magmas anidros da série charnockitica, há ca. $560 \mathrm{Ma}$, já em ambientes tipicamente extensionais. Re-equilíbrios químicos significativos em monazita e xenotima em rochas graníticas, particularmente do Batólito Natividade da Serra, ocorreram há ca. $530 \mathrm{Ma}$, e definem um evento tectono-térmico que também afetou alguns migmatitos, granitos e charnockitos dos terrenos Embu e Serra dó Mar. $\mathrm{Na}$ área estudada não são encontradas evidências claras de eventos magmáticos expressivos neste periodo e as principais atividades parecem estar representadas pela reativação de zonas de cizalhamento, causando deformação e recristalização em graus variáveis nas rochas, associadas mais para Leste com a Orogênese Cabo Frio.

INTRODUÇÃO

A datação química com microssonda eletrônica (EPMA) de minerais portadores de RRE, com destaque para monazita e xenotima, tem se mostrado como uma ferramenta poderosa para a datação de rochas metapelíticas, migmatitos e granitos (e rochas sedimentares no caso de xenotima) e, particularmente, para elucidar relações petrogenéticas entre fases minerais e a sua evolução temporal. Este método permite, de fato, estabelecer uma cronologia absoluta em processos petrológicos importantes em escalas meso- e microscópica, informações que têm se revelado essenciais para a compreensão da evolução da crosta continental, uma parte substancial da qual é predominantemente constituída por rochas de natureza poligenética. Desde o estabelecimento do método de forma mais sistemática por Suzuki e Adachi (1991), o número de trabalhos envolvendo desde aspectos metodológicos até aplicações para situações geológicas diversas é muito significativo (Montel et al. 1994, Cocherie et al. 1998, Williams et al. 1999, Vlach e Gualda 2000, Foster et al. 2004, Gonçalves et al. 2004, Jercinoic e Williams 2005, Hetherington 
et al. 2007, Jercinovi et al. 2008, Martins et al. no prelo, Vlach, submetido e referências citadas por estes autores).

Diversas características tornam a datação destes minerais interessante em geologia. Por um lado, os campos de estabilidade amplos de xenotima e monazita permitem tonam-as estáveis em ambientes que incluem deste a diagênese (no caso de xenotima) e ambientes tipicamente hidrotermais até ambientes de metamorfismo de médio a alto grau e anatexia, bem como em granitos e riolitos de natureza marginal ou tipicamente peraluminosa e certas rochas alcalinas, incluindo carbonatitos (e.g., Franz et al. 1996, Chang et al. 1998, Hetherington et al. 2007). Adicionalmente, evidências geológicas e dados experimentais recentes têm demonstrado que a difusão de $\mathrm{Pb}$ é insignificante na estrutura da monazita sob condições de temperatura típicas dos processos geológicos mencionados e que a abertura do sistemas químicos e isotópicos neste mineral deve estar associada preferencialmente a processos de dissolução e reprecipitação (e.g. Vlach 2001, Seidoux-Guillaume et al. 2002, Gardés et al. 2007).

A precisão dos resultados do método pode ser cerca de uma ordem de grandeza inferior a dos métodos isotópicos tradicionais (TIMS) e pouco inferior ou mesmo similar a dos métodos isotópicos pontuais (SHRIMP) mas, em contrapartida, as análises com EPMA são as que possibilitam a melhor resolução espacial, permitindo a análise de volumes que variam de poucas a 1 ou 2 dezenas de $\mu^{3}$ (Pyle et al. 2005, Jercinovic et al. 2008, Vlach, submetido). Adicionalmente, o método químico permite a realizar datações em um contexto integrado com análises que permitem avaliar relações e evolução textural, mineralógica, parâmetros intensivos, etc.

Apesar do grande número de trabalhos sobre o tema, existem poucos exemplos de aplicação da datação de monazita e xenotima de forma sistemática para a análise da evolução cronológica de grandes áreas ou cinturões metamórficos. O presente trabalho reúne, de forma integrada, os resultados obtidos para rochas metamórficas, migmatíticas e graníticas diversas que afloram no Terreno Embu e vizinhanças, leste do estado de São Paulo, SE do Brasil. O objetivo principal deste trabalho é a apresentação sistemática das datações obtidas para esta área nos últimos anos, cuja estratigrafia, evolução geológica e situação tectônica ainda são sujeitas a debate (cf. Campos Neto 2000, Janasi et al. 2003, Heilbron et al. 2004). Demonstra-se que o método é muito eficiente para aa elaboração de um arcabouço geocronológico lógico em cinturões 
metamórficos da crosta continental desenvolvidos sob condições de temperaturas moderadas a altas, permitindo determinar com precisão adequada as idades de eventos metamórficos, do magmatismo granítico associado, e de eventuais eventos posteriores de retrabalhamento, em condições mais tipicamente hidrotermais e de baixa temperatura.

Os resultados obtidos e as possiveis implicações geológicas são discutidos a luz das informações disponiveis para estes segmento da Faixa Ribeira. Questões mineralógicas e petrológicas especificas envolvendo os minerais e as rochas estudados serão discutidas em trabalhos complementares, que estão sendo submetidos e/ou preparados.

\section{SITUAÇÃo GEOLÓGICA E GECRONOLOGIA GERAL}

O desenvolvimento do ramo norte do Sistema Orogênico Mantiqueira ou Faixa Ribeira na região sudeste do Brasil (Figura 1) está ligado ao fechamento do Oceano Adamastor e geração do supercontinente Gondwana que ocorreu no intervalo entre o Neoproterozóico e o Cambriano. Este sistema orienta-se na direção NE e foi formado por episódios discretos de colagens e justaposição de fragmentos de crosta tidos como remanescentes do supercontinente Rodinia (genericamente denominados terrenos), entre ca. 610 e $530 \mathrm{Ma}$, devido a aproximação do Craton Kalahari aos Cratons São Francisco-Congo e Rio da Plata, estes últimos unidos há ca. 630 Ma. (e.g. Almeida et al. 1981, Brito Neves et al. 1999, Campos Neto 2000, Heilbron et al. 2004). Na zona central deste sistema definem-se os terrenos terrenos Apiaí, São Roque e Embu, cujas relações mútuas bem como com os terrenos das Faixas Brasilia e Ribeira ainda não são pouco conhecidas (e.g. Heilbron et al. 2004).

O Terreno Embu (Hasui 1975, Campos Neto 2000, Heilbron et al 2004) aflora na região leste do Estado de São Paulo. Apresenta orientação NNE e está constituido por xistos e gnaisses de médio a alto grau metamórfico, migmatitos e quantidades subordinadas de ortognaisses e de rochas meta-vulcânicas e cálcio-silicáticas. Em geral a qualidade das exposições neste terreno não é boa devido aos elevados graus de alteração intempérica e à ocupação humana. Informações mais completas existem para a região a leste da cidade de São Paulo, onde 
Fernandes et al. (1990) reconheceram três unidades estratigráficas principais: a Unidade Redenção da Serra, basal, constituída por seqüências metapelíticas e psamíticas, anfibolitos, gnaisses cálcio-silicáticos e subordinadamente mármores; a Unidade Rio Paraibuna, intermediária, dominada por seqüências clasto-químicas e a Unidade Rio Una, com predomínio de mica-xistos e quartzitos imaturos. A infraestrutura destas seqüências corresponde ao Complexo Rio Capivari, que apresentan natureza ortognássica e migmatítica e idade paleoproterozóica (Babinski et al 2001).

As paragêneses minerais presentes nos xistos e gnaisses indicam que o metamorfismo corresponde às zonas de sillimanita + muscovita e sillimanita - feldspato potássico, com fusão parcial limitada observada ocasionalmente em gnaisses quartzo-fedspáticos (Vieira et al. 1990, Fernandes et al. 1990). Dados geotermobarométricos indicam pressões e temperaturas da ordem de 5-6 kbar e $680-730^{\circ} \mathrm{C}$, respectivamente (Vieira et. al.1990, Augusto e Vlach dados inéditos). Datações preliminares de monazita em equilibrio com granada e sillimanita com microssonda eletrônica indicaram idades de ca. 790 Ma para o metamorfismo principal no Terreno Embu (Vlach 2001, um valor pouco superior aos obtidos por Vieira e Tassinari 1988, ca. 750 Ma com o método $\mathrm{Rb} / \mathrm{Sr}$ em rocha total).

Os limites do Terreno Embu para NW com o Complexo Piracaia no domínio da Nappe Socorro e com o Terreno Serra do Mar para SE são de natureza tectônica e correspondem às zonas de cizalhamento dextrais Caucaia - Rio Jaguari e Cubatão, respectivamente. O Complexo Piracaia corresponde à Unidade Migmatítica Superior da Nappe Socorro e é constituído por uma seqüência metassedimentar migmatítica contendo metabasitos, quartzitos feldspáticos, horblenda gnaisses, ortognaisses e mármores (cf. Campos Neto e Basei 1983, Heilbron et al. 2004). Datações isotópicas e com microssonda eletrônica indicam idades de ca. 620-630 Ma para o metamorfismo e migmatização (e.g., Basei et al. 1995, Vlach e Gualda 2000, Martins et al. no prelo). O Terreno Serra do Mar é constituído principalmente por sillimanita granada gnaisses e migmatitos com intercalações de quartzitos, biotita gnaisses bandados, rochas metabásicas e cálcio-silicáticas (Campos Neto 2000, Heilbron et al. 2004). Determinações U/Pb (SHRIMP) em zircão resultaram em idades próximas a 570 Ma para o metamorfismo de gnaisses kinzigíticos da região de São Sebastião, estado de São Paulo (Tassinari et al. 1999). 
A caracterização geral do magmatismo granitico e da sua estratigrafia na zona central da Faixa Ribeira foi revisada por Janasi et al. (2003) e Heilbron et al. (2004). Na região do Terreno Embu, o magmatismo granítico se caracteriza, quando comparado ao extensivo magmatismo dos terrenos vizinhos (e.g., Apiai, Nappe Socorro), por apresentar de biotita ( \pm ) muscovita granitos marginalmente a tipicamente peraluminosos, com contribuições crustais significativas. Entretanto, estudos em detalhe deste magmatismo ainda são escassos (cf. Janasi et al. 2003, Vlach submetido) e mesmo as relações geológicas, as afinidades tipológicas e a estratigrafia ainda são pouco conhecidas. Os dados disponiveis (e.g. Tassinari 1988, Janasi et al. 2003) sugerem que rochas graníticas se colocaram em três períodos durante o neoproterozóico. Um magmatismo precoce está representado por biotita-tonalitos e -granodioritos colocados proximamente ao pico metamórfico e a fase principal F1 de deformação das encaixantes (Fernandes et al. 1990), há ca. 810 Ma (Cordani et al. 2002) e posteriormente convertidos em ortognaisses do fácies anfibolito. Biotita monzogranitos porfiriticos com foliações de fluxo e de estado sólido, que constituem o Batólito Quebra Cangalha, orientado NNE, possiveimente se colocaram entre 720 e $650 \mathrm{Ma}$. O magmatismo mais jovem na região do Terreno Embu está representado por plutons sin-tectônicos de dimensões mais reduzidas (e.g. Mogi das Cruzes, Mauá, Santa Branca) e, no Terreno Serra do Mar, pelo expressivo Batólito Natividade da Serra, com ca. $800 \mathrm{~km}^{2}$ de área estimada de exposição. As rochas típicas que afloram nestas ocorrências são biotita granitos porfiríticos e biotita muscovita granitos inequigranulares a equigranulares com estruturas planares que combinam fluxo magmático com deformação de estado sólido em intensidades variáveis. As idades (Rb-Sr em rocha total, calculadas segundo o algoritmo de Williamson 1968, e U-Pb-TIMS em monazita) disponiveis concentram-se no intervalo entre ca. 625 e $530 \mathrm{Ma}$ (e.g. Tassinari 1988, Janasi et al. 2003) e não permitem ainda definir melhor a estratigrafia deste magmatismo. Rochas intrusivas da série charnockítica, típicas do Terreno Serra do Mar na região de Ubatuba, apresentam idades Rb-Sr entre 550 e 560 Ma (Gasparini e Mantovani 1979) e Pb-Pb através do método de Kober em zircão de ca. $560 \mathrm{Ma}$ e $530 \mathrm{Ma}$, interpretadas como idades de cristalização e de re-equilíbrio, respectivamente (MacLuf e Schorscher 2001). 
Amostras típicas de paragneisses pelíticos e pelítico-psamíticos (04), migmatitos (02), ortognaisses (02) e rochas graníticas moderada a francamente peraluminosos (05) dos terrenos Embú e Serra do Mar e do Complexo Piracaia, foram selecionadas para este trabalho (ver localização na Figura 1).

As análises de monazita e xenotima foram efetuadas em seções delgadas polidas cobertas com fina película de C (ca. $250 \mathrm{~nm}$ ) no Laboratório de Microssonda Eletrônica do Instituto de Geociências da Universidade de São Paulo, que conta com um equipamento JEOL-JXA8600 provido de 05 espectrômetros WDS, e um sistema de automação Voyager 4.3 da Thermo-Noran. Análise textural sob microscopia de luz transmitida e refletida e imagens BSE de alta resolução foram utilizadas para a seleção de cristais e para a localização de pontos a serem quantificados. As condições instrumentais utilizadas para as análises quantitativas foram $15 \mathrm{kV}, 300 \mathrm{nA}$ e 2-4 $\mu \mathrm{m}$ para a voltagem de aceleração da coluna, corrente e diâmetro do feixe eletrônico, respectivamente, para monazita e $200 \mathrm{nA}, 5 \mu \mathrm{m}$ para xenotima. Protocolos e procedimentos analíticos e de tratamento de dados utilizados no laboratório, com ênfase para monazita, são apresentados e discutidos em detalhe por Vlach (submetido, ver também Vlach and Gualda 2000 e Martins et al. no prelo); protocolos específicos para xenotima serão apresentados em uma próxima contribuição. Estes procedimentos permitem obter análises praticamente completas para monazita e xenotima nas corridas para datação.

Cristais de monazita de amostras de referência com resultados U/Pb (TIMS, SHRIMP) em monazita e/ou zircão concordantes foram utilizados rotineiramente para controle das calibraçб̃es elementais e dos resultados obtidos (ver detalhes em Vlach sumetido). Adicionalmente, como os resultados apresentados foram obtidos em diferentes corridas analíticas, os resultados de cada nova corrida foram cruzados com os de corridas anteriores, pela reanálise de alguns pontos representativos de cristais mais típicos. 
As correções das interferências das linhas Th $M$ sobre $U M \beta$ e Th $M$ e $Y L$ sobre $P b M \alpha$ (monazita) ou U M sobre $\mathrm{Pb} M \beta$ (xenotima) foram efetuadas com o programa Age_Cor, de uso interno do laboratório, que se utiliza de procedimento similar ao apresentado por Fialin et al. (1997). A conversão dos dados de intensidades e as correções para os efeitos de matriz foram efetuadas com o programa PROZA disponivel no sistema Voyager (e.g. Bastin e Heilijiers 1990). Os limites de detecção alcançados para $\mathrm{Pb}, \mathrm{U}$ e Th são próximos a 80, 90, 90 e 100, 90 , 90 para monazita e xenotima, respectivamente. Os erros das determinações individuais de $\mathrm{Th}, \mathrm{U}$ e $\mathrm{Pb}$ representam a soma dos erros devidos a estatistica de contagem e instrumentais, atribuindo-se um valor algo arbitrário de $2 \%$ relativo para estes últimos.

As conversões dos dados analíticos para proporções catiônicas e fórmulas estruturais foram feitas como o programa MinCal (Gualda and Vlach, inédito). Os resultados de datação obtidos são apresentados na forma de isócronas químicas e médias ponderadas de populações estatísticamente homogêneas. Idades pontuais, calculadas por iteração da equação básica de idade e/ou por modelamento de Monte Carlo, parâmetros para os cálculos isocrônicos e respectivos erros foram computados com programa Mona_Age (cf. Vlach submetido), que insere automaticamente os resultados e chama o programa Isoplot (Ludwig 2003) para o cálculo final de idades isocrônicas e médias ponderadas. Por conveniência, as quantidades Th* (que representa

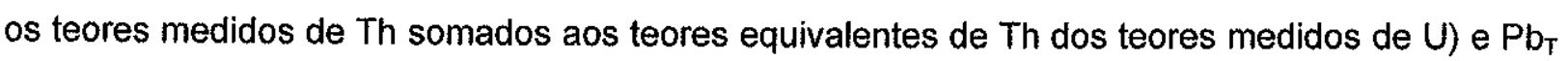
são expressas na forma cations para a representação e os cálculos isocrônicos; nos casos em que a dispersão dos pontos foi inadequada para o ajuste das isócronas, elas foram forçadas para a origem, i.é. $\left[\left(\mathrm{Th}^{*}, \mathrm{~Pb}_{\mathrm{T}}\right)=(0 \pm 0.04,0 \pm 0.02)\right]$, cf. detalhes em Vlach (submetido). Todos os dados e resultados foram computados e são apresentados para um nivel de confiança de $95 \%$.

Em geral foram obtidas cerca de 20-35 análises pontuais para cada população isócrona, homogênea. A qualidade das análises foi avaliada pelo fechamento analítico (admitindo-se variação máxima de máxima de ca. $1 \%$ em porcentagem em peso de óxidos) e adequação das proporções catiónica à fórmula estrutural de cada mineral (admitindo-se variação máxima de 2 \%). Análises que não obedeceram estes critérios foram sistematicamente rejeitadas. No caso de algumas amostras de migmatitos do Terreno Serra do Mar, dados obtidos para alguns cristais de xenotima foram descartados, uma vez que as concentrações de $\mathrm{Pb}_{\mathrm{T}}$ são baixas, da ordem de 400 - 
600 ppm, próximas ao limite de quantificação (cf. Potts 1996), inviabilizando a obtenção de idades pontuais com erros satisfatórios.

\section{RESULTADOS}

Ao total foram obtidas mais de 500 análises pontuais praticamente completas para monazita e outras 70 para xenotima dos gnaisses pelíticos e psamíticos, ortognaisses e granitos intrusivos estudados neste trabalho. Dados analíticos representativos são apresentados nas Tabelas 1 e 2, respectivamente. Os dados completos podem ser obtidos através de solicitação ao autor.

Idades químicas para o metamorfismo regional e a geração de migmatitos

\section{Terreno Embu}

Para a determinação das idades de metamorfismo neste terreno foram estudadas três amostras de granada-sillimanita-biotita gnaisses com andesina, feldspato potássico e alguma muscovita. Dados parciais foram apresentados por Vlach (2001). A amostra EM-020, da área a leste da cidade de São Paulo, inclue níveis psamíticos e pelíticos de granulações médias adjacentes. Os minerais principais cristalizaram pouco antes da deformação F1. A superimposição de uma paragênese de grau mais baixo, da facies xistos verdes, caracterizada principalmente por uma segunda geração de biotita + muscovita, ocorreu durante a fase deformação F3 (Fernandes et al. 1990). Resultados geotermométricos indicam que a paragênese principal cristalizou sob ca. $710^{\circ} \mathrm{C}$ e $5.5 \mathrm{kbar}$ (Augusto e Vlach dados inéditos). As amostras VGR-292A e E1\&2 são representativas a região a Sudoeste. A amostra VGR-292A representa um gnaisse psamíticopelítico de granulação média. Caracteriza-se por apresentar quantidades mais expressivas de sillimanita e granada, menores de biotita e razão modal feldspato alcalino/plagioclásio superiores as das demais amostras; o feldspato alcalino chega a ser mesopertítico. A amostra E-1\&2, um 
testemunho de sondagem, é de natureza francamente psamítica e de granulação mais grossa. Os resultados geotermométricos obtidos nesta região são similares (Vieira et al. 1990). Ambas as amostras, mas marcadamente a amostra E-1\&2, apresentam a superfície principal $S$ transposta por uma zona de cizalhamento com mergulho para SW, não registrada na amostra da região leste, que resulta em deformação e, em parte, recristalização dos minerais primários. Uma nova geração de biotita e muscovita, além de fibrolita e turmalina cristalizaram em parte simultaneamente ou imediatamente após esta deformação e encontram-se superpostas a mineralogia principal.

Nestas amostras, a monazita aparece mais tipicamente como cristais idiomórficos isolados, associados como granada, sillimanita e biotita ou como inclusões menores, arredondadas, em granada, biotita, quartzo e feldspatos. Zonamentos composicionais concêntricos, oscilatórios, setoriais ou ainda mais complexos e irregulares são bem evidenciados em imagens BSE (Figuras 2 a 4) e aparecem melhor marcados nas amostras VGR-292A e EM020. $\mathrm{Na}$ amostra E1\&2, com deformação mais forte, cristais de monazita próximos aos planos de cizalhamento apresentam-se estirados e com texturas em morteiro e sliding (Figura 2). Alguns cristais dos niveis pelíticos da amostra EM-020 são tipicamente poligenéticos e mostram claras feições de dissolução e reprecipitação (Figura 4).

Nas Figuras 2, 3 e 4 apresentam-se imagens BSE de cristais representativos analisados, localização dos pontos analíticos nestes cristais, bem como um sumário dos resultados obtidos para datação química, representados na forma de isócronas $\mathrm{Th}^{*}$ - $\mathrm{PbT}$ e de médias ponderadas pelos erros das determinações individuais, indicados nas análises representativas apresentadas nas Tabelas 1 e 2. As idades médias e isocrónicas calculadas para a cristalização de monazita primária variam entre ca. 789 e $800 \mathrm{Ma}$ e são praticamente idênticas para as três amostras. Os erros obtidos são da ordem de $10 \mathrm{Ma}$, considerando-se as idades médias ponderadas, mas alcançam 20 Ma nos cálculos isocrónicos devido à dispersão dos pontos no diagrama e ao número significativo de pontos equivalentes ( $\mathrm{Neq})$, considerando-se os erros individuais. As estimativas de erro obtidas através das médias ponderadas são em geral adequadas, desde que as análises pontuais sejam efetuadas sob condições bem controladas (cf. Vlach submetido). A idade de ca. $790 \mathrm{Ma}$ é, portanto, interpretada como a idade que mais se aproxima do pico metamórfico dos metassedimentos do Terreno Embu. 
As análises obtidas em zonas mais deformadas e/ou estiradas de cristais de monazita da amostra E-1\&2 resultam em valores sistematicamente inferiores (ca. 700-760), com uma média ponderada próxima a $730 \mathrm{Ma}$. A aplicação do modelo de mistura para conjuntos de dados com populações de idade contrastadas de Sambridge e Compston (1994), confome implementado no programa Isoplot (idades de desmistura), de Ludwig (2003) para os dados desta amostra resulta em valores médios de $792 \pm 7$ e $729 \pm 13 \mathrm{com}$ um valor para o misfit de 0.87 , que é bem adequado e dá suporte estatístico para considerar os resultados significativos. A idade mais jovem é interpretada como representativa do evento deformacional.

No caso da amostra EM-020, as evidéncias texturais indicam que alguns cristais de monazita são tipicamente poligenéticos, observando-se que uma geração tardia, com contatos lobados, que corroi e substitui parcialmente a monazita primária, através de mecanismos de dissolução e reprecipitação. Esta geração de monazita apresenta padrões de REE distintos, com relativo enriquecimento em HREE e Y (Tabela 1, Vlach dados inéditos) e é interpretada como síncrona ao retrometamorfismo em facies xistos verdes, portanto, à fase de deformação regional F3 e à colocação de plutons sin-tectônicos (cf. adiante). Os resultados obtidos com a rotina de desmistura indicam uma idade média bem controlada de $593 \pm 13$ Ma para este evento.

\section{Terreno Serra do Mar}

As duas amostras de migmatitos do Terreno Serra do mar estudadas (SM-03 e SM-07) foram coletadas em pedreiras desativadas nas proximidades de São Sebastião, ao longo da rodovia Rio-Santos e mostram similaridades. O mesossoma corresponde a um biotita paragnaisse de granulação média. A amostra SM-03 apresenta biotita com pleocroísmo em vermelho a amarelo pálido e alguma granada, com freqüência mostrando sinais de corrosão e substituição por mica, enquanto a amostra SM-7 apresenta biotita com tons de pleocroísmo em tons predominantemente verde e não apresenta granada. Andesina é o plagioclásio predominante e muscovita é ocasional em ambas amostras. As frações neossomáticas são constituídas por leuco monzogranito de granulação média com espessuras milimétricas a centimétricas, com biotita e muscovita bem desenvolvida. Niveis mais ricos em biotita e minerais acessórios caracterizam o 
melanossoma. Mesossoma e neossoma encontram-se deformados e porfiroclastos com extinção ondulante de plagioclásio são relativamente comuns, sugerindo que, pelo menos em parte, os minerais máficos encontram-se recristalizados. Em ambas as amostras foram analisados cristais representativos das frações leuco- e melanossomáticas (Figuras 5 e 6 ). No primeiro caso, os cristais de monazita mostram tendência bem mais acentuada ao idiomorfismo e zonamentos composicionais mais regulares. Diminutas inclusões de apatita idiomórfica, acompanhando possíveis faces de crescimento dos cristais, indicam claramente que estes cristais se formaram a partir da cristalização de magmas. Um único cristal, observado em leucossoma da amostra SM07, apresenta uma zona irregular marcada por coeficiente de retro-espalhamento inferior e com aspecto externo corroído, contornado por monazita idiomórfica; os contatos entre estas zonas são marcados por uma fina zona com coeficiente de retroespalhamento significativamente superior (Figura 6). Os cristais observados nas zonas melanossomáticas, a exeção de algumas inclusões, apresentam em geral contornos mais irregulares e zonamentos mais complexos. Alguma xenotima ocorre como cristais subidiomórficos ou xenomórficos no melanossoma da amostra SM-07. A partição de Gd entre monazita e xenotima (Gratz e Heinrich 1998) para esta amostra indica temperaturas de equilibrio entre 670 e $780^{\circ} \mathrm{C}$ (Vlach dados inéditos).

As idades médias calculadas para a amostra SM-03 são de $592 \pm 10$ e $594 \pm 11$ Ma para cristais do leucossoma e do melanossoma, respectivamente. A monazita presente no melanossoma da amostra SM-07 resulta em valores similares, com média em $588 \pm 11 \mathrm{Ma}$. Os dados obtidos para os cristais do leucossoma sugerem, entretanto, um caráter poligenético, observando-se três concentrações distintas de valores: uma população, amplamente predominante, com ca. $596 \pm 15 \mathrm{Ma}$, idade similar as obtidas para as populações da amostra SM03, uma população concentrada ca. $675 \mathrm{Ma}$, a qual corresponde aos pontos analisados nos núcleos corroídos dos cristais idiomórficos acima mencionados, e uma terceira população com valores mais jovens, próximos a $530 \mathrm{Ma}$, que corresponde a bordas externas encontradas em dois cristais. O número de análises para estas últimas populações é baixo e um detalhamento adicional é necessário para definí-las com melhor precisão.

Estes resultados sugerem que o evento metamórfico-migmatítico ocorreu há aproximadamente $590 \pm 10 \mathrm{Ma}$, uma idade um pouco mais antiga quando comparada à obtida (ca. 
$571 \pm 10 \mathrm{Ma}$, U-Pb em zircão, SHRIMP) por Tassinari et al. (1999) para gnaisses kinzigíticos da região. Estes autores também obtiveram uma análise bem mais jovem em borda de cristal de zircão, que se aproxima de $500 \mathrm{Ma}$. A interpretação mais imediata que se coloca é a de que estas idades mais jovens estejam relacionadas ao evento deformacional que afetou toda esta seqüência. As idades próximas a 675 Ma são de interpretação mais dificil, mas em conjunto com dados a serem apresentados adiante, parecem estar associadas a um evento geológico de caráter regional, ainda pouco definido.

\section{Complexo Piracaia}

A amostra EM-004B analisada corresponde a um biotita-muscovita-granada gnaisse do Complexo Piracaia, coletada em região próxima a Zona de Cisalhamento Caucaia - Rio Jaguari que marca o contato entre este complexo e o Terreno Embu. No afloramento, a foliação metamórfica principal de baixo ângulo de mergulho para SE é cortada por uma foliação NNE de cizalhamento com mergulho moderado a alto. Em seções delgadas, a estrutura milonítica fica ressaltada pela presença de porfiroclastos de plagioclásio com extinção ondulante (andesina), granada e, eventualmente, biotita vermelha. A matriz recristalizada apresenta biotita vermelha pouco mais clara e muscovita em palhetas de dimensões mais reduzidas. Os porfiroclastos de granada encontram-se fortemente fraturados e parcial ou totalmente substituido por micas e minerais féisicos recristalizados em condições de facies xistos verdes. Zonas constituídas apenas por muscovita contornadas pela foliação de cisalhamento parecem substituir antigos cristais de aluminossilicato.

A monazita aparece como porfiroclastos rotacionados, por vezes bem fraturados, as vezes com contornos idiomórficos, as vezes com contornos corroídos associados a biotita e muscovita recristalizadas e também como cristais subarredondados preservados como inclusões em restos de granada. A majoria dos cristais maiores associados às micas apresenta bordas irregulares com coeficientes de retro-espalhamento mais baixos (Figura 7). Os resultados analíticos, aliados às variações composicionais (Vlach dados inéditos), indicam o caráter poligenético da maioria destes cristais e a deconvolução das idades pontuais resulta em duas populações significativas: uma 
principal com ca. $628 \pm 9 \mathrm{Ma}$ e outra com ca. $587 \pm 11$, esta última associada às bordas transformadas dos cristais (Figura 7). O primeiro valor é compativel com as idades obtidas para o pico metamórfico dos metassedimentos do Complexo Piracaia (e.g. Vlach e Gualda 2000, Heilbron et al. 2004), enquanto que a idade mais jovem seguramente deve estar associada ao processo de deformação e formação da paragênese de baixo grau que se superimpôs. É interessante ressaltar que esta última idade é igual a idade obtida para a fase de deformação F3 nos metassedimentos do Terreno Embu e a idade principal do magmatismo granítico jovem nesta região (ver a seguir).

\section{Idades químicas para o magmatismo granítico}

\section{Ortognaisses e o magmatismo tonalitico-granodioritico precoce}

As amostras EM-010 e EM-011B representam variedades de ortognaisses peraluminosos com textura inequigranular a equigranulares com granulações grossa e média, respectivamente, que afloram como lentes e corpos alongados de espessuras diversas, orientados segundo NNE, com marcada foliação subvertical. Os melhores afloramentos ocorrem em cortes da rodovia dos Tamoios, nas proximidades da cidade de Paraibuna. São rochas com composições que variam de tonalitica (EM-010) a granodiorítica (EM-011B) e contatos aparentemente transicionais entre si. Biotita vermelha é o mineral máfico típico (cf. descrições em Vlach submetido). A amostra EM011B apresenta ocasionalmente granada de cristalização mais tardia, alguma muscovita e raros cristais de xenotima. Nestas rochas, a monazita ocorre tipicamente como cristais xenomórficos, subarredondados ou corroídos em graus variáveis, que apresentam típicas coronas de reação compostas apatita + torita, allanita e epídoto com quantidades significativas de elementos terras raras; os volumes de apatita e de torita são subordinados em relação aos de allanita e epidoto (Figuras 8). Nas coronas, apatita e torita tendem a se concentrar nas zonas internas, allanita e epidoto nas zonas mais externas e a sua formação está relacionada a metamorfismo superimposto às rochas originais (Vlach submetido). Coronas similares, menos desenvolvidas, 
aparecem também sobre cristais de xenotima na amostra EM-011B. A partição de Gd entre monazita e xenotima (Gratz e Heinrich 1998) nesta última amostra sugere temperaturas de equilíbrio entre 780 e $850^{\circ} \mathrm{C}$, compativeis com cristalização magmática.

As idades químicas obtidas para monazita das duas amostras e para xenotima da amostra EM-011B situam-se entre 787 e 794 Ma (Figuras 8 e 9), com médias ponderadas entre $786 \pm 10$ e $793 \pm 14 \mathrm{Ma}$. Três análises individuais da amostra EM-010 resultaram em valores inferiores, entre 650 e $710 \mathrm{Ma}$, sugerindo abertura poterior do sistema químico. Estes valores são mais jovens, mas perfeitamente comparáveis com a idade de $811 \pm 13$ Ma obtida através do método U/Pb (SHRIMP) em zircão por Cordani et al. (2002) para biotita gnaisse granodiorítico coletado na região sudoeste da cidade de São Paulo e interpretada como a idade de cristalização das rochas intrusivas originais. Merece ser destacado que estes autores apresentam seis análises pontuais com graus variáveis de discordância e que o único ponto exatamente concordante apresenta uma idade de ca. $794 \mathrm{Ma}$, valor muito próximo ao das idades químicas ora apresentadas para os ortognaisses da região leste. Assim acredita-se que a colocação deste magmatismo se deu há cerca de $790 \mathrm{Ma}$, sendo possivelmente sincrônico com o evento de metamorfismo principal no Terreno Embu. Estes resultados, aliados às temperaturas de equilibrio obtidas, dão suporte adicional para a conclusão de que cristais de monazita preservados em sistemas coroníticos como o caso dos encontrados nestas rochas em geral mantém o seu sistema químico inalterado (e.g. Finger et al. 1998, Vlach submetido) e registram as idades da cristalização magmática original.

\section{O Batólito Quebra Cangalha}

A amostra analisada do Batólito Quebra Cangalha corresponde a um biotita monzogranito porfirítico a localmente inequigranular. Biotita, com tons de pleocroísmo em vermelho a amarelo pálido, é o máfico principal, ocasionalmente acompanhada por muscovita nos termos mais evoluídos. Os acessórios típicos são apatita, zircão, ilmenita além de monazita, xenotima nos granitos mais evoluídos, allanita, epidoto e torita. Os megacristais de feldspato alcalino revelam orientação de fluxo magmático, mas a matriz da rocha apresenta evidências marcadas de deformação e recristalização em estado sólido. Os cristais de monazita e xenotima, esta 
relativamente rara, apresentam zonamentos composicionais oscilatórios ou setoriais. Monazita aparece por vezes com contornos fortemente corroídos (Figura 10), indicando desequilibrio, provavelmente ainda em ambiente magmático. De outras vezes a monazita e, em parte a xenotima, apresentam-se parcial ou completamente substituídas por agregados coroníticos contendo allanita/epidoto, apatita e torita. Neste trabalho foram analisados um cristal de monazita corroído desprovido de corona e cristais de monazita e xenotima envolvidos por finas CAAT. As temperaturas de equilibrio calculadas para o par monazita - xenotima de acordo com Gratz e Heinrich (1998) situam-se entre 750 e $820^{\circ} \mathrm{C}$.

As médias ponderadas obtidas para as determinações individuais em monazita indicam valores de $670 \pm 6 \mathrm{Ma}$, enquanto um número relativamente reduzido de determinações para xenotima resultou em $682 \pm 14 \mathrm{Ma}$. Estes valores são perfeitamente comparáveis dentro do intervalo de erros; os valores obtidos para monazita devem ser mais adequados devido ao número maior de determinações analíticas e aos erros individuais menores. Estes valores são mais jovens quando comparados aos de uma isócrona $\mathrm{Rb}-\mathrm{Sr}$ de referência incluindo amostras variadas do batólito, que resultou em melhor alinhamento de ca. $710 \pm 50 \mathrm{Ma}$ ( calculado com o algorítmo de Williamson 1968, K. Kawashita, comunicação pessoal) e são similares a resultados isotópicos U$\mathrm{Pb}$ em monazita preliminares, com discordância significativa, apresentados por Janasi et al. (2003).

Na região não se encontram bem definidos eventos importantes de geração de magmas graníticos com idades similares (v. também Janasi et al. 2003). Por outro lado, os migmatitos do Terreno Serra do Mar parecem guardar registros de algum evendo nesta época e dados preliminares para uma amostra de monzogranito porfiroclástico do denominado Maciço Jambeiro, contendo biotita com pleocroísmo em tons esverdeados como máfico essencial, localizado a noroeste do Batólito Quebra Cangalha resultaram em duas populações de idades, um preservada em alguns núcleo de cristais de monazita, com ca. $800 \mathrm{Ma}$, outra predominante com ca. 640-660 Ma (Augusto e Vlach, dados inéditos). É importante salientar também que, nos domínios das Nappes Socorro, Guaxupé (cf. Figura 1) e no Terreno Carrancas, para nordeste, são conhecidos eventos de colocação de magmas cálcio-alcalinos, possivelmente associados ao período da convergência pré-colisional brasiliana principal, no intervalo de ca. 640-670 Ma (Hackspacher et 
al. 2003, Campos Neto et al. 2004). Adicionalmente, a presença de zonas reliquiares em cristais de monazita de metassedimentos e migmatitos do Complexo Piracaia com valores desta ordem de grandeza também aponta para a existência de algum evento geológico regional neste período (Vlach e Gualda 2000, Martins et al. no prelo).

\section{Os plutons Mauá e Mogi das Cruzes}

Duas amostras representativas de fácies petrográficas típicas destes plutons foram analisadas neste trabalho. A amostra EM-014A corresponde a um biotita monzogranito porfirítico e a amostra EM-025A represente um bioitita muscovita monzogranito equigranular a levemente inequigranular do Pluton Mogi das Cruzes. Descrições petrográficas mais detalhadas destas amostras são encontradas em Vlach (submetido). Na primeira amostra, a monazita aparece tipicamente formando cristais com contornos parcialmente idiomórficos que se alternam com contornos fortemente corroídos e encontram-se invariavelmente envolvidos por mantos de apatita + torita + allanita + epidoto (CAAT), com espessuras variáveis (Figura 11). A maioria dos cristais aparece como inclusões em biotita que, por sua vez, mostra também figuras de corrosão sugestivas de desequilibrio. Filipov e Janasi (2001) sugerem um origem externa para os cristais de biotita e, por extensão, para os cristais de monazita associados, mas Vlach (submetido) sugere que a corrosão destes cristais está ligada ao próprio processo de geração e evolução magmática.

$\mathrm{Na}$ amostra representativa do Pluton Mogi das Cruzes, a monazita aparece em duas gerações bem distintas. Uma primeira geração, tipicamente mais rica em Th e $U$ (e, portanto em Th*, cf. Figura 12) é de cristalização precoce e forma cristais com zonamento composicional leve e contornos irregulares, parcialmente cooridos, sempre envolvidos por CAAT, que aparecem mais tipicamente como cristais isolados ou inclusões em biotita. Uma geração mais tardia, aparece como pequenos cristais mais límpidos, pouco zonados, notadamente mais pobres em Th e U, idiomórficos e desprovidos de coronas, associados principalmente com quartzo e, eventualmente, com muscovita. A xenotima ocorre como raros cristais idiomórficos com finas coronas CAAT, por vezes contendo inclusões corroídas de monazita de primeira geração (Figura 12). A aplicação do 
geotermômetro de Gratz e Heinrich (1998) sugere temperaturas de equilibrio da ordem de 700 $750^{\circ} \mathrm{C}$ para xenotima e monazita de primeira geração.

As idades químicas (Figuras 11 e 12) para monazita e xenotima das amostras destes plutons são equivalentes, com médias ponderadas entre $591 \pm 9$ Ma (Mauá) e $591 \pm 8$ e $592 \pm 7$ Ma (Mogi das Cruzes, monazita e xenotima, respectivamente). Os dados obtidos para as duas gerações de monazita são exatamente iguais dentro da margens de erro, indicando que as suas origens devem estar associadas a variações locais dos parâmetros associados a evolução dos magmas graníticos originais. A idade química da amostra do Puton Mauá é idêntica a idade apresentada por Filipov e Janasi (2001) para monazita de uma outra amostra, analisada através do método isotópico U/Pb (TIMS), com uma fração muito próximo à concordia, em $588 \pm 2 \mathrm{Ma}$. Os dados isotópicos obtidos o Pluton Mogi das Cruzes mostraram-se fortemente discordantes, fato que possivelmente esteja associado a inclusão indevida de cristais com CAAT nas frações analisadas; mas, de qualquer forma, a idade ${ }^{207} \mathrm{~Pb} /{ }^{208} \mathrm{~Pb}$ de ca. $580 \mathrm{Ma}$ (Janasi et al. 2003) é compativel com os resultados apresentados.

Em conclusão o magmatismo granítico jovem, moderada a fortemente peraluminoso, sintectônico, no Terreno Embu, representado pelos plutons estudados, ocorreu há ca. $590 \mathrm{Ma}$.

\section{O Batólito Natividade da Serra}

Duas amostras, representativas das fácies petrográficas mais típicas presentes no batólito, foram analisadas para este trabalho. Ambas as amostras apresentam estruturas planares: na variedade porfiritica, os megacristais de feldspato alcalino revelam orientação tipicamente de fluxo magmático, mas a matriz mostra deformação e alguma recristalização das fases félsicas indicando contribuição de mecanismos de deformação em estado sólido, na variedade equigranular a deformação de estado sólido parece ser mais intensa. Nestas amostras, a biotita, em tons de vermelho a amarelo pálido (EM-013A) e castanho avermelhada a levemente esverdeada (EM-017A) é o mineral máfico típico. A amostra EM-013, coletada na borda da extremidade leste do batólito, é um biotita monzogranito porfirítico com megacristais de feldspato potássico orientados em uma matriz de granulação média, com alguma muscovita e turmalina de 
cristalização mais tardia. Nesta amostra a monazita ocorre como cristais maiores idiomórficos, isolados, ou como inclusões de cristais menores em biotita, feldspato potássico e quartzo. A maioria dos cristais apresenta forte zonamento composicional oscilatório, ora regular ora muito irregular; alguns cristais isolados são de natureza tipicamente poligenética e apresentam bordas lobadas com espessuras variáveis de uma geração mais jovem, que substitui parcialmente a monazita primária (Figura 13). A amostra EM-17A provém da zona central do batólito e corresponde a um muscovita biotita monzogranito mais evoluido com textura equigranular de granulação média. A muscovita é notadamente mais abundante e, além de monazita, esta amostra já apresenta alguns raros cristais de xenotima (Figura 14). Alguns cristais de monazita, particularmente os maiores que aparecem isolados, são poligenéticos, com zonamentos composicionais complexos em que se observam zonas internas irregulares, de aspecto residual, envolvidas e parcialmente substituídas por zonas, predominantes, com coeficientes de retroespalhamento mais elevados, mais ricas em Th e $U$. Outros cristais são relativamente mais homogêneos e de cristalização aparentemente mais tardia e parecem estar em equilíbrio com a xenotima. As temperaturas médias de equilíbrio avaliadas segundo a proposta de Gratz e Heinrich (1988) são da ordem de 650 a $700^{\circ} \mathrm{C}$ (Vlach dados inéditos).

Os dados Th-U-Pb obtidos (Figuras 13 e 14) para a monazita primária, amplamente predominante na amostra EM-013, indicam uma idade média de cristalização magmática de $589 \pm$ $6 \mathrm{Ma}$ enquanto a geração tardia que a substitui parcialmente, ou mesmo sobrecresce, apresenta uma idade média de $532 \pm 10 \mathrm{Ma}$. Idades similares foram obtidas para a amostra EM-017A, mas, neste caso, é muito interessante que a freqüência das populações de idade é notadamente inversa, observando-se que a geração predominante apresenta valores da ordem de $529 \pm 6 \mathrm{Ma}$, enquanto as zonas internas irregulares dos cristais maiores, isolados, apresentam idades reliquiares que se concentram em $587 \pm 11$ Ma.

Estas idades químicas, aliadas às evidências texturais e as variações composicionais de monazita, particularmente da amostra A-013A (demonstrando claramente origem a partir de cristalização magmática, Vlach dados inéditos) indicam que o valor próximo a 590 Ma deve corresponder à idade real de cristalização da monazita primária, enquanto as idades mais jovens, 
próximas a $530 \mathrm{Ma}$, devem representar um evento posterior que possibilitou a abertura química em graus variáveis da monazita e xenotima, mais intenso nas zonas centrais e nos fácies mais diferenciados do batólito. A idade de cristalização magmática é pouco mais antiga que a idade obtida com isócrona $\mathrm{Rb}-\mathrm{Sr}$ em rocha total (Tassinari 1988) e comparável com determinações isotópicas U-Pb convencionais em monazita (Vlach et al. 2002, Janasi et al. 2003).

A análise comparativa dos dados químicos e isotópicos disponíveis para monazita destas amostras permite extrair algumas considerações relevantes, comentadas rapidamente em Vlach et al. (2002). Na prática, diferentes frações de monazita destas amostras resultaram em idades isotópicas U-Pb com discordâncias pequenas ou ausentes de ca. 590, 570 e $530 \mathrm{Ma}$. Os dados pontuais obtidos com microssonda mostraram que os valores mais alto e mais baixo têm significado geológico, mas o valor intermediário não representa nada além do fato de que a fração analisada corresponde uma mistura de domínios intra-grão ou de grãos diferentes com idades reais próximas a 590 e $530 \mathrm{Ma}$. A projeção do resultado isotópico intermediário muito próximo a concórdia reflete a diferença relativamente pequena entre os dois eventos (ca. $60 \mathrm{Ma}$ ) e demonstra os cuidados necessários para interpretações de determinações isotópicas mesmo que que os resultados sejam concordantes ou quase concordantes.

\section{DIscUSSÃo}

\section{Sumário da cronologia dos eventos metamórficos e magmáticos}

As determinações geocronológicas obtidas no presente trabalho revelam e, em parte, reafirmam três episódios principais de metamorfismo no segmento crustal estudado.

No Terreno Embu o metamorfismo principal, em facies anfibolito sob condições médias estimadas de ca. $5.5 \mathrm{kbar}$ e cc. $700^{\circ} \mathrm{C}$ ocorreu há cerca de ca. $790 \mathrm{Ma}$. As relações texturais indicam que a monazita, pelo menos em parte da sua história de cristalização, esteve em equilíbrio com granada, sillimanita e biotita e, portanto, esta idade deve se aproximar significativamente da idade do pico térmico do evento metamórfico. A coerência dos resultados 
obtidos para rochas de natureza mais tipicamente psamítica, pelito-psamítica e pelitica sugere que os cristais de monazita estudados não incorporam, mesmo nos dois primeiros casos, frações herdadas significativas das rochas fontes nos sedimentos originais e reafirmam, que neste tipo de rochas, eventual monazita herdada deve se desestabilizar em condições de metamorfismo de baixo grau e ser consumida, reaparecendo após em temperaturas mais elevadas, na transição para o fácies anfibolito (e.g. Lanzirotti e Hanson 1996).

As seqüências superiores do Complexo Piracaia foram metamorfoseadas em fácies anfibolito há ca. $625 \mathrm{Ma}$, uma idade bem conhecida em literatura (Vlach e Gualda 2000, Campos Neto et al. 2004, Heilbron et al. 2004). No Terreno Serra do Mar, os dados químicos e isotópicos disponiveis indicam que processos metamorfismo em facies anfibolito, anatexia parcial e geração de migmatitos ocorreram há ca. $590-570$ ? Ma. A diferença de ca. 20 Ma verificada entre os resultados químicos e os dados U-Pb em zircão obtidos com SHRIMP e apresentados por Tassinari et al. (1999) merece investigações adicionais em maior detalhe.

Pelo menos três fases principais de magmatismo granítico (sensu latu) ocorreram no Terreno Embu e duas no Terreno Serra do Mar.

No Terreno Embu, rochas tonalíticas e granodioríticas peraluminosas, atualmente ortognaisses, definem um importante magmatismo precoce há ca. $790 \mathrm{Ma}$, muito próximo ao pico do metamorfismo regional. Entretanto, não são conhecidas relações geológicas claras que permitam assegurar se este magmatismo ocorreu pouco antes, concomitantemente, ou mesmo pouco após o metamorfismo regional. Após um intervalo de ca. 120 Ma colocaram-se granitos peraluminosos que constituem o Batólito Quebra Cangalha na região leste deste terreno. As idades obtidas, entre 670 e 680 Ma., são as únicas obtidas para granitos intrusivos no Terreno Embu, mas guardam correspondência com importantes fases de magmatismo cálcio-alcalino em terrenos vizinhos. O magmatismo granítico jovem, representado pelos plutons Mauá e Mogi das Cruzes ocorreu certamente há ca. 590 Ma e está claramente associado ao desenvolvimento ou reativação de importantes zonas de cizalhamento orientadas NNE que certamente controlaram a colocação dos magmas e foram responsáveis pela fase de deformação F3 (Fernandes et al. 1990) e concomitante retro-metamorfismo em facies xistos verdes registrados nos metassedimentos do Terreno Embu e nas regiões limitrofes do Complexo Piracaia. 
Merece ser mencionado que o Pluton Santa Branca (Figura 1), que guarda similaridades geológico-estruturais, petrográficas e mineralógicas com os plutons Mauá e Mogi das Cruzes, apresentou uma idade isotópica principal U-Pb em monazita de ca. $540 \mathrm{Ma}$ (três frações), sugerindo um possível quarto episódio de geração de granitos neste terreno (Janasi et al. 2003) ou alternativamente um episódio importante de abertura dos sistemas químicos e isotópicos em monazita.

No Terreno Serra do Mar, os dados químicos obtidos para amostras do Batólito Natividade da Serra registram um periodo importante de colocação de granitos peraluminosos também há ca. $590 \mathrm{Ma}$ seguido de um evento de re-equilíbrio há ca. $530 \mathrm{Ma}$. Uma amostra do facies central deste batólito, a exemplo dos dados isotópicos disponíveis para o Pluton Santa Branca no Terreno Embu, apresenta idades químicas predominantes próximas há 530 Ma e subordinadas; reliquiares, de ca. $590 \mathrm{Ma}$. Um evento magmático posterior, tipicamente de caráter pós-orogênico ou anorogênico, está representado pela colocação das rochas da série charnockítica que afloram em Ubatuba (MacLuf e Schorscher 2001). É interessante notar que o evento de ca. $530 \mathrm{Ma}$ também encontra-se bem registrado nos migmatitos e charnockitos deste terreno.

\section{Deformação, recristalização e recomposição dos relógios químicos}

Diversas entre as amostras estudadas apresentam monazita e/ou xenotima de natureza poligenética que registram pelo menos duas populações distintas de idades.

O caso da amostra E-1\&2 da região oeste do Terreno Embu é unico no sentido de que não foram observados contrastes significativos nas imagens BSE e mesmo nas composições químicas entre as duas populações de idades. Isto sugere que este seja um caso de recristalização induzida pela cominuição dos cristais originais submetidos à deformação cizalhante, sem interações substanciais com fluídos metamórficos. Nos demais casos, as imagens BSE mostram contatos bruscos, bem definidos e freqüentemente lobados, mostrando que a geração mais jovem claramente invade e substitui a anterior, mantendo as faces cristalinas originais. Estas evidências indicam claramente um mecanismo dominado por reações especificas e não por processos 
simples de difusão. Estes exemplos, excepcionalmente bem marcados nas amostras EM-020 e EM013A, refletem sem dúvida o resultado de processos de dissolução e reprecipitação induzidos pela fase fluida. A desestabilização de monazita por reações de dissolução também parece apropriada para explicar as micro-estruturas observadas em alguns dos granitos intrusivos e em leucossoma de migmatitos do Terreno Serra do Mar.

As situações que envolvem substituição de monazita e/ou xenotima por coronas com apatita, torita, allanita e epidoto, nos ortognaisses e granitos intrusivos do Terreno Embu também indicam que mecanismos envolvendo reações com a fase fluída e monazita e xenotima foram importantes na história pós-magmática destas rochas. Entretanto, os grãos reliquiares presentes nestas coronas parecem preservar a totalidade das suas assinaturas químicas originais, incluindo os elementos determinantes de idade $\left(\mathrm{Th}, \mathrm{U}\right.$ e $\mathrm{Pb}_{\mathrm{T}}$, cf. Vlach submetido, ver também Finger et al. 1988) e os resultados químicos registram a idade real de cristalização magmática.

Os parâmetros que regulam reações de dissolução e reprecipitação envolvem a disponibilidade de uma fase fluída e possibilidade de movimentação pela rocha hospedeira, a composição desta fase e os seus parâmetros intensivos. A avaliação destes parâmetros năo é ainda possivel e não é o objetivo do trabalho. Um contribuição futura analisará especificamente estilos contrastados de re-equilibração de monazita em metassedimentos e granitos e implicações para a caracterização da fase fluída. Não se pode identificar ou avaliar também as contribuições relativas da rocha hospedeira e as das rochas encaixantes mas, sem dúvida, a deformação e a recristalizaçăo induzida pela movimentação ao longo das zonas de cizalhamento teve papel fundamental nos processos e deve ter facilitado o fluxo e a percolação da fase fluida.

Os resultados obtidos para a amostra do Complexo Piracaia mostram que a geração mais jovem de monazita foi gerada durante o retro-metamorfismo em fácies xistos verdes, sincrônico com a movimentação da zona de cizalhamento Caucaia - Rio Jaguari, com as zonas de cizalhamento que possibilitaram a colocação dos granitos sin-tectónicos jovens nos Terrenos Embu e Serra do Mar e também com o retro-metamorfismo em facies xistos verdes nos metassedimentos do Terreno Embu.

Os granitos e migmatitos dos terrenos Embu e Serra do Mar apresentam evidências estruturais e texturais claras de deformação acompanhada de recristalização em maior ou menor 
grau. Outra observação interessante está relacionada à variação nas cores de pleocroismo da biotita, o máfico mais típico nestas rochas. Assim, a amostra E-013A, a biotita é tipicamente vermelha; na amostra E-017A, as cores são mais suaves e puxam para tons de verde, finalmente, no caso comentado do Pluton Santa Branca são tipicamente verdes. Os resultados quimicos obtidos mostram predomínio de monazita com ca. 590 Ma. no primeiro caso, ca. 530 Ma no segundo e dados isotópicos parecem indicar uma idade de 530 Ma para este último pluton (Janasi et al. 2003). No caso dos migmativos SM-03 e SM-07, os únicos que apresentam evidências de superposição de um evento há ca. 530 Ma apresentam também biotitas verdes.

Se as variações das tonalidades de pleocroismo nas micas representam variações na composição química original dos magmas e/ou respectivas temperaturas de cristalização ou, alternativamente, representam re-equilibrios posteriores, associados à deformação regional, é uma questão que mereceria investigações detalhadas. Com base nos resultados para a amostra EM-013A, interpreta-se aqui que as idades mais jovens, em torno de 530 Ma representam apenas re-equilíbrios. Os resultados de MacLuf e Schorscher (2001) também apontam nesta direção.

\section{Implicações para a evolução geológica}

Idades de metamorfismo e magmatismo da ordem de 780-800 Ma são reportadas para diversos domínios do Brasil continental. Encontram-se definidos eventos de metamorfismo e magmatismo granítico na Faixa Brasília (Ferreira Filho et al. 1994) e de metamorfismo, magmatismo granítico juvenil e vulcânicas associadas a arco magmático na região Sul da Província Mantiqueira (Babinsky et al. 1996, Hartmann et al. 2000). No Estado de São Paulo, foram obtidas idades similares em rochas graniticas e em zonas reliquiares de cristais de monazita de migmatitos na região do Complexo Piracaia (Negri et al. 2002, Martins et al. no prelo).

Os ortognaisses estudados neste trabalho e os analisados na região sudoeste por Cordani et al (2002), são rochas cujos protólitos guardam similares com os denominados granitos de "tipoS" australianos (composições tonalíticas a granodioríticas predominantes, tipicamente peraluminosos com biotita vermelha abundante, etc., e.g. White e Chappel 1988). Entretanto, não apresentam cordierita e a granada aparece eventualmente em variedades granodioriticas, fatos 
que poderiam significar diferenças na profundidade de colocação e cristalização dos magmas. $O$ primeiros autores sugem ser este um magmatismo associado a um arco continental. As idades comparáveis deste magmatismo e do metamorfismo reginal em facies anfibolito neste terreno parecem caracterizar ambientes tectônicos tipicamente convergentes neste periodo, incompativeis com fragmentação continental do denominado supercontinente Rodinia (ver também Piper 2007).

O magmatismo granítico crustal representado pelo Batólito Quebra Cangalha, há ca. 670 Ma., é mais ou menos isócrono com magmatismo cálcio-alcalino relacionado à subducção de placa oceânica na região da nappe Socorro-Guaxupé (Campos Neto et al. 2004), porém o seu significafo tectônico é incerto, uma vez que a colagem do Terreno Embu ocorreu após este evento. De fato, o metamorfismo em fácies anfibolito que afetou as seqüencias do Complexo Piracaia, há ca. $625 \mathrm{Ma}$, não se encontra registrado no Terreno Embu e, portanto, estes segmentos crustais estavam desconectados. Após ca. 100-80 Ma., no Terreno Serra do Mar, encontra-se registrado um evento de metamorfismo regional de temperaturas médias a altas; mais ou menos contemporaneamente, magmas graníticos com contribuições crustais significativas se colocaram nos terrenos Embu e Serra do Mar, controlados por importantes zonas de cizalhamento NNE. Estas zonas retro-metamorfosearam os messedimentos Embu e Piracaia para a facies xistos verdes em niveis crustais mais elevados. É provável que justaposição destes terrenos, especialmente do Terreno Embu e do Complexo Piracaia e a atual configuração da Faixa Ribeira nesta região remonte a esta época (ver também Campos Neto et al. 2004, Passarelli et al. 2004) e esteja ligada principalmente a zonas de cizalhamento com componentes transcorrentes predominantes. Um magmatismo charnockítico, de ambientação pós-orogênica ou mesmo anorogênica, parece concluir o ciclo no Terreno Serra do Mar há ca. $560 \mathrm{Ma}$.

Os evento tectônicos mais jovens na região, há $530 \mathrm{Ma}$, parecem limitados à reativação das zonas de cizalhamento pré-estabelecidas e afetaram ambos os terrenos Embu e Serra do Mar, causando deformação e rearranjos mineralógicos, texturais e estruturais. Representam uma atividade associada à Orogênese Cabo Frio, definida para Leste no Estado do Rio de Janeiro (e.g. Schmidtt et al. 1999, Campos Neto et al. 2004) e devem ter contribuido significativamente para o soerguimento destes segmentos crustais. Não são conhecidos eventos magmáticos importantes na região estudada com idades similares, mas ocorrências de rochas graníticas com idades 
isotópicas bem definidas entre 500 e $540 \mathrm{Ma}$ ocorrem na região da costa dos estados de São Paulo e Paraná e/ou em ilhas continentais próximas (L. Cury, V. Janasi, comumicações verbais). $\mathrm{Na}$ contrapartida africana, eventos de metamorfismo regional e magmatismo granítico com idades similares caracterizam o denominado Cinturão Garieb (Frimmel e Fölling 2004).

\section{AGRADECIMENTOS}

O autor agradece à Fundação de Amparo a Pesquisa do Estado de São Paulo (FAPESP) pelo apoio contínuo ao Laboratório de Microssonda Eletrônica do Instituto de Geociências da Universidade de São Paulo. Agradecimentos também são devidos a Marcos Mansueto, que prestou o necessário suporte laboratorial, Francisco Negri e Silvia Vieira que forneceram as amostras VR292A e E-1\&2, respectivamente, da região oeste do Terreno Embu e Francisco Negri e Valdecir Janasi que acompanharam o autor em etapas de campo na área enfocada.

\section{REFERÊNCIAS}

Almeida, F.F.M., Hasui, Y., Brito Neves, B.B., Fuck, R.A., 1981. Brazilian structural provinces: An introduction. Earth Science Reviews, 17:1-29.

Babinsky, M., Tassinari, C.C.G., Nutman, A.P., Sato, K., Martins, P.O.R., lyer, S.S., 2001. U/Pb SHRIMP zircon ages of migmatites from the basement of the Embu Complex, Ribeira Folded Belt, Brazil: indications for $\approx 1.4-1.3 \mathrm{Ga} \mathrm{Pb}-\mathrm{Pb}$ and $\mathrm{Rb}-\mathrm{Sr}$ "isochron" ages of no geological meaning. In: South American Symposium on Isotope Geology, 3. Pucón. Actas, p.91-93 (CD-ROM).

Babinsky, M., Chemale Jr., F., van Schmus, W.R., Harmann, L.A., Silva, L.C., 1996. Juvenile accrection at 750-700 Ma in southern Brazil. Geology, 25:439-442. 
Basei, M.A.S., Siga Jr., O., Sato K., Sproesser, W.M., 1995. A metodologia urânio-chumbo na Universidade de São Paulo: Princípios metodológicos, aplicações e resultados obtidos. Anais da Academia Brasileira de Geociências, 67:221-237.

Bastin, G.F., Heijligers, H.J.M., 1990. Progress in electron-probe microanalysis. Materialwissenschaft und Werkstoffechnik, 21:216-221.

Brito Neves, B.B., Campos Neto, M.C., Fuck, A.R., 1999. From Rodinia to Western Gondwana: an approach to the Brasiliano-Pan African Cycle and orogenic collage. Episodes, 22:155-166.

Campos Neto, M.C., 2000. Orogenic systems from Southwestern Gondwana: an approach to Brasiliano-Pan African Cycle and orogenic collage in Southeastern Brazil. In: Cordani, U.G., Milani, E.J., Thomaz Filho, A., Campos, D.A. (ed). Tectonic evolution of South America: $31^{\circ}$ International Geological Congress (Rio de Janeiro, Brasil), p. 335-365.

Campos Neto, M.C., Basei, M.A.S., 1983. Evolução estrutural brasiliana no nordeste de São Paulo: dobramentos superpostos e esboço estratigráfico e tectônico. In: Simpósio Regional de Geologia, 4. São Paulo. Atas, 1:61-78.

Campos Neto, M.C., Basei, M.A.S., Vlach, S.R.F., Caby, R., Szabó, G.A.J., 2004. Migração de orógenos e superposição de orogêneses: Um esboço da colagem brasiliana no sul do Craton São Francisco, SE-Brasil. Geologia USP (Série Científica), 4:13-40.

Cocherie, A., Legendre, O. Peucat, J-J., Kouamelan, A.N., 1998. Geochronology of poligenetic monazites constrained by in situ electron microprobe Th-U-total lead determination: Implications for lead behavior in monazite. Geochimica et Cosmochimica Acta, 62:24752497.

Cordani, U.G., Coutinho, J.M.V., Nutman, A.P., 2002. Geochronological constraints for the age of the Embu Complex, São Paulo, Brazil. Journal of South American Sciences, 14:903-910.

Fernandes, A.J., Campos Neto, M.C., Figueiredo, M.C.H., 1990. O Complexo Embu no leste do Estado de São Paulo: limites e evolução geológica. In: XXXVI Congresso Brasileiro de Geologia (Natal, Brasil), Anais, 6:2755-2763.

Ferreira Filho, C.F., Kamo, S.L., Fuck, R.A., Krogh, T.E., Naldrett, A.J., 1994. Zircon and rutile U$\mathrm{Pb}$ geochronology of the Niquelândia layered mafic and ultramafic intrusion, Brasil: 
constraints for the timing of magmatism and high grade metamorphism. Precambrian Research, 68:241-255.

Fialin, M. Outrequin, M., Staub, P-F., 1997. A new tool to treat peak overiaps in electron-probe microanalysis of rare-earth-element L-series X-rays. European Journal of Mineralogy, 9:965-968.

Filipov, M., Janasi, V.A., 2001. The Mauá granitic massif, central Ribeira Belt, São Paulo: petrography, geochemistry and U-Pb dating. Revista Brasileira de Geociências, 31:341348.

Finger, F., Broska, I., Roberts, M.P., Schermaier, A., 1998. Replacement of primary monazite by apatite-allanite-epidote coronas in amphibolite facies granite gneiss from the eastern Alps. American Mineralogist, 83:248-258.

Foster, G., Parrish, R.R., Horstwood, M.S.A., Chenery, S. Pyle, J., Gibson, H.D., 2004. The generation and prograde P-T-t points and paths: a textural, compositional, and chronological study of metamorphic monazite. Earth and Planetary Science Letters, 228:125-142.

Frimmel, H.E., Fölling, P.G. 2004. Late Vendian closure of the Adamastor Ocean: timing of tectonic inversion and syn-orogenic sedimentation in the Gariep Basin. Gondwana Research, 7: 685-699.

Gasparini, P., Mantovani, M.S.M., 1979. Geochemistry of charnokites from São Paulo State, Brazil. Earth and Planetary Science Letters, 42:311-320.

Gardés, E., Montel, J-M, Seydoux-Guillaume, A.M., Wirth, R., 2007. Pb diffusion in monazite: New constraints from the experimental study of $\mathrm{Pb} 2+\leftrightarrow \mathrm{Ca} 2+$ interdiffusion. Geochimica et Cosmochimica Acta, 71:4036-4043.

Gratz, R., Heinrich, W., 1998. Monazite-xenotime thermometry. Experimental calibration of the miscibility gap in the binary system $\mathrm{CePO}_{4}-\mathrm{YPO}_{4}$. American Mineralogist, 82:772-780.

Hackspacher, P.C., Fetter, A.H., Ebert, H.D., Janasi, V.A., Dantas E.L., Oliveira, M.A.F., Braga, I.F., Negri, F.A., 2003. Magmatismo há ca. 640-660 Ma no Domínio Socorro: Registros de convergência pré-colisional na aglutinação do Gondwana Ocidental. Geologia USP (Série Científica), 3:85-96. 
Harmann, L.A., Leite, J.A.D., Da Silva, L.C., Remus, M.V.D., McNauthon, N.J., Groves, D.I., Fletcher, I.R., Santos, J.O.S., Vazconcellos, M.A.Z., 2000. Advances in SHRIMP geochronology and their impact on understanding the tectonic and metallogenic evolution of southern Brazil. Australian Journal of Earth Sciences, 47:829-844.

Hasui, Y., 1975. Geologia da Folha São Roque. Boletim do Instituto de Geociências da Universidade de São Paulo, 6:157-183.

Heilbron M., Pedrosa-Soares A.C., Campos Neto M.C., Silva L.C., Trouw R.A.J. \& Janasi V.A. 2004. Província Mantiqueira. In: V. Mantesso-Neto, A. Bartorelli, C.D.R. Carneiro \& B.B. Brito Neves (eds). Geologia do Continente Sul-Americano: Evolução da Obra de Fernando Flávio Marques de Almeida, Beca, São Paulo, pp.: 203-234

Hetherington, C.J., Jercinovic, M.J., Willians, M.L., Mahan, K., 2008. Understanding geological processes with xenotime: composition, chronology, and a protocol for electron probe microanalysis. Chemical Geology, 254:133-147.

Janasi, V.A., Alves, A., Vlach, S.R.F., Leite, R.J., 2003. Granitos peraluminosos da porção central da Faixa Ribeira, Estado de São Paulo: Eventos de reciclagem da crosta continental no Neoproterozóico. Geologia USP (Série Científica), 3:13-24.

Jercinovic, M.J., Williams, M.L., Lane, E.D., 2008. In-situ trace element analysis of monazite and other fine-grained accessoty minerals by EPMA. Chemical Geology, 254:197-215.

Kingsbury, J.A., Miller, C.F., Wooden, J.J., Harrison, T.M., 1993. Monazite paragenesis and U.Pb systematics in rocks of the eastern Mojave Desert, California, U.S.A.:Implications for themochronometry. Chemical Geology, 110:147-167.

Lanzirotti, A., Hanson, G.N., 1996. Geochronology and geochemistry of multiple generations of monazite from the Wepawaug Schist, Conecticut, USA: Implications for monazite stability im metamorphic rocks. Contributions to Mineralogy and Petrology, 125:332-340.

Ludwig, K.R., 2003. Isoplot 3.00. A Geochronological Toolkit for Microsoft Excel. Berkeley Geochronological Center Special Publication, 4. 70 p.

MacLuf, S., Schorscher, J.H.D., 2001. Petrogênese das rochas charnokíticas e aplitos intrusivos do Complexo Charnockítico de Ubatuba, SP. In: Simpósio de Geologia do Sudeste, 7. Rio de Janeiro. Boletim de Resumos, p.46. 
Martins, L. Vlach, S.R.F., Janasi, V.A., in press, Reaction microtextures of monazite: correlation between chemical and age domains in the Nazaré Paulista migmatite, SE Brazil. Chemical Geology,

Montel, J-M., Foret, S. Veschambre, M., Nicollet, C., Provost, A., 1996. Electron microprobe dating of monazite. Chemical Geology, 13:37-53.

Negri, F.A., Oliveira, M.A.F., Macambira, M.J.B., Vlach, S.R.F., 2002. Magmatismo granítico com idade $\mathrm{Pb}-\mathrm{Pb}$ de $780 \mathrm{Ma}$ nos Domínios Socorro e Embu na Região de São Francisco Xavier (SP), sudeste brasileiro. In: Congresso Brasileiro de Geologia, 41, João Pessoa, Anais, p. 458.

Parrish, R.R., 1990. U-Pb dating of monazite and its applications to geological problems. Canadian Journal of Earth Science, 27:1431-1450.

Parslow, G.R., Brandstatter, F., Kurat, G. Thomas, D.J., 1985. Chemical ages and mobility of U and Th in anatectites of the Cree Lake zone, Saskatchewan. Canadian Mineralogist, 23:543-552.

Passarelli, C.R., Basei, M. A.S., Campos Neto, M.C., Siga Jr., O., Prazeres Filho, H.J., 2004. Geocronologia e geologia isotópica dos terrenos pré-cambrianos da porção Sul-Oriental do Estado de São Paulo. Geologia USP (Série Científica), 4:55-74.

Piper, J.D.A., 2007. The Neoproterozoic supercontinent Paleopangea. Gondwana Research, 12:202-227.

Potts, P.J., 1996. A Handbook of Silicate Rock Analysis, 622 p. Chapman Hall, London.

Pyle, J.M., Spear, F.S., Wark, D.A., Daniel, C.G., Storm, L.C., 2005. Contributions to precision and accuracy of monazite microprobe ages. American Mineralogist, 90:547-577.

Rapp, R.P., Watson, E.B., 1986. Monazite solubility and dissolution kinetics: implications of the thorium and ligh rare earth chemistry of felsic magmas. Contributions to Mineralogy and Petrology, 94:304 316.

Sambridge, M.S., Compston, W., 1994. Mixture modeling of multi-component data sets with application to ion-probe zircon ages. Earth and Planetary Science Letters, 128:373-390. 
Scherrer, N.C., Engi, M. Gnos, E., Jakob, V., Lechti, A., 2000. Monazite analysis: from sample preparation to microproge age dating and REE quantification. Schweizerische Mineralogische und Petrographische Mitteilungen, 80:93-105.

Schmidtt, R.S., Trow, R.A.J., van Schmus, W.r., 1999. The characterization of a Cambrian (520 Ma) tectonometamorphic event in the coastal domain of the Ribeira Belt (SE Brazil) using $\mathrm{U} / \mathrm{Pb}$ in syntectonic veins. $\mathrm{In}$ : South American Symposium on Isotope Geology, 3. (Córdoba, Argentina), Actas, 103-106.

Seydoux-Guillaume, A-M., Paquette, J-L., Wiedenbeck, M., Montel, J-M., Heinrich, W., 2002. Experimental resetting of the U-Th-Pb systems in monazite. Chemical Geology, 191:165181.

Steiger, R.H., Jäger, E., 1977. Subcomission on geochronology: convention on the use of decay constants in geo- and cosmochronology. Earth and Planetary Science Letters, 36:359-362.

Suzuki, K., Adachi, M. 1991. Precambrian provenance and Silurian metamorphism of the Tsubonosawa paragneiss in the South Kitakami Terrane, Northeast Japan, revealed by the chemical Th-U-total $\mathrm{Pb}$ isochron ages of monazite, zircon and xenotime. Geochemical Journal, 25:357-376.

Tassinari, C.C.G., 1988. As idades das rochas e dos eventos metamórficos da porção sudeste do Estado de São Paulo e sua evolução crustal. Tese de Doutorado (inédita). Instituto de Geociéncias da Universidade de São Paulo, 236 p.

Tassinari, C.C.G., Cordani, U.G., Correia, C.T., Nutman, A.P., Kinny, P., Dias Neto, C.M., 1999. Dating of granulites by SHEIMP U-Pb systematics in Brazil: constraints fo $r$ teh age of the metamorphism of proterozoic orogenies. $I n$ : South American Symposium on Isotope Geology, 2. Cordoba, AG. Actas, 371-373.

Vieira, S.R.S.S., Tassinari, C.C.G., 1988. Estudo petrológico e geocronológico das rochas da região de Embu-Guaçu, estado de São Paulo. In: Congresso Brasileiro de Geologia, 35. Belém. Anais, 3:1391-1399.

Vieira, S.R.S.S., Coutinho, J.M.V., Alves, F.R., 1990. Geologia e evolução geológica da região de Embu-Guaçu - Parelheiros, São Paulo. Revista Brasileira de Geociências, 20:277-281. 
Vlach, S.R.F., em submissão. Análise de datação ThuU-Pb de monazita em microssonda eletrônica: procedimentos analíticos e de tratamento de dados.

Vlach, S.R.F., em submissão. Mecanismos de substituição de monazita e xenotima por coronas de apatita-allanita-epidoto-torita em rochas ortognáissicas e graníticas do Terreno Embu (SE do Brasil) e implicações: evidências texturais e químicas.

Vlach, S.R.F., 2001. Microprobe monazite constrainst for an early (ca. $790 \mathrm{Ma}$ ) Brasiliano Orogeny: The Embu Terrane, Southeastern Brazil. In: South American Symposium on Isotope Geology, 3. Pucón. Extended Abstracts Volume (CD-ROM), p. 265-268.

Vlach, S.R.F., Gualda, G.A.R., Chiessi, C.M., 1999. Electron microprobe monazite dating: first results for two granites from Southeastern Brazil. In: South American Symposium on IsotopeGeology, 2. Cordoba, AG. Actas, 518-521.

Vlach, S.R.F., Gualda, G.A.R., 2000. Microprobe monazite dating and the ages of some granitic and metamorphic rocks from Southeastern Brazil. Revista Brasileira de Geociências, $30: 214-218$.

Vlach, S.R.F., Del Lama, E.A., 2002. Idades Th-U-Pb de monazita e geotermobarometria de rochas metapelíticas de alto grau do Sistema Orogênico Itabuna-Salvador-Curaçá, BA, Brasil: um estudo em microssonda eletrônica. Geologia USP (Série Científica), 2:9-22.

Vlach, S.R.F., Janasi, V.A., Alves, A., 2002. Sistemática U.Pb de datação de monazita em rochas graníticas: Identificação de eventos superpostos no Batólito Natividade da Serra pela combinação de TIMS e datação química por microssonda eletrônica. In: Congresso Brasileiro de Geologia, 41. João Pessoa. Boletim de Resumos, p. 511.

White, A.J.R., Chappell, B.W., 1988. Some supracrustal (S-type) granites of the Lachland Folded Belt. Transactions of the Royal Society of Edinburg. Earth Sciences, 79:169-181.

Williamson, J.H., 1968. Least-squares fitting of a straight line. Canadian Journal of Physics, 46:1845-1847. 
Figura 1. Mapa geológico da região leste do Estado de São Paulo e Províncias Estruturais da região SE do Brasil. Províncias estruturais (/nset). AFB, BFB e RFB: Faixas de Dobramento Araçuaí, Brasília e Ribeira. GN, SN and AAN: Nappes Guaxupé, Socorro e Ariruoca-Andrelândia. Principais Terrenos da Província Mantiqueira: AP: Apiaí, E: Embu, JF: Juiz de Fora, SM: Serra do Mar, CF: Cabo Frio. SFC e PC: Cratons São Francisco e Paraná (limites pontilhados inferidos). Geologia Geral: 1: coberturas fanerozóicas e rochas alcalinas mesozóicas (branco), 2: granitos tardi- a pós-orogênicos de "tipo-A", 3: biotita granitos equigranulares, 4: biotita granitos porfiríticos, 5: hornblenda biotita granitos porfiríticos, 6: Nappe Socorro (predominantemente migmatitos), 7: Terreno Apiai: Grupos São Roque, Itaberaba e Açungui (seqüências terrígenas e vulcanosedimentares de baixo a médio grau metamórfico), 8: Terreno Embu (predominantemente rochas supracrustais de médio a alto grau de metamorfismo), 9: Terreno Serra do Mar (paragnaisses e ortognaisses migmatíticos), 10: Migmatitos antigos do embasamento pré Neoproterozóico. Linhas cheias: zonas de transcorrência neoproterozóicas, Linhas cheias pontilhadas: limites de estado. Geologia modificada de Campos Neto (2000) e referências citadas. Códigos indicam localização das amostras estudadas no presente trabalho.

Figura 2. Diagrama isocrônico $\mathrm{Pb}_{\mathrm{T}}$ vs $\mathrm{Th}$, histograma de distribuição de idades pontuais (insef), imagens BSE em modo composicional de cristais representativos de monazita com localização das análises pontuais efetuadas e diagrama ilustrando a variação das idades pontuais e respectivos erros para o paragnaisse E-1\&2 da região oeste do Terreno Embu, estado de São Paulo. Os parâmetros PrF e Neq representam, respectivamente, a probabilidade de ajuste da reta e o número de pontos equivalentes no diagrama isocrônico considerando-se os erros individuais indicados pelas barras de erros. O parâmetro f representa a fração relativa de cada população de idades estatisticamente significativa. Observar, na imagem BSE da esquerda, cristal de monazita idiomórfico, fraturado e parcialmente rompido, e na imagem da direita, cristal de monazita estirado, com textura tipo morteiro. Nesta última, círculos escuros representam pontos com idades entre 770 e $820 \mathrm{Ma}$, círculos claros idades entre 710 e $750 \mathrm{Ma}$, bi = biotita. Os círculos desenhados nas imagens não se encontram em escala por questões de visibilidade. Barras 
horizontais mais claras no último diagrama representam as idades médias obtidas para cada população. Ver discussão e referências no texto.

Figura 3. Diagrama isocrônico $\mathrm{Pb}_{\mathrm{T}}$ vs $\mathrm{Th}^{*}$, imagens $\mathrm{BSE}$ em modo composicional de cristais representativos de monazita com localização das análises pontuais efetuadas e diagrama ilustrando a variação das idades pontuais e respectivos erros para o paragnaisse EM-VR292A da região oeste do Terreno Embu, estado de São Paulo. O parâmetro Neq representa o número de pontos equivalentes no diagrama isocrônico considerando-se os erros pontuais individuais. 0 vetor desenhado na imagem a esquerda representa perfil composicional obtido com 10 pontos analíticos (1-10) regularmente espaçados entre si. Os círculos desenhados nas imagens não se encontram em escala por questões de visibilidade. Barra horizontal clara no último diagrama representa a idade média obtida ponderada pelos erros das determinações individuais. Ver discussões e referências no texto.

Figura 4. Diagramas ilustrando os resultados obtidos para a datação química e imagens BSE de cristais de monazita de paragnaisse EM-020 da região leste do Terreno Embu, estado de São Paulo. Observar na imagem BSE esquerda cristal de monazita com zonamento composicional concêntrico e bordas de corrosão e substituição sobre a monazita primária, com idades mais jovens de ca. $590 \mathrm{Ma}$. À direita cristal homogêneo incluso em granada, incluindo parcialmente cristal de zircão (zr). Para outros detalhes, ver legenda das Figuras 2 e 3 . Discussões no texto.

Figura 5. Diagramas ilustrando os resultados obtidos para a datação química e imagens BSE de monazita do migmatito SM-03 da região costeira de Ubatuba, Terreno Serra do Mar, estado de São Paulo. Observar nas imagens BSE que a monazita presente no leucossona é tipicamente idiomórfica e contém inclusões de apatita (ap) distribuidas ao longo de potenciais faces de crescimento, enquanto a presente no melanossoma é sub- a xenomórfica e apresenta zonamento composicional mais irregular. Outros detalhes de legenda como nas Figuras 2 e 3. Discussões no texto. 
Figura 6. Diagramas ilustrando os resultados obtidos para a datação química e imagens de monazita do migmatito SM-07 da região costeira de Ubatuba, Terreno Serra do Mar, estado de São Paulo. Outros detalhes de legenda como nas Figuras 2 e 3 . Discussões no texto.

Figura 7. Diagramas ilustrando os resultados obtidos para a datação química e imagens de monazita paragnaisse EM-004B do Complexo Piracaia, leste do estado de São Paulo. Outros detalhes de legenda como nas Figuras 2 e 3. Discussões no texto.

Figura 8. Diagramas ilustrando os resultados obtidos para a datação química e imagem BSE de monazita do ortognaisse tonalítico EMS-010, da região leste do Terreno Embu, estado de São Paulo. Observar na imagem BSE cristal de monazita corroído, em corona de substiuição formada por apatita (ap), torita (th), allanita (aln) e epidoto (ep). Outros detalhes de legenda como nas Figuras 2 e 3. Discussões no texto.

Figura 9. Diagramas ilustrando os resultados obtidos para a datação química e imagens BSE de monazita e xenotima do ortognaisse granodiorítico EMS-011B, da região leste do Terreno Embu, estado de São Paulo. Observar na imagem BSE esquerda, cristal de monazita corroído com corona de substiuição formada por apatita (ap), allanita (aln) e epidoto (ep), à direita, cristal de xenotima de tendência idiomórfica, com zonamento composicional irregular e elevado número de inclusões de apatita na borda superior. Outros detalhes de legenda como nas Figuras 2 e 3. Discussões no texto.

Figura 10. Diagramas ilustrando os resultados obtidos para a datação química e imagens BSE de monazita e xenotima do granito EM-8\&9 do Batólito Quebra Cangalha, região leste do Terreno Embu, estado de São Paulo. Observar na imagem BSE esquerda, cristal de monazita com tendência idiomórfica contendo inclusões idiomórficas de apatita e, à direita, cristais de monazita fortemente corroídos e cristal mais idiomórfico de xenotima. Ap: apatita, mnz: monazita, zr: zircão, xen: xenotima. Outros detalhes de legenda como nas Figuras 2 e 3 . Discussões no texto. 
Figura 11. Diagramas ilustrando os resultados obtidos para a datação química e imagens BSE de monazita do granito EM-014A, do Pluton Mauá, região centro-leste do Terreno Embu, estado de São Paulo. Observar nas imagens BSE a presença de coronas de substituição constituidas por apatita, torita, allanita e epidoto e a forte corrosão parcial do cristal da esquerda. Outros detaihes de legenda como nas Figuras 2 e 3 . Discussões no texto.

Figura 12. Diagramas ilustrando os resultados obtidos para a datação química e imagens BSE de monazita e xenotima do granito EM-025A, do Pluton Mogi das Cruzes, região centro-leste do Terreno Embu, estado de São Paulo. Observar nas imagens BSE cristal límpido de monazita contendo inclusões de apatita incluso em quartzo e forte zonamento oscilatório na xenotima que contêm incluões de monazita e apatita e finas bordas parcialmente corroídas e substituídas. Outros detalhes de legenda como nas Figuras 2 e 3 . Discussões no texto.

Figura 13. Diagramas ilustrando os resultados obtidos para a datação química e imagens BSE de monazita para o granito porfirítico EM-013A, do Batólito Natividade da Serra, região leste do Terreno Embu, estado de São Paulo. Observar nas imagens BSE cristal idiomórfico com leve zonamento concêntrico e bordas de corrosão e subsituição da monazita primária (esquerda) e cristal com marcado zonamento irregular (direita). As zonas de subsituição apresentam idades de ca. 530 Ma. Outros detalhes de legenda como nas Figuras 2 e 3 . Discussões no texto.

Figura 14. Diagramas ilustrando os resultados obtidos para a datação química e imagens BSE de monazita e xenotima para o granito equigranular EM-017, do Batólito Natividade da Serra, região leste do Terreno Embu, estado de São Paulo. Observar nas imagens BSE cristais de tendências idiomórficas de monazita e xenotima em contato mútuo reto, sugestivo de equilíbrio (esquerda) e cristal de monazita com forte zonamento irregular (direita); neste cristal, as zonas mais escuras apresentam idades de ca. $590 \mathrm{Ma}$. Outros detalhes de legenda como nas Figuras 2 e 3. Discussões no texto. 


\section{LEGENDA DE TABELAS}

Tabela 1. Análises químicas pontuais (\% em peso de óxidos) e idades pontuais representativas para monazita presente em paragnaisses, migmatitos, ortognaisses e granitos intrusivos do Terreno Embu e vizinhanças. bd: abaixo do limite de detecção.

Tabela 1. Análises químicas pontuais (\% em peso de óxidos) e idades pontuais representativas para xenotima presente em ortognaisses e granitos intrusivos do Terreno Embu e vizinhanças. bd: abaixo do limite de deteç̧ão. 


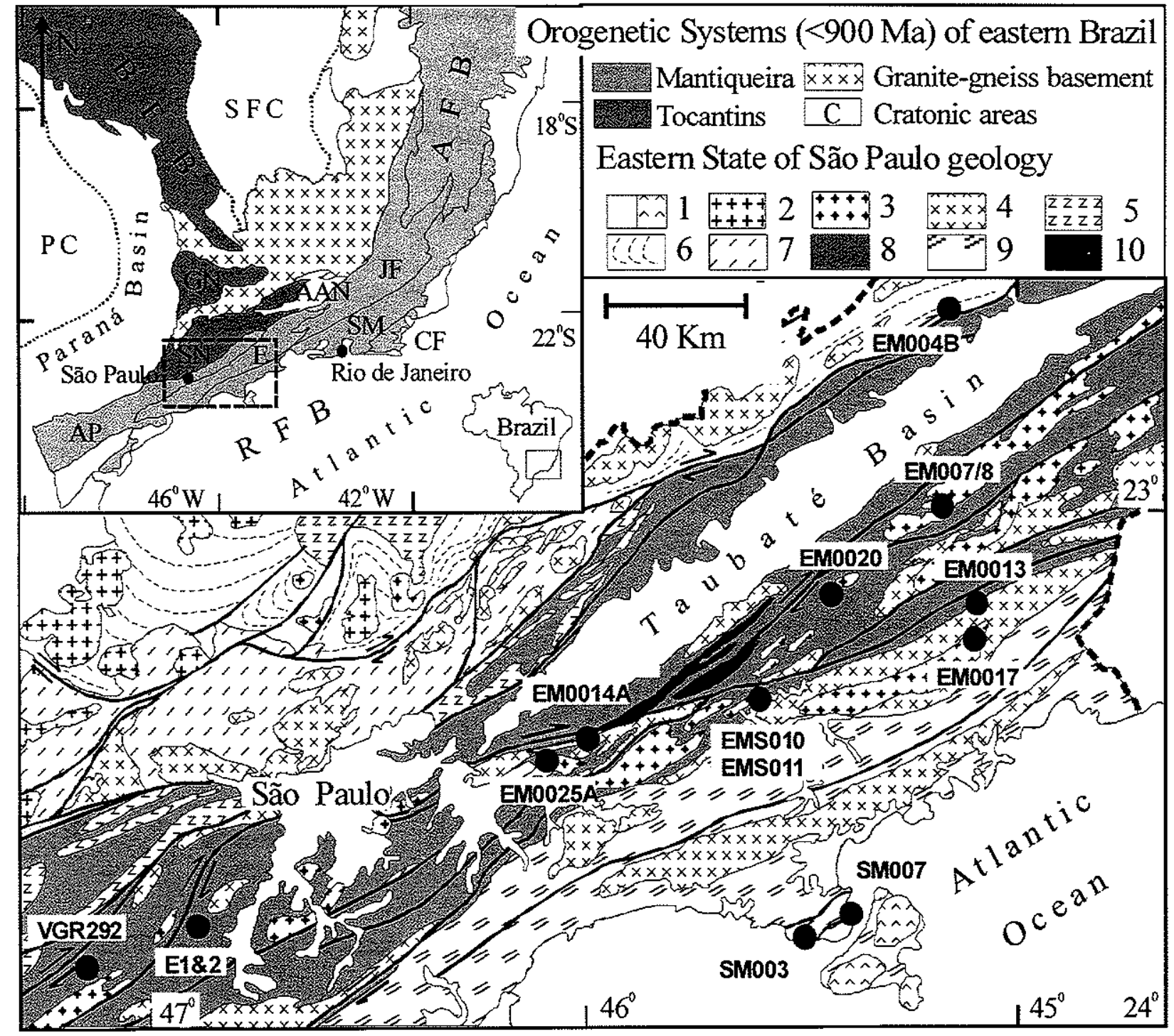

Figura 1 


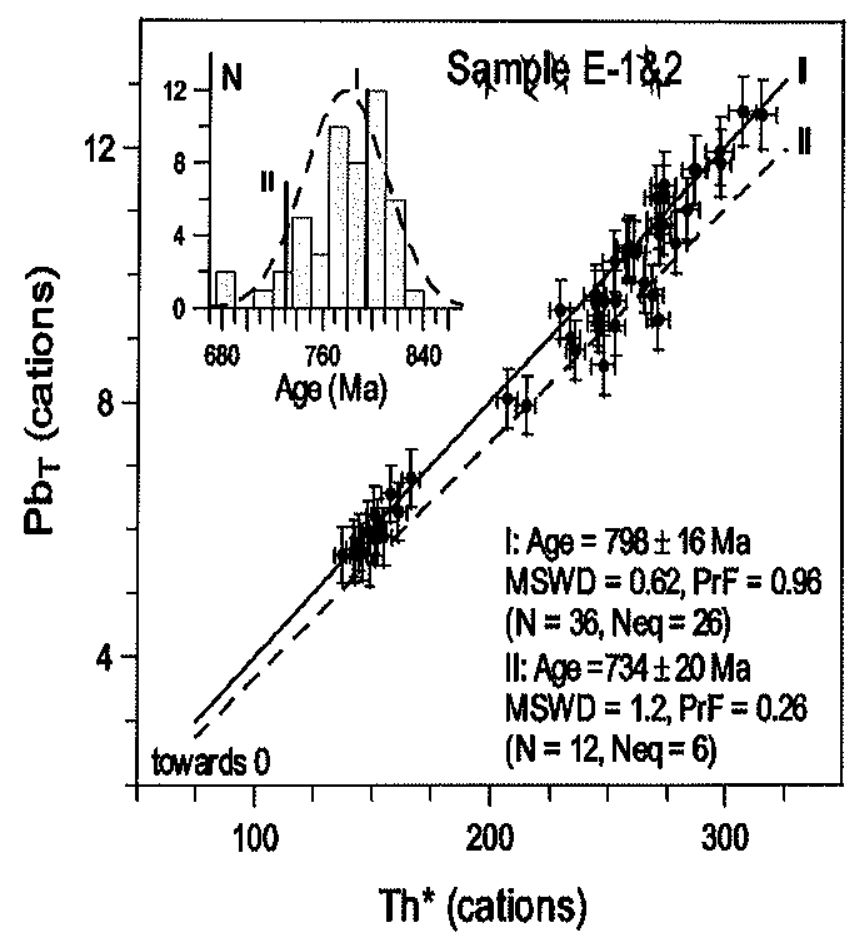

Westem Embu paragneiss Unmixing ages (Ma) l: $792 \pm 7(f=0.77), \quad$ II: $729 \pm 13(f=0.23)$ Relative Misfit $=0.87$
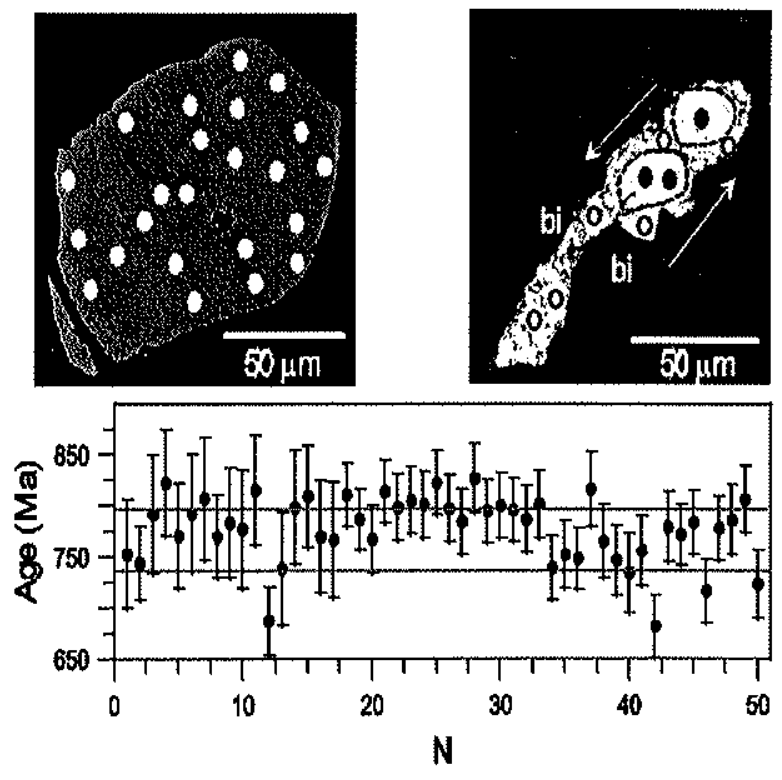

Figura 2
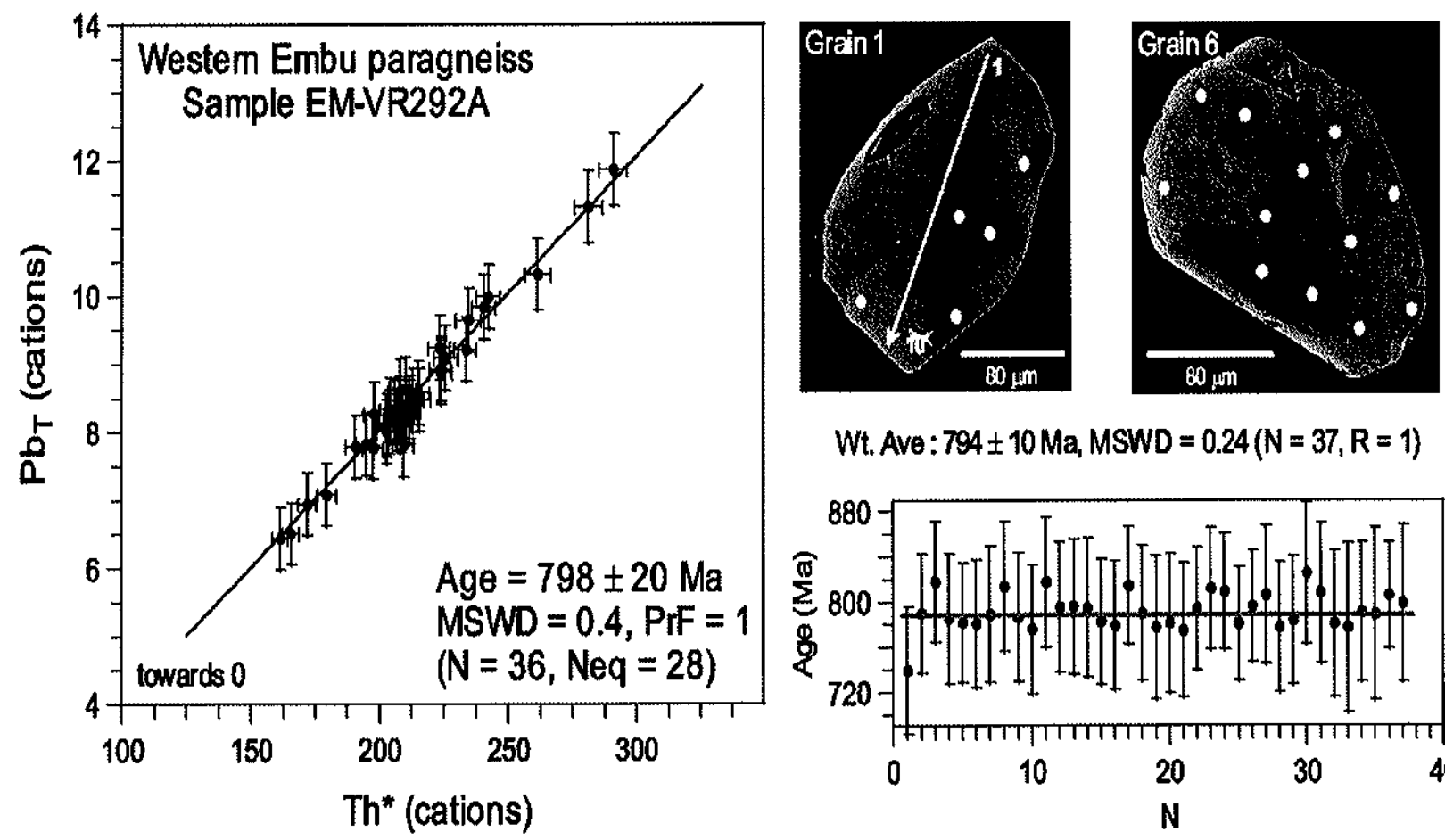

Wt. Ave: $794 \pm 10 \mathrm{Ma}, \mathrm{MSWD}=0.24(\mathrm{~N}=37, \mathrm{R}=1)$

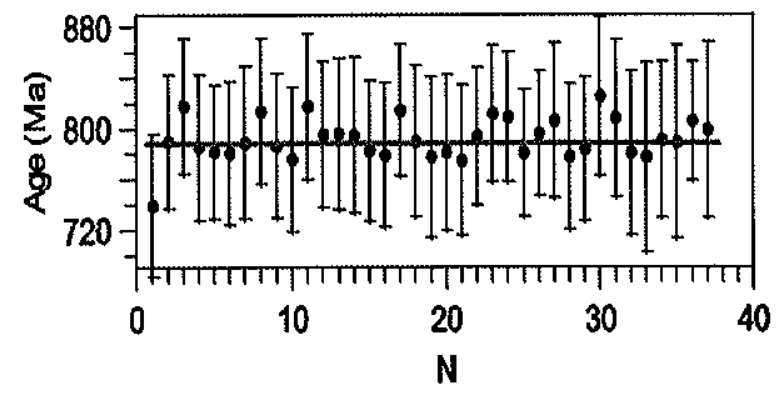

Figura 3 


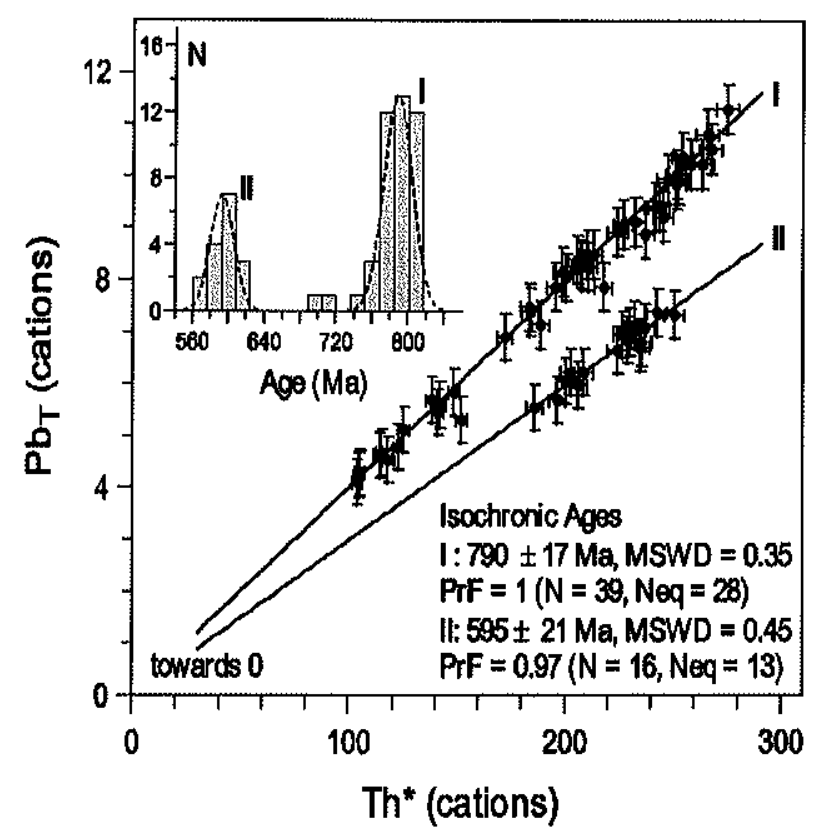

Estem Embu paragneiss Em-020 unmix ages (Ma) l: $789 \pm 10(f=0.71), \quad$ Il: $593 \pm 14(f=0.29)$ Relative Misfit $=0.55$
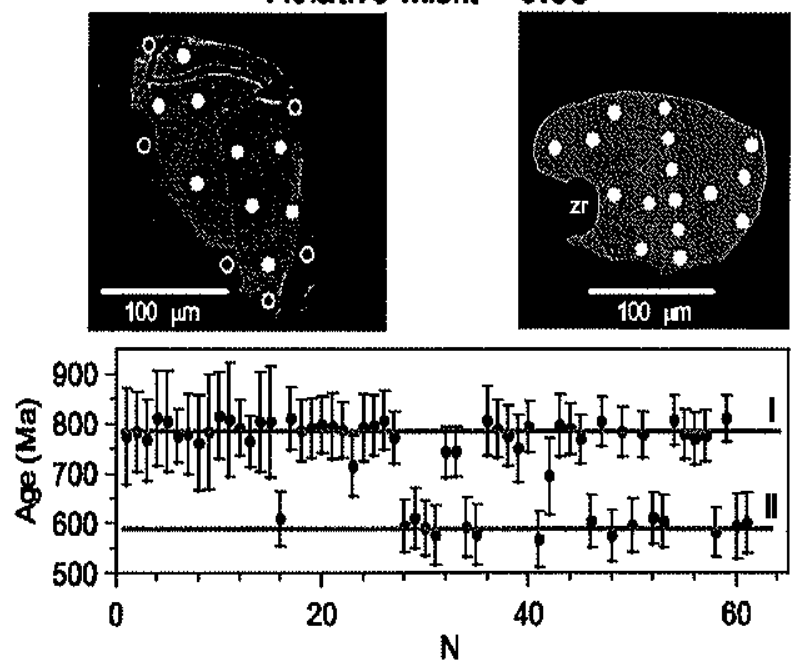

Figura 4

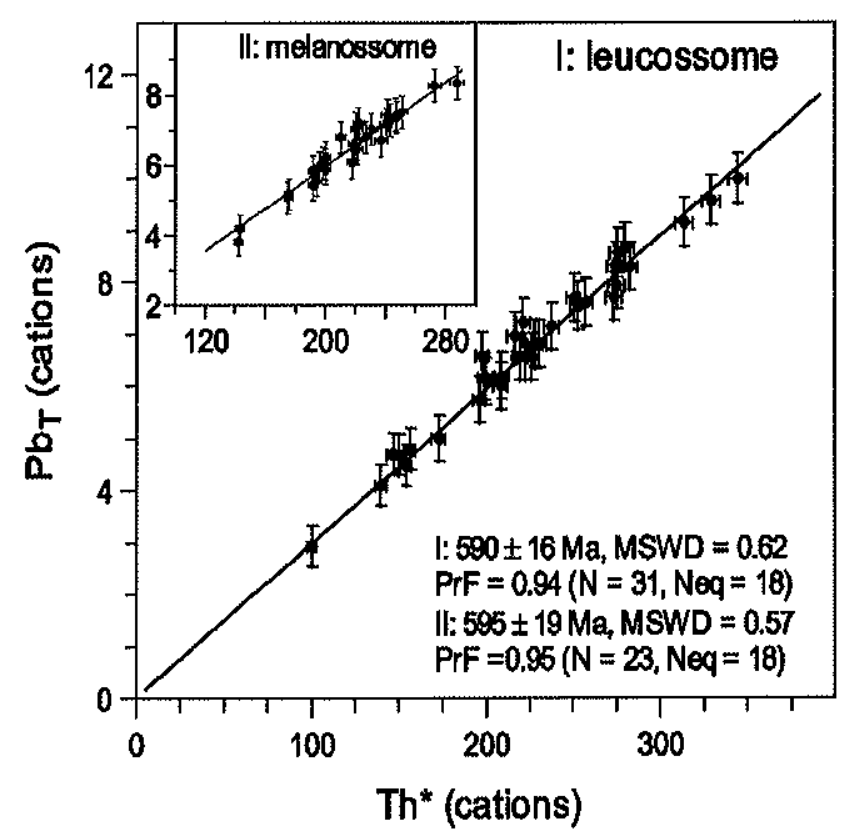

Costeiro Migmatite SM-03. Ave. ages (Ma): Leucossome : $592 \pm 10, \mathrm{MSWD}=0.35, \mathrm{PrF}=1$ Melanossome: $594 \pm 11, \mathrm{MSWD}=0.34, \mathrm{PrF}=1$
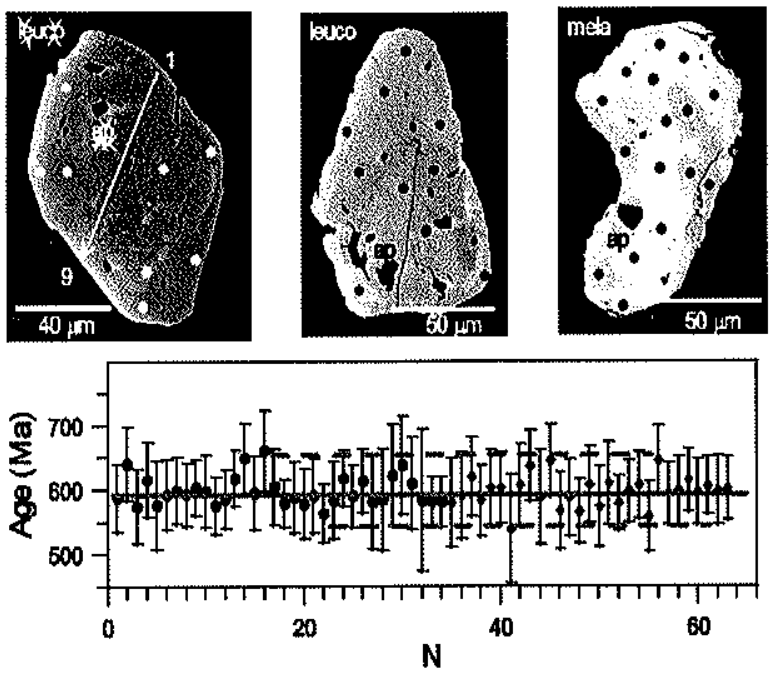

Figura 5 


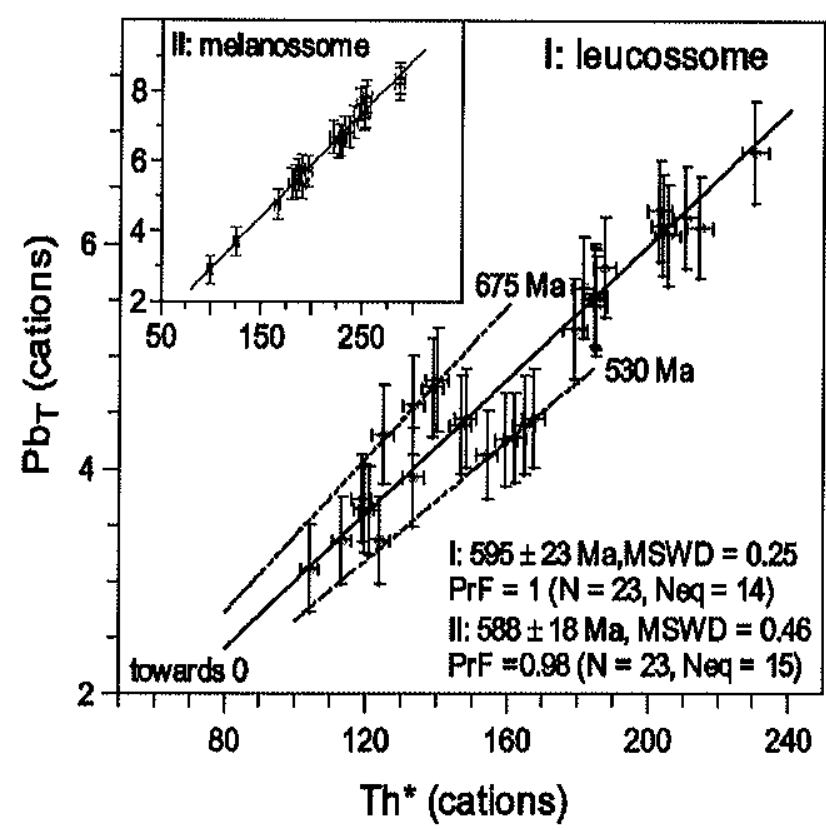

Costeiro Migmatite SM-07. Ave. ages (Ma) :

Leucossome : $596 \pm 15, \mathrm{MSWD}=0.14, \mathrm{PrF}=1$

Melanossome: $588 \pm 11, \mathrm{MSWD}=0.27, \mathrm{PrF}=1$
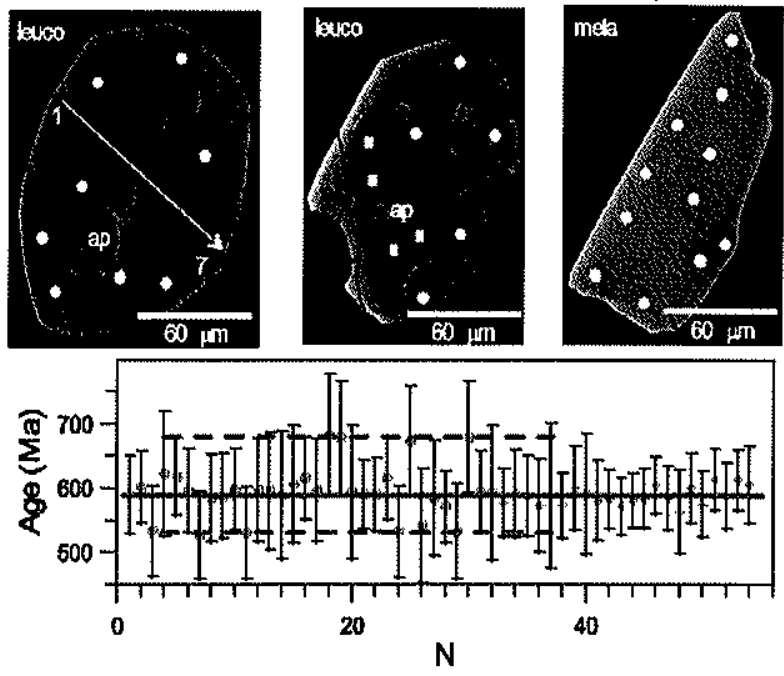

Figura 6

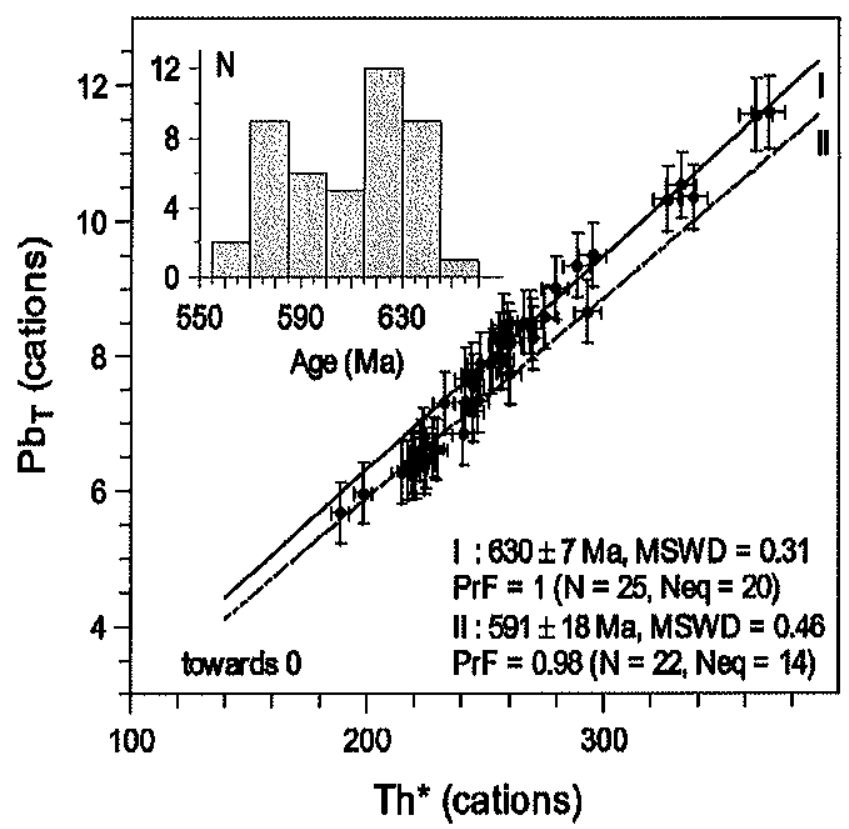

Paragneiss EM-004B. Wt. Ave. ages (Ma):

$\mathrm{I}: 628 \pm 9, \mathrm{MSWD}=0.19, \mathrm{PrF}=1$

II: $587 \pm 11, M S W D=0.28, P r F=1$
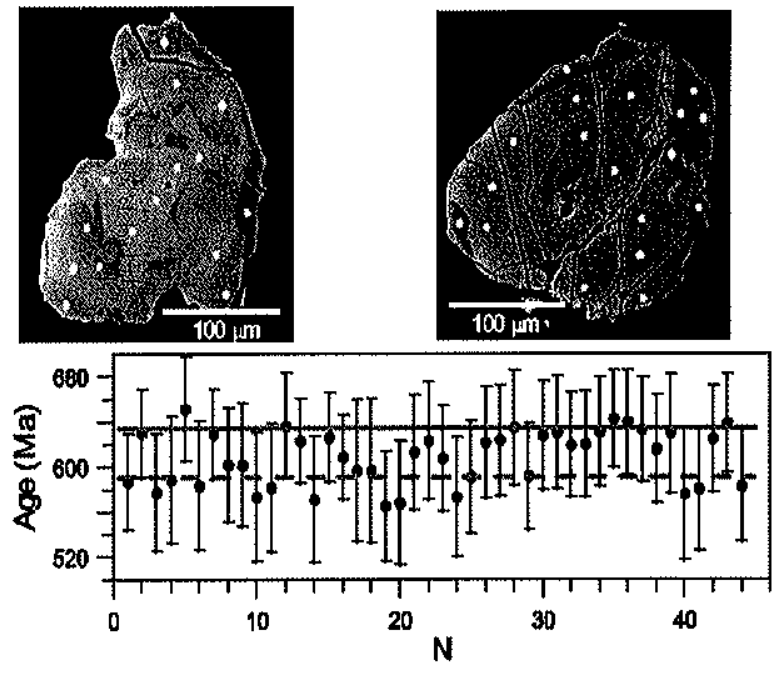

Figura 7 

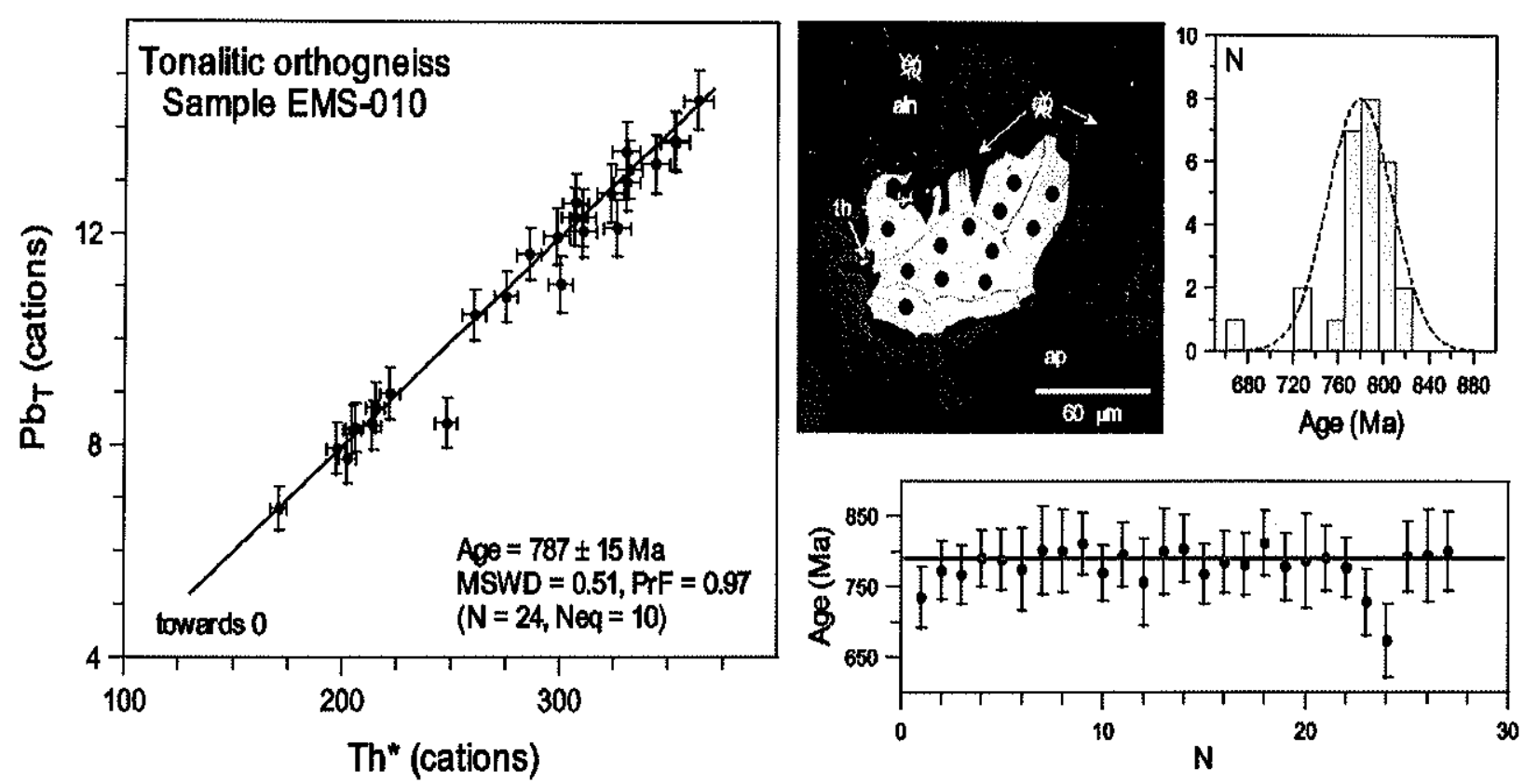

Figura 8

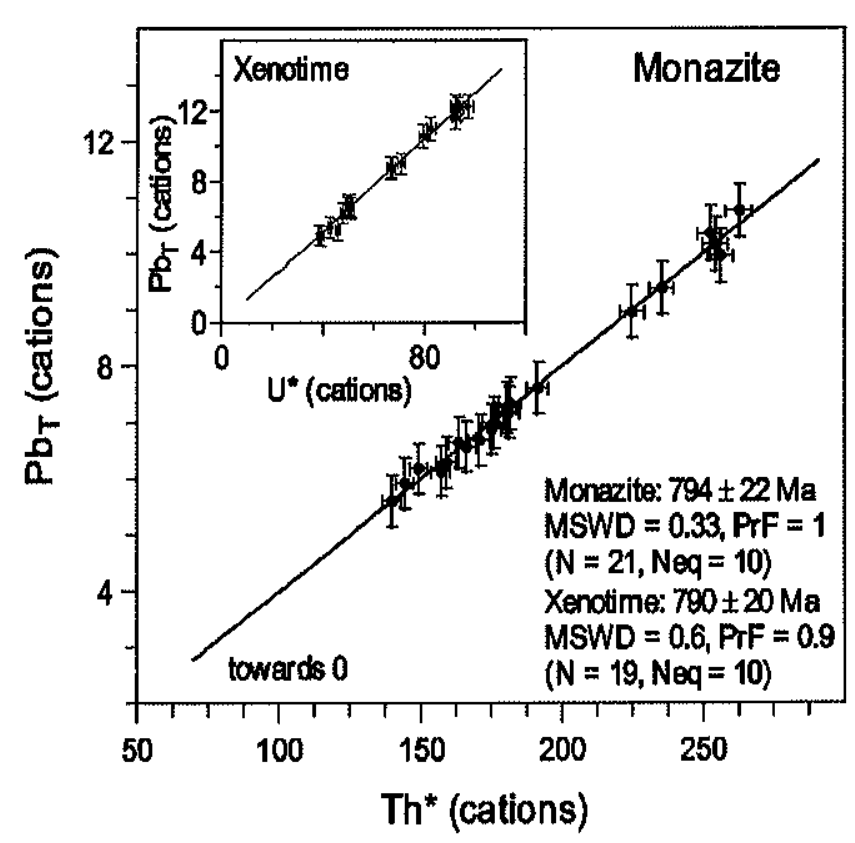

Orthogneiss EMS-011B Wt. Ave. ages (Ma): Monazite : $792 \pm 14, \mathrm{MSWD}=0.21, \mathrm{PrF}=1$ Xenotime: $793 \pm 14, M S W D=0.44, P r F=1$

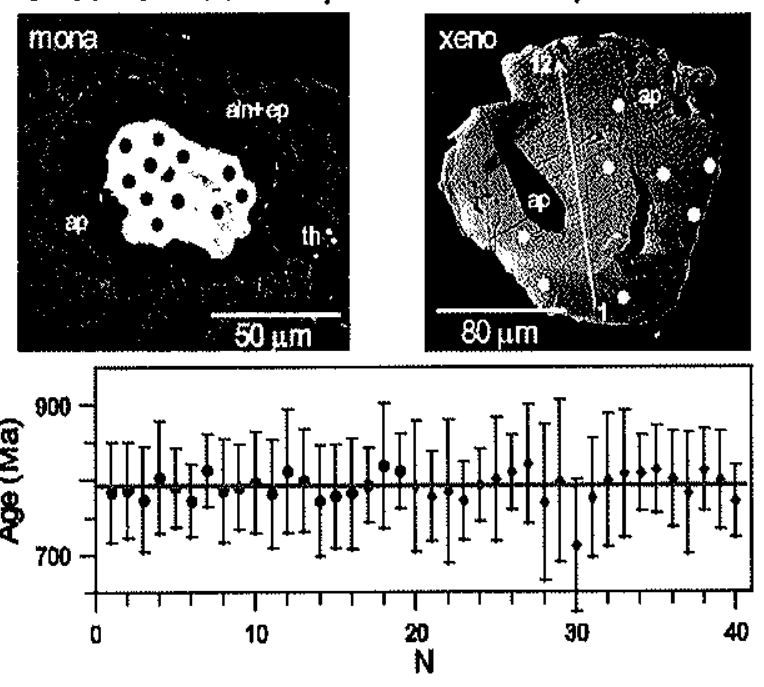

Figura 9 


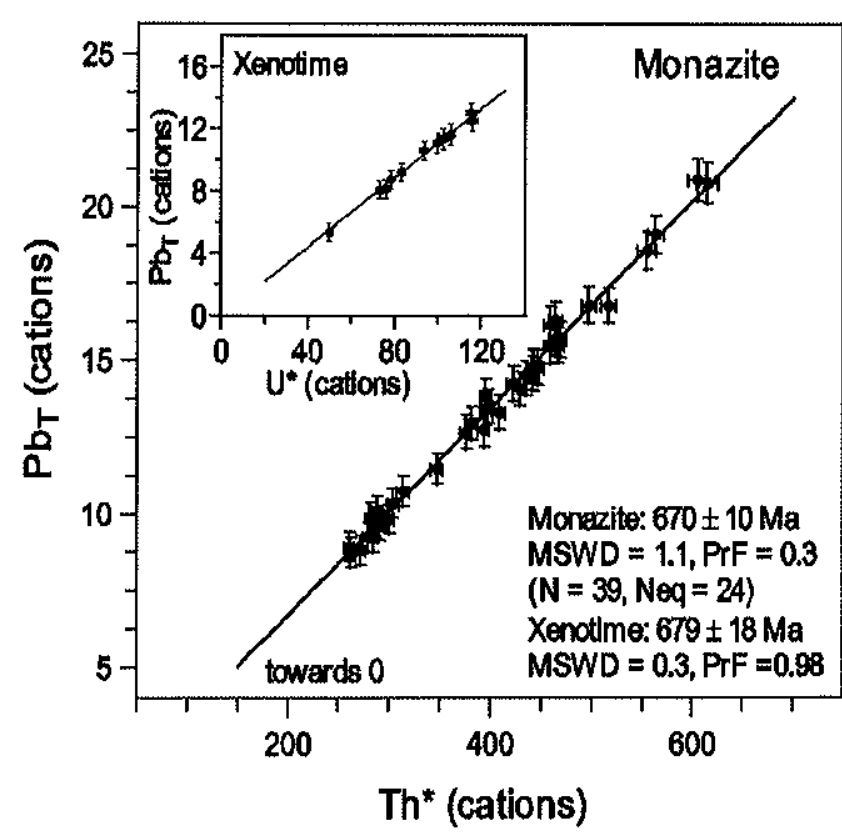

Figura 10

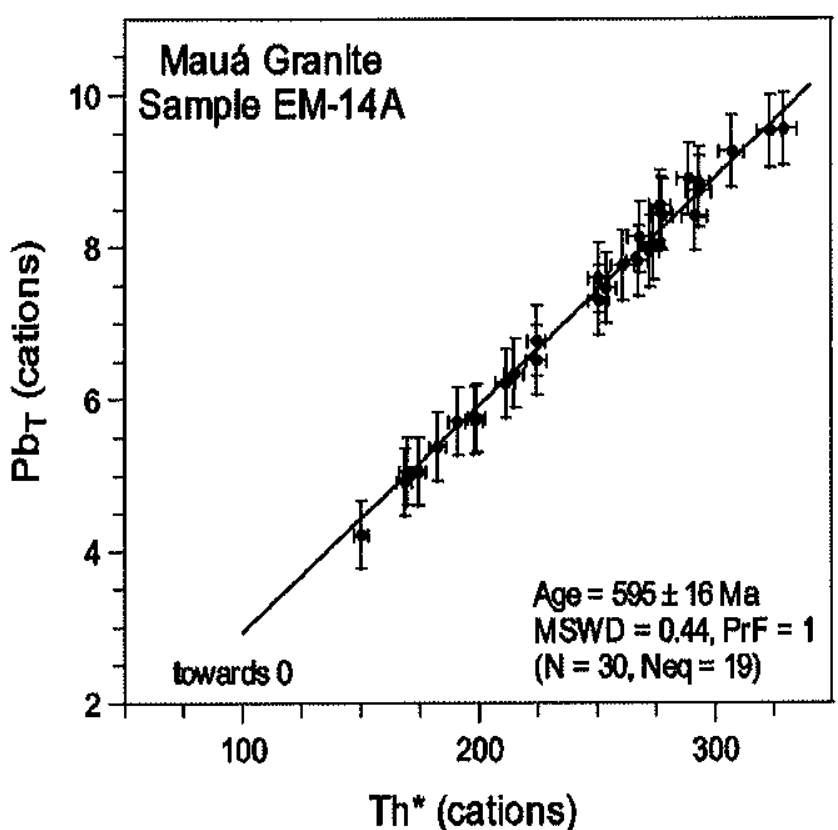

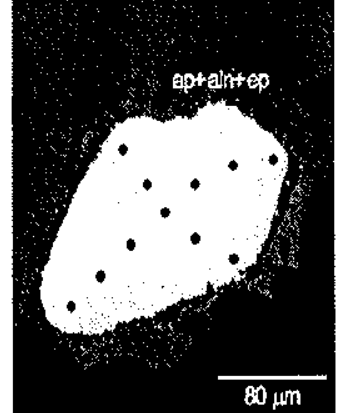

Wt. Average Age: $591 \pm 9 \mathrm{Ma}, \mathrm{MSWD}=0.24, \mathrm{PrF}=1$

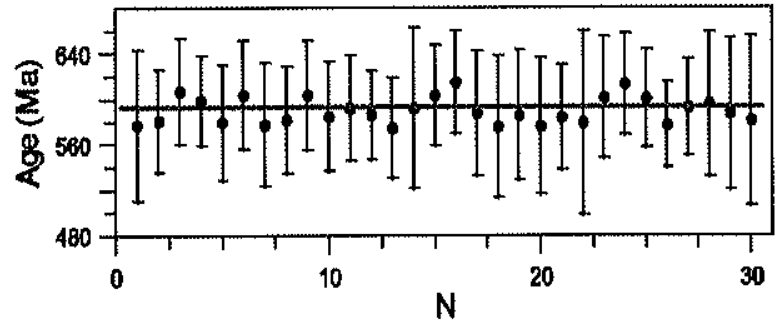

Figura 11 


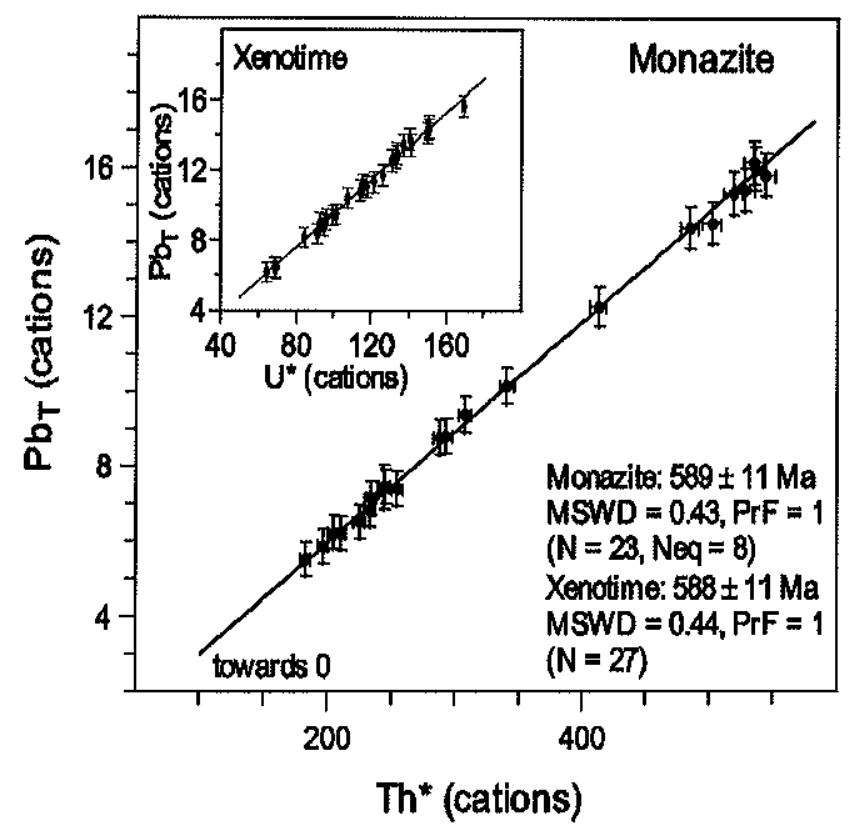

Mogi das Cruzes granite. Ave. ages (Ma):

Monazite : $591 \pm 8, \mathrm{MSWD}=0.28, \mathrm{PrF}=1$

Xenotime: $592 \pm 7, \mathrm{MSWD}=0.31, \mathrm{PrF}=1$
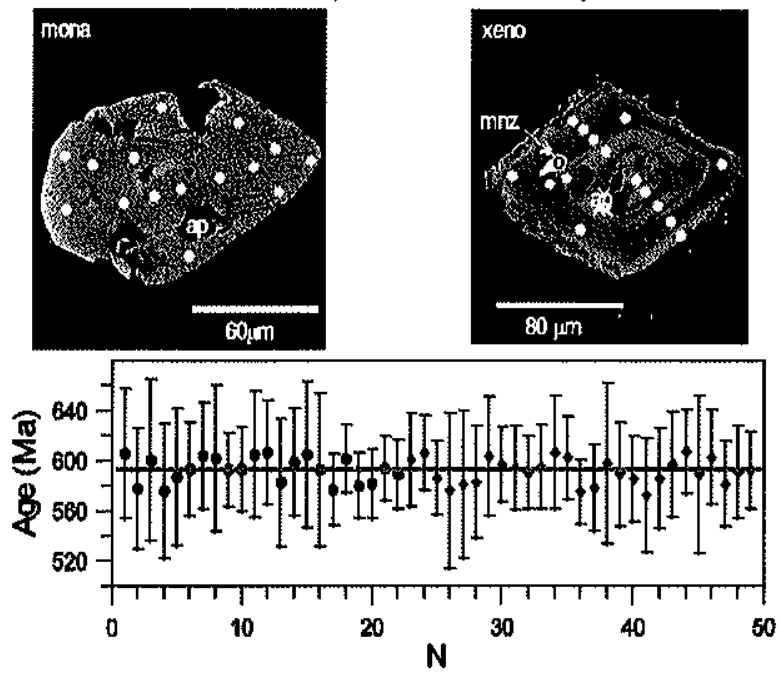

Figura 12

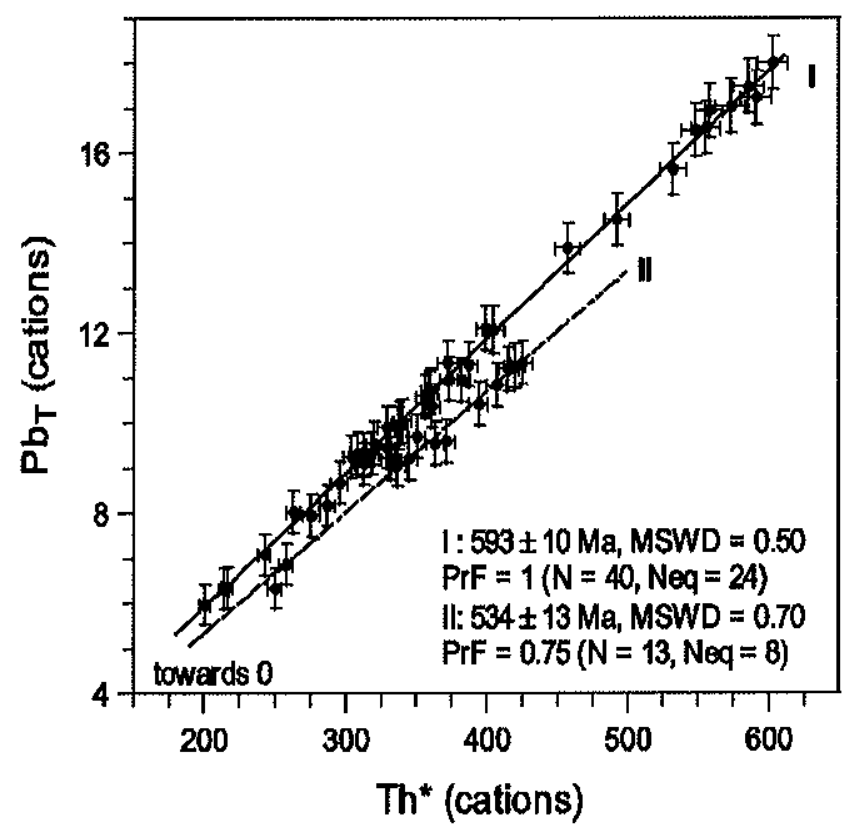

Natividade granite(EM-13A). Ave. ages (Ma):

$1: 589 \pm 6$, MSWD $=0.32$, PrF $=1$

II: $532 \pm 10$, MSWD $=0.43, \mathrm{PrF}=0.95$
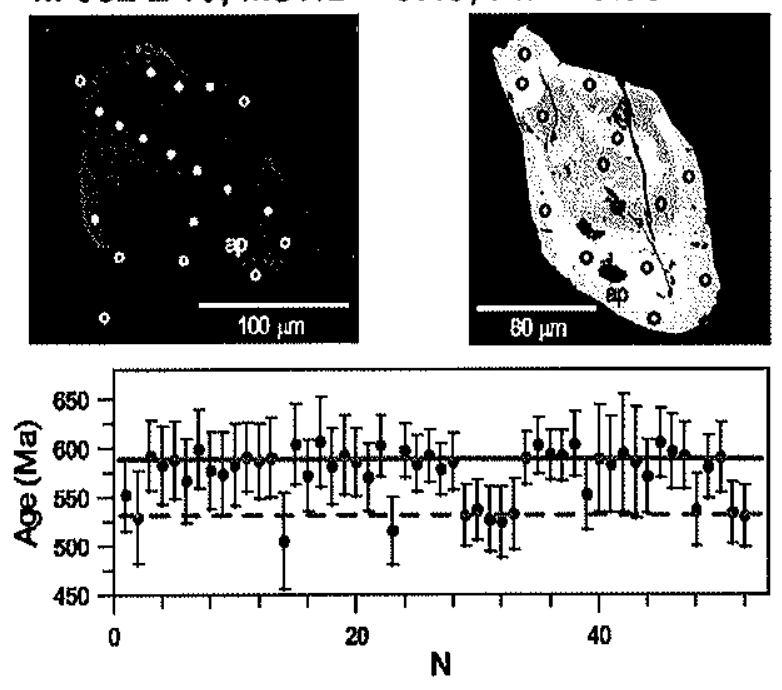

Figura 13 


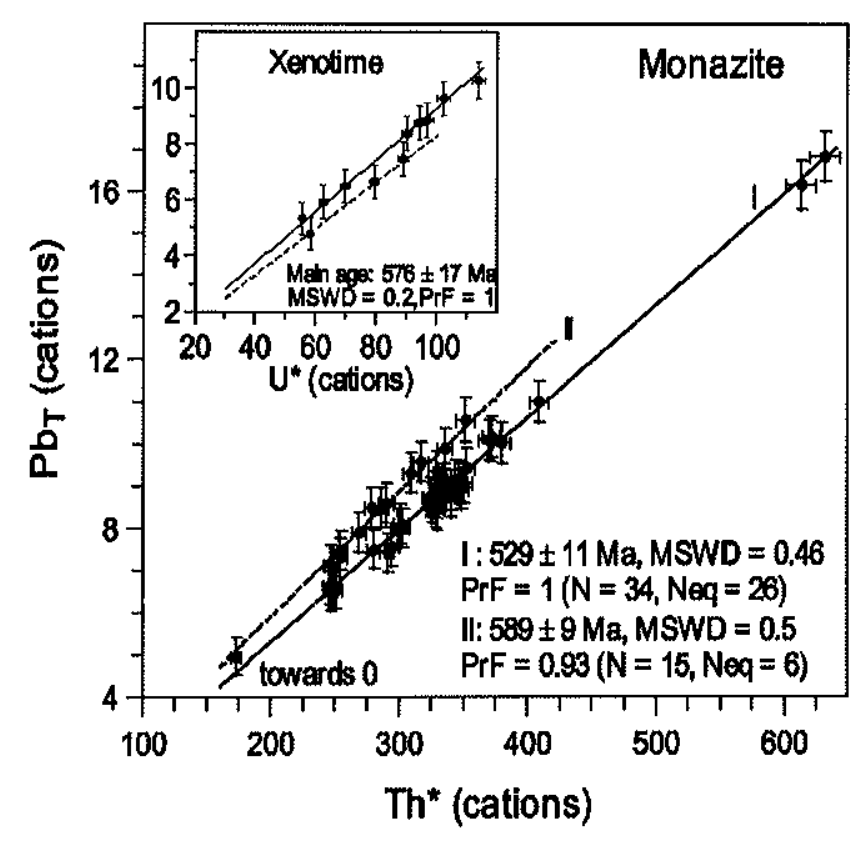

Natividade granite(EM-17). Ave. ages (Ma):

$\mathrm{I}: 529 \pm 6, \mathrm{MSWD}=0.27, \mathrm{PrF}=1$ (mon)

II: $587 \pm 11, M S W D=0.3, \operatorname{PrF}=1$ (mon)
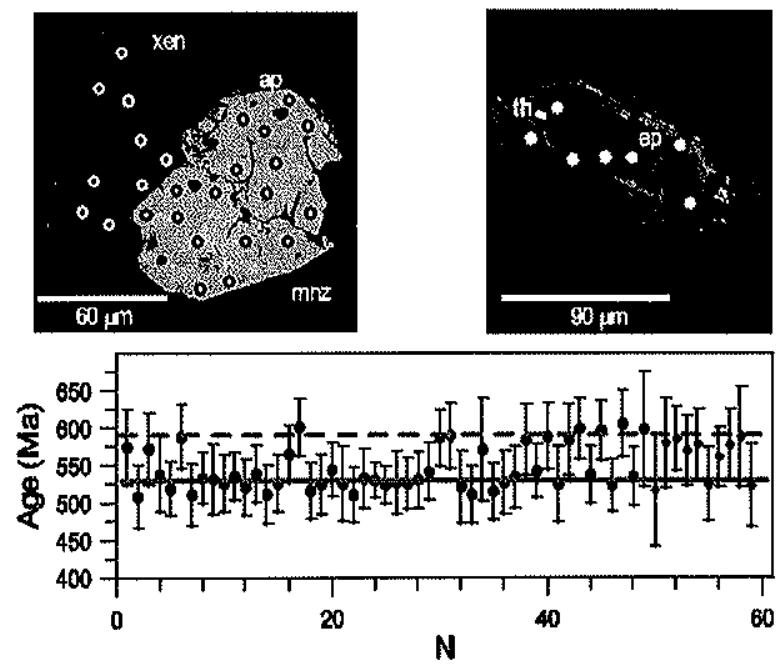

Figura 14 
Tabela 1

\begin{tabular}{|c|c|c|c|c|c|c|c|c|c|c|c|c|c|c|c|c|}
\hline \multirow{3}{*}{$\begin{array}{l}\text { Sample } \\
\text { Grain } \\
\text { Spot }\end{array}$} & \multirow{3}{*}{$\begin{array}{r}E 1 \& 2 \\
1 \\
1, \mathrm{r} \\
\end{array}$} & \multirow{3}{*}{$\begin{array}{r}6 \\
6, r \\
\end{array}$} & \multicolumn{3}{|c|}{ EM-VGR292 } & \multicolumn{3}{|l|}{$E M-020$} & \multicolumn{2}{|c|}{ SM3 feucossome } & \multicolumn{2}{|c|}{ melanossome } & \multicolumn{2}{|c|}{ SM7 leucossome } & \multicolumn{2}{|c|}{ melanossome } \\
\hline & & & 2 & 1 & 4 & 2 & 5 & 7 & 1 & 16 & 2 & 9 & 12 & 2 & 4 & 3 \\
\hline & & & $2, i$ & 1,10 & 4,10 & 7,1 & $5, r$ & $7, r$ & 3 & 3 & 6 & 2 & 1 & 36 & 1 & 60 \\
\hline $\mathrm{SiO}_{2}$ & 0.33 & 0.26 & 0.64 & 0.23 & 0.22 & 0.05 & 0.41 & 0.09 & 0.13 & 0.14 & 0.12 & 0.11 & 0.10 & 0.08 & 0.09 & 0.14 \\
\hline $\mathrm{ThO}_{2}$ & 3.83 & 3.42 & 7.63 & 4.64 & 4.78 & 2.08 & 5.19 & 5.14 & 4.61 & 5.10 & 2.69 & 2.73 & 3.68 & 3.66 & 4.21 & 4.52 \\
\hline $\mathrm{UO}_{2}$ & 0.07 & 0.06 & 0.21 & 0.31 & 0.24 & 0.54 & 0.24 & 0.27 & 0.19 & 0.21 & 0.74 & 0.57 & 0.52 & 0.37 & 0.54 & 0.49 \\
\hline $\mathrm{Al}_{2} \mathrm{O}_{3}$ & 0.08 & 0.09 & 0.03 & bd & bd & bd & bd & 0.04 & bd & 0.02 & 0.07 & 0.02 & 0.04 & 0.06 & 0.05 & 0.03 \\
\hline $\mathrm{La}_{2} \mathrm{O}_{3}$ & 15.08 & 15.90 & 13.56 & 12.79 & 12.97 & 15.63 & 14.64 & 12.95 & 14.01 & 13.31 & 13.53 & 14.40 & 13.82 & 13.11 & 13.41 & 13.81 \\
\hline $\mathrm{Ce}_{2} \mathrm{O}_{3}$ & 30.76 & 32.23 & 29.02 & 29.19 & 29.68 & 31.68 & 30.41 & 27.86 & 29.18 & 28.42 & 28.37 & 28.92 & 28.30 & 28.53 & 28.01 & 28.33 \\
\hline $\mathrm{Pr}_{2} \mathrm{O}_{3}$ & 3.23 & 3.29 & 3.19 & 3.25 & 3.35 & 3.30 & 3.36 & 3.17 & 3.28 & 3.12 & 3.29 & 3.19 & 3.20 & 3.18 & 3.14 & 2.86 \\
\hline $\mathrm{Nd}_{2} \mathrm{O}_{3}$ & 12.06 & 11.61 & 12.32 & 11.87 & 12.16 & 11.90 & 12.20 & 11.77 & 11.83 & 12.45 & 12.79 & 12.32 & 11.32 & 11.82 & 11.56 & 11.36 \\
\hline $\mathrm{Sm}_{2} \mathrm{O}_{3}$ & 1.55 & 1.28 & 2.01 & 2.21 & 2.22 & 1.95 & 1.83 & 1.98 & 2.06 & 2.30 & 2.59 & 2.20 & 1.76 & 1.97 & 2.01 & 1.83 \\
\hline $\mathrm{Gd}_{2} \mathrm{O}_{3}$ & 0.86 & 0.73 & 0.97 & 1.85 & 1.82 & 1.31 & 1.15 & 1.85 & 1.45 & 1.71 & 2.01 & 1.80 & 1.53 & 1.63 & 1.60 & 1.49 \\
\hline $\mathrm{Tb}_{2} \mathrm{O}_{3}$ & 0.04 & 0.12 & bd & bd & bd & 0.04 & $n$ & 0.18 & 0.06 & 0.15 & 0.23 & 0.14 & 0.20 & 0.16 & 0.25 & 0.13 \\
\hline $\mathrm{Dy}_{2} \mathrm{O}_{3}$ & 0.24 & 0.15 & 0.06 & 0.86 & 0.54 & 0.31 & 0.15 & 0.89 & 0.66 & 0.64 & 0.68 & 0.61 & 0.85 & 0.75 & 0.86 & 0.72 \\
\hline $\mathrm{Er}_{2} \mathrm{O}_{3}$ & bd & bd & bd & bd & bd & bd & bd & bd & 0.09 & bd & 0.11 & 0.06 & 0.22 & 0.22 & 0.15 & 0.13 \\
\hline $\mathrm{Yb}_{2} \mathrm{O}_{3}$ & 0.09 & 0.10 & 0.06 & 0.10 & 0.08 & 0.08 & 0.05 & 0.11 & 0.13 & 0.10 & 0.07 & 0.08 & 0.17 & 0.22 & 0.14 & 0.13 \\
\hline $\mathrm{Y}_{2} \mathrm{O}_{3}$ & 0.59 & 0.50 & 0.04 & 1.62 & 1.04 & 0.68 & 0.29 & 2.19 & 1.57 & 1.47 & 1.82 & 1.44 & 2.78 & 2.79 & 2.34 & 2.51 \\
\hline $\mathrm{FeO}$ & bd & bd & bd & bd & bd & bd & 0.12 & 0.18 & bd & $b d$ & bd & bd & $b d$ & 0.05 & 0.05 & bd \\
\hline $\mathrm{CaO}$ & 0.55 & 0.53 & 1.03 & 0.84 & 0.82 & 0.58 & 0.79 & 1.17 & 0.90 & 0.98 & 0.68 & 0.60 & 0.89 & 0.83 & 1.07 & 1.22 \\
\hline $\mathrm{PbO}$ & 0.13 & 0.12 & 0.28 & 0.19 & 0.19 & 0.13 & 0.20 & 0.15 & 0.14 & 0.15 & 0.13 & 0.12 & 0.14 & 0.12 & 0.15 & 0.15 \\
\hline $\mathrm{P}_{2} \mathrm{O}_{5}$ & 30.21 & 30.11 & 29.34 & 29.92 & 30.02 & 30.12 & 29.75 & 30.67 & 30.03 & 29.85 & 29.97 & 29.90 & 30.34 & 30.57 & 30.12 & 30.46 \\
\hline Sum & 99.70 & 100.51 & 100.37 & 99.91 & 100.14 & 100.39 & 100.76 & 100.67 & 100.34 & 100.13 & 99.90 & 99.21 & 99.87 & 100.12 & 99.72 & 100.31 \\
\hline \multicolumn{17}{|c|}{ Age-determining elements (ppm), individual spot ages, and standard errors ( $95 \%$ confidence intervai) } \\
\hline Th & 33670 & 30050 & 67030 & 40810 & 42030 & 18310 & 45590 & 45170 & 40530 & 44780 & 23630 & 24000 & 32340 & 32170 & 37010 & 39750 \\
\hline SE & 745 & 671 & 1399 & 888 & 911 & 438 & 973 & 965 & 868 & 954 & 535 & 541 & 705 & 702 & 799 & 853 \\
\hline$u$ & 660 & 510 & 1810 & 2693 & 2089 & 4790 & 2080 & 2370 & 1705 & 1815 & 6523 & 4988 & 4621 & 3223 & 4726 & 4304 \\
\hline SE & 110 & 110 & 116 & 132 & 118 & 153 & 117 & 119 & 115 & 116 & 177 & 156 & 151 & 136 & 153 & 148 \\
\hline $\mathrm{Pb}$ & 1220 & 1160 & 2600 & 1778 & 1719 & 1210 & 1880 & 1420 & 1280 & 1362 & 1233 & 1075 & 1261 & 1151 & 1351 & 1419 \\
\hline SE & 93 & 92 & 113 & $\quad 97$ & 96 & 93 & 97 & 94 & 94 & 94 & 93 & 93 & 93 & 93 & 94 & 94 \\
\hline $\begin{array}{l}\text { Age } \\
\text { (Ma) }\end{array}$ & 753 & 807 & 787 & 789 & 776 & 780 & 791 & 596 & 616 & 596 & 607 & 591 & 589 & 598 & 572 & 585 \\
\hline$S E$ & 53 & 60 & 30 & 39 & 39 & 55 & 37 & 37 & 46 & 42 & 45 & 50 & 44 & 48 & 40 & 39 \\
\hline
\end{tabular}


Tabela 1, cont

\begin{tabular}{|c|c|c|c|c|c|c|c|c|c|c|c|c|c|c|c|c|}
\hline Sample & EM004B & & EMS010 & $011 B$ & EM8\&9 & & EM014A & & EM025A & & EM13A & & & & EM017 & \\
\hline Grain & 3 & & 1 & 2 & 3 & 6 & 1 & 1 & 1 & 2 & 4 & 4 & 6 & 6 & 1 & 2 \\
\hline Spot & $1, n$ & $2 i$ & 4 & 8 & 2 & 1 & 39 & 31 & $3, i$ & $6, \mathrm{i}$ & 8 & 9 & $8, r$ & $9, r$ & 6 & 9 \\
\hline $\mathrm{SiO}_{2}$ & 0.29 & 0.36 & 1.29 & 0.37 & 0.10 & 0.15 & 0.98 & 0.77 & 0.55 & 0.39 & 0.66 & 0.85 & 0.33 & 0.41 & 0.67 & 0.55 \\
\hline $\mathrm{ThO}_{2}$ & 6.25 & 8.46 & 8.50 & 4.18 & 6.25 & 5.72 & 6.20 & 4.90 & 4.30 & 8.47 & 6.94 & 8.08 & 7.94 & 8.14 & 6.88 & 6.09 \\
\hline $\mathrm{UO}_{2}$ & 0.29 & 0.35 & 0.33 & 0.14 & 2.05 & 1.43 & 0.70 & 0.52 & 0.16 & 1.71 & 0.26 & 0.40 & 0.91 & 0.69 & 0.24 & 0.40 \\
\hline $\mathrm{Al}_{2} \mathrm{O}_{3}$ & bd & 0.02 & 0.02 & 0.02 & 0.01 & 0.02 & 0.04 & 0.03 & 0.09 & 0.02 & bd & bd & 0.04 & 0.04 & 0.03 & 0.02 \\
\hline $\mathrm{La}_{2} \mathrm{O}_{3}$ & 12.95 & 11.33 & 13.88 & 14.91 & 14.06 & 12.58 & 13.12 & 14.28 & 16.16 & 10.19 & 14.75 & 12.58 & 13.62 & 13.86 & 14.88 & 15.80 \\
\hline $\mathrm{Ce}_{2} \mathrm{O}_{3}$ & 30.76 & 29.20 & 26.84 & 29.26 & 27.71 & 27.89 & 27.82 & 29.18 & 31.84 & 25.32 & 29.36 & 28.52 & 27.62 & 29.14 & 29.65 & 28.86 \\
\hline $\mathrm{Pr}_{2} \mathrm{O}_{3}$ & 3.43 & 3.52 & 3.00 & 3.00 & 2.81 & 3.09 & 3.03 & 3.16 & 3.21 & 2.98 & 3.03 & 3.30 & 2.94 & 3.13 & 3.13 & 2.74 \\
\hline $\mathrm{Nd}_{2} \mathrm{O}_{3}$ & 12.62 & 12.85 & 11.56 & 11.36 & 8.93 & 11.28 & 11.13 & 10.76 & 10.91 & 10.62 & 10.92 & 11.55 & 10.41 & 10.39 & 10.77 & 9.68 \\
\hline $\mathrm{Sm}_{2} \mathrm{O}_{3}$ & 2.07 & 2.34 & 1.77 & $\{.57$ & 2.04 & 2.35 & 2.02 & 1.75 & 1.45 & 2.59 & 1.81 & 1.98 & 1.84 & 1.75 & 1.81 & 1.42 \\
\hline $\mathrm{Gd}_{2} \mathrm{O}_{3}$ & 0.66 & 0.87 & 1.31 & 1.16 & 1.42 & 1.67 & 1.62 & 1.28 & 0.78 & 1.89 & 1.00 & 1.06 & 1.37 & 0.96 & 1.02 & 1.03 \\
\hline $\mathrm{Tb}_{2} \mathrm{O}_{3}$ & bd & bd & 0.13 & 0.07 & 0.21 & 0.19 & 0.16 & 0.19 & 0.09 & 0.21 & 0.09 & 0.06 & 0.13 & 0.07 & 0.02 & 0.02 \\
\hline $\mathrm{Dy}_{2} \mathrm{O}_{3}$ & 0.04 & 0.09 & 0.57 & 0.69 & 0.54 & 0.73 & 0.75 & 0.61 & 0.19 & 0.96 & 0.30 & 0.35 & 0.57 & 0.33 & 0.39 & 0.53 \\
\hline $\mathrm{Er}_{2} \mathrm{O}_{3}$ & bd & bd & 0.08 & 0.11 & 0.06 & 0.08 & 0.16 & 0.10 & 0.04 & 0.11 & 0.05 & 0.08 & bd & bd & 0.11 & 0.11 \\
\hline $\mathrm{Yb}_{2} \mathrm{O}_{3}$ & 0.00 & 0.02 & 0.10 & 0.13 & 0.10 & 0.13 & 0.15 & 0.12 & 0.10 & 0.16 & 0.12 & 0.15 & 0.13 & 0.12 & 0.10 & 0.07 \\
\hline $\mathrm{Y}_{2} \mathrm{O}_{3}$ & 0.07 & 0.10 & 1.49 & 2.05 & 1.51 & 1.64 & 2.33 & 1.75 & 0.62 & 2.19 & 0.75 & 0.96 & 1.35 & 0.56 & 0.82 & 1.81 \\
\hline $\mathrm{FeO}$ & bd & bd & 0.04 & bd & $b d$ & bd & bd & 0.16 & bd & bd & bd & bd & 0.09 & 0.05 & bd & bd \\
\hline $\mathrm{CaO}$ & 1.13 & 1.55 & 0.68 & 0.94 & 1.64 & 1.39 & 0.54 & 0.97 & 0.47 & 1.91 & 0.87 & 0.91 & 1.60 & 1.46 & 0.89 & 0.82 \\
\hline $\mathrm{PbO}$ & 0.19 & 0.26 & 0.32 & 0.16 & 0.37 & 0.30 & 0.21 & 0.16 & 0.12 & 0.36 & 0.19 & 0.24 & 0.25 & 0.23 & 0.19 & 0.17 \\
\hline $\mathrm{P}_{2} \mathrm{O}_{5}$ & 29.60 & 29.52 & 28.25 & 30.15 & 30.11 & 30.15 & 28.80 & 29.05 & 29.51 & 29.85 & 29.41 & 28.85 & 29.89 & 29.62 & 29.29 & 29.50 \\
\hline Sum & 100.35 & 100.84 & 100.13 & 100.27 & 99.91 & 100.76 & 99.76 & 99.73 & 100.58 & 99.94 & 100.55 & 99.92 & 101.05 & 100.97 & 100.88 & 99.59 \\
\hline
\end{tabular}

Age-determining elements (ppm), individual spot ages, and standard errors ( $95 \%$ confidence intervai)

\begin{tabular}{|c|c|c|c|c|c|c|c|c|c|c|c|c|c|c|c|c|}
\hline Th & 59420 & 74300 & 74660 & 36770 & 54900 & 50230 & 54460 & 43060 & 37820 & 74460 & 61030 & 70960 & 69740 & 71500 & 60440 & 53490 \\
\hline SE & 1260 & 1574 & 1557 & 794 & 1159 & 1064 & 1150 & 919 & 814 & 1553 & 1281 & 1483 & 1454 & 1490 & 1270 & 1129 \\
\hline U & 2580 & 3090 & 2871 & 1192 & 18078 & 12573 & 6204 & 4557 & 1380 & 15043 & 2266 & 3500 & 8050 & 6050 & 2103 & 3505 \\
\hline SE & 122 & 135 & 124 & 113 & 391 & 288 & 173 & 151 & 113 & 332 & 119 & 139 & 207 & 150 & 118 & 139 \\
\hline $\mathrm{Pb}$ & 1794 & 2397 & 3012 & 1448 & 3480 & 2797 & 1975 & 1514 & 1154 & 3312 & 1797 & 2195 & 2320 & 2160 & 1783 & 1555 \\
\hline$S E$ & 97 & 111 & 117 & 95 & 122 & 115 & 98 & 95 & 93 & 120 & 97 & 100 & 102 & 100 & 97 & 95 \\
\hline $\begin{array}{l}\text { Age } \\
(\mathrm{Ma})\end{array}$ & 587 & 630 & 790 & 786 & 673 & 675 & 586 & 580 & 605 & 594 & 583 & 591 & 537 & 527 & 588 & 533 \\
\hline SE & 33 & 31 & 26 & 47 & 25 & 28 & 30 & 37 & 49 & 23 & 33 & 29 & 21 & 22 & 33 & 33 \\
\hline
\end{tabular}


Tabela 2

\begin{tabular}{|c|c|c|c|c|c|c|c|c|c|c|c|c|c|}
\hline \multirow{3}{*}{$\begin{array}{l}\text { Sample } \\
\text { Grain } \\
\text { Spot }\end{array}$} & \multirow{3}{*}{$\begin{array}{r}\text { EMSO11B } \\
1 \\
9 \\
\end{array}$} & & \multicolumn{3}{|c|}{$E 7 \& 8$} & \multicolumn{3}{|c|}{$E M-025$} & \multicolumn{5}{|c|}{$E M-017$} \\
\hline & & & \multirow{2}{*}{$\begin{array}{l}2 \\
1 \\
\end{array}$} & \multirow{2}{*}{$\begin{array}{l}1 \\
2 \\
\end{array}$} & \multirow[b]{2}{*}{7} & \multirow{2}{*}{$\begin{array}{l}2 \\
4 \\
\end{array}$} & \multirow{2}{*}{$\begin{array}{r}1 \\
2 \\
\end{array}$} & \multirow[b]{2}{*}{3} & \multirow{2}{*}{$\begin{array}{r}4 \\
4 \\
\end{array}$} & \multicolumn{3}{|c|}{2} & \multirow[b]{2}{*}{$7, \mathrm{i}$} \\
\hline & & 4 & & & & & & & & 5 & $4, r$ & $1, r$ & \\
\hline $\mathrm{SiO}_{2}$ & 0.23 & 0.19 & 0.33 & 0.26 & 0.65 & 0.43 & 0.97 & 1.01 & 0.36 & 0.60 & 0.71 & 0.40 & 0.68 \\
\hline $\mathrm{ThO}_{2}$ & 0.16 & 0.20 & 0.16 & 0.08 & 0.13 & 0.14 & 0.99 & 1.11 & 0.36 & 0.59 & 0.80 & 0.53 & 0.69 \\
\hline $\mathrm{UO}_{2}$ & 1.21 & 0.94 & 1.76 & 1.92 & 2.91 & 2.35 & 3.30 & 3.50 & 1.64 & 2.57 & 2.38 & 1.26 & 2.07 \\
\hline $\mathrm{Al}_{2} \mathrm{O}_{3}$ & 0.00 & 0.00 & 0.00 & 0.00 & 0.03 & 0.10 & 0.00 & 0.00 & 0.00 & 0.00 & 0.00 & 0.00 & 0.00 \\
\hline $\mathrm{La}_{2} \mathrm{O}_{3}$ & 0.00 & 0.00 & 0.00 & 0.00 & 0.00 & 0.00 & 0.00 & 0.00 & 0.00 & 0.00 & 0.00 & 0.00 & 0.00 \\
\hline $\mathrm{Ce}_{2} \mathrm{O}_{3}$ & 0.06 & 0.13 & 0.09 & 0.08 & 0.14 & 0.09 & 0.11 & 0.13 & 0.08 & 0.09 & 0.08 & 0.09 & 0.12 \\
\hline $\mathrm{Pr}_{2} \mathrm{O}_{3}$ & 0.00 & 0.00 & 0.00 & 0.00 & 0.00 & 0.00 & 0.09 & 0.07 & 0.00 & 0.00 & 0.00 & 0.00 & 0.00 \\
\hline $\mathrm{Nd}_{2} \mathrm{O}_{3}$ & 0.42 & 0.46 & 0.45 & 0.38 & 0.45 & 0.41 & 0.42 & 0.44 & 0.40 & 0.40 & 0.30 & 0.27 & 0.33 \\
\hline $\mathrm{Sm}_{2} \mathrm{O}_{3}$ & 0.61 & 0.59 & 0.57 & 0.74 & 0.82 & 0.81 & 0.54 & 0.53 & 0.58 & 0.64 & 0.46 & 0.40 & 0.41 \\
\hline $\mathrm{Gd}_{2} \mathrm{O}_{3}$ & 2.08 & 2.22 & 2.13 & 2.95 & 2.99 & 2.97 & 1.85 & 1.81 & 1.96 & 2.05 & 1.67 & 1.55 & 1.59 \\
\hline $\mathrm{Tb}_{2} \mathrm{O}_{3}$ & 0.58 & 0.58 & 0.64 & 0.89 & 0.87 & 0.84 & 0.54 & 0.54 & 0.60 & 0.56 & 0.49 & 0.44 & 0.51 \\
\hline $\mathrm{Dy}_{2} \mathrm{O}_{3}$ & 5.27 & 5.50 & 5.44 & 6.33 & 6.33 & 6.34 & 4.85 & 4.83 & 5.22 & 5.11 & 4.63 & 4.49 & 4.45 \\
\hline $\mathrm{HO}_{2} \mathrm{O}_{3}$ & 1.24 & 1.40 & 1.39 & 1.27 & 1.22 & 1.10 & 1.29 & 1.23 & 1.35 & 1.32 & 1.16 & 1.26 & 1.23 \\
\hline $\mathrm{Er}_{2} \mathrm{O}_{3}$ & 4.45 & 4.36 & 3.98 & 3.39 & 3.33 & 3.27 & 4.07 & 4.17 & 4.01 & 4.04 & 4.24 & 4.36 & 4.44 \\
\hline $\mathrm{Tm}_{2} \mathrm{O}_{3}(\mathrm{c})$ & 0.69 & 0.72 & 0.58 & 0.51 & 0.51 & 0.49 & 0.64 & 0.65 & 0.64 & 0.65 & 0.62 & 0.67 & 0.67 \\
\hline $\mathrm{Yb}_{2} \mathrm{O}_{3}$ & 4.41 & 4.94 & 3.58 & 3.25 & 3.21 & 3.08 & 4.23 & 4.20 & 4.29 & 4.37 & 3.81 & 4.25 & 4.22 \\
\hline $\mathrm{Lu}_{2} \mathrm{O}_{3}$ & 0.84 & 0.86 & 0.74 & 0.56 & 0.74 & 0.54 & 0.74 & 0.64 & 0.73 & 0.71 & 0.77 & 0.67 & 0.70 \\
\hline $\mathrm{Y}_{2} \mathrm{O}_{3}$ & 41.39 & 41.42 & 42.27 & 41.64 & 39.68 & 39.75 & 41.11 & 40.87 & 42.74 & 41.84 & 42.62 & 43.43 & 42.83 \\
\hline $\mathrm{FeO}$ & 0.02 & 0.00 & 0.00 & 0.02 & 0.02 & 0.67 & 0.00 & 0.02 & 0.24 & 0.20 & 0.07 & 0.05 & 0.05 \\
\hline $\mathrm{CaO}$ & 0.08 & 0.07 & 0.09 & 0.20 & 0.39 & 0.42 & 0.08 & 0.08 & 0.06 & 0.12 & 0.26 & 0.03 & 0.08 \\
\hline $\mathrm{PbO}$ & 0.15 & 0.10 & 0.20 & 0.18 & 0.29 & 0.24 & 0.31 & 0.32 & 0.15 & 0.23 & 0.22 & 0.12 & 0.17 \\
\hline $\mathrm{P}_{2} \mathrm{O}_{5}$ & 34.75 & 34.67 & 34.78 & 34.74 & 34.34 & 34.37 & 33.74 & 33.38 & 34.90 & 34.30 & 33.90 & 34.60 & 34.40 \\
\hline Total & 98.65 & 99.34 & 99.20 & 99.39 & 99.05 & 98.38 & 99.86 & 99.51 & 100.31 & 100.38 & 99.16 & 98.87 & 99.63 \\
\hline \multicolumn{14}{|c|}{ Age-determining elements (ppm), individual spot ages, and standard errors ( $95 \%$ confidence interval) } \\
\hline Th & 1440 & 1750 & 1440 & 660 & 1120 & 1190 & 8730 & 9710 & 3200 & 5180 & 7020 & 4700 & 6050 \\
\hline SE & 153 & 164 & 153 & 151 & 152 & 152 & 258 & 272 & 172 & 199 & 228 & 194 & 217 \\
\hline$U$ & 10683 & 8260 & 15493 & $\{6922$ & 25627 & 20676 & 29078 & 30846 & 14413 & 22629 & 20968 & 11105 & 18250 \\
\hline$S E$ & 255 & 210 & 344 & 370 & 540 & 443 & 609 & 646 & 325 & 483 & 449 & 263 & 395 \\
\hline $\mathrm{Pb}$ & 1360 & 1020 & 1870 & 1690 & 2700 & 2200 & 2850 & 2929 & 1341 & 2160 & 2000 & 1110 & 1550 \\
\hline SE & 123 & 122 & 126 & 125 & 141 & 128 & 142 & 143 & 123 & 128 & 126 & 122 & 124 \\
\hline Age (Ma) & 808 & 770 & 778 & 662 & 695 & 699 & 606 & 586 & 589 & 602 & 585 & 598 & 525 \\
\hline SE & 65 & 83 & 46 & 48 & 36 & 40 & 31 & 29 & 52 & 35 & 37 & 63 & 41 \\
\hline
\end{tabular}




\title{
CAPÍTULO IV
}

\author{
Mecanismos de substituição de monazita e xenotima por coronas de \\ apatita-torita-allanita-epidoto em rochas ortognáissicas e graniticas do \\ Terreno Embu (SE do Brasil) e implicações: evidências texturais e
} químicas

RESUMO

Coronas constituídas por zonas mais ou menos concéntricas de apatita + torita, envolvidas por allanita e estas últimas por epidoto, são bem conhecidas e se formam tipicamente como mantos que substituem parcialmente cristais de monazita primários em rochas graníticas e leucossomas de migmatitos submetidos a metamorfismo em facies anfibolito ou a transformações deutéricas/hidrotermais em certas rochas graníticas. Coronas deste tipo manteando monazita e também xenotima, estas últimas ainda não conhecidas em literatura, são feições comuns em rochas ortognássicas de composições tonalíticas a granodioriticas e monzogranitos intrusivos sintectônicos de idades neoproteozóicas que afloram no Terreno Embu, Estado de São Paulo, SE do Brasil.

Evidências micro-estruturais e texturais em imagens BSE, mapas composicionais e dados químicos pontuais obtidos com EPMA para as fases minerais envolvidas indicam que as reações de substituição decorreram da interação destes minerais com fluídos metamórficos e/ou deutéricos que forneceram $\mathrm{Ca}, \mathrm{Al}, \mathrm{Fe}$, Si e voláteis $\left(\mathrm{F}, \mathrm{H}_{2} \mathrm{O}\right)$. A zona interna de apatita, contendo inclusões diminutas de torita, pseudomorfoseia os cristais originais de monazita sugerindo que a 
apatita aproveitou o arcabouço estrutural $(\mathrm{P}, \mathrm{Si}) \mathrm{O}_{4}$ da estrutura original. Os RRE foram lixiviados para fora da zona da apatita formada e, em combinação com $\mathrm{Ca}, \mathrm{Al}, \mathrm{Fe}$, Si e voláteis presentes nos fluídos intersticiais, precipitaram sob a forma de allanita e epidoto. A substituição da xenotima envolve, pelo menos em parte, a formação de uma segunda geração de xenotima, rica em inclusões de torita, a qual é substituida por apatita que, por sua vez é envolvida por allanita e epidoto. Ao contrário das coronas sobre monazita, a zona da apatita nas coronas sobre xenotima é ocasionalmente constituida por agregados de cristais iso-orientados. Os dados químicos e os volumes envolvidos das fases sugerem, no caso da monazita, que as coronas podem ter evoluido como um sistema aproximadamente fechado no que se refere aos elementos principais que a constituem (Th, REE, P), entretanto, a mesma interpretação não pode ser sustentada no caso dos sistemas coroníticos com xenotima e quantidades significativas de LREE devem ter sido fornecidas pelos fluidos, enquanto $Y e$, possivelmente, HREE foram liberados.

As micro-estruturas (contatos bruscos, com figuras de corrosão, restos de monazita e/ou xenotima irregularmente distribuidos na zona da apatita, ausência de perfís claros de difusão) favorecem em ambos os casos reações de substituição controladas por processos de dissolução parcial (com precipitação de uma geração secundária no caso de xenotima), acompanhada pela cristalização, em parte simultânea, das fases que constituem os mantos. A morfologia das coronas nos ortognaisses, sem um zona anelar típica de apatita, sugere que coronas regulares e centradas como as observadas nos granitos são menos estáveis e tendem a se reorganizar internamente sob condições térmicas e cinéticas adequadas.

Os contatos entre a monazita ou xenotima reliquiares e a zona adjacente da apatita são bruscos e as composições químicas das fases primárias são preservadas, mesmo nas zonas próximas aos contatos. As idades químicas $\mathrm{Th}-\mathrm{U}-\mathrm{Pb}_{\mathrm{T}}$ obtidas para cristais e/ou restos preservados são representativas da idade de cristalização das fases primárias preservadas metaestavelmente no sistema coronítico. As evidências obtidas no caso de coronas sobre xenotima indicam significativa mobilidade de RRE e $Y$ para dentro e para fora das coronas e interpretações petrológicas sustentadas na imobilidade destes elementos merecem alguma cautela.

As coronas desenvolvidas nos ortognaisses estão associadas a ambientes de fácies anfibolito porém não é claro se ligado a eventos de metamorfismo regional ou a expresssivas 
zonas de cizalhamento. No caso dos granitos sin-tectônicos, as estruturas coroníticas refletem a remobilização de fluídos associada a movimentos transcorrentes ao longo de zonas de cisalhamento regionais, que condicionaram a colocação dos plutons e também os deformaram e parcialmente e recristalizaram, em condições mais brandas, compativeis com o facies xistos verdes.

INTRODUÇÃO

A mineralogia e petrologia dos fosfatos de $R E E+Y$ monazita e xenotima têm sido objeto de inúmeros estudos na última década. A monazita $\left[(\mathrm{Ce}, \mathrm{La}, \mathrm{Nd}, \mathrm{Th}) \mathrm{PO}_{4}\right]$ e a xenotima $\left[(\mathrm{Y}, \mathrm{HREE}) \mathrm{PO}_{4}\right]$ ocorrem em granitos moderada a fortemente peraluminosos, peralcalinos (xenotima) e metapelitos de médio a alto grau metamórfico em quantidades bem subordinadas mas são de fundamental importância porque incorporam a grande maioria dos elementos terras raras (REE) presentes na rocha hospedeira e, portanto, controlam a sua distruição nos processos petrológicos associados à diferenciação e evolução da crosta continental (e.g. Bea 1996, Franz et al. 1996, Chang et al. 1998). Estes minerais apresentam campo de estabilidade amplo e são estáveis sob condições diagenéticas (xenotima), hidrotermais, magmáticas e metamórficas diversas e a sua importância para geocronologia de alta resolução e geotermometria tem se revelado crescente (Suzuki e Adachi 1991, Montel et al. 1996, Gratz e Heinrich, 1998, Pyle et al. 2001, Jercinovic et al. 2005, Hethrington et al. 2008, Martins et al., no prelo, Vlach submetido e referências citadas). Adicionalmente, a aplicação da monazita como material fixador de nuclídeos radioativos provenientes de rejeitos nucleares tem sido intensamente investigada e se mostrado muito promissora (e.g. Oelkers e Montel 2008).

O interesse no conhecimento da estabilidade deste minerais nos diferentes ambientes em que ocorrem tem motivado investigação crescente. Os mecanismos de alteração hidrotermal de monazita em rochas graníticas foram abordados por Poitrasson et al. (1996) e Townsend et al. (2000). As reações de formação e/ou quebra envolvendo monazita e allanita em ambientes metamórficos envolvendo rochas para- e orto-derivadas são discutidos em Bingen et al. (1996), Finger et al. (1998), Bingen e van Breemen (1998), Förster et al. (2002) e Wing et al. (2003) entre 
diversos outros. A substituição de monazita, estável em codições de médio a alto grau em rochas metapeliticas, por apatita e allanita em condições de baixo grau jé é bem conhecida na literatura (e.g. Lanzirotti e Hanson 1996). A geração de coronas de substituição constituídas por apatita + allanita + epidoto sobre monazita em rochas graniticas submetidas a metamorfismo regional em fácies anfibolito foi tratada com detalhes por Finger et al. (1998). Claeson (2002) discute a substituição parcial de monazita por apatita, allanita e torita em leucotonalitos metaluminosos, associada a processos deutéricos e/ou hidrotermais.

No presente trabalho documenta-se a ocorrência de coronas de apatita + allanita + epidoto sobre monazita e coronas similares sobre xenotima, ainda não reportadas em literatura, em diferentes situações geológicas associadas à evolução do magmatismo granítico do Terreno Embu, Leste do Estado de São Paulo, SE do Brasil. São apresentados dados de natureza textural e química para sistemas coroníticos centrados em monazita e xenotima presentes em ortognaisses tonalíticos mais antigos e granitos sin-tectônicos intrusivos jovens, ambos de idades neoproterozóicas, e discutidos possiveis mecanismos para a geração e desenvolvimento destes sistemas em ambientes metamórficos e pós-magmáticos. Evidências para a mobilidade dos elementos envolvidos nas reações de formação das coronas nestes ambientes e implicações geocronológicas e petrológicas são enfatizadas.

\section{SITUAÇÃO GEOLÓGICA E OCORRÊNCIA DE CORONAS DE SUBSTITUIÇÃO EM MONAZITA E XENOTIMA}

O Terreno Embu (Hasui 1975, Campos Neto 2000, Heilbron et al. 2004) aflora na região Leste do Estado de São Paulo e faz parte do ramo norte do Sistema Orogênico Mantiqueira (Figura 1). Este sistema está orientado NNE e foi formado através de episódios discretos de colagem de terrenos remanescentes do super-continente Rodínia entre 610 e $530 \mathrm{Ma}$ e junção dos cratons Kalahari, São Francisco-Congo e Rio da Plata (Brito Neves et al. 1999, Campos Neto 2000). O Terreno Embú é composto por xistos e gnaisses de médio a alto grau metamórfico, migmatitos, e quantidades subordinadas de ortognaisses, rochas meta-vulcânicas e cálciosilicáticas. A qualidade das exposições neste terreno não é boa, devido à alteração intempérica e a ocupação humana nas vizinhanças da Grande São Paulo. Informações geológicas mais 
completas estão disponíveis para a área a Leste da cidade de São Paulo, onde quartzitos, metapelitos rítmicos e uma seqüência metavulcano-sedimentar com grau metamórfico aumentando de xistos verdes para anfibolito em direção NW cobre rochas migmatíticas do embasamento mais antigo (Fernandes et al. 1990). Evidências de fusão parcial limitada aparecem em gnaisses quartzo-feldspáticos. Dados geotermobarométricos sugerem que o metamorfismo atingiu pressões e temperaturas da ordem de $5-6$ kbar e $680-730^{\circ} \mathrm{C}$ respectivamente (Vieira et. al.1990, Augusto e Vlach dados inéditos).

O magmatismo granitico no Terreno Embú ainda não é completamente conhecido (cf. Janasi et al. 2003, Vlach submetido). Os dados geocronológicos sugerem que rochas graníticas se colocaram em três períodos no neoproterozóico. Um magmatismo precoce é constituido por biotita-tonalitos e -granodioritos colocados proximamente ao pico metamórfico e à fase principal de deformação das encaixantes (Fernandes et al. 1990) há ca. 790-810 Ma (Cordani et al. 2002, Vlach submetido) e posteriormente convertidos em ortognaisses do fácies anfibolito. Monzogranitos porfiriticos a inequigranulares, com foliação de fluxo e de estado sólido, que constituem o Batólito Quebra Cangalha, orientado NNE, possivelmente se colocaram há ca. 650680 Ma. Plútons sin-tectônicos mais jovens e de dimensões mais reduzidas (e.g. Mogi das Cruzes, Mauá), constituídos por biotita- e muscovita-biotita monzogranitos, se colocaram ao longo de zonas de cizalhamento NNE em torno de $590 \mathrm{Ma}$. Na zona limítrofe entre os terrenos Embu e Serra do Mar, um evento mais jovem, com idades em torno de 520-540 Ma, encontra-se registrado em monazita poligenética de monzogranito do Batólito Natividade da Serra (Figura 1), colocado também há ca. $590 \mathrm{Ma}$. Acredita-se este último evento esteja associado à reativação de zonas de cizalhamento NNE por ocasião da Orogênese Cabo Frio (e.g. Schmidt et al. 1999, Campos Neto 2000).

A monazita é acessório típico, presente na maioria dos para- e orto-gnaisses e dos granitos intrusivos que afloram neste terreno, xenotima ocorre mais esporadicamente e sempre em quantidades subordinadas mas também é relativamente comum, particularmente nos facies mais diferenciados dos ortognaisses e dos granitos. Na maioria das amostras examinadas ao microscópio petrográfico encontram-se em maior ou menor grau evidências de desequilíbrios em monazita e/ou xenotima marcadas por vezes por feições de corrosão e, mais freqüentemente, por 
feições de substiuição parcial ou total por uma assembléia constituída por apatita, allanita, epidoto e torita, que tipicamente aparecem formando coronas (CAAE) com morfologias variadas, ora bem finas e regulares, ora mais irregulares, manteando cristais corroídos de monazita ou xenotima. Em raros casos foram observados diminutos agregados de allanita + epidoto e apatita possivelmente associados a substiuição total de monazita e/ou xenotima.

\section{AMOSTRAS ESTUDADAS E MÉTODOS ANALÍTICOS}

Foram selecionadas para este estudo três amostras de rochas graniticas do Terreno Embu que representam diferentes situações geológicas e/ou apresentam diferentes tipos de sistemas coroníticos. A localização das amostras é indicada na Figura 1.

A primeira amostra corresponde a um ortognaisse de composição tonalítica com estrutura fortemente orientada e granulação grossa. A datação quimica Th-U- $\mathrm{Pb}_{\mathrm{T}}$ em monazita revelou idades, interpretadas como de colocação e cristalização, próximas a $790 \mathrm{Ma}$ (Vlach submetido). A foliação é marcada pelos agregados de cristais de plagioclásio bem geminados segundo as Lei da Albita, combinada ou não com a Lei de Carlsbad, e quartzo recristalizado, contornados por cristais bem desenvolvidos de biotita. O zonamento concêntrico, por vezes oscilatório, no intervalo da andesina observado em cristais tabulares de plagioclásio, é a principal textura reliquiar observada. A biotita, com pleocroísmo em tons de vermelho a amarelo pálido é o máfico típico a chega a constituir até $20 \%$ modal da rocha. Os minerais acessórios típicos são zircão formando prismas curtos idiomórficos e bem desenvolvidos, apatita, allanita, epidoto e torita.Monazita aparece apenas como fase reliquiar nas CAAE. Muscovita mais tardia aparece substituindo alguma biotita e o plagioclásio apresenta leve saussuritização.

As duas outras amostras analisadas são representativas dos plutons Mauá e Mogi das Cruzes e correspondem, respectivamente, a biotita e muscovita-biotita monzogranitos holo- a leucocráticos com estruturas maciças ou levemente orientadas. A colocação destes plutons está associada a extensas zonas de transcorrência direcionadas NNE e ocorreu há ca. 590 Ma (Janasi et al. 2003, Vlach submetido). Não existem evidências marcadas de eventos metamórficos 
regionais posteriores a colocação destes plutons, a menos de reativações mais recentes das zonas de cizalhamento, em parte associada à Orogênese Cabo Frio (ca. 520-540 Ma, Schmidt et al. 1999, Vlach submetido). A biotita apresenta tonalidades pleocroísmo em castanho avermelhado (Mogi das Cruzes) a castanho levemente esverdeado (Mauá). Os minerais acessórios são similares mas incluem também alguma turmalina. O granito Mogi das Cruzes apresenta adicionalmente xenotima, enquanto o Granito Mauá apresenta titanita tardia.

Imagens de eletrons retro-espalhados (BSE) em modo composicional, mapas de raios $X$ composicionais (WDS e EDS), análises WDS pontuais quantitativas para monazita, allanita, epidoto e apatita e análises qualitativas EDS para torita foram obtidas em seções delgadas polidas cobertas com fina película de C (ca. $250 \mathrm{~nm}$ ) no Laboratório de Microssonda Eletrônica do Instituto de Geociências da Universidade de São Paulo. O laboratório conta com um equipamento JEOL-JXA8600 provido de 05 espectrômetros WDS, 01 espectrômetro EDS e um sistema de automação Voyager 4.3 da Thermo-Noran. Mapas composicionais para Si $(K \alpha), A l(K \alpha), F e(K \alpha)$, Ce $(L \alpha)$, Dy $(L \alpha)$, Ca $(K \alpha), P(K \alpha)$ e Th $(M \alpha)$ foram obtidos por varredura do feixe eletrônico (dot mapping) sob condições de $20 \mathrm{kV}$ e $100 \mathrm{nA}$ para a voltagem de aceleração da coluna e corrente do feixe eletrônico, com resolução de 256 vs 256 pixéis e tempo de integração de $0.1 \mathrm{~s} /$ pixel. As imagens foram obtidas para os menores sistemas coroníticos encontrados, analisados sob magnificações superiores a 700, para minimizar os efeitos de defocalização (e.g. Goldstein et al. 1992) mas, ainda assim, a defocalização e a não correção para a radiação de fundo e para os efeitos de matriz dão significado semi-quantitativo para estas imagens.

As análises quantitativas pontuais foram efetuadas sob condições de $15 \mathrm{kV}, 300$ nA e 2-4 $\mu \mathrm{m}$ e $20 \mathrm{kV}, 50 \mathrm{nA}, 5 \mu \mathrm{m}$ para a voltagem de aceleração da coluna, corrente e diâmetro do feixe eletrônico para monazita e allanita, epidoto e apatita, respectivamente. No caso de xenotima, a corrente do feixe foi menor $(200 \mathrm{nA})$ e o diâmetro maior $(5 \mu \mathrm{m})$. Os procedimentos analíticos e de tratamento de dados adotados no laboratório para monazita e allanita/epidoto são encontrados em detalhes em Vlach (submetido) e Vlach e Gualda (2007), protocolos para análises de xenotima e apatita serão publicados em breve. As correções para os efeitos de matriz foram efetuadas com o programa PROZA (e.g. Bastin e Heilligiers 1990) disponivel no sistema Voyager. Os teores de Tm em xenotima foram estimados por interpolação, considerando-se a média geométrica dos valores 
normalizados obtidos para $\mathrm{Er}$ e $\mathrm{Yb}$. Os cristais de torita presentes nas CAAE apresentam sempre dimensões diminutas, em geral inferiores a $10 \mu \mathrm{m}$, inviabilizando análises quantitativas adequadas com WDS e este mineral foi caracterizado qualitativamente com EDS. As proporções catiônicas foram obtidas com o programa MinCal (Gualda e Vlach inédito) e as proporções em volume das fases minerais envolvidas nas coronas foram estimadas com base nas imagens BSE.

\section{REsultados}

\section{Relações texturais de substiuição de monazita e xenotima}

Os aspectos texturais mais típicos envolvendo os minerais primários e secundários presentes nas coronas das amostras estudadas são ilustrados em imagens BSE na Figura 2 e em imagens BSE e mapas composicionais para os elementos químicos mais relevantes envolvidos na Figura 3.

A monazita e xenotima límpidas e idiomórficas, sem evidências de transformações póscristalização aparecem apenas como inclusões preservadas, notadamente em quartzo, e somente nos granitos intrusivos. Nos demais casos, os cristais de monazita e xenotima que ocorrem isolados, intersticiais ou como inclusões em micas encontram-se em típica situação de desequilibro. No ortognaisse EMS-010 a monazita nunca ocorre isolada, apenas nos sistemas coroníticos. A monazita presente nos granitos Mauá e Mogi das Cruzes apresenta sempre coronas de substituição desenvolvidas em maior ou menor grau. Os cristais de xenotima da amostra EM-025A (Granito Mogi das Cruzes), mesmo os mais idiomórficos com coronas desenvolvidas de forma muito incipiente, quando observados em detalhe apresentam zonas marginais muito finas, micrométricas, de uma geração posterior de xenotima que substitui parcialmente a geração primária.

Nos ortognaisses e granitos do Terreno Embu em que monazita e xenotima coexistem, observam-se freqüentemente contatos mútuos retos sugerindo cristalização em equilíbrio. A presença de inclusões corroídas de monazita em xenotima, mas nunca de xenotima em monazita, 
na amostra EM-025A é uma evidência de que estes minerais se formaram em parte simultaneamente, a xenotima iniciando a cristalização um pouco depois. Dados geotermométricos baseados no conteúdo em $Y$ de monazita em equilíbrio com xenotima e na partição de $G d$ entre monazita e xenotima para esta amostra (e.g. Gratz e Heinrich 1998), são consistentes com cristalização em ambientes magmáticos $\left(700-750^{\circ} \mathrm{C}\right.$, Vlach dados inéditos).

Merece ser destacado que a monazita presente em alguns granitos do Terreno Embu apresenta figuras de corrosão típicas, como as ilustradas para uma amostra do Granito Quebra Cangalha (EM7\&8, cf. localização na Figura 1) e para a amostra estudada do granito Mauá. No primeiro caso, coronas de substituição são observadas em alguns cristais corroídos, mas não em outros. No segundo caso, as coronas observadas sobre contatos corroídos são similares quanto a constituição e espessura às observadas sobre faces cristalinas. Estas observações, aliadas às inferências extraidas para geração das coronas discutidas a seguir, sugerem que estes processos de corrosão não estão vinculados com o desenvolvimento das coronas, mas sim representam fenômenos anteriores relacionados à evoluçăo magmática. No caso da amostra EM-014A estudada e também de amostras do Batólito Quebra Cangalha, os padrões regulares de zonamento químico e as idades $\mathrm{Th} U-\mathrm{Pb}_{\mathrm{T}}$ iguais às idades químicas obtidas para cristais preservados e determinações isotópicas indicam natureza magmática cogenética para os cristais corroídos, possivelmente desestabilizados por variações locais de parâmetros intensivos e/ou extensivos de geração e evolução magmática.

\section{Coronas centradas em monazita}

A morfologia dos sistemas coroníticos presentes nos granitos Mauá e Mogi das Cruzes é muito similar as descritas em literatura por Finger et al. (1998) e Claeson (2002). Os relíctos de monazita presentes nas regiões centrais das coronas apresentam zonamentos composicionais de tipo concêntrico, em geral oscilatório, ou ainda em setores, entretanto estas características não são acentudas nas imagens uma vez que os contrastes foram ajustados para ressaltar o sistema coronítico como um todo. Os contornos da monazita são muito variáveis: ora são subarredondados e mais regulares, ora são bem irregulares, com evidências de corrosão ou 
ainda, notadamente quando as coronas encontram-se em estado incipiente de desenvolvimento, perfeitamente idiomórficos.

Nos mantos do sistema coronítico, a zona interna é relativamente homogênea e está constituída principalmente por apatita que mostra contatos abruptos com a monazita manteada, por vezes levemente interpenetados. As bordas externas da zona da apatita são muito regulares e parecem mimetizar as bordas externas idiomórficas dos cristais originais de monazita (ver também Finger et al. 1998). Por vezes, diminutos relictos corroídos de monazita aparecem ainda preservados na zona da apatita. Uma característica também típica desta zona é a presença de inclusões em quantidades variáveis, mas sempre significativas, de torita, na forma de inclusões diminutas, xenomórficas, goticulares a alongadas e com contornos subarredondados. No caso das coronas observadas na amostra do ortognaisse EMS-010 a situação é bem contrastada entretanto: a zona da apatita é tipicamente descontínua e irregular, observando-se que a monazita encontra-se parcialmente em contato direto com a zona da allanita, descrita a seguir. Adicionalmente, os contatos externos da apatita parecem ser definidos por faces próprias, antes que por faces herdadas da monazita original e a torita parece ter preferência por se concentrar nas zonas de contato entre apatita e monazita. As estimativas médias obtidas para volume considerando todo o intercrescimento indicam quantidades entre 12 e $26 \%$ e entre $17-29$ e 20 $23 \%$ de monazita e apatita (+torita) nas amostras de ortognaisse e granitos respectivamente.

As zonas de allanita e do epidoto apresentam morfologia bem diversificada nos granitos. Em alguns dos mantos são observadas zonas finas, mas muito bem marcadas de allanita, sempre localizadas na região interna, circundadas por uma zona mais expressiva de epidoto externa. Nestes casos a zona da allanita (ca. $18 \%$ vol.) é relativamente mais rica em Fe e pobre em Al e Ca quando comparada com a zona do epidoto (ca. $45 \%$ vol.). Os contatos da zona da allanita com a zona da apatita são abruptos e regulares e com a zona do epidoto são, embora também abruptos, finamente interpenetrados. Em outros sistemas coroniticos, não aparecem zonas contrastadas e bem definidas de allanita e epidoto, e sim uma zona híbrida caracterizada por allanita finanemente intercrescida com epidoto que ocupam volumes relativos de ca. $50 \%$. É interessante observar que no caso do granito Mogi das Cruzes, estes mantos híbridos de allanita e epidoto não se restringem ao sistema coronítico centrado em monazita apenas e aparecem 
envolvendo um cristal prismático de zircão, parcialmente incluido na monazita original. Nesta mesma amostra, em algumas áreas diminutas da zona híbrida, os mapas composicionais revelam baixas emissões de $\mathrm{Ca}, \mathrm{P}$ e $\mathrm{Ce}$, altas de $\mathrm{Si}$ e $\mathrm{Al}$ e intermediárias a altas de $\mathrm{Fe}$, incompatíveis com o quimismo das fases constituintes da corona. Possivelmente trate-se de um filossilicato. No ortognaisse EMS-010, a distinção entre as zonas de allanita e epidoto não é tão clara nas imagens BSE, mas sugere que a primeira seja dominante, observando-se que os mantos são bem mais homogêneos e apenas nos seus limites externos define-se uma zona relativamente pouco espessa com coeficientes de retroespalhamento significativamente inferiores mais típicos de epidoto. Em conjunto, estas zonas ocupam cerca de $62 \%$ em vol, do sistema coronítico.

Considerando apenas os minerais presentes nas coronas, os volumes de apatita ( + torita) e allanita + epidoto são da ordem de 29 e $71 \%$ no ortognaisse e variam entre $24-32$ e $76-68 \%$ nos granitos. No caso do sistema em que ambas as zonas da allanita e do epidoto estão bem definidas (amostra EM-014A) cerca de $22 \%$ da corona está constituída por allanita e $54 \%$ por epidoto. Neste caso, os volumes de epidoto são bem superiores aos equivalentes calculados por Finger et al. (1998) para coronas presentes em monazita do ortognaisse Granatspitz. Entretanto, as proporções médias obtidas para as zonas da apatita e allanita+epidoto são bem similares, sugerindo que esta discrepância deva-se em parte à dificuldade de se estabelecer limites químicos e, portanto, em imagens BSE, precisos entre allanita e epidoto (cf. a seguir).

\section{Coronas centradas em xenotima}

Diversos aspectos distintos e peculiares caracterizam a substituição de xenotima na amostra do granito Mogi das Cruzes, quando comparados com os descritos para monazita, como ilustrados nas Figuras 2 e 3 . Cristais idiomórficos, como o apresentado em duas imagens (Figura 2. E e F), com zonamento composicional oscilatório de natureza indubidavelemente magmática, com inclusões idiomórficas de apatita e corroída de monazita, mostram um fino manto constituído essencialmente por allanita e epidoto que apresenta continuidade em zonas de fraturas e contatos intergranulares entre as fases minerais félsicas da rocha hospedeira. A observação deste cristal sob contraste mais acentuado ressalta uma fina borda externa, irregular, de uma geração mais 
tardia de xenotima, com coeficientes de retroespalhamento menores, contendo diminutas inclusões de apatita em algumas áreas e de torita em outras. Na Figura 21 ilustra-se a situação em que a xenotima primária foi quase que totalmente consumida, restando apenas alguns restos corroídos dentro de apatita contendo diminutas inclusốes de torita, contornada por um manto de allanita e epidoto de dimensões micrométricas. A apatita aparece como cristal único que mantém a forma original do cristal primário de xenotima.

As imagens G e H da Figura 2 são particularmente relevantes para a compreensão dos mecanismos envolvidos nos processos de substituição de xenotima. Na primeira delas observamse dois cristais de xenotima parcialmente substituidos por apatita, que constitui uma zona homogênea contendo número significativo de inclusões diminutas de torita. Mais importante entretando é a verificação de que a zona da apatita faz contato direto com feldspato alcalino e quartzo, faltando a zona externa de allanita e epidoto, que aparece somente em algumas áreas, particularmente associadas a regiões intergranulares da rochas hospedeira. A Figura $\mathrm{H}$ mostra a imagem em detalhe de um destes cristais, sob maior contraste, com zonamento regular e inclusões idiomórficas de apatita. Nota-se claramente uma zona constituída por uma geração tardia de xenotima, com coeficientes de retro-espalhamento menores, que apresenta elevado número de inclusões goticulares a alongadas de torita, por vezes parecendo se distribuir de forma radial em relação a zona primária. Os contatos desta zona são levemente irregulares com a xenotima primária e variam de leve a fortemente irregulares, com típicos contornos de corrosão com a zona externa de apatita. Ambas as morfologias sugerem fortemente a atuação de processos de dissolução e reprecipitação.

Nas imagens da Figura 3 são ilustrados outros aspectos associados a substituição avançada de xenotima por CAAE. Neste exemplo a apatita ( $42 \%$ em volume do sistema total) aparece mais tipicamente como agregados de diversos cristais, os espaços intersticiais estando ocupados preferencialmente por torita contendo quantidades significativas de HREE, como verificado no mapa de distribuição do Dy. Alguns restos corroídos de xenotima (marcados pelo Dy, com ca. $5 \%$ vol.) aparecem nesta zona, bem como diminutas pontuações relativamente ricas em Al que ocupam fraturas ou zonas de contato entre cristais de apatita. As zonas de allanita e epidoto não são contínuas e/ou bem definidas e representam em conjunto, ca. 53 \% vol: Em 
algumas áreas estes minerais aparecem finamente interscrescidos, enquanto que em outras a allanita está ausente, observando-se contatos diretos entre apatita e epidoto ou ainda, como observado no lado oposto do agregado, uma fina zona de allanita envolve apatita, seguida por uma zona de epidoto, mais rica em Ca e Al, que por sua vez está envolvida por uma nova zona de allanita.

As estimativas médias dos volumes, considerando apenas os minerais de alteração que aparecem nas coronas, indicam claramente uma maior participação da apatita nas CAAE centradas com xenotima (ca. $40-50 \%$ ) quando comparadas com as equivalentes em monazita.

\section{Variações composicionais das fases minerais}

Análises quimicas representativas de monazita, xenotima, allanita/epidoto e apatita obtidas para coronas selecionadas em monazita das três amostras estudadas e em xenotima para a amostra EM-025A são apresentadas nas Tabelas 1 e 2. As principais características e variações composicionais são discutidas a seguir. Dados para REE em rocha total disponiveis (Alves A., com. escrita) são apresentados para comparação nos diagramas que ilustram os padrões de distribuição dos REE das fases minerais no caso dos granitos Mauá e Mogi das Cruzes.

\section{Monazita e xenotima primárias}

A monazita presente nas coronas do ortognaisse EMS-010 e do granito EMS-014A contém teores superiores a $85 \%$ na molécula de monazita [(LREE)PO 4 ] e quantidades nos intervalos entre 4.5-8.5, 2.0-5.5 e 1.5-3.0 das moléculas de xenotima $\left[(\mathrm{Y}, \mathrm{HRRE}) \mathrm{PO}_{4}\right]$, huttonita $\left(\mathrm{ThSiO}_{4}\right)$ e brabantita $\left[(\mathrm{Ca}, \mathrm{Th})\left(\mathrm{PO}_{4}\right)_{2}\right]$; as quantidades $\mathrm{REE}+\mathrm{Y}$ não variam significativamente e se situam em geral entre 3.5-3.7 e 3.6-3.7, respectivamente. A monazita do granito apresenta teores em média superiores na molécula de xenotima e em $U$ e inferiores nas moléculas de huttonita e brabantita, bem como em Fe (cf. Tabela 1). Os padrões de REE (Figura 4) são típicos de 
monazita-(Ce), observando-se que o fracionamento entre as LREE e HREE é em média maior na amostra EMS-010, com razões $\mathrm{Ce}_{N} / \gamma_{\mathrm{N}}$ variando entre 40 e 70 (EMS-010) e entre 30 e 50 (EM014A). As razões $S m_{N} / N d_{N}$ são em média superiores na amostra EM-014A. As variações composicionais são melhor marcadas nos cristais do granito, sendo em geral de tipo concentrico, por vezes levemente oscilatório, ou mesmo setorial. As bordas dos cristais, junto as zonas de apatita, são em geral relativamente mais ricas em $P, R R E+Y$ e pobres em Th, $U$ e Si. Estas variações composicionais são comuns em ambientes de cristalização magmática e são condicionadas principalmente pela atuação dos vetores branbantítico, [Ca,(Th,U)][REE]-2, e huttonítico $[(T h, U), S i][P]_{-1}[R E E]_{-1}$ (Förster 1998), além da substituição simples Y[RRE]-1.

As coronas observadas na monazita de primeira geração textural da amostra EM-025A não serão abordadas em detalhe neste trabalho, mas apresenta-se na Tabela 1 duas análises representativas de monazita a título de comparação, uma vez que esta é a única amostra estudada em que monazita e xenotima primárias coexistem. As composições são bem contrastadas quando comparadas com as das demais amostras estudadas, com quantidades significativamente maiores da molécula de xenotima $(9.0-11.0 \%)$ e brabantita $(8.0-9.0 \%)$ e menores de monazita $(79.0-81.0 \%)$ e huttonita $(1.2-2.0 \%)$. As quantidades de $U$ são de 3 a 5 vezes superiores. Os fracionamentos observados nos padrões de RRE na região das LREE e entre as LREE e HREE são também significativamente menores (cf. Tabela 1).

A xenotima desta amostra contém entre 93 e $95 \%$ da molécula [(Y,HRRE)PO 4 , e entre 0.009-0.045, 0.04-0.12, 0.82-0.90 cpfu de Th, $U$ e REE respectivamente. Os padrões de REE (Figura 5) mostram forte fracionamento entre as LREE e HREE e na região das LREE, com razões $\mathrm{Ce}_{\mathrm{N}} / \mathrm{Ho}_{\mathrm{N}}$ inferiores a 0.01 e razões $S \mathrm{~m}_{\mathrm{N}} / \mathrm{Nd}_{\mathrm{N}}$ entre 3.5 e 5.0. Os zonamentos composicionais tipicamente observados são de tipo concêntrico, oscilatório, e se devem principalmente a variações nas abundâncias relativas de $S i, P$, Th, $U$ e $Y$ e HREE, que podem ser adequadamente acomodadas pelo vetor de substituição [Th,U][Si][Y, RRE $]_{-1}[P]_{-1}$ (e.g., Förster 2006). Zonamento setorial é mais raro. 


\section{Allanita e epidoto}

A nomenclatura para os minerais do grupo do epidoto e especialmente o limite entre allanita e epidoto ainda não se encontram bem definidos em literatura. Alguns autores classificam como epidoto os minerais com valores de REE $\leq 0.5 \mathrm{cpfu}$, outros em REE + Th $\leq 0.5 \mathrm{cpfu}$ (e.g. Gieré e Sorensen 2004). Utilizar-se-á aqui o primeiro destes limites.

As composições obtidas para allanita e epidoto das amostras estudadas são projetadas no diagrama $(E T R+Y+T h+S r)$ vs $\mathrm{Al}^{\top}$ de Petrik et al. (1995) na Figura 6 . Os teores em $\mathrm{Al}^{\top}$ variam entre 1.9 e $2.6 \mathrm{cpfu}$, sendo notadamente inferiores para no caso da amostra do granito EMS-014A. As composições de allanita e epidoto das amostras do ortognaisse EMS-010 e granito EM-025A são significativamente mais ricas no componente clinozoizita e os pontos analiticos se distribuem próximos a junção clinozoizita-allanita, enquanto que as análises da amostra EM-14A mostram-se relativamente mais homogêneas e se situam próximas a junção epidoto-allanita, mais perto da allanita. As variações composicionais implícitas neste diagrama são bem acomodadas pelos vetores $[\mathrm{Ca}]\left[\mathrm{Fe}^{3+}\right][\mathrm{REE}]_{-1}\left[\mathrm{Fe}^{2+}\right]_{-1}$ e [Ca][Al] [REE]-1[ $\left[\mathrm{Fe}_{2+}\right]_{-1}$ (e.g. Petríck et al. 1995). As razões $\mathrm{Fe}^{3+} /\left(\mathrm{Fe}^{2+}+\mathrm{Fe}^{3+}\right)$ inferidas (cf. restrições em Vlach e Gualda, 2007) para o granito EM-014A são em média superiores $(0.2-0.5)$ quando comparados aos das duas outras amostras $(<0.3)$, enquanto uma situação inversa é observada para o índice de saturação em alumina $[\mathrm{A} / \mathrm{CNK}=$ $\mathrm{Al}_{2} \mathrm{O}_{3} /\left(\mathrm{Al}_{2} \mathrm{O}_{3}+\mathrm{CaO}+\mathrm{Na}_{2} \mathrm{O}\right)$ em proporções moleculares], que se situa nos intervalos 0.7-0.9 e 0.80.9 , respectivamente. Merece ser também salientado que a allanita presente nas coronas dos granitos intrusivos apresenta quantidades bem mais significativas dos elementos $\mathrm{HFS} \mathrm{TiO}_{2}$ e $\mathrm{ZrO}_{2}$ (até 0.55 e $0.52 \%$ em peso, respectivamente) e razões $\mathrm{Fe}^{\top} /\left(\mathrm{Fe}^{\top}+\mathrm{Al}\right.$ ) mais elevadas quando comparada com a presente no ortognaisse tonalítico.

Os pontos representativos das análises obtidas para a amostra do ortognaisse EMS-010 sugerem um certo contínuo composicional entre epidoto (clinozoizita) e allanita neste diagrama, enquanto que os dados apresentados por Finger et al. (1998) e os nossos dados para allanita e epidoto das coronas da amostra EM-025A, sugerem um intervalo composicional melhor definido entre estes minerais. Um perfil composicional com seis análises para as zonas da allanita e do epidoto do ortognaisse é apresentado na Figura 7 . Os contrastes de número atômico médio 
observados nas imagens BSE sugerem que os pontos 1,2 e 3 correspondam a zona da allanita, de maior expressão nestas coronas, os demais a epidoto. O diagrama mostra que, da zona central para a periferia da corona, $\mathrm{Al}_{2} \mathrm{O}_{3}, \mathrm{CaO}$ e $\mathrm{Y}_{2} \mathrm{O}_{3}$, em parte $\mathrm{UO}_{2}$ aumentam enquanto que os $\mathrm{LREE}$, $\mathrm{ThO}_{2}$ e $\mathrm{FeO}^{\top}$ (menos marcado) diminuem. As variações mais bruscas observadas nas tendências de $\mathrm{Y}_{2} \mathrm{O}_{3}$ e $\mathrm{ThO}_{2}$ marcam bem o limite allanita-epidoto deduzido nas imagens. A exeção do comportamento oposto de $\mathrm{Nd}_{2} \mathrm{O}_{3}$ e $\mathrm{Sm}_{2} \mathrm{O}_{3}$, as tendências observadas para esta corona são similares as descritas por Finger et al. (1998).

As abundâncias de REE+Y variam para allanita e epidoto entre 0.25 e $0.70 \mathrm{cpfu}$. A comparação dos padrões de ETR observados para monazita primária e allanita/epidoto (Figura 4) para as amostras do ortognaisse e do granito EM-014A revelam fracionamentos distintos, as razões $C e_{N} / Y_{N}$ variando nos intervalos 40-70 e 30-50, respectivamente. A comparação das razões $\mathrm{Sm}_{N} / \mathrm{Nd}_{N}$ e $\mathrm{Ce}_{N} / \mathrm{Y}_{\mathrm{N}}$ em monazita e allanita/epidoto mostra que a exeção de três análises do granito, elas variam inversamente e, mais importante, em sentidos contrários: enquanto a monazita do ortognaisse apresenta valores mais baixos e altos para $S m_{N} / N_{N}$ e $C e_{N} / Y_{N}$, respectivamente, a situação inversa é observada no caso do granito (Figura 8). Entretanto, três análises de allanita deste granito mostram diminuição acentuada, particularmente de $\mathrm{Sm}$, que resulta em forte queda nas razões $S m_{N} / N d_{N}$. A allanita e o epidoto presentes nas coronas sobre xenotima no granito EM-025A, são mais ricas em HREE quando comparados com os da amostra A-014A, com fracionamento mais leve entre as LREE e HREE (Figura 5) e razões $C_{N} / Y_{N}$ entre 11 e 30 .

As análises de allanita e epidoto das coronas sobre xenotima da amostra do granito Mogi das Cruzes mostram uma tendência inversa entre as razões $S m_{N} / \mathrm{Nd}_{N}$ e $\mathrm{Fe}^{\top} /\left(\mathrm{Fe}^{\top}+\mathrm{Al}\right)$, uma tendência também destacada quando se analisa o conjunto disponivel de análises para as demais amostras (Figura 8).

\section{Apatita e torita}

A apatita presente nas coronas centradas em monazita é relativamente homogênea e pura, com quantidades de REE $+Y$ inferiores a 0.03 e entre 0.08 e 0.16 cpfu no ortognaisse e no 
granito EM-014A. A apatita nesta última amostra também apresenta quantidades maiores de Si e e Th, que alcançam 0.21 e $0.06 \mathrm{cpfu}$. Os padrões são pouco fracionados, com razões $\mathrm{Ce}_{\mathrm{N}} N_{\mathrm{N}}$ nos intervalos 2-4 e 8-18, respectivamente (Figura 4). A apatita presente nas coronas em xenotima do granito EM-025A (Figura 5) apresenta $0.04<(R R E)^{\top}<0.08$, Th $<0.02$ e Si $<0.15$ cpfu. E tipicamente mais rica em HREE, com razões $\mathrm{Ce}_{\mathrm{N}} / \mathrm{Y}_{\mathrm{N}}$ e $\mathrm{Ce}_{\mathrm{N}} / \mathrm{Gd}_{\mathrm{N}}$ entre 0.0 e 1.5 inferiores a unidade, respectivamente.

Análises quantitativas de torita não foram obtidas devido as dimensões dos cristais presentes. Toritas típicas descritas em literatura apresentam teores relativamente baixos de $(E T R)^{\top}$, inferiores a ca. 7 \% em peso de óxido, embora encontre-se na literatura descrições em que estes teores alcançam 20 \% (e.g., Staatz et al. 1976, Augusto e Vlach, dados inéditos). De acordo com os dados destes autores, a torita parece não incorporar os REE de forma seletiva como a monazita e a xenotima. Espectros qualitativos EDS para cristais de torita das coronas estudadas revelam que este mineral contém quantidades subordinadas de REE e que a torita presente nas coronas centradas em xenotima do granito EM-025A é significativamente mais rica em HREE.

\section{DISCUSSÃo}

\section{Natureza e mecanismos de substituição}

\section{Coronas centradas em monazita}

A cristalização de allanita ou monazita como principal mineral portador de LREE em rochas graníticas está condicionada principalmente à disponibilidade de $\mathrm{Ca}$ no sistema e as relações entre $\mathrm{Ca}$, álcalis e Al que controlam a cristalização de feldspatos e das fases minerais máficas principais coexistentes. Broska et al. (2000) atribuem, por exemplo, a substituição de allanita por 
monazita durante a cristalização magmática de rochas tonalíticas e granodioríticas peraluminosas ao decréscimo em Ca no sistema, pela sua incorporação preferencial em plagioclásio.

A desestabilização da monazita primária nas rochas estudadas e geração das CAAE indica aumento significativo das atividades de $\mathrm{Si}, \mathrm{Al}, \mathrm{Fe}^{\top}, \mathrm{Ca}$ e voláteis no sistema. Estes elementos podem ser liberados pela desestabilização de plagioclásio e biotita primários, ou estarem originalmente presentes como material fluído residual permeando interstícios da rocha hospedeira ou ainda ambos. Finger et al (1998) testaram o balanço químico considerando os volumes e as composições das fases envolvidas no processo de substituição e verificaram que, no que se refere aos elementos principais constituintes de monazita (LREE, $Y, T h, U$ e $P$ ), as abundâncias relativas medidas na monazita primária e nas CAAP são equivalentes, concluindo que estes sistemas coroníticos podem ser bem aproximados para sistemas geoquímicos fechados em relação a eles. Estes resultados, aliados à morfologia tipicamente concêntrica dos sistemas, levaram os autores a interpretar que a cinética de reação foi controlada por mecanismos de difusão dos elementos formadores da monazita para os minerais coroníticos e vice-versa. A difusão dos LREE para fora da estrutura da monazita e a entrada de Ca, Si e voláteis permitiria a cristalização da zona adjacente de apatita, com alguma torita, e a combinação dos LREE com soluções externas contendo $\mathrm{Si}, \mathrm{Al}, \mathrm{Ca}, \mathrm{Fe}$ e voláteis propiciaria a formação de allanita e epidoto, a primeira substituinto epidoto previamente formado nas zonas internas devido a maior disponibilidade de LREE nestas, uma vez que as taxas de difusão destes elementos são baixas. O Y cedido pela monazita, devido ao seu menor raio e compatibilidade nas estruturas de allanita e epidoto tenderia a se concentrar nas porções mais externas da zona do epidoto e, portanto, da zona coronítica. Em princípio, uma conclusão similar poderia ser alinhavada para os sistemas coroníticos estudados, particularmente no caso dos granitos EM-014A e EM-025, considerando a semelhança morfológica dos sistemas coroníticos, as composições e os volumes das fases, similares aos estimados pelos autores $(24,33,43 \%$ vol. de apatita+torita, allanita e epidoto, respectivamente).

Entretanto algumas observações ressaltadas acima parecem se opor a modelos que consideram sistemas fechados e processos de difusão. Por exemplo, na Figura 3 aparece uma situação em que mantos de allanita e epidoto se extendem para fora do sistema coronítico, 
precipitando diretamente sobre as extremidades de um cristal idiomórfico de zircão, originalmente em parte incluso na monazita; diversos sistemas não apresentam zonas bem definidas de allanita (interna) e epidoto (externa), mas sim uma espécie de zona híbrida onde estes minerais aparecem intimamente intercrescidos; os contatos entre monazita e apatita sugerem que a primeira sofreu processos de corrosão e restos corroídos de monazita são encontrados preservados na zona da apatita. Adicionalmente, as variações composicionais núcleo- borda observadas em monazita são compativeis com cristalização magmática e perfís típicos de difusão estão ausentes; as datações químicas $\mathrm{Th}-\mathrm{U}-\mathrm{Pb}_{\mathrm{T}}$ homogêneas, considerando-se os erros, também não são compativeis com qualquer mobilidade diferencial importante entre estes elementos (cf. Vlach submetido).

Estudos experimentais recentes têm mostrado que a difusão de diversos elementos não é significativa em monazita sob condições crustais normais. Experimentos com monazita em condições hidrotermais realizados por Seydoux-Guillaume et al. (2002) sob condições de temperatura e composição da fase fluída variadas não revelaram processos de difusão importantes. Experimentos com fluídos contendo $\mathrm{CaCl}_{2} \operatorname{sob} 1000^{\circ} \mathrm{C}$ resultaram, entretanto, em dissolução da monazita original e recristalização de uma nova geração, mais rica em Ca, Y, e Si e, em parte, $\mathrm{U}$. As abundâncias de $\mathrm{Ce}, \mathrm{P}$, Th e $\mathrm{Pb}$ não sofreram mudanças significativas e, notadamente, os autores não observaram perfis característicos de difusão.

Assim, as evidenncias texturais, composicionais e experimentais sugerem uma origem alternativa para estes sistemas coroníticos e favorecem, em um primeiro estágio, um mecanismo de dissolução da monazita e seguida por precipitação da apatita, através de uma reação de tipo:

$$
3(\mathrm{LRRE}) \mathrm{PO}_{4}+5 \mathrm{Ca}^{2+}+(\mathrm{OH}, \mathrm{F})^{1-}=\mathrm{Ca}_{5}\left(\mathrm{PO}_{4}\right)_{3}(\mathrm{~F}, \mathrm{OH})+3(\mathrm{LRRE})^{3+}
$$

O balanço das abundâncias e $\mathrm{P}$ entre monazita e apatita sugere que a neoformação de apatita deve ter aproveitado o arcabouço pré-existente dos tetraedros $\mathrm{P}(\mathrm{Si}) \mathrm{O}_{4}$, o que explicaria o os contatos externos da apatita acompanhando com perfeição os limites externos do cristal original de monazita. Poitrasson et al. (1996) descrevem monazita alterada em rochas graníticas submetidas a processos hidrotermais de cloritização em que as unidades estruturais $\mathrm{P}(\mathrm{Si}) \mathrm{O}_{4}$ parecem ter sido mantidas durante o processo. Parte do Th, $U$ e quantidades pouco importantes 
de REE, combinados com Si, possivelmente em parte também fornecido pelos fluídos, seriam retidos na forma de torita.

Uma quantidade insignificante das LRRE liberadas durante esta reação é incorporada na apatita, mas a parte mais substancial é liberada para a zona externa do sistema, onde combinada com $\mathrm{Ca}, \mathrm{Al}, \mathrm{Si}, \mathrm{Fe}$ e voláteis das soluções intersticiais formaria as zonas externas da allanita e epidoto. A disposição interna da allanita em relação ao epidoto observada em algumas destas zonas seria compativel com a maior disponibilidade de LREE nas zonas mais próximas do cristal original de monazita. Em dependência da maior ou menor disponibilidade de zonas permeáveis à migração dos fluídos e a estabilidade destes, allanita e epidoto poderiam precipitar também em regiões algo mais afastadas do sistema coronítico.

Resta ainda explicar a morfologia distinta dos sistemas coroníticos observados no ortognaisse EMS-010. Se por um lado as proporções relativas entre as fases envolvidas não são muito diferentes, a apatita aparece melhor desenvolvida, como mantos parciais descontínuos que se projetam opostamente a monazita e mesmo como inclusões de dimensões significativas na zona da allanita que apresentam formas cristalinas próprias. A sugestão é que estas diferenças estão relacionadas a questões cinéticas. Temperaturas mais elevadas e principalmente a manutenção destas temperaturas por um tempo mais prolongado poderiam possibilitar um arranjo, ou um rearranjo a partir de morfologias similares às descritas para os granitos, do sistema como um todo para uma configuração energética interna mais estável.

\section{Coronas centradas em xenotima}

O desenvolvimento das coronas centradas em xenotima é em princípio, incompatível com sistemas fechados. Embora avaliações quantitativas não possam ser elaboradas com a precisão desejável devido ausência de dados quantitativos para a torita, fase importante na zona da apatita, a simples inspeção das composições de xenotima, apatita, allanita e epidoto (cf. Tabelas 1 e 2, Figura 5) mostra que as composições das coronas de apatita (+ torita) + allanita + epidoto não podem ser balanceadas adequadamente com as composições da xenotima primária, a possível 
exeção do $P$, uma vez que os espectros EDS obtidos para torita não indicam quantidades elevadas de REE e $Y$ na sua estrutura. Assim, quantidades significativas de LREE de $Y$ e talvez HREE devem ter sido introduzidas e extraídas respectivamente do sistema.

O desenvolvimento das coronas também é notadamente diferente. As imagens obtidas para alguns cristais sugerem que em um primeiro momento, a xenotima primária é substituída por um intercrescimento constituído por uma nova xenotima e torita, desenvolvido em graus variáveis de intensidade (cf. Figuras 2 e 3). A geração dos diminutos cristais de torita observados na xenotima neoformada pode estar associada a mecanismos de dissolução e reprecipitação combinada ou não com mecanismos de exsolução simples induzidos pelos fluídos hidrotermais, através de uma reação do tipo:

$$
\text { Xenotima }_{1}=\text { Xenotima }_{2}+\mathrm{Th}(\mathrm{U}) \mathrm{SiO}_{4}
$$

Em que a xenotima(2) é necessariamente mais pobre em Th (U) e Si e rica em REE e P. A hipótese de exsolução encontra suporte no fato de que xenotima e torita são minerais isoestruturais do grupo espacial $14_{1} / a m d$. É importante ressaltar que a morfologia destes cristais é muito similar a dos cristais observados na zona da apatita e que eles não são observados como inclusões na xenotima primária. Em outras situações, parece haver neoformação de xenotima com inclusões de apatita em finas bordas externas de reação da xenotima primária. Acredita-se que isto se deva a pouca disponibilidade original de Th e/ou $U$, inviabilizando a formação de torita.

Os contatos entre a zona da apatita e a xenotima neoformada mostram evidências de corrosão da última, sugerindo que ela foi parcialmente consumida para a formação da apatita. Nos sistemas coroníticos em que a xenotima foi quase que totalmente substituída, observa-se que a apatita aparece ora como cristal único pseudomorfoseando com perfeição os contornos externos da xenotima pretérita, ora como agregados de cristais de tendências idiomórficas, situação em que a torita tende a se concentrar intersticialmente a eles. Em alguns sistemas coroníticos estas zonas de apatita + torita não estão manteadas por allanita e/ou epidoto, indicando que a sua geração não está implicitamente vinculada com o desenvolvimento destes minerais. Nestes casos, a cristalização de allanita e epidoto parece estar associada à proximidade de zonas de fraqueza 
intergranulares da rocha hospedeira, regiões de aporte externo mais significativo de fluidos. Estas evidências aliadas, a presença de cristais reliquiares de xenotima fortemente corroídos e de distribuição irregular na zona da apatita, também parecem inviabilizar processos ligados a difusão simples e favorecem novamente mecanismos de dissolução e reprecipitação.

Uma reação análoga a apresentada para os sistemas centrados em monazita pode ser escrita para a formação de apatita, na forma:

$$
3(\mathrm{Y}) \mathrm{PO}_{4}+5 \mathrm{Ca}^{2+}+(\mathrm{OH}, \mathrm{F})^{1-}=\mathrm{Ca}_{5}\left(\mathrm{PO}_{4}\right)_{3}(\mathrm{~F}, \mathrm{OH})+3(\mathrm{Y})^{3+}
$$

A apatita formada registra parte da assinatura geoquímica da xenotima original, mostrando típico enriquecimento relativo em HREE. A allanita e o epidoto nas coronas são também mais enriquecidos em HREE, quando comparados aos equivalentes observados para monazita, uma assinatura também adquirida. Por outro lado, parte significativa das LREE e do $Y$ foi necessariamente introduzida e extraída do sistema, respectivamente, implicando em maior mobilidade destes elementos na rocha hospedeira.

\section{Metamorfismo vs alteração pós-magmática}

As evidências geológicas e petrográficas disponíveis permitem vincular os sistemas coroníticos presentes no ortognaisse EMS-010 com processos metamórficos que transformaram tonalitos e granodioritos mais antigos em ortognaisses. Estes sistemas são comuns em rochas graníticas peraluminosas metamorfosedas em fácies anfibolito (cf. Finger et al. 1998) e a sua geração deve ter ocorrido sob temperaturas inferiores a ca. $700^{\circ} \mathrm{C}$, uma vez que, em ortognaisses peraluminosos equilibrados em temperaturas mais elevadas, a monazita reaparece como fase tipicamente estável no sistema (e.g. Bingen et al. 1996, Büttner e Kruhl 1997, Bingen e Breemen 1998). A idade deste evento metamórfico ainda não está bem estabelecida. Datações dos cristais de monazita dos sistemas coroníticos da amostra estudada e de monazita e xenotima de um ortognaisse granodioritico do mesmo corpo intrusivo através do método Th-U-Pb $\mathrm{P}_{T}$ com 
microssonda eletrônica revelam idades da ordem de $790 \mathrm{Ma}$ equivalentes, considerando-se os erros, às idades obtidas para o metamorfismo principal dos metassedimentos do Terreno Embu (Vlach 2001, submetido), o que pode indicar um caráter sincrônico para o magmatismo. Assim a deformação e recristalizaçăo que originaram estas rochas pode ter ocorrido em períodos mais recentes e mesmo estarem associadas a zonas de cizalhamento, sob condições de temperaturas mais elevadas.

Os granitos intrusivos EM-014A e EM-025A por sua vez, são de natureza sin-tectônica, apresentam formas alongadas ou mesmo estiradas e a sua colocação está condicionada a expressivas zonas de cizalhamento orientadas NNE que cortam todo o Terreno Embu. Ao contrário do observado no ortognaisse, rearranjos texturais e mineralógicos de temperatura relativamente baixa (e.g., sericitização e saussuritização de plagioclásio, cloritização de biotita, neoformação de muscovita, titanita, etc.) são comuns e relativamente abundantes nas amostras estudadas. Apresentam idades químicas $\mathrm{Th}-\mathrm{U}-\mathrm{Pb}_{\mathrm{T}}$ em monazita e xenotima e isotópicas em monazita próximas a 590 Ma (Janasi et al. 2003, Vlach submetido). Neste terreno não existem evidências para um evento metamórfico regional nesta época, apenas no Terreno Serra do Mar, vizinho a Sudoeste (cf. Figura 1, Vlach submetido). Um evento mais jovem, com ca. 530 Ma, está registrado em bordas de dissolução-reprecipitação de monazita poligenética no Granito Natividade da Serra e sugere que os terrenos Embu e Serra do Mar foram afetados em graus variáveis pela Orogênese Cabo Frio definida no estado do Rio de Janeiro, para Leste, que teria sido responsável por importantes reativações nas zonas de cizalhamento pré-existentes (Vlach submetido).

Coronas centradas em monazita podem estar associadas a processos metamórficos ou deutérico-hidrotermais, pós-magmáticos (Finger et al. 1998, Claeson 2002) e no caso dos granitos sin-tectônicos as coronas desenvolvidas em monazita e/ou xenotima devem estar ligadas a própria evolução pós-magmática das rochas hospedeiras, sob alguma deformação regional. De qualquer forma, parece claro que as coronas presentes nos ortognaisses se desenvolveram em ambientes de temperaturas e pressões maiores, compatíveis com o fácies anfibolito, enquanto condições mais brandas, compatíveis com o fácies xisto-verde teriam atuado sobre os granitos intrusivos. Temperaturas e intervalos de tempo diferenciados no caso das alterações observadas nos granitos e no ortognaisse devem explicar as diferentes caracteristicas morfológicas dos 
sistemas coroníticos e permitido um arranjo mais equilibrado, variações composicionais mais contínuas entre as zonas da allanita e do epidoto e composições mais puras para apatita no último caso.

\section{Implicações para geocronologia e mobilidade de elementos HFS}

As idades químicas obtidas com microssonda eletrônica, para monazita e xenotima dos sistemas coroniticos, mesmo para alguns restos corroídos de cristais de monazita e xenotima preservados na zona da apatita são idênticos, considerando-se os intervalos de erros das idades pontuais (ca. 25-50 Ma), aos obtidos para cristais idiomórficos, sem coronas, preservados como inclusões em quartzo e perfeitamente compatíveis com resultados de determinações isotópicas U$\mathrm{Pb}$ (TIMS) independentes. Assim, como ressaltado por Finger et al. (1998) para o caso de monazita, as composições dos cristais de monazita e xenotima presentes nos sistemas coroníticos são mantidas inalteradas não somente para os elementos principais formadores destes minerais, como também para $T h, U$ e $\mathrm{Pb}_{\mathrm{T}}$ e idades reais, representativas da cristalização primária podem ser obtidas. Por outro lado, a seleção de grãos para datações isotópicas convencionais (U/Pb, TIMS) deve ser criteriosa e requer a eliminação de grãos com bordas coroníticas, que tipicamente resultam em aspecto superficial mais irregular, menor trnasparência e colorações algo mais escuras para os grãos. Alguns dados isotópicos U-Pb (TIMS) obtidos para frações de monazita de granitos do Terreno Embu apresentam de fato graus variáveis de discordância (e.g. Janasi et al. 2003) que podem refletir situações deste tipo ou, alternativamente, frações que incluam diferentes gerações de monazita. A abrasão controlada destes sistemas pode eliminar adequadamente as coronas de substituição.

As informações texturais e químicas apresentadas para os sistemas coroníticos centrados em monazita indicam que a mobilidade de elementos como REE (menor para os LRRE, possivelmente maior para HREE e $\mathrm{Y}$ ), Th e $U$ induzidas pela circulação de fluídos com composições adequadas pode ser muito significativa em rochas graníticas em escalas, inter- ou intra-cristalinas, (ver também Finger et al. 1998). Nos casos envolvendo xenotima, a mobilidade, 
particularmente dos LREE e do $\mathrm{Y}$, necessariamente ocorreu em escalas mais expressivas na rocha hospedeira observando-se também variações significativas das razões $\mathrm{Sm} / \mathrm{Nd}$ ao longo das zonas da allanita e do epidoto. No caso da amostras EM-025A, o processo de substituição de monazita eventualmente pode ter contribuido para a origem de parte dos LREE adicionados nas coronas sobre xenotima. É interessante observar que as bordas de monazita poligenética do Granito Natividade da Serra reequilibradas em ca. 530 Ma são algo mais enriquecidas em LRRE quando comparadas com monazita primária, sugerindo que os fluidos hidrotermais deveriam conter quantidades significativas destes elementos (Vlach, submetido e dado inéditos).

Nos casos em que os fluidos intersticiais têm capacidade de incorporarar REE em abundâncias significativas e se a rocha hospedeira apresenta canais criados e/ou multiplicados por mecanismos de deformação que facilitem a sua percolação, a remobilização destes elementos pode provavelmente ocorrer em escalas mais significativas. Neste sentido, interpretações petrológicas embasadas na imobilidade destes elementos em rochas graníticas, particularmente de caráter mais evoluído, devem ser tomadas com cautela.

\section{NOTAS CONCLUSIVAS}

Coronas constituidas por zonas constituidas por apatita+torita, seguida de allanita e após epidoto com REE na zona externa, ocorrem como mantos concéntricos ou mais irregulares que substiuem parcialmente monazita e xenotima em ortognaisses do fácies anfibolito e granitos intrusivos sin-tectônicos do Terreno Embu, Estado de São Paulo, SE do Brasil. Evidências microestruturais e texturais, mapas composicionais e análises quantitativas pontuais indicam que estes mantos são produtos de reações de desestabilização das fases minerais primárias através de mecanismos de dissolução e cristalização influenciados pelos fluídos metamórficos e/ou deutéricos/hidrotermais com disponibilidade, entre outros elementos, de $\mathrm{Ca}, \mathrm{Al}, \mathrm{Fe}, \mathrm{Si}$ e voláteis.

As coronas centradas em monazita podem ter se desenvolvido em sistemas aproximadamente fechados no que tange os elementos químicos principais que a constituem (e.g. REE, Th, P). A entrada de Ca e voláteis paralelizada pela lixiviação dos RRE da estrutura da 
monazita permitiu a cristalização pseudomórfica de apatita, possivelmente aproveitando o arcabouço estrutural dos tetraedros $(\mathrm{P}, \mathrm{Si}) \mathrm{O}_{4}$ da monazita original. Externamente a zona da apatita, a combinação dos REE liberados com os fluídos intersticiais propiciou a formação de allanita e epidoto, este último em geral distribuídos nas zonas mais externas dos mantos. As coronas, tipicamente concêntricas no caso dos granitos, são mais irregulares no caso dos ortognaisses, sugerindo neste caso significativa reorganização e possível recristalização dos mantos para uma configuração estrutural mais estável.

A geração das coronas sobre xenotima envolve processos mais complexos, que inclue a formação de uma geração secundária de xenotima rica em micro-inclusões de torita, a qual precede a formação da zona da apatita. Nestes casos, as texturas indicam claramente que a apatita consome a xenotima secundária. Nos casos em que a substituição é mais efetiva, nota-se que a zona da apatita está constituída por vezes por alguns cristais iso-orientados, ao invés de um cristal único, situação mais típica da apatita observada sobre a monazita e os volumes deste mineral nas coronas centradas em xenotima são significativamente superiores. Ao contrário dos sistemas coroníticos centrados em monazita, os resultados analiticos indicam que quantidades significativas de LRRE, que permitiram cristalização de allanita e epidoto com REE, devem ter sido introduzidas pelas soluções intersticiais e parcelas significativas de $Y$ e possivelmente HREE foram liberadas pela xenotima primária para o meio ambiente.

Em ambos os casos os dados não são compativeis com a interpretação de que as reações de substituição tenham sido dominadas por processos de difusão química, como sugerido por Finger et al. (19988), mas sim que processos de dissolução e cristalização devem ter sido predominantes. Não existem evidências da superimposição de um evento de metamorfismo regional após a colocação dos plutons intrusivos, indicando que a deformação sin-magmática que controlou a sua colocação e também ocasionou posterior deformação de estado sólido deve ter fornecido a energia necessária e facilitado a percolação dos fluidos que motivaram as reações de substituição da monazita e da xenotima primárias, em condições compatíveis com o fácies xistos verdes, portanto mais brandas quando comparadas as que geraram os ortognaisses mais antigos.

Os dados quimicos mostram que as composições de monazita e xenotima primárias sobre as quais as coronas são desenvolvidas são preservadas, mesmo nas zonas imediatas aos 
contatos com a zona da apatita. As datações pontuais com o método químico Th-U-Pb $\mathrm{Pb}_{T}$ refletem idades reais de cristalização destas fases. Naturaimente, cristais manteados não são adequados para determinações isotópicas convencionais e necessitam ser eliminados ou purificados. $O$ processo de substituição, particularmente no caso de xenotima, pode envolver remobilização significativa de elementos como REE e $\mathrm{Y}$ para fora e para dentro do sistema coronítico e, portanto, se as estruturas da rocha encaixante facilitam o fluxo de soluções, as interpretações embasadas na imobilidade destes elementos devem ser analisadas de forma criteriosa.

\section{AGRADECIMENTOS}

O autor agradece à Fundação de Amparo a Pesquisa do Estado de São Paulo (FAPESP) pelo apoio contínuo ao Laboratório de Microssonda Eletrônica do Instituto de Geociências da Universidade de São Paulo, Marcos Mansueto pelo necessário suporte laboratorial, Adriana Alves por ceder dados inéditos de REE em rocha total das amostras dos granitos intrusivos e Valdecir $A$ Janasi pelo acompanhamento em etapas de campo para coleta de amostras na região do Terreno Embu e vizinhanças.

\section{REFERÊNCIAS}

Bastin, G.F., Heijligers, H.J.M., 1990. Progress in electron-probe microanalysis. Materialwissenschaft und Werkstoffechnik, 21:216-221.

Bea, F., 1996. Residence of REE, Y, Th, and $U$ in granites and crustal protoliths: Implications for the chemistry of crustal melts. Journal of Petrology, 37:521-552.

Boynton, W.V., 1984. Cosmochemistry of the rare earth elements: meteorite studies. In: Henderson, P. (Ed.), Rare earth element geochemistry. Elsevier. Amsterdan, pp. 63-114. 
Bingen, B., Breemen, O. Van, 1998. U-Pb monazite ages in amphibolite- to granulite-facies orthogneiss reflect hydrous mineral brekdown reactions: Sveconorwegian Province of SW Norway. Contributions to Mineralogy and Petrology, 132:336-353.

Bingen, B., Demaiffe, D., Hertogen, J., 1996. Redistribution of rare earth elements, thorium, and uranium over accessory minerals in the course of amphibolite to granulite metamorphism: The role od apatite and monazite in orthogneisses from southwestern Norway. Geochimica et Cosmochimica Acta, 60:1341-1354.

Brito Neves, B.B., Campos Neto, M.C., Fuck, A.R., 1999. From Rodinia to Western Gondwana: an approach to the Brasiliano-Pan African Cycle and orogenic collage. Episodes, 22:155-166.

Bütner, S.H., Kruhl, J., 1997. The evolution of a late Variscan high-T/low-P region: The southeastern margin of the Bohemian massig. Geologische Rundschau, 86:21-38.

Campos Neto, M.C., 2000. Orogenic systems from Southwestern Gondwana: an approach to Brasiliano-Pan African Cycle and orogenic collage in Southeastern Brazil. In: Cordani, U.G., Milani, E.J., Thomaz Filho, A., Campos, D.A. (ed). Tectonic evolution of South America: $31^{\circ}$ International Geological Congress (Rio de Janeiro, Brasil), p. 335-365.

Chang, L.L.Y., Howie, R.A., Zussman, J., 1998. Rock Forming Minerals, Vol 5B. Nonsilicates:Sulphates, Carbonates, Phosphates, Halides, $2^{\text {nd }}$ Ed., 383 p. The Geological Society, London.

Claeson, D. T., 2002. Stability of REE-bearing minerals in a metaluminous leucotonalite from the Eriksberg gabbro, Transcandinavian Igneous Belt, Sweden. Neues Jahrbuch für Mineralogie - Abhandlungen, 177(3):277-291.

Cordani, U.G., Coutinho, J.M.V., Nutman, A.P., 2002. Geochronological constraints for the age of the Embu Complex, São Paulo, Brazil. Journal of South American Sciences, 14:903-910

Fernandes, A.J., Campos Neto, M.C., Figueiredo, M.C.H., 1990. O Complexo Embu no leste do Estado de São Paulo: limites e evolução geológica. In: XXXVI Congresso Brasileiro de Geologia (Natal, Brasil), Anais, 6:2755-2763.

Finger, F., Broska, I., Roberts, M.P., Schermaier, A., 1998. Replacement of primary monazite by apatite-allanite-epidote coronas in amphibolite facies granite gneiss from the eastern Alps. American Mineralogist, 83:248-258. 
Filipov, M., Janasi, V.A., 2001. The Mauá granitic massif, central Ribeira Belt, São Paulo: petrography, geochemistry and U-Pb dating. Revista Brasileira de Geociências, 31:341348 .

Förster, H.-J., 2006. Composition and origin of intermediate solid solutions in the system thoritexenotime-zircon-coffinite. Lithos, 88:35-55.

Förster, H.-J., 1998. The chemical composition of REE-Y-Th-U-rich accessory minerals in peraluminous granites of the Ersgebirge-Fichtelgebirge region, Germany, Part I: The monazite-(Ce)-brabantite solid solution series. American Mineralogist, 83:259-272.

Foster, G., Gibson, H.D., Parrish, R., Horstwood, J.F., Tindle, A., 2002. Textural, chemical and isotopic insights into the nature and behaviour of metamorphic monazites. Chemical Geology, 191:183-207.

Franz, G., Andrehs, G., Rhede, D., 1996. Crystal chemistry of monazite and xenotime from Saxothuringian-Moldanubian metapelites, NE Bavaria, Germany. European Journal of Mineralogy, 8:1097-1118.

Gardés, E., Montel, J-M, Seydoux-Guillaume, A.M., Wirth, R., 2007. Pb diffusion in monazite: New constraints from the experimental study of $\mathrm{Pb} 2+\leftrightarrow \mathrm{Ca} 2+$ interdiffusion. Geochimica et Cosmochimica Acta, 71:4036-4043.

Gieré, R., Sorensen, S.S., 2004. Allanite and other REE-rich epidote-group minerals. In: Liebscher, A., Franz, G. (Eds.). Epidotes. Reviews in Mineralogy and Geochemistry, vol. 56, pp. 431493.

Goldstein, J.I., Newbury, D.E., Echlin, P. , Joy, D.C., Romig Jr., A.D., Lyman, C.E., Fiori, C., Lifshin, E., 1992. Scanning Electron Microscopy and X-Ray Microanalysis, $2^{\text {nd }}$ Ed., $820 \mathrm{p}$., Plenum Press, New York.

Gratz, R., Heinrich, W., 1998. Monazite-xenotime thermometry. Experimental calibration of the miscibility gap in the binary system $\mathrm{CePO}_{4}-\mathrm{YPO}_{4}$. American Mineralogist, 82:772-780.

Hasui, Y., 1975. Geologia da Folha São Roque. Boletim do Instituto de Geociências da Universidade de São Paulo, 6:157-183.

Heilbron M., Pedrosa-Soares A.C., Campos Neto M.C., Silva L.C., Trouw R.A.J. \& Janasi V.A. 2004. Província Mantiqueira. In: V. Mantesso-Neto, A. Bartorelli, C.D.R. Carneiro \& B.B. 
Brito Neves (eds). Geologia do Continente Sul-Americano: Evolução da Obra de Fernando Flávio Marques de Almeida, Beca, São Paulo, pp.: 203-234

Hetherington, C.J., Jercinovic, M.J., Willians, M.L., Mahan, K., 2008. Understanding geological processes with xenotime: composition, chronology, and a protocol for electron probe microanalysis. Chemical Geology, 254:133-147.

Janasi, V.A., Alves, A., Vlach, S.R.F., Leite, R.J., 2003. Granitos peraluminosos da porção central da Faixa Ribeira, Estado de São Paulo: Eventos de reciclagem da crosta continental no Neoproterozóico. Geologia USP (Série Científica), 3:13-24.

Jercinovic, M.J., Williams, M.L., 2005. Analytical perils (and progress) in electron microprobe trace element analysis applied to geochronology: background acquisition, interferences, and beam irradiation effects. American Mineralogist, 90:526-546.

Lanzirotti, A., Hanson, G.N., 1996. Geochronology and geochemistry of multiple generations of monazite from the Wepawaug Schist, Conecticut, USA: Implications for monazite stability im metamorphic rocks. Contributions to Mineralogy and Petrology, 125:332-340.

Martins, L., Vlach, S.R.F., Janasi, V.A., no prelo. Reaction microtextures of monazite: correlation between chemical and age domains in the Nazaré Paulista migmatite, SE Brazil. Chemical Geology.

Montel, J-M., Foret, S. Veschambre, M., Nicollet, C., Provost, A., 1996. Electron microprobe dating of monazite. Chemical Geology, 13:37-53.

Oelkers, E.H., Montel, J.-M., 2008. Phosphates and nuclear waste storage. Elements, 4:113-116.

Petrík, I., Broska, I., Lipka, J. Siman, P., 1995. Granitoid allanite-(Ce): substitutions relations, redox conditions and REE distributions (On an example of l-type granitoids, Western Carpathians, Slovakia). Geologica Carpathica, 46: 79-94.

Podor, R., Cuney, M., 1997. Experimental study of Th-bearing LaPO4 (780 C, $200 \mathrm{Mpa})$ : Implications for monazite and actinide orthophosphate stabilyity. American Mineralogist, 82:765-771.

Poitrasson, F., Chenery, S., Bland, D.J., 1996. Contrasted monazite hydrothermal alteration mechanisms and their geological implications. Earth and Planetary Science Letters, 145:79-96. 
Pyle, J.M., Spear, F.S., Rudnick, R.L., DcDonough, W.F., 2001. Monazite-xenotime-garnet equilibrium in metapelites and new monazite-garnet therrmometer. Journal of Petrology, 42:2083-2107.

Schmidtt, R.S., Trow, R.A.J., van Schmus, W.r., 1999. The characterization of a Cambrian (520 Ma) tectonometamorphic event in the coastal domain of the Ribeira Belt (SE Brazil) using $\mathrm{U} / \mathrm{Pb}$ in syntectonic veins. In South American Symposium on Isotope Geology, 3. (Córdoba, Argentina), Actas, 103-106.

Seydoux-Guillaume, A-M., Paquette, J-L., Wiedenbeck, M., Montel, J-M., Heinrich, W., 2002.

Experimental resetting of the U-Th-Pb systems in monazite. Chemical Geology, 191:165181.

Staatz, M.H., Adams, J.W. Wahiberg, J.S., 1976. Brown, yellow, orange, and greenish-black thorites from the Seerie Pegmatite, Colorado. Journal of Reseach United States Geological Survey, 4:575-582.

Suzuki, K., Adachi, M. 1991. Precambrian provenance and Silurian metamorphism of the Tsubonosawa paragneiss in the South Kitakami Terrane, Northeast Japan, revealed by the chemical Th-U-total $\mathrm{Pb}$ isochron ages of monazite, zircon and xenotime. Geochemical Journal, 25:357-376.

Townsend, K.J., Miller, C.F., D'Andrea, J.L., Ayers, J.C., Harrison, T.M., Coath, C.D., 2000. Low temperature replacement of monazite in the Ireteba granite, Southern Nevada: geochronological implications. Chemical Geology, 172:95-112.

Vieira, S.R.S.S., Coutinho, J.M.V., Alves, F.R., 1990. Geologia e evolução geológica da região de Embu-Guaçu - Parelheiros, São Paulo. Revista Brasileira de Geociências, 20:277-281.

Vlach, S.R.F., em submissão. Análise de datação Th-U-PbT de monazita em microssonda eletrônica: procedimentos analíticos e de tratamento de dados.

Vlach, S.R.F., em submissão. Idades do metamorfismo e do magmatismo granítico no Terreno Embu e vizinhanças (SE do Brasil) e implicações: Uma contribuição da datação Th-U-PbT de monazita e xenotima com EPMA. 
Vlach, S.R.F., 2001. Microprobe monazite constrainst for an early (ca. $790 \mathrm{Ma}$ ) Brasiliano Orogeny: The Embu Terrane, Southeastern Brazil. In: South American Symposium on Isotope Geology, 3. Pucón. Extended Abstracts Volume (CD), p. 265-268.

Vlach, S.R.F., Gualda, G.A.R., 2007. Allanite and chevkinite in A-type granites and syenites of the Graciosa Province, southern Brazil. Lithos, 97:98-121.

Wing, B.A., Ferry, J.M. Harrison, T.M., 2003. Prograde destruction and formation of monazite and allanite during contact and regional metamorphism of pelites: petrology and geochronology. Contributions to Mineralogy and Petrology, 145:228-250.

\section{LEGENDA DE FIGURAS}

Figura 1. Mapa geológico da região leste do Estado de São Paulo e Províncias Estruturais da região SE do Brasil. Provincias estruturais (Inset). AFB, BFB e RFB: Faixas de Dobramento Araçuaí, Brasília e Ribeira. GN, SN and AAN: Nappes Guaxupé, Socorro e Ariruoca-Andrelândia. Principais Terrenos da Província Mantiqueira: AP: Apiaí, E: Embu, JF: Juiz de Fora, SM: Serra do Mar, CF: Cabo Frio. SFC e PC: Cratons São Francisco e Paraná (limites pontilhados inferidos). Geologia Geral: 1: coberturas fanerozóicas e rochas alcalinas mesozóicas (branco), 2: granitos tardi- a pós-orogênicos de "tipo-A", 3: biotita granitos equigranulares, 4: biotita granitos porfiríticos, 5: hornblenda biotita granitos porfiríticos, 6: Nappe Socorro (predominantemente migmatitos), 7: Terreno Apiai: Grupos São Roque, Itaberaba e Açungui (sequiências terrígenas e vulcanosedimentares de baixo a médio grau metamórfico), 8: Terreno Embu (predominantemente rochas supracrustais de médio a alto grau de metamorfismo), 9: Terreno Serra do Mar (paragnaisses e ortognaisses migmatíticos), 10: Migmatitos antigos do embasamento pré Neoproterozóico. Linhas cheias: zonas de transcorrência neoproterozóicas, Linhas cheias pontilhadas: limites de estado. Geologia modificada de Campos Neto (2000) e referências citadas. Códigos se referem à localização das amostras estudadas: EMS-010: ortognaisse tonalítico, EM-014A: Granito Mauá, EM-025A: Granito Mogi das Cruzes, EM-7\&8, Batólito Quebra Cangalha. 
Figura 2. Imagens de eletrons retroespalhados (BSE) em modo composicional ilustrando diversos aspectos texturais típicos de monazita, xenotima e sistemas coroníticos. Abraviações: aln: allanita, ap: apatita, bi: biotita, ep: epidoto, kfs: feldspato potássico, mnz: monazita, mu: muscovita, pl: plagioclásio, qz: quartzo, th: torita, xen: xenotima A. Cristais corroídos de monazita ao lado de cristal de xenotima. Observar cristais corroidos com fina e sem CAAE (corona de apatita + allanita + epidoto) e CAAE parcial em xenotima (Granito Quebra Cangalha, EM-008), B: monazita corroida, com típica CAAE concêntrica parcialmente incluída em biotita do granito Mauá (EM014A). Notar finas pontuações claras constituidas por torira na zona da apatita, C: monazita com corona de tipo irregular no ortognaisse tonalítico EMS-010. Observar que a apatita não envolve totalmente monazita, como em B, D: monazita parcialmente idiomórfica, parcialmente corroída, em parte incluída em cristal de biotita, contendo inclusões de torita, com fina CAAE regularmente distribuida sobre os contornos idomórficos e corroídos, E: cristal idiomórfico de xenotima contendo inclusões idiomórficas de apatita e corroída de monazita, com fina CAAE, F: imagem E com contraste mais forte, destacando marcado zonamento oscilatório e a presença de uma geração posterior de xenotima como finas bordas de substituição sobre a xenotima primária. Observar desenvolvimento local de diminutas inclusões de apatita e de torita, G: cristais de xenotima corroidos, com coronas diversas. Observar que localmente as coronas estão constituídas apenas por apatita, que contém inúmeras incluões diminutas de torita, allanita e epidoto aparecem apenas em parte das coronas, $\mathrm{H}$ : detalhe da imagem anterior com contraste acentuado. Observar uma geração posterior de xenotima contendo inúmeras inclusões de torita que substitui a xenotima primária e que esta geração apresenta contornos externos corroídos nas zonas de contato com apatita, l: restos corroídos de xenotima em apatita com corona de allanita + epidoto. Observar que a apatita, com inclusões de torita, pseudomorfoseia o cristal original de xenotima com perfeição. Ver discussão no texto.

Figura 3. Imagens BSE em modo composicional e mapas composicionais para sistemas coroníticos selecionados centrados em monazita para os granitos EM-025A e EM-014A e centrados em xenotima para o granito EM-025A, respectivamente. Em monazita, $\mathrm{P}, \mathrm{Ce}, \mathrm{Th}, \mathrm{Al}$ e Fe analisados com WDS, Ca e Si com EDS, em xenotima, P, Ce,Th, Dy, Fe com WDS, Al e Si 
com EDS. Abreviações nas imagens BSE como na Figura 2. Observar que a zona da apatita, marcada por $\mathrm{P}$ e $\mathrm{Ca}$ apresenta contornos retos que parecem corresponder com possiveis contornos dos cristais originais de monazita, que apresentam-se parcialmente corroídos. No sistema da amostra EM-025A, a allanita (melhor marcada pelo Ce e, em parte $\mathrm{Fe}$ ) e o epidoto (Ca, $\mathrm{Al})$ aparecem com contatos mútuos muito irregulares, interpenetrados, enquanto que na amostra EM-014A, zonas bem definidas de allanita (interna) e epidoto (externa) são claras. No sistema envolvendo xenotima, a apatita aparece tipicamente como agregado de diversos cristais, com contornos externos "amebóides". Ver discussões no texto.

Figura 4. Padrões de distribuição dos REE para monazita primária e para allanita, epidoto e apatita das coronas presentes nos ortognaisses e no granito Mauá e para rocha total do granito Mauá. Fatores de normalização de acordo com Boynton (1984). Monazita: losangos, allanita e epidoto: círculos, apatita: triângulos, rocha total: quadrados.

Figura 5. Padrões de distribuição dos REE para xenotima primária, allanita, epidoto e apatita de coronas e rocha total para o granito Mogi das Cruzes. Fatores de normalização de acordo com Boynton (1984). Xenotima: losangos, allanita e epidoto: círculos, apatita: triângulos, rocha total: quadrados.

Figura 6. Diagrama RRE+Th+Sr vs AIT (Petrik et al., 1995) ilustrando as variações composicionais de allanita e epidoto nos sistemas coroníticos estudados. Círculos vazios: granito EM-014A, estrelas: granito EM-025A, círculos: ortognaisse EMS-010. Losangos e triângulos em tons claros correspondem as análises de allanita e epidoto obtidas por Finger et al. (1998) e Claeson (2002), respectivamente, em sistemas coroníticos centrados em monazita.

Figura 7. Diagrama ilustrando as variações dos principais óxidos ao longo das zonas da allanita e do epidoto para sistema coronitico do ortognaisse EMS-010. O ponto 1 corresponde a parte mais interna da zona da allanita, 06 a borda externa da zona do epidoto. 
Figura 8. Diagramas de variação para os sistemas coroníticos estudados. (A): variação das razões $\mathrm{Sm} / \mathrm{Nd}$ em função das razões $\mathrm{Ce} / \mathrm{Y}$ para monazita e/ou xenotima e allanita-epidoto coexistentes e (B) variações das razões $\mathrm{Sm} / \mathrm{Nd}$ (valores normalizados) com o parâmetro $\mathrm{Fe}^{\top} /\left(\mathrm{Fe}^{\top}+\mathrm{Al}\right.$ ) nas zonas da allanita e do epidoto.

\section{LEGENDA DE TABELAS}

Tabela 1. Composições químicas (\% em peso de óxidos) e proporções catiônicas representativas de monazita e xenotima primárias para o ortognaisse EMS-010 e os granitos EM-014A e EM025A. Valores de $\mathrm{Tm}_{2} \mathrm{O}_{3}$ calculados por interpolação nas análises de xenotima. na = não analisado, bd = abaixo do limite de detecção.

Tabela 2. Composiçőes químicas (\% em peso de óxidos) e proporções catiônicas representativas de allanita, epidoto e apatita presentes nos sistemas coroníticos do ortognaisse EMS-010 e dos granitos EM-014A e EM-025A. bd = abaixo do limite de detecção. 


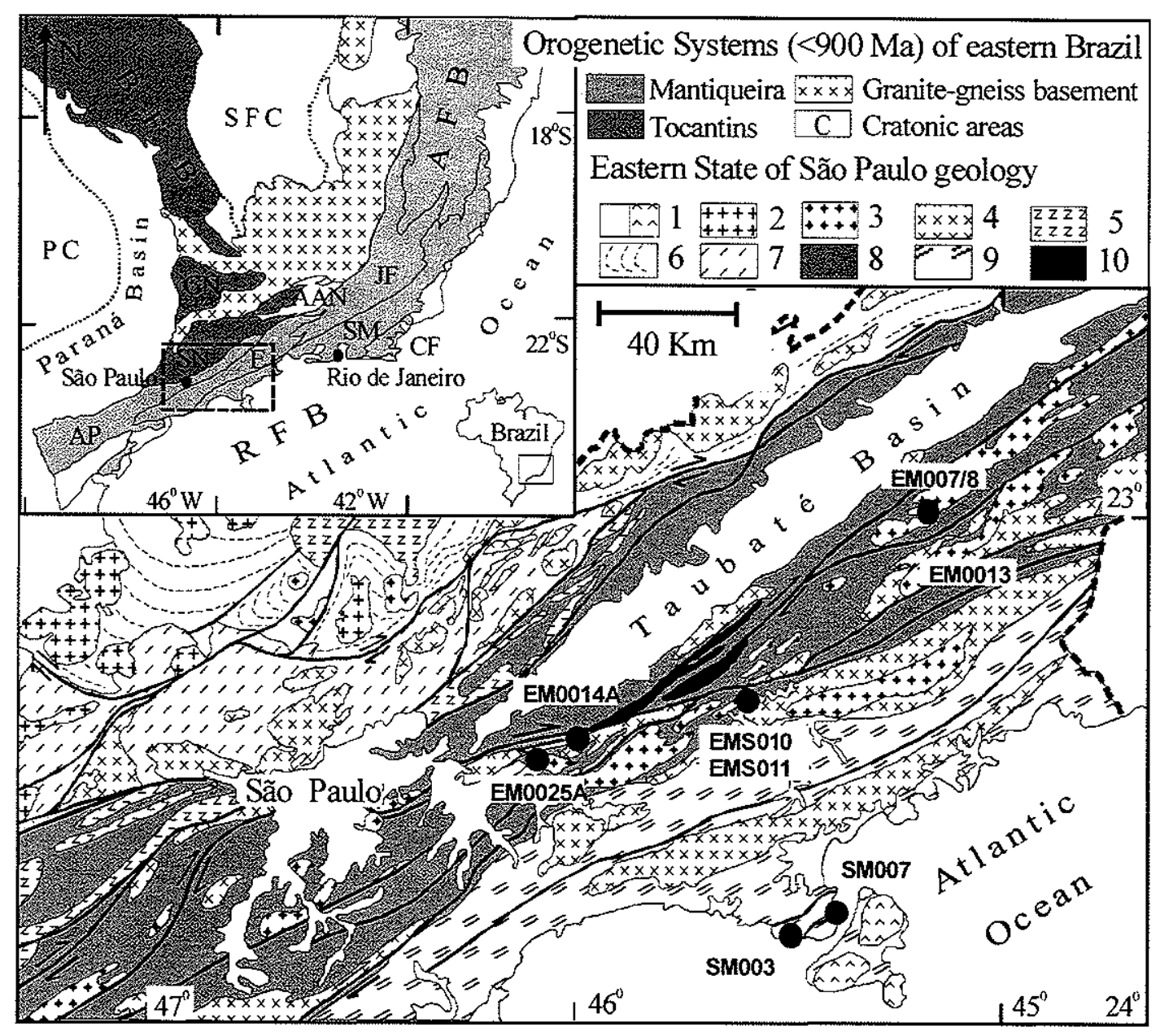

Figura 1 

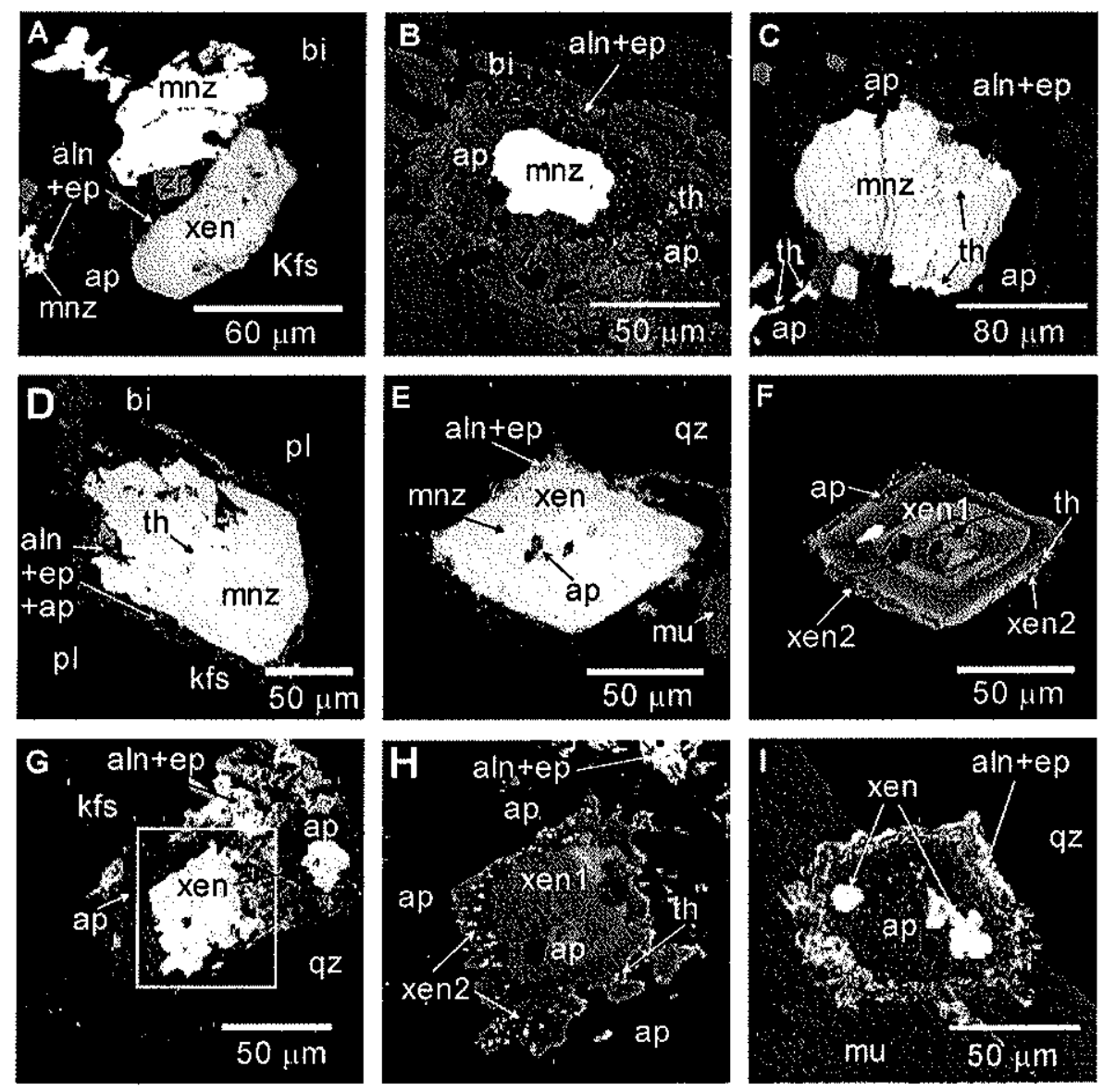

Figura 2 

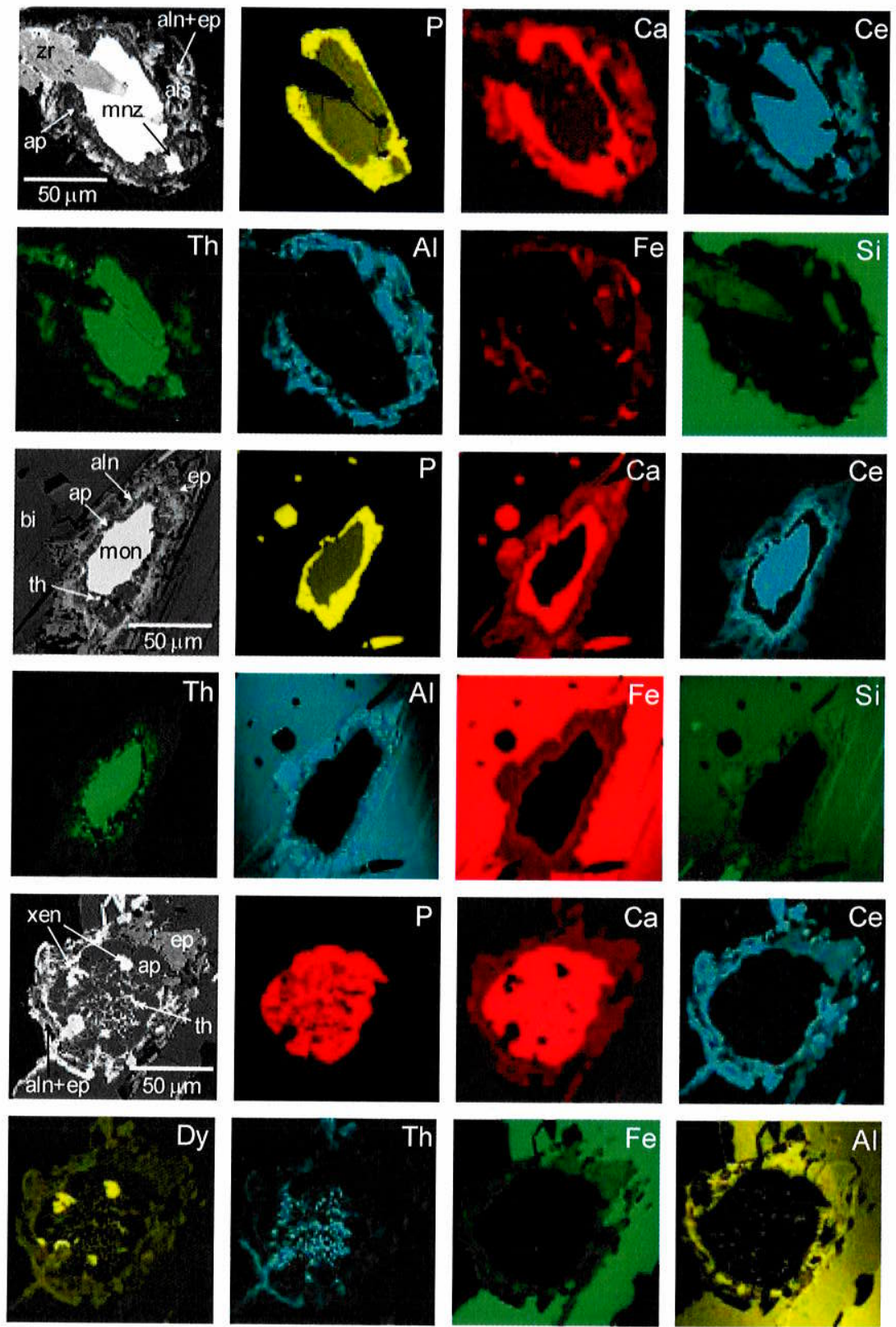

Figura 3 


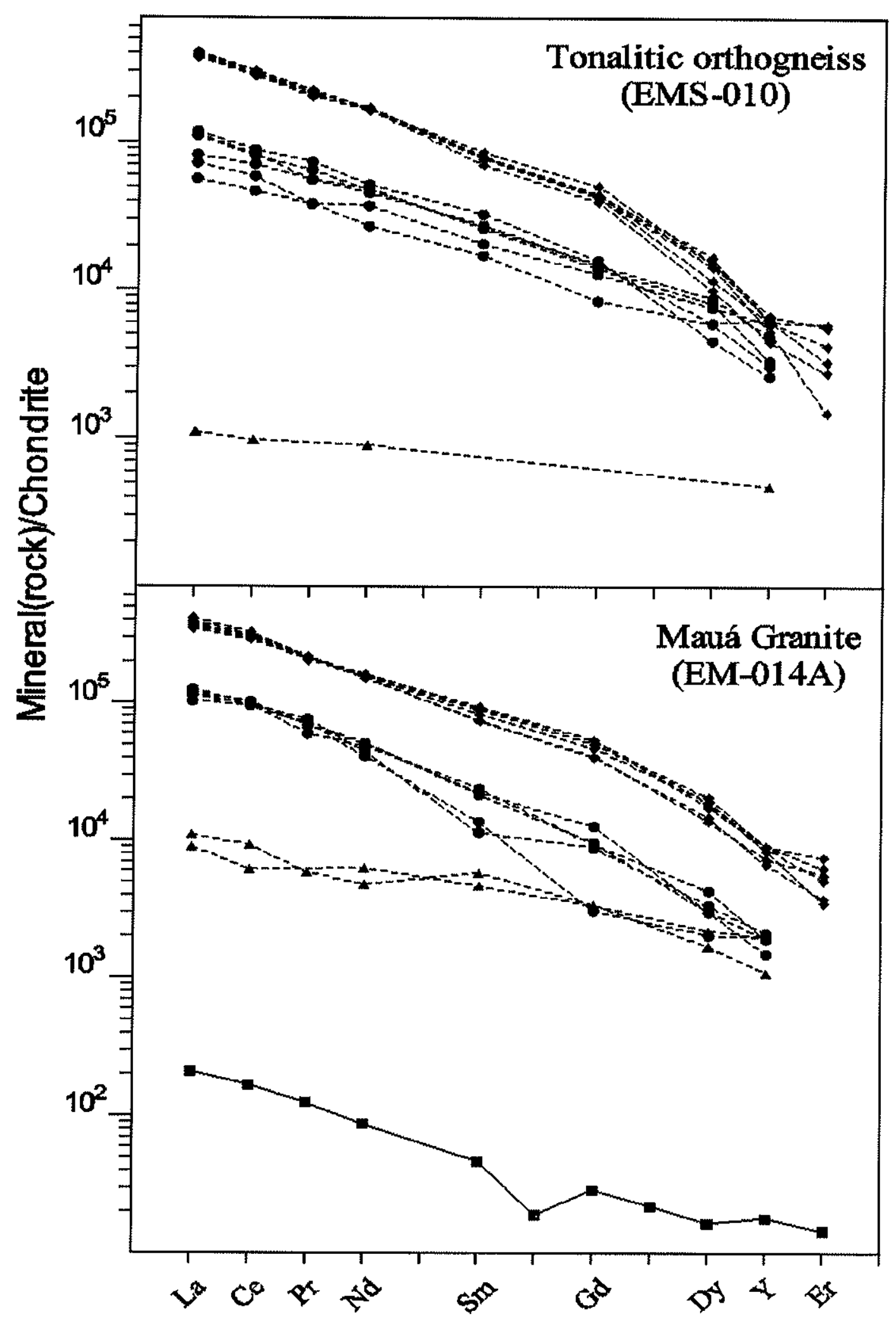

Figura 4 


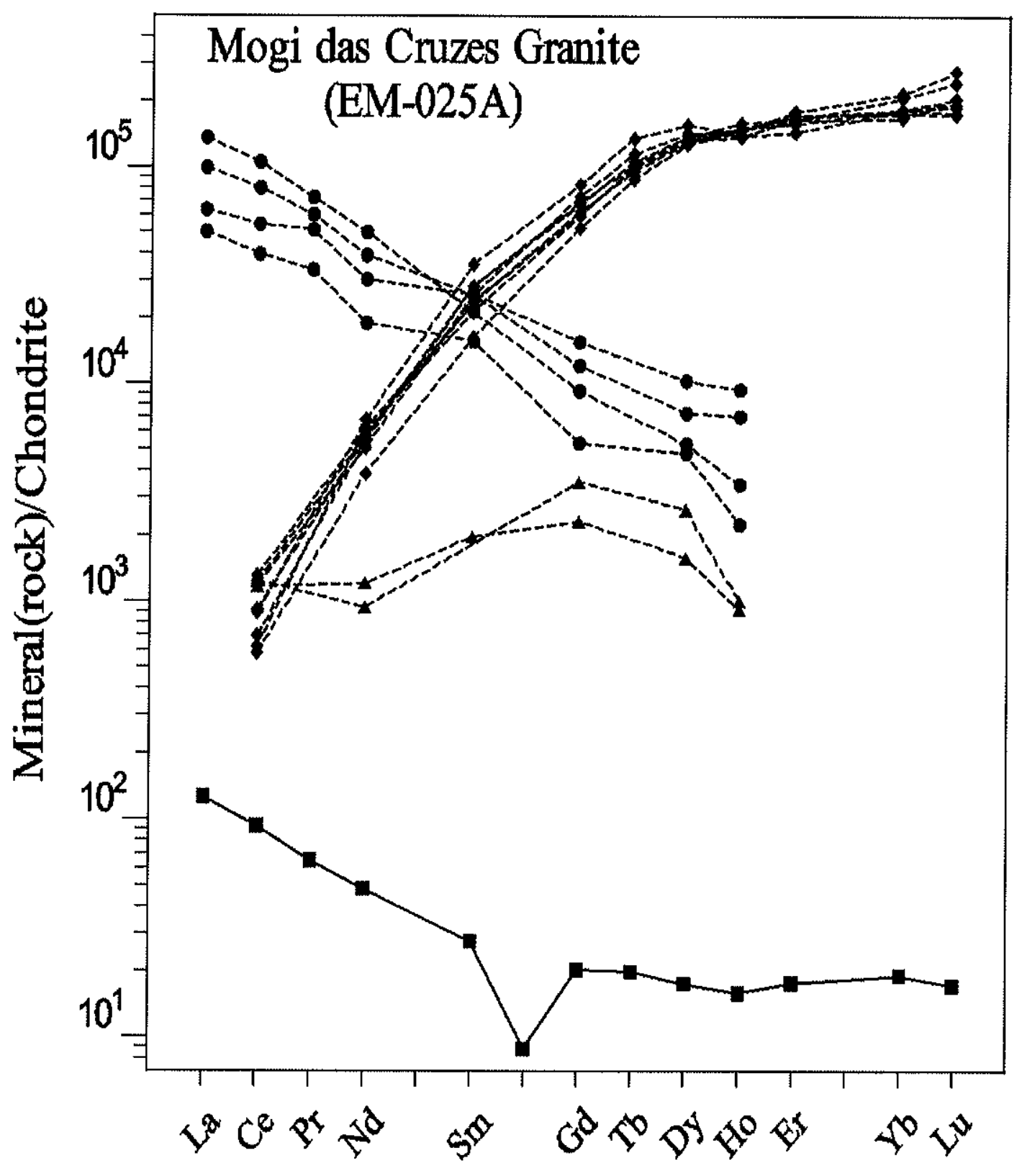

Figura 5 


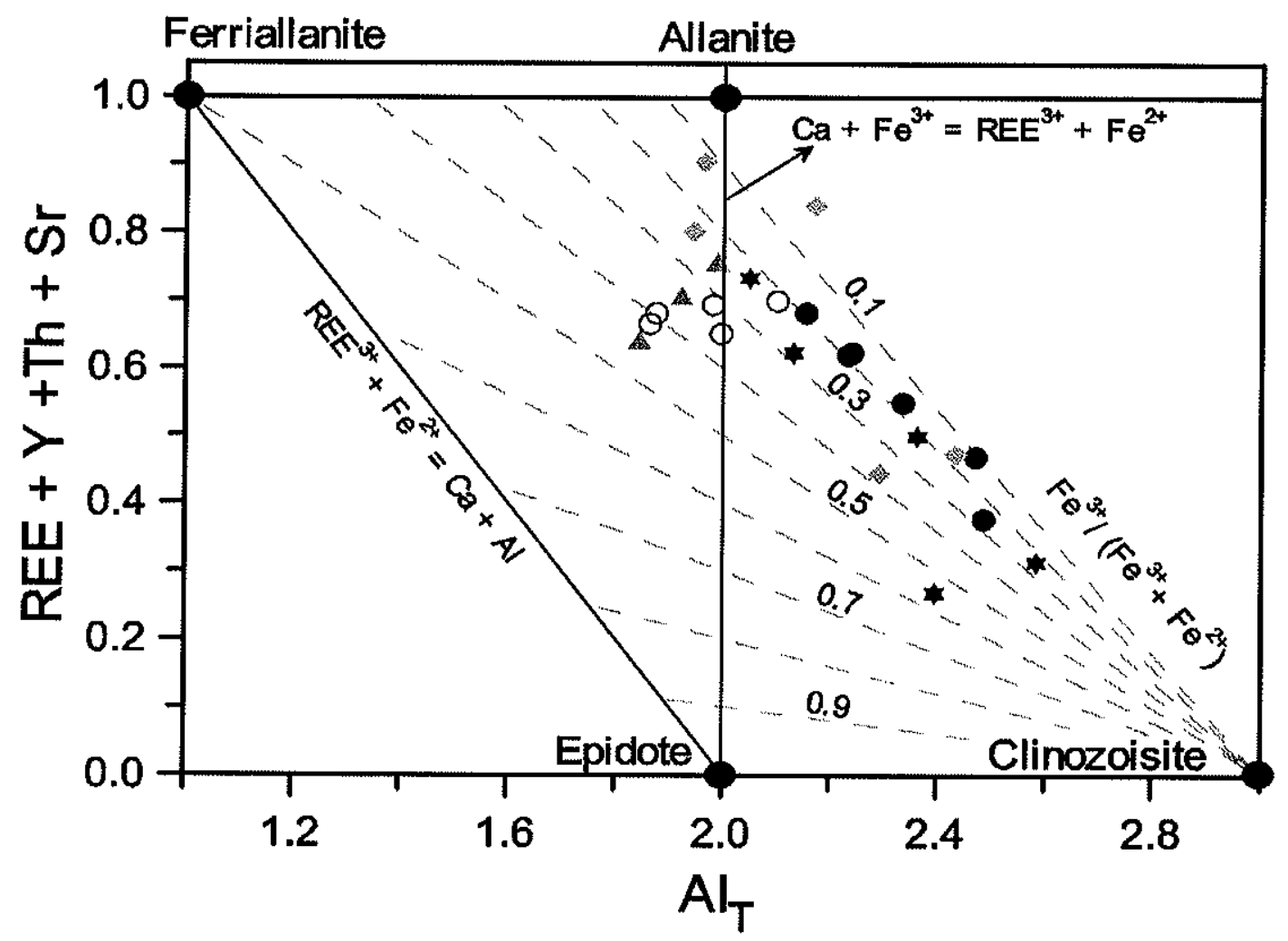

Figura 6 


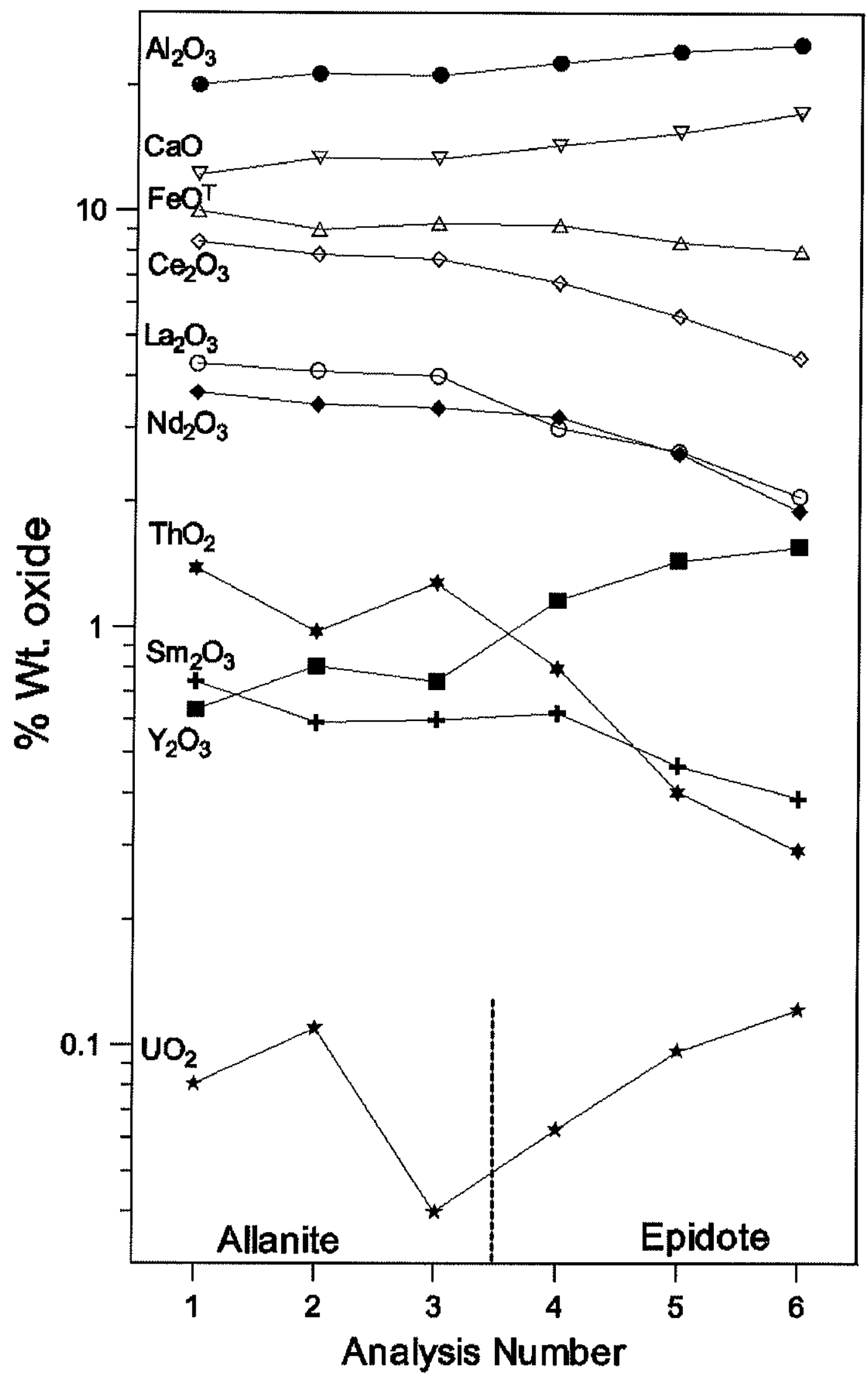

Figura 7 

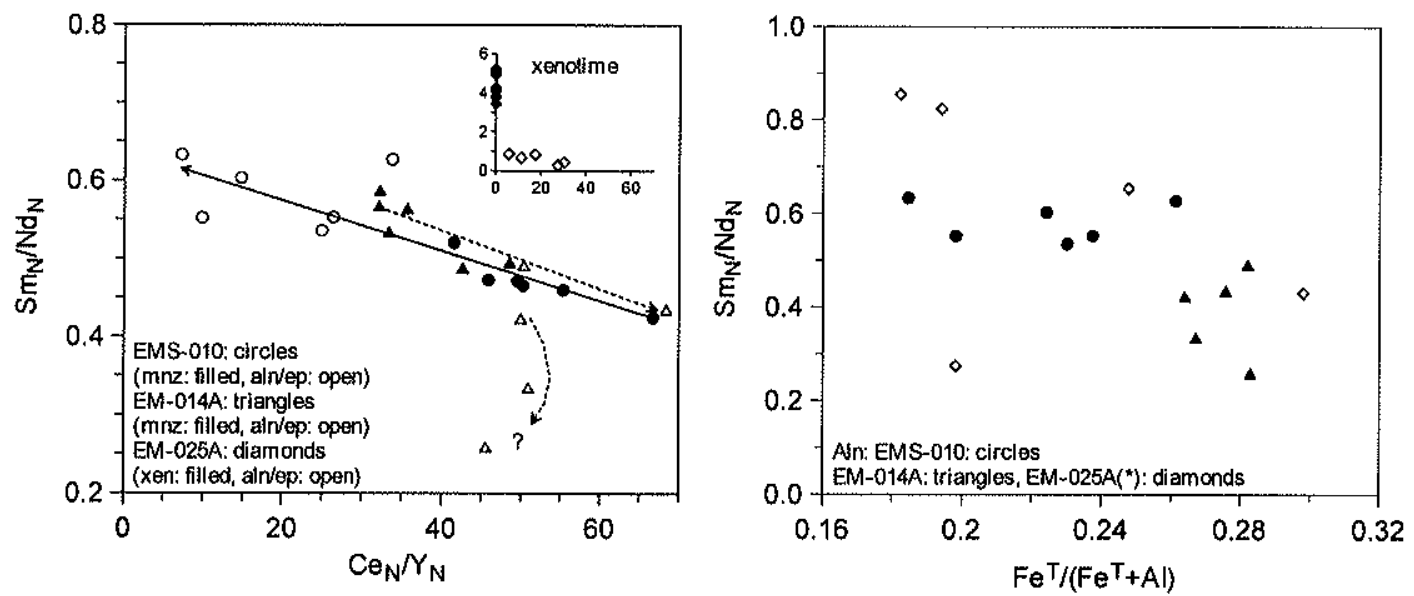

Figura 9 
Tabela 1

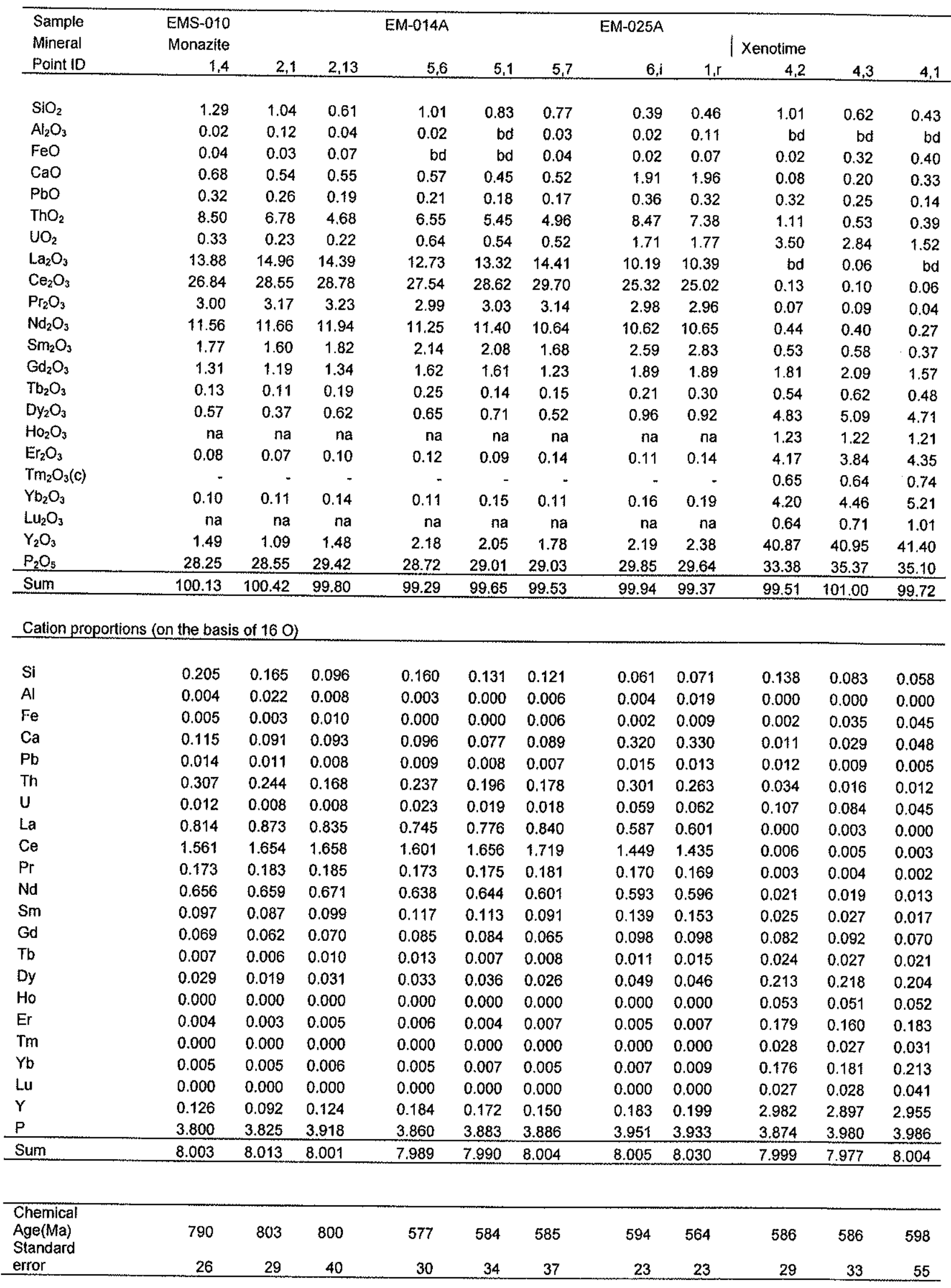


Tabela 2

\begin{tabular}{|c|c|c|c|c|c|c|c|c|c|c|c|c|c|c|c|}
\hline $\begin{array}{l}\text { Sample } \\
\text { Mineral } \\
\text { Point 1D } \\
\end{array}$ & $\begin{array}{r}\text { EMS-010 } \\
\text { Allanite } \\
7 \\
\end{array}$ & 6 & 4, & $\begin{array}{r}\text { Apatite } \\
1, \\
\end{array}$ & 2 & $\begin{array}{r}\text { M-014A } \\
\text { Allanite } \\
4, \\
\end{array}$ & 3, & 4 & $\begin{array}{r}\text { Apatite } \\
1, \\
\end{array}$ & 1, & $\begin{array}{r}\text { M-025A } \\
\text { Allanite } \\
5 \\
\end{array}$ & 6 & 3 & $\begin{array}{r}\text { Apatite } \\
3 . \\
\end{array}$ & 2, \\
\hline $\mathrm{SiO}_{2}$ & 33.29 & 34.16 & 35.03 & 0.16 & 0.11 & 32.56 & 32.85 & 35.34 & 0.37 & 0.92 & 32.43 & 33.54 & 36.21 & 0.14 & 0.19 \\
\hline $\mathrm{TiO}_{2}$ & 0.22 & 0.14 & 0.10 & bod & bd & 0.30 & 0.31 & 0.54 & bd & bd & 0.44 & 0.53 & 0.17 & 0.03 & bd \\
\hline $\mathrm{Al}_{2} \mathrm{O}_{3}$ & 20.10 & 22.77 & 25.18 & 0.04 & bd & 17.48 & 19.00 & 18.42 & 0.03 & 0.10 & 18.72 & 22.48 & 24.55 & $b d$ & 0.02 \\
\hline $\mathrm{FeO}$ & 10.02 & 9.27 & 8.03 & 0.14 & 0.05 & 8.99 & 10.20 & 9.31 & 0.10 & 0.24 & 11.21 & 7.06 & 8.33 & 0.12 & 0.13 \\
\hline Mno & 0.56 & 0.47 & 0.38 & 0.03 & 0.05 & 0.52 & 0.54 & 0.55 & 0.04 & 0.04 & 0.76 & 0.73 & 0.54 & 0.06 & 0.10 \\
\hline $\mathrm{MgO}$ & 0.79 & 0.54 & 0.36 & 0.02 & bd & 0.10 & 0.12 & 0.23 & bd & bd & 0.10 & 0.18 & 0.04 & bd & bd \\
\hline $\mathrm{CaO}$ & 12.25 & 14.38 & 17.25 & 55.47 & 54.84 & 12.63 & 11.52 & 11.75 & 53.84 & 54.06 & 12.17 & 14.55 & 19.06 & 55.22 & 54.93 \\
\hline Sro & $b d$ & bd & bd & bd & 0.03 & 0.07 & bd & bd & bd & $b d$ & bd & 0.05 & bd & bo & $b d$ \\
\hline $\mathrm{Na}_{2} \mathrm{O}$ & 0.05 & 0.03 & 0.02 & 0.03 & 0.04 & 0.37 & 0.29 & 0.48 & 0.04 & 0.04 & 0.04 & 0.47 & 0.05 & 0.02 & 0.04 \\
\hline $\mathrm{K}_{2} \mathrm{O}$ & bd & 0.02 & 0.04 & $b d$ & bd & 0.07 & 0.04 & 0.05 & 0.02 & $b d$ & 0.08 & 0.07 & 0.04 & 0.02 & bd \\
\hline $\mathrm{ZrO}_{2}$ & bd & bd & bd & bd & bd & 0.21 & 0.29 & 0.52 & bd & bd & $b d$ & 0.34 & 0.04 & bd & $b d$ \\
\hline $\mathrm{ThO}_{2}$ & 1.39 & 0.80 & 0.29 & bd & bd & 0.73 & 0.34 & 0.54 & 0.94 & 1.04 & 0.13 & 0.33 & 0.08 & 0.10 & 0.40 \\
\hline $\mathrm{UO}_{2}$ & 0.08 & 0.06 & 0.12 & bd & bd & 0.08 & 0.07 & 0.17 & bo & bd & 0.05 & 0.25 & $b d$ & bd & $b d$ \\
\hline $\mathrm{La}_{2} \mathrm{O}_{3}$ & 4.30 & 3.01 & 2.07 & bd & 0.04 & 4.57 & 4.37 & 3.76 & 0.49 & 0.18 & 4.95 & 2.31 & 1.83 & 0.09 & 0.14 \\
\hline $\mathrm{Ce}_{2} \mathrm{O}_{3}$ & 8.42 & 6.74 & 4.44 & 0.19 & 0.09 & 9.50 & 9.74 & 9.10 & 0.95 & 0.50 & 9.94 & 5.16 & 3.74 & 0.12 & 0.11 \\
\hline $\mathrm{Pr}_{2} \mathrm{O}_{3}$ & 1.06 & 0.80 & 0.55 & bd & 0.04 & 1.03 & 0.98 & 1.01 & 0.08 & 0.04 & 1.03 & 0.73 & 0.48 & bd & 0.04 \\
\hline $\mathrm{Nd}_{2} \mathrm{O}_{3}$ & 3.67 & 3.21 & 1.91 & bd & 0.06 & 2.90 & 3.59 & 3.61 & 0.34 & 0.24 & 3.50 & 2.12 & 1.33 & 0.07 & 0.09 \\
\hline $\mathrm{Sm}_{2} \mathrm{O}_{3}$ & 0.74 & 0.63 & 0.39 & bd & bd & 0.31 & 0.51 & 0.49 & 0.08 & 0.00 & 0.49 & 0.58 & 0.36 & $b d$ & 0.05 \\
\hline $\mathrm{Gd}_{2} \mathrm{O}_{3}$ & 0.48 & 0.44 & 0.25 & bd & bd & 0.09 & 0.38 & 0.29 & 0.09 & 0.02 & 0.28 & 0.46 & 0.16 & 0.11 & 0.07 \\
\hline $\mathrm{Dy}_{2} \mathrm{O}_{3}$ & 0.17 & 0.33 & 0.22 & bd & $b d$ & 0.08 & 0.11 & 0.11 & 0.08 & 0.11 & 0.20 & 0.38 & 0.18 & 0.10 & 0.06 \\
\hline $\mathrm{Yb}_{2} \mathrm{O}_{3}$ & bd & 0.05 & 0.09 & bd & $b d$ & 0.04 & 0.04 & 0.07 & bd & bd & bd & 0.14 & bd & bd & 0.04 \\
\hline $\mathrm{Y}_{2} \mathrm{O}_{3}$ & 0.64 & 1.17 & 1.57 & 0.13 & 0.12 & 0.48 & 0.36 & 0.46 & 0.14 & 0.18 & 0.83 & 2.26 & 0.55 & 0.24 & 0.22 \\
\hline $\mathrm{P}_{2} \mathrm{O}_{5}$ & 0.02 & bd & $b d$ & 41.92 & 41.58 & 0.04 & 0.04 & bd & 40.46 & 40.50 & $b d$ & 0.05 & $b d$ & 41.68 & 41.37 \\
\hline$F$ & bd & $b d$ & bd & 2.15 & 1.87 & bd & $b d$ & bd & 2.57 & 2.98 & bd & bd & bd & 2.71 & 2.53 \\
\hline $\mathrm{O}=\mathrm{F}$ & - & - & - & 0.90 & 0.79 & - & - & - & 1.08 & 1.25 & - & - & - & 1.14 & 1.07 \\
\hline Sum & 98.26 & 99.03 & 98.30 & 99.42 & 98.17 & 93.13 & 95.69 & 96.81 & 99.57 & 99.97 & 97.38 & 94.76 & 97.77 & 99.72 & 99.48 \\
\hline
\end{tabular}


Tabela 2, cont.

\begin{tabular}{|c|c|c|c|c|c|c|c|c|c|c|c|c|c|c|c|}
\hline $\begin{array}{l}\text { Sample } \\
\text { Mineral } \\
\text { Point ID } \\
\end{array}$ & $\begin{array}{r}\text { EMS-010 } \\
\text { Allanite } \\
7, \\
\end{array}$ & 6, & 4 & $\begin{array}{r}\text { Apatite } \\
1 \\
\end{array}$ & 2, & $\begin{array}{r}\text { M-014A } \\
\text { Allanite } \\
4, \\
\end{array}$ & 3, & 4 & $\begin{array}{r}\text { Apatite } \\
1 . \\
\end{array}$ & 1 & $\begin{array}{r}M-025 \mathrm{~A} \\
\text { Allanite } \\
5\end{array}$ & 6 & 3 & $\begin{array}{r}\text { Apatite } \\
3, \\
\end{array}$ & 2. \\
\hline \multicolumn{16}{|c|}{ Cation proportions [allanite and epidote: 8 cations and $12.5 \mathrm{O}$, Apatite $6(\mathrm{Si}+\mathrm{P})$ ] } \\
\hline $\mathrm{Si}$ & 3.029 & 2.975 & 2.936 & 0.027 & 0.019 & 3.132 & 3.083 & 3.249 & 0.065 & 0.157 & 3.012 & 2.993 & 2.999 & 0.024 & 0.033 \\
\hline $\mathrm{Ti}$ & 0.015 & 0.009 & 0.006 & 0.000 & 0.000 & 0.022 & 0.022 & 0.037 & 0.000 & 0.000 & 0.031 & 0.035 & 0.010 & 0.004 & 0.000 \\
\hline Al & 2.156 & 2.337 & 2.487 & 0.008 & 0.000 & 1.981 & 2.102 & 1.997 & 0.005 & 0.019 & 2.050 & 2.364 & 2.397 & 0.000 & 0.003 \\
\hline FellI & 0.046 & 0.136 & 0.246 & 0.000 & 0.000 & 0.051 & 0.002 & 0.000 & 0.000 & 0.000 & 0.143 & 0.117 & 0.324 & 0.000 & 0.000 \\
\hline $\mathrm{Fe}$ & 0.716 & 0.539 & 0.317 & 0.020 & 0.007 & 0.671 & 0.798 & 0.716 & 0.015 & 0.035 & 0.728 & 0.410 & 0.253 & 0.017 & 0.019 \\
\hline $\mathrm{Mn}$ & 0.043 & 0.035 & 0.027 & 0.005 & 0.007 & 0.042 & 0.043 & 0.043 & 0.006 & 0.005 & 0.060 & 0.055 & 0.038 & 0.009 & 0.014 \\
\hline $\mathrm{Mg}$ & 0.107 & 0.070 & 0.044 & 0.006 & 0.000 & 0.015 & 0.017 & 0.031 & 0.000 & 0.001 & 0.013 & 0.024 & 0.005 & 0.000 & 0.000 \\
\hline $\mathrm{Ca}$ & 1.194 & 1.341 & 1.549 & 10.003 & 9.983 & 1.301 & 1.159 & 1.158 & 9.996 & 9.871 & 1.211 & 1.391 & 1.691 & 10.021 & 10.028 \\
\hline $\mathrm{Sr}$ & 0.000 & 0.000 & 0.000 & 0.000 & 0.003 & 0.004 & 0.000 & 0.000 & 0.000 & 0.000 & 0.000 & 0.003 & 0.000 & 0.000 & 0.000 \\
\hline $\mathrm{Na}$ & 0.009 & 0.005 & 0.003 & 0.009 & 0.014 & 0.068 & 0.052 & 0.085 & 0.013 & 0.014 & 0.008 & 0.082 & 0.008 & 0.008 & 0.014 \\
\hline $\mathrm{K}$ & 0.000 & 0.003 & 0.004 & 0.000 & 0.000 & 0.009 & 0.005 & 0.006 & 0.004 & 0.000 & 0.010 & 0.008 & 0.005 & 0.003 & 0.000 \\
\hline $\mathrm{Zr}$ & 0.000 & 0.000 & 0.000 & 0.000 & 0.000 & 0.010 & 0.013 & 0.023 & 0.000 & 0.000 & 0.000 & 0.015 & 0.001 & 0.000 & 0.000 \\
\hline Th & 0.029 & 0.016 & 0.006 & 0.000 & 0.000 & 0.016 & 0.007 & 0.011 & 0.037 & 0.040 & 0.003 & 0.007 & 0.001 & 0.004 & 0.015 \\
\hline$U$ & 0.002 & 0.001 & 0.002 & 0.000 & 0.000 & 0.002 & 0.002 & 0.003 & 0.000 & 0.000 & 0.001 & 0.005 & 0.000 & 0.000 & 0.000 \\
\hline La & 0.144 & 0.097 & 0.064 & 0.000 & 0.003 & 0.162 & 0.151 & 0.128 & 0.031 & 0.011 & 0.170 & 0.076 & 0.056 & 0.006 & 0.009 \\
\hline $\mathrm{Ce}$ & 0.281 & 0.215 & 0.136 & 0.012 & 0.006 & 0.335 & 0.335 & 0.306 & 0.060 & 0.031 & 0.338 & 0.169 & 0.113 & 0.007 & 0.007 \\
\hline Pr & 0.035 & 0.025 & 0.017 & 0.000 & 0.002 & 0.036 & 0.034 & 0.034 & 0.005 & 0.002 & 0.035 & 0.024 & 0.014 & 0.000 & 0.003 \\
\hline $\mathrm{Nd}$ & 0.119 & 0.100 & 0.057 & 0.000 & 0.004 & 0.099 & 0.120 & 0.118 & 0.021 & 0.015 & 0.116 & 0.067 & 0.039 & 0.004 & 0.005 \\
\hline Sm & 0.023 & 0.019 & 0.011 & 0.000 & 0.000 & 0.010 & 0.016 & 0.016 & 0.005 & 0.000 & 0.016 & 0.018 & 0.010 & 0.000 & 0.003 \\
\hline Gd & 0.014 & 0.013 & 0.007 & 0.000 & 0.000 & 0.003 & 0.012 & 0.009 & 0.005 & 0.001 & 0.008 & 0.014 & 0.004 & 0.006 & 0.004 \\
\hline Dy & 0.005 & 0.009 & 0.006 & 0.000 & 0.000 & 0.002 & 0.003 & 0.003 & 0.004 & 0.006 & 0.006 & 0.011 & 0.005 & 0.005 & 0.003 \\
\hline$Y b$ & 0.000 & 0.001 & 0.002 & 0.000 & 0.000 & 0.001 & 0.001 & 0.002 & 0.000 & 0.000 & 0.000 & 0.004 & 0.000 & 0.000 & 0.002 \\
\hline Y & 0.031 & 0.054 & 0.070 & 0.012 & 0.010 & 0.024 & 0.018 & 0.023 & 0.013 & 0.016 & 0.041 & 0.107 & 0.024 & 0.022 & 0.020 \\
\hline$P$ & 0.001 & 0.000 & 0.000 & 5.973 & 5.981 & 0.003 & 0.003 & 0.000 & 5.935 & 5.843 & 0.000 & 0.004 & 0.000 & 5.976 & 5.967 \\
\hline Sum & 8.000 & 8.000 & 8.000 & 16.074 & 16.040 & 8.000 & 8.000 & 8.000 & 16.220 & 16.068 & 8.000 & 8.000 & 8.000 & 16.116 & 16.149 \\
\hline 0 & 12.500 & 12.500 & 12.500 & 25.076 & 25.042 & 12.500 & 12.500 & 12.597 & 25.292 & 25.078 & 12.500 & 12.500 & 12.500 & 25.137 & 25.171 \\
\hline$F$ & - & - & - & 1.143 & 1.005 & - & - & - & 1.407 & 1.606 & - & - & - & 1.449 & 1.365 \\
\hline AVCNK & 0.899 & 0.869 & 0.801 & - & - & 0.740 & 0.885 & 0.829 & - & - & 0.840 & 0.823 & 0.706 & - & - \\
\hline $\mathrm{Fe}^{\top} /\left(\mathrm{Fe}^{\tau}+\mathrm{Al}\right)$ & 0.261 & 0.224 & 0.185 & 0.706 & 0.765 & 0.267 & 0.276 & 0.264 & 0.734 & 0.642 & 0.298 & 0.182 & 0.194 & 0.902 & 0.864 \\
\hline
\end{tabular}




\section{CAPÍTULO V}

\section{Comentários gerais sobre análise, datação e aplicações da monazita}

\section{Análise crítica do método químico com microssonda eletrônica e aplicabilidade}

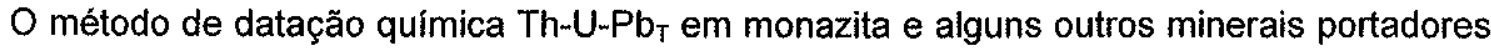
de Th e $U$ é relativamente simples, eficaz e resulta em informações com excelentes graus de reprodutibilidade e acurácia. A sua implantação deve ser analisada e efetuada especificamente para cada equipamento, uma vez que cada EPMA apresenta características próprias que não se repetem mesmo em equipamentos equivalentes. Alguns comentários sobre o método implementado e os resultados apresentados nos capítulos anteriores, parcialmente complementados, são adicionados a seguir.

Os procedimentos para análise de monazita podem ser considerados similares aos utilizados em análises acuradas de elementos menores e traços com EPMA e exigem avaliações bem mais cuidadosas para com as condições de preparação de amostras e para o set-up instrumental e elemental. Os objetivos são obter, por um lado, a melhor resolução espacial e a melhor relação entre as intensidadades do característico e da radição de fundo possíveis e, pelo outro, a deteriorização mínima da amostra em análise. A análise criteriosa de interferências espectrais, dos procedimentos para evitá-las ou minimizá-las e, quando não possível, corrigí-las de forma quantitativa, são questões muito críticas para a obtenção de dados apropriados, particularmente para a quantificação de $\mathrm{U}$ e $\mathrm{Pb}$. A fluorescéncia secundária inter- e intracristalina pode reduzir a resolução espacial em quase uma ordem de grandeza (e.g. Jercinovic et al. 2008). 
Encontram-se atualmente em literatura procedimentos bem complexos que envolvem diversas etapas de preparação e análise (e.g. Jercinovic e Williams 2005). O presente autor acredeita que procedimentos deste tipo ainda não se justificam considerando os erros esperados para a maioria dos equipamentos disponiveis. Procedimentos mais simples, como o implementado no laboratório do Instituto de Geociências (Vlach 2001, este trabalho), que resultam em informações com reprodutibilidade e acurácia compativeis com método devem, sem dúvida, ser priorizados. Não há, por exemplo, necessidade de se calcular as intensidades de background da linha espectral do $\mathrm{Pb}$ por meio de interpolaçoes não lineares do espectro como acentuado pelos autores quando se utiliza de metalização convencional com C; de fato, a interpolação linear, seguida por correções adequadas para as interferências do Th sob a linha caracteristica e a região de interesse para mensuração de bakcground, dá resultados excelentes, com erros bem inferiores aos erros estatísticos de integração de contagens. Neste aspecto, a disponibilização de padrões certificados de monazita com composições variadas e idades bem determinadas para a comunidade cientifica é uma questão crítica, uma vez que somente com eles o método e os diversos protocolos analíticos existentes poderão ser adequadamente comparados e aferidos.

Os resultados obtidos no laboratório nos últimos anos para amostras de referência interna de monazita de rochas graníticas e metassedimentos pelíticos, com determinações isotópicas alternativas por TIMS, um caso SHRIMP em zircão e outro caso Ar/Ar em biotita de granito herciniano que cobrem o intervalo entre 800 e $300 \mathrm{Ma}$ da escala de tempo geológico são praticamente idênticos dentro dos intervalos dos respectivos erros.

Entre os diversos procedimentos para tratamento de dados existentes, o de aplicabilidade mais simples e adequada para quaisquer situações, é o proposto por Montel et al. (1996), baseado no cálculo de idades pontuais, para cada determinação analítica, identificação de diferentes populações cronológicas, quando o caso, e cálculo de idades médias, ponderadas pelos erros individuais, para cada população isócrona. Os erros são representados pelo erro padrão da média, calculado igualmente com base nos erros individuais. O único inconveniente do método está premissa de que o $\mathrm{Pb}$ comum ou inicial, incorporado pela monazita quando da sua formação, é nulo ou pelo menos insignificante em relação do $\mathrm{Pb}$ total medido, uma condição em geral satisfeita nas situações naturais (e.g. Parrish 1990). 
Os erros associados às deteminações de $\mathrm{Pb}$ são críticos uma vez que a propagação dos erros para as idades calculadas depende essencialmente deles. Pad um certo procedimento analítico, estes erros estão diretamente relacionados às abundâncias de $\mathrm{Pb}$ na amostra, as quais dependem das quantidades de Th e $U$ presentes e do tempo decorrido. Assim, os erros associados à cada determinação pontual, bem como o limite de aplicabilidade do método, podem ser estimados, a priori, a partir de quantidades conhecidas de $\mathrm{Th}, \mathrm{Pb}$ e da idade. Os erros propagados para as determinações pontuais são subestimados quando os erros associados à estatística de contagens são considerados representativos dos erros totais, sem consideração dos erros instrumentais envolvidos (ver também Lisowiec 2006). Quando a reprodutibilidade das determinações é consistente e os erros associados às determinações individuais não são muito elevados (ca. $<60 \mathrm{Ma}$ ), cerca de 25 a 35 análise pontuais são suficientes para resultar em erros padrões da média adequados para cada população isócrona.

Os modelos isocrônicos são adequados quando as populações isócronas apresentam variações composicionais suficientes para resultar em dispersão adequada das quantidades de Th e/ou U que permitam obter parâmetros de regressão linear com erros compatíveis. Por outro lado nas situações em que as quantidades iniciais de $\mathrm{Pb}$ são significativas, porém constantes, ou alternativamente, se o procedimento analítico adotado incorporar algum erro sistemático que some ou adicione quantidades constantes no valores medidos de $T h, U$ ou $\mathrm{Pb}_{T}$, a aplicação dos métodos isocrônicos é a mais adequada. Estas quantidades, normalmente expressas em \% em peso de óxidos ou mesmo de elementos (e.g. Suzuki e Adachi 1990), são expressas em proporções atômicas no nosso procedimento, uma representação mais lógica que permite inserir diretamente os dados no programa Isoplot (Ludwig 2003) para cálculos isocrônicos e outros.

A datação de monazita alguns outros minerais portadores de Th e/ou $U$, com destaque para a xenotima, são ferramentas poderosas para estabelecer idades de eventos metamórficos, e alguns hidrotermais que se desenvolveram em ambientes de crosta continental, sob condições de temperaturas médias a altas. No caso de cristais ou frações cristalinas poligenéticas, a resolução espacial do método resolve diversas questões relacionadas à discordância de idades isotópicas obtidas com métodos convencionais de "amostra" e/ou "cristal total" que podem conduzir a interpretações geocronológicas equivocadas (e.g., Vlach e Dantas 2001, Vlach et al. 2002). 
Adicionalmente, o método é único porque permite associar aspectos micro-estruturais e/ou texturais, com variações composicionais e também com parâmetros intensivos de cristalização (cf, a seguir), convertendo-se em ferramenta muito poderosa para a identificação e a análise de fenômenos petrológicos registrados, por vezes, somente em micro-escala, e para estabelecer caminhos evolutivos P-T-t em cinturões metamórficos.

A datação de torita é perfeitamente factivel para rochas jovens, uma vez a susceptibilidade deste mineral frente aos fenômenos metamícticos é muito elevada. No laboratório foram obtidos dados adequados para cristais de torita com idades de ca. 75-85 Ma, presentes em nefelina sienitos da llha de São Sebastião (Augusto e Vlach dados inéditos) e para veios carbonatíticos da região do Maciço Alcalino Poços de Caldas (e.g. Ulbrich et al. 2002).

\section{Aplicações geotermométricas}

Estudos experimentais do equilibrio entre monazita e xenotima e a determinação do intervalo de miscibilidade no sistema $\mathrm{CePO}_{4^{-}} \mathrm{YPO}_{4}$ foram desenvolvidos por Gratz e Heinrich (1997). Estes autores determinaram para este experimento que a variação da fração molar de $Y$ $\left(X_{Y}^{\text {mon }}\right)$ na molécula de monazita obedece a seguinte relação:

$X_{Y}^{m o n}=\frac{(1.459+0.0852 \times P) \times e^{0.002274 \times T}}{100}$

Eq. 1

Em que a pressão $(P)$ é dada em kbar e a temperatura $(T)$ em ${ }^{\circ} \mathrm{C}$. Os autores argumentam que, apesar das composições puras utilizadas no experimento, este sistema é uma aproximação bem razoável para as situações naturais e, portanto, a Equação 1 poderia ser empregada para uma primiera aproximação das temperaturas de equilíbrio de monazita e xenotima em rochas graníticas e metamórficas, entretanto os limites do intervalo de miscibilidade não puderam ser definidos com a segurança adequada pelos autores. 
Os mesmos autores, em 1998, estudaram experimentalmente a partição de Gd entre monazita e xenotima, partindo de soluções sólidas de composição simples (Ce, Gd, Y) $\mathrm{PO}_{4}$, obtendo a seguinte relação entre o coeficiente de distribuição deste elemento $\left(D_{G d}\right)$ entre monazita e xenotima e a temperatura:

$$
D_{G d}=\frac{X_{G d}^{m o n}}{X_{G d}^{x e n}}=-0.5886+1.591 \times 10^{-3} \times T
$$

em que X é a fração molar de $\mathrm{Gd}$ em monazita ou xenotima e a temperatura $\mathrm{T}$ é dada $\mathrm{em}{ }^{\circ} \mathrm{C}$.

Estas relações são relevantes porque permitem avaliar se estes minerais cristalizaram em equilibrio ou não e, em caso afirmativo, estimar as temperaturas correspondentes, as quais são imortantes, em conjunto com informações de idades e químicas para ambos os minerais, para avaliar a evolução mineralógica e petrológica de rochas ígneas e metamórficas. Experimentos com composições mais próximas às encontradas na natureza e a determinação mais precisa da superficie de miscibilidade poderiam refinar significativamente estes geotermômetros.

A aplicação da equação 2 para alguns dos granitos estudados no Terreno Embu (cf. Capítulo III) resultou em valores coerentes, sistematicamente mais elevados para as rochas menos evoluídas e compativeis com a cristalização magmática em equilíbrio para estas fases. No caso especifico do Pluton Mogi das Cruzes, os resultados apresentados (ca. $700-750^{\circ} \mathrm{C}$ ) são coerentes com as temperaturas de saturação de REE (Montel 1993) obtidas por A. Alves (trabalho em preparação). A discussão específica destas aplicações será objeto de contribuições futuras.

$O$ equilíbrio entre monazita e granada de $A l$ e $Y\left(Y A I G=Y_{3} A l_{2} A_{3} O_{12}\right)$, ou fração de $Y A I G$ em granadas típicas de metapelitos foi estudado por Pyle et al. (2001) com base na equação YAIG $+(\mathrm{OH})$-Apatita + (25/4) Quartzo = (5/4) Grossulária + (5/4) Anortita + (3) YPO - -Monazita + (1/2) $\mathrm{H}_{2} \mathrm{O}$, para a qual foi obtida a seguinte função para $\mathrm{T}$ :

$T=-273.15+\frac{1.45 \times P+447772( \pm 32052)}{567( \pm 40)-R \ln K_{E q}}$ 
em que $R$ é a constante dos gases, $T$ é dada em ${ }^{\circ} \mathrm{C}$ e $\mathrm{P}$ em bar. A constante de equilibrio $\mathrm{K}_{\mathrm{Eq}}$ é calculada na forma:

$$
K_{E q}=\frac{X_{C a, G r t}^{15 / 4} \times X_{C a, P l g}^{5 / 4} \times X_{Y, M n z}^{3} \times \int_{H_{2} O}^{1 / 2}}{X_{Y, G r l}^{3} \times X_{O H, A p}}
$$

em que $X_{Y}$, Grt é a fração molar de $Y$ na granada. A aplicação desta equação para os metassedimentos da amostra EM-20, assumindo condições de $f_{\mathrm{H} 2 \mathrm{O}}$ entre 1500 e 3000 e $\mathrm{X}_{\mathrm{OH}}$ de 0.2 , resultou em temperaturas entre 650 e $750^{\circ} \mathrm{C}$, perfeitamente comparáveis com as obtidas por geotermometria convencional baseada no equilíbrio biotita+granada+plagioclásio+sillimanita (Augusto e Vlach, dados inéditos).

\section{Estabilidade de monazita e xenotima em rochas graniticas e metamórficas}

A estabilidade de monazita em relação à apatita e allanita em rochas orto- e parametamórficas é relativamente bem conhecida (e.g. Lanzirotti e Hanson 1996, Bingen et al. 1996, Wing et al. 2003). A geração de típicas coronas de substiuição parcial constituidas por apatita + torita, allanita e epidoto relacionadas ao metamorfismo de rochas graníticas peraluminosas e a processos deutéricos foi bem caracterizada por Finger et al, (1998) e Claeson (2002), ao passo que mecanismos contrastados de alteração hidrotermal de monazita em rochas graníticas foram abordados por Poitrasson et al. (1996) e Townsend et al. (2000).

O Capitulo IV foi dedicado a alguns destes temas e discute as caracteristicas morfológicas e químicas de sistemas coroníticos em monazita desenvolvidos em ortognaisses e granitos inttrusivos e implicações para a sua origem e para o comportamento de alguns elementos nestes ambientes. As contribuições mais relevantes são o reconhecimento de micro-estruturas análogas em xenotima e os mecanismos que geraram estes sistemas. Os resultados obtidos indicam que, ao contrário dos interpretações correntes que apelam para processos dirigidos por difusão, as evidências morfológicas apontam para reações de substituição dirigidas por mecanismos de dissolução parcial e reprecipitação de novas fases minerais em equilíbrio, sob a influência de 
fluídos residuais de cristalização e/ou metamórficos. Estes mecanismos possibilitam a mobilização significativa, pelo menos em micro-escala, dos RRE e $Y$ e devem ser considerados quando da interpretação geoquimica dos padrões de distribuição elemental que os envolvem.

O exemplo apresentado neste trabalho, bem como diversos estudos similares na literatura, mostram que estudos de detalhe abordando a distribuição e o comportamento dos elementos que aparecem em quantidades de traços nas rochas e estão concentrados tipicamente em fases minerais acessórias, são ferramentas essenciais de apoio às interpretações relativas à evolução mineralógica e petrológica.

\section{Aplicaçōes industriais}

Monazita comum, particularmente quando concentrada volumetricamente em quantidades significativas em placeres, pode se converter em importante fonte para LREE, Th e, eventualmente U. Greenwood e Earnshaw (1984) apresentam e discutem alguns dos procedimentos industriais utilizados para a extração e concentração destes elementos.

Uma das aplicações mais interessantes e que tem merecido estudos sistemáticos já há vários anos está relacionada a questão da fixação de resíduos radioativos derivados de reatores e da indústria nuclear em geral. Mais de uma dezena de isótopos radioativos, particularmente elementos dos grupos dos lantanídeos e actinídeos, com vidas médias variáveis entre alguns a centenas de anos podem potencialmente ser fixados e armazenados conveninentemente na estrutura da monazita. A utilização de fosfatos como monazita são interessantes porque estes

minerais são muito resistentes a deteriorização à metamictização e porque apresentam solubilidades e, portanto, taxas de dissolução, bem baixas (cf. Oelkers et al. 2008).

\section{Referências biliográficas}


Bingen, B., Demaiffe, D., Hertogen, J., 1996. Redistribution of rare earth elements, thorium, and uranium over accessory minerals in the course of amphibolite to granulite metamorphism: The role od apatite and monazite in orthogneisses from southwestern Norway. Geochimica et Cosmochimica Acta, 60:1341-1354.

Claeson, D. T., 2002. Stability of REE-bearing minerals in a metaluminous leucotonalite from the Eriksberg gabbro, Transcandinavian Igneous Belt, Sweden. Neues Jahrbuch für Mineralogie - Abhandlungen, 177(3):277-291.

Finger, F., Broska, I., Roberts, M.P., Schermaier, A., 1998. Replacement of primary monazite by apatite-allanite-epidote coronas in amphibolite facies granite gneiss from the eastern Alps. American Mineralogist, 83:248-258.

Greenwood, N.N., Earnshaw, A., 1984. Chemistry of the elements. Butterworth-Heinemann Ltd. Oxford. $1542 \mathrm{p}$.

Jercinovic, M.J., Williams, M.L., 2005. Analytical perils (and progress) in electron microprobe trace element analysis applied to geochronology: background acquisition, interferences, and beam irradiation effects. American Mineralogist, 90:526-546.

Jercinovic, M.J., Williams, M.L., Lane, E.D., 2008. In-situ trace element analysis of monazite and other fine-grained accessoty minerals by EPMA. Chemical Geology, 254:197-215.

Lanzirotti, A., Hanson, G.N., 1996. Geochronology and geochemistry of multiple generations of monazite from the Wepawaug Schist, Conecticut, USA: Implications for monazite stability im metamorphic rocks. Contributions to Mineralogy and Petrology, 125:332-340.

Lisowiec, N., 2006. Precision estimation in electron microprobe monazite dating: Repeated measurements versus statistical (Poisson) based calculations. Chemical Geology, 234:223235.

Ludwig, K.R., 2003. Isoplot 3.00. A Geochronological Toolkit for Microsoft Excel. Berkeley Geochronological Center Special Publication, 4. 70 p.

Montel, J-M., 1993. A model for monazite-melt equilibrium and application to the generation of granitic magmas. Chemical Geology, 110:127-146.

Oelkers, E.H., Montel, J.-M., 2008. Phosphates and nuclear waste storage. Elements, 4:113-116. 
Parrish, R.R., 1990. U-Pb dating of monazite and its applications to geological problems. Canadian Journal of Earth Science, 27:1431-1450.

Poitrasson, F., Chenery, S., Bland, D.J., 1996. Contrasted monazite hydrothermal alteration mechanisms and their geological implications. Earth and Planetary Science Letters, 145:79-96.

Pyle, J.M., Spear, F.S., Rudnick, R.L., McDonough, W.F., 2001. Monazite-xenotime-garnet equilibrium in metapelites and a new monazite-garnet thermometer. Journal of Petrology, 42:2083-2107.

Suzuki, K., Adachi, M. 1991. Precambrian provenance and Silurian metamorphism of the Tsubonosawa paragneiss in the South Kitakami Terrane, Northeast Japan, revealed by the chemical Th-U-total $\mathrm{Pb}$ isochron ages of monazite, zircon and xenotime. Geochemical Journal, 25:357-376.

Townsend, K.J., Miller, C.F., D’Andrea, J.L., Ayers, J.C., Harrison, T.M., Coath, C.D., 2000. Low temperature replacement of monazite in the Ireteba granite, Southern Nevada: geochronological implications. Chemical Geology, 172:95-112.

Ulbrich, H. H. G. J., Vlach, S. R. F., Ulbrich, M. N. C. \& Kawashita, K., 2002. Penecontemporaneous syenitic-phonolitic and basic-ultrabasic-carbonatitic rocks at the Poços de Caldas alkaline massif, SE Brazil: geologic and geochronologic evidence. Revista Brasileira de Geociências, 32: 15-26.

Vlach, S.R.F., 2001. Geocronologia de minerais acessórios pelo método Th-U-Pb total com microssonda eletrônica: monazita, torita, xenotima e uraninita. Programa de pós-Graduação em Mineralogia e Petrologia. Instituto de Geociências. USP. (inédito). 81 p.

Vlach, S.R.F., Dantas, E.L., 2001. Polygenetic monazite from the São José do Campestre Massif, Borborema Province, NE Brazil: insights from EPMA chemical and dating studies. In: South American Symposium on Isotope Geology, 3. Pucón, CH. Extended Abstracts (CD), p. 8386.

Vlach, S.R.F., Janasi, V.A., Alves, A., 2002. Sistemática U-Pb de datação de monazita em rochas graníticas: Identificação de eventos superpostos no Batólito Natividade da Serra pela

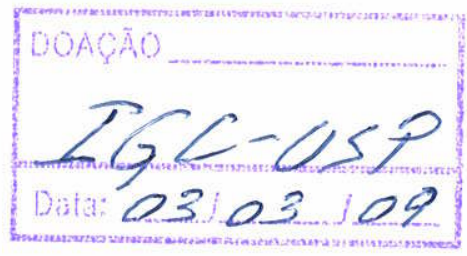


combinação de TIMS e datação química por microssonda eletrônica. In: Congresso Brasileiro de Geologia, 41. João Pessoa. Boletim de Resumos, p. 511.

Wing, B.A., Ferry, J.M. Harrison, T.M., 2003. Prograde destruction and formation of monazite and allanite during contact and regional metamorphism of pelites: petrology and geochronology. Contributions to Mineralogy and Petrology, 145:228-250. 


\section{Agradecimentos}

O autor gostaria de expressar os agradecimentos à Fundação de Amparo à Pesquisa do Estado de São Paulo (FAPESP) pelo contínuo apoio ao Laboratório de Microssonda Eletrônica do Departamento de Mineralogia e Geotectônica do Instituto de Geociências de forma geral e especificamente por dar o necessário suporte financeiro para a instalação de uma infraestrutura laboratorial adequada, através de Projetos Temáticos coordenados pelo Prof. Celso B. Gomes, Projetos de Infraestrutura geral, coordenados pelos Profs. Vicente A. V. Girardi e Adilson Carvalho e especificamente Projeto de Infraestrutura especifico para a modernização dos sistemas de automação do laboratório, coordenado pelo autor.

Agradecimentos são devidos também aos funcionários e docentes do Instituto de Geociências pelo suporte e apoio geral, amizade e discussões sobre diversos aspectos instrumentais, mineralógicos, petrológicos e geocronológicos, mesmo aqueles que questionaram em várias ocasiões a viabilidade e a importância do método de datação química com microssonda eletrônica. O autor não deseja mencionar nomes porque corre o risco de esquecer alguns importantes face a urgência imposta de conclusão deste texto, entretanto devem ser destacados Marcos Mansueto e Paulo Molinaro pelo apoio operacional no Laboratório de Microssonda e na seção de preparação de amostras e o Dr. Guilherme A.R. Gualda pela colaboração efetiva para a concretização do programa Age_Mona, sem o qual os dados obtidos nestes anos não poderiam ser adequadamente computados. 


\section{ERRATA}

Não houve tempo hábil para a revisão final do texto por parte do autor e infelizmente diversos erros constam do texto. Os principais devem ser corrigidos como segue.

Localização

(página, parágrafo, linha)

pg 6, pr $3, \operatorname{lin} 2$

pg 7, pr 1, lin 2

pg 7, pr $2, \operatorname{lin} 2$

pg $7, \operatorname{pr} 2, \operatorname{lin} 12$

pg $8, \operatorname{pr} 3$, lin 5

pg $8, \operatorname{pr} 3$, lin 6

pg 12, pr 4, lin 3

pg 20, pr 2 , lin 5

pg 21, pr $2, \operatorname{lin} 4$

pg 28, pr $3, \operatorname{lin} 9$

pg 29, pr $3, \operatorname{lin} 4$

pg 35, pr 2, 13

pg 41, pr 1, lin 2

pg 52, pr $3, \operatorname{lin} 2$

pg 53, pr 4 lin 5

pg 66, pr 4, lin 4

pg 83, pr 2, lin 2

pg 84, pr 3 , lin 10

pg 85, pr 3 , lin 5

pg 90, pr 2, pli 2

pg $91, \mathrm{pr} 2$, lin 2

pg. 91, pr $3, \operatorname{lin} 1$

pg 92, pr 1, lin 12

pg 97, pr 2, lin 3

pg 106, pr 1, lin 2

pg 136, subtítulo

pg 142, pr 1, lin 8

pg 144, par 2, lin 5

pg 149, par 1, lin 1

pg 152, par 2, lin 12 onde está

micro-esturutal

são mais raras

gera

significativa no durante

e da disponibilização

quantiticação

Isoplol

podem ser tornar

A influência

imortante

conseqüencia

quamtidades

a exeção

quantitatito

instersticial

verticas

permitem tonam-as

ainda não são

hoblenda

como granada

que uma geração

Serra do mar

a exeção

represente um bioitita

comumicações

substiuição

branbantítico

a exeçăo

exeção do $\mathrm{P}$

trnasparência leia-se

micro-estrutural

é mais rara

geram

significativa durante

e a disponibilização

quantificação

Isoplot

podem se tornar

As influências

importante

conseqüencia

quantidades

à exceção

quantitativo

intersticial

verticais

tornam-as

ainda são

hornblenda

com granada

uma geração

Serra do Mar

à exceção

representa um biotita

comunicações

substituição

brabantítico

à exceção

exceção do $P$

transparência 